UWWERSITY

OF

TORONTE

HARAKY 
$\therefore \quad$

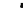

.

.

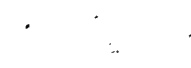

.

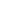
. 


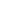




\section{ÜBER PARONOMASIE \\ IN DEN SEMITISCHEN SPRACHEN}

VON

H. RECKENDORF 
asemit.

R2984

\section{ÜBER PARONOMASIE}

\section{IN DEN SEMITISCHEN SPRACHEN}

EIN BEITRAG

ZUR

ALLGEMEINEN SPRACHWISSENSCHAFT

Vox

H. RECKENDORF

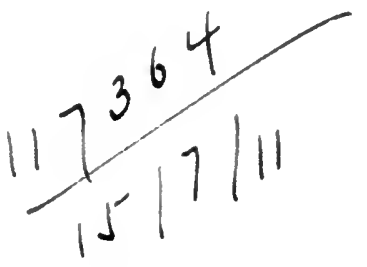

VERLAG VON ALFRED TÖPELMANN (VORMALS J. RICKER) GIESSEN 1909 


\section{Vorrede.}

Wer einen Blick in das Belegmaterial der vorliegenden Untersuchungen wirft, könnte meinen, es solle von einer der Ausgeburten „orientalischen Schwulstes" mit der geziemenden Pose Kunde gegeben werden. Darum sei gleich an der Schwelle ausgesprochen, $\mathrm{da}$ es sich um eine nüchterne sprachwissenschaftliche Untersuchung handelt; denn es wird sich zeigen, daß die Paronomasie einer derartigen Betrachtung zugänglich ist, ja sie vielfach als die einzig berechtigte geradezu erfordert. Was unterParonomasie zu verstehen ist, findet man in der Einleitung. Zweck der Arbeit ist, das Wesen der Paronomasie, ihre Ursachen und grammatischen Wirkungen zu untersuchen.

Man kann nun fragen: welche Wortformen treten in paronomastisches Verhältnis? Und: wie gestalten sich syntaktische Verhältnisse, wenn ihre Bestandteile paronomastisch sind? Danach zerfällt die Untersuchung in zwei Hauptteile: „Das Wort in der Paronomasie" und ,die Paronomasie der Syntagmen".

Es gibt allerdings auch Paronomasie innerhalb eines einzelnen

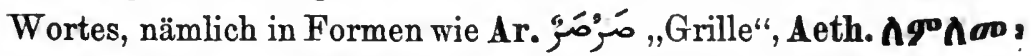

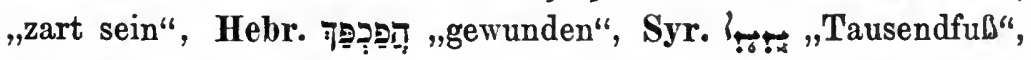
Ass. dandannu ,mächtig" usw. usw., und man könnte auch diese Gebilde nach den angegebenen beiden Richtungen hin untersuchen. Indes ist darauf nicht eingegangen; es sei auf Brockelmann, Grundriß der vergl. Gram. d. sem. Spr. § 158 ff. 240. 257 F verwiesen.

Nach der andern Seite hin beschränkt sich die Darstellung auf diejenigen paronomastischen Vorgänge, die sich innerhalb des ein- 
fachen und zusammengesetzten Satzes abspielen; was darüber hinausliegt, ist verwickelt und grammatisch schwer zu packen. Nur im ersten Teile des Buches, in dem das syntaktische Verhältnis nicht in Betracht kommt, ist die Grenze des Satzes manchmal überschritten. Interessant wäre aber namentlich eine Untersuchung der Fälle, in denen die Rede nicht von dem anfänglichen Sprecher, sondern von einem andern fortgesponnen wird; s. Röthe, Brentanos ,Ponce de Leon' (Abh. der Gött. Ges.d. Wiss. N. F. V Nr. 1). Die Paronomasien beruhen in letzterem Falle, dem Zwiegespräch, entweder auf Fortführung des Gedankens aus eigenem Antriebe, oder sie sind durch den andern Sprecher ausdrücklich veranlaßt, sei es als Antwort auf eine Frage, sei es als Stellungnahme zu einer Aufforderung. Es werden z. B. vorangegangene Wörter als Schlagwörter herausgegriffen, um angezweifelt und nochmals überdacht zu werden; sie werden im Frageton oder Ausruf ausgesprochen, sei es mit darangeknüpften Bemerkungen, sei es ohne solche. Das Wort erscheint in der gleichen syntaktischen Verbindung oder in einer andern; es ist oft eine ganze Gruppe ron Wörtern mit der gleichen oder mit abgeänderter Wortstellung, in ersterem Falle mit Beibehaltung der Wortberührung oder mit Sprengung der Wortberührung. Manchmal greifen die paronomasierenden Wörter weit über den unmittelbar vorangehenden Zusammenhang hinweg oder sind aus einem größeren Abschnitte zusammengerafft, dessen Inhalt sie angeben. Eine Zwischenstufe würde das Zwiegespräch unter zwei Augen bilden, z. B. die rhetorische Frage oder die Selbstbefragung wie بنول .... الناسى يقولون ,was werden die Leute sagen?! Sie werden sagen, wir hätten usw." Tab. II1 322,5. Als beliebter Kunstgriff in der Erzählungsliteratur, z. B. Was sagte nun der Bohnenverkäufer zu ihm? Er sagte zu ihm ..." Tales 63, 17. usw.

Es gibt kein syntaktisches Verhältnis, das nicht auch paronomastisch auftritt; daher wird sich ein Bild der gesamten Syntax, ron einem bestimmten Gesichtspunkte aus betrachtet, ergeben. Es ist auch Wert darauf gelegt, die Mannigfaltigkeit der Be- 
ziehungen bei jeder sich bietenden Gelegenheit aufzuzeigen. Denn im Ganzen ist das Semitische reich an Paronomasien. So namentlich das Hebräische. Den Gegenpol dazu bildet das Assyrische. Da mir das bereits feststand, ging ich mit einiger Spannung an die Tell-el Amarna-Texte: Würden sie den Paronomasienreichtum des Hebräischen in assyrischem Gewande zeigen? Das Ergebnis war, daß sich das palästinensische Assyrisch hinsichtlich der Verwendung der Paronomasie nicht in nennenswerter Weise vom bodenständigen Assyrischen unterscheidet. Da angesichts des sonstigen Sprachcharakters der Texte die Möglichkeit, daß assyrische Sekretäre die Verfasser sind, nicht in Betracht kommt, so hat also das vorhebräische Palästinensisch nicht den Paronomasienreichtum des Hebräischen gehabt.

Da es sich großenteils um Erscheinungen handelt, die auch außerhalb des Semitischen, vielleicht gar in allen Sprachen, wiederkehren, so dürften die Ergebnisse als Bausteine in der allgemeinen Sprachwissenschaft verwendbar sein. Die semitischen Sprachen eignen sich aber wegen ihrer auch in schlichter Prosa zahlreichen, vielfältigen und grammatisch notwendigen Paronomasien in besonderem Maße zum Studium der Paronomasie.

Die abendländischen Übersetzungen nehmen gewöhnlich viel zu viel Paronomasien aus den semitischen Texten mit herüber und verleihen dadurch dem sprachlichen Ausdruck oft ein Gewicht, ja eine Überladenheit, die dem Geist des Originals nicht entspricht (vgl. § 2,4). Das gilt auch für die Bibelübersetzungen, nur daß wir da gegen Vieles abgestumpft sind. Und so möchten sich denn die vorliegenden Forschungen auch durch hermeneutische Winke nützlich machen.

Auf statistische Feststellungen und auf literarische Charakteristik mußte, wie auf manches andere, verzichtet werden. Es sollten nur die großen $Z$ üge, namentlich die durchgehenden, entwickelt werden.

Das Arabische ist am reichsten mit Belegen bedacht, was nicht 
nur persönliche Gründe hat, sondern auch durch die Reichhaltigkeit und Vortrefflichkeit des Quellenstoffs veranlaßt ist. Da außerdem der Belegstoff natürlich für keine Sprache vollständig ist, so kann die Zahl der Belege keine Vorstellung von der vergleichsweisen Häufigkeit der Paronomasie in den einzelnen semitischen Sprachen geben. Hätten wir von dem althebräischen Schrifttum so umfängliche Denkmäler wie vom arabischen, so würde die Ausbreitung der Paronomasie im Althebräischen noch ganz anders hervortreten. So spärliche Sprachreste vollends, wie z. B. das Phönizische sie bietet, machen selbst eine nur annähernd richtige Beurteilung des Häufigkeitsverhältnisses unmöglich. Ungern habe ich mich entschlossen, meine aethiopischen Sammlungen dem Buche einzuverleiben und es nur der Vollständigkeit halber getan, Vieles jedoch zurückgehalten. Es muß also hier und überhaupt vor dem argumentum e silentio gewarnt werden. Paronomasien in Übersetzungen dürfen eigentlich nur verwendet werden, wenn sie nicht schon in der Vorlage gestanden haben; dann allerdings sind sie ganz besonders lehrreich, vgl. aus dem Aeth. Gen. 2,9. 3,6, 8,15. 12,4. 13,12. 18,30. 19,24. 22,12. 30,30. 50,4. Ex. 14, 25 usw. Sprachen, aus denen ich nur wenig oder nur für bestimmte paronomastische Erscheinungen gesammelt hatte, sind völlig unberücksichtigt geblieben. Sonach hätten eigentlich auch die Belege aus den aram. und phön. Inschriften unterdrückt werden können. Die Durchführung der Untersuchung ist jeweils am Arab. vorgenommen; erforderlichen Falls verweisen eingeklammerte Buchstaben vor den Belegen der andern Sprachen auf die durch kursive Buchstaben am Rande kenntlich gemachten entsprechenden Stücke des arabischen Teils.

Mein Dank gebührt E. Littmann, der mir trotz drängender eigener Arbeiten eine Korrektur gelesen hat.
Freiburg i. B., Mai 1909.
H. Reckendorf. 


\section{Inhaltsverzeichnis.}

Einleitung.

I. Die Verwendung der Paronomasie. Seite

$\S 1$. Wesen der Paronomasio . . . . . . . . . . . . . . 1

§ 2. Freie und gebundene Paronomasie . . . . . . . . . . . 9

§3. Wechselbeziehung der paronomastischen Wörter. . . . . 19

Das Wort in der Paronomasie.

II. Das Nomen in der Paronomasie.

§ 4. Wurzelverwandte bedeutungsverschiedene Nominalformen . . 23

§ 5. Wurzelverwandte synonyme Nominalformen . . . . . . . 26

§ 6. Die Determination paronomastischer Nomina . . . . . . . 29

§ 7. Paronomastische Nomina in Kontrast . . . . . . . . . . 33

III. Nomen und Pronomen.

§ 8. Allgemeines . . . . . . . . . . . . . . . . . . . 49

§ 9. Freier Gebrauch des Nomens . . . . . . . . . . . . . 50

$\$$ 10. Gebundener Gebrauch des Nomens . . . . . . . . . . 53

IV. Das Verbum in der Paronomasie.

$\S 11$. Wurzelverwandte bedeutungsverschiedene Verbalformen . . 59

$\S$ 12. Wurzelverwandte synonyme Verbalformen. . . . . . . . 69

V. § 13. Allgemeine Verba . . . . . . . . . . . . . . 72

VI. § 14. Nominalformen und Verbalformen . . . . . . 74

Die Paronomasie der Syntagmen.

VII. Nominalsatz.

§ 15. Die paronomastischen Bestandteile . . . . . . . . . . 77

§ 16. Bedeutung der Paronomasie . . . . . . . . . . . . . 78

§ 17. Zum Gebrauch der Paronomasie im Nominalsatz . . . . . 82

VIII. Verbalsatz.

§ 18. Die paronomastischen Bestandteile . . . . . . . . . . 83

§ 19. Bedeutung der Paronomasie im Verbalsatz . . . . . . 84

IX. Attribut.

$\S 20$. Die paronomastischen Bestandteile. . . . . . . . . . . 91

§ 21. Bedeutung der Paronomasie de Attributs. . . . . . . . 95

§ 22. Zum Gebrauch der Paronomasie des Attributs . . . . . . 97

X. Akkusativ.

§ 23. Effizierte innere abstrakte Objekte . . . . . . . . 100

24. Akkusativ der Vergleichung . . . . . . . . . . . 114 
8oito

§ 25. Effizierte konkrete Objekte . . . . . . . . . . . . 116

$\S 26$. Affizierte Objekte . . . . . . . . . . . . . . . . . 120

$\S 27$. Objekt und Subjekt . . . . . . . . . . . . . . . 123

$\S 28$. Sonstige Akkusative . . . . . . . . . . . . . . . . 124

§ 29. Doppelter Akkusativ . . . . . . . . . . . . . . . 126

$\S$ 30. Anhang: Adverbien . . . . . . . . . . . . . . . 126

XI. $\S 31$ Genitiv . . . . . . . . . . . . . . . 127

XII. Praepositionen.

§ 32. Die paronomastischen Bestandteile . . . . . . . . . . 132

$\S 33$. Besprechung einiger Praepositionen . . . . . . . . . . 134

XIII. Beiordnung.

$\S 34$. Wiederholung von Ausdrücken . . . . . . . . . . . 136

$\S$ 35. Verstärkung durch Doppelsetzung . . . . . . . . . . 139

§ 36. Distributive Ausdrücke . . . . . . . . . . . . . . . 146

$\S$ 37. Reziproke Ausdrücke . . . . . . . . . . . . . . 150

XIV. Nebensatz.

§ 38. Allgemeines . . . . . . . . . . . . . . . . . 152

§ 39. Substantivsätze . . . . . . . . . . . . . . . . . . 155

$\S$ 40. Relativsätze . . . . . . . . . . . . . . . . . . 156

$\S$ 41. Adverbialsätze . . . . . . . . . . . . . . . . . . 167

$\S$ 42. Paronomasie bei Vereinigung zweier Nebensätze . . . . . 173

XV. § 43. Isolierung . . . . . . . . . . . . . . . . 173

Index . . . . . . . . . . . . . . . . . 175

Nachträge und Berichtigungen . . . . . . . . . . 176 


\section{Einige Abkürzungen.}

Afr.

A ht țal

'A mda S Ș.

Ann.

Arabia petr. = A. Musil, Arabia petraea. III. Ethnologischer Reiscbericht. Wien 1908.

Arab. Volksl. = Sachau, Arabische Volkslieder aus Mesopotamien. Abh. der Berl. Akad. 1889.

BA

$=$ Beiträge zur Assyriologie und semit. Sprachwissenschaft.

Bar Șabba a $\bar{e}=$ Patrologia Syriaca Bd. II. 1907.

Beduinengescb. $=$ E. Littmann, Arabische Beduinenerzählungen, Schriften der wissenschaftl. Ges. in Straßburg 2. 3.

Centralar. $\quad=$ Socin, Diwan aus Centralarabien. Abb. d. sächs. Ges. d. W., phil. hist. Cl. Bd. 19.

Chrest.

Contes

Damas

Due framm.

Eskender

Gadla Ar.

Ḥa di r.

Hassān

Houw.

Jak. Ser. Jak. Ser. Hom.

$=$ Afraates ed. Parisot usw. (Patrologia Syriaca)

= zitiert nach der Beiruter Ausgabe von Salhani 1905, nach Seiten und Zeilen.

$=$ Histoire des guerres d' Amda Șyon. Journal as. $1889 \mathrm{Bd}$. XIV.

$=$ The annals of the kings of Assyria ed. Budge and King. 1902.

= Dillmann, Chrestomathia aethiopica.

= Contes arabes modernes .. . par G. Spitta-Bey. Leiden 1883.

= Contes de Damas, recueillis ... par J. Oestrup. Leiden 1897.

$=$ Di due frammenti relativi alla storia di Abissinia. Rendiconti della Acc. d. Lincei. Serie V. Sc. mor. 1893. Vol. II. S. $579 \mathrm{ff}$.

= Histoire d' Eskender etc. rois d' Éthiopie. Jour. nal as. 1894 I $319 \mathrm{ff}$.

= Guidi, Il „Gadla Aragâwî̀. Atti della Accademia dei Lincei, 1894, Vol. II. S. 54 ff.

= v. Landberg, Etudes sur les dialectes de l' Arabie méridionale. Premier Volume : Haḍramoût. Leiden 1901.

= H̦assān ibn Tâbit. Tunis 1281.

= Der arab. Dialekt der Houwāra. Abb. d. sächs. G. d. W. phil. hist. Cl. Bd. XV, 1.

= Jakob von Serug. beigedruckt der Sāhdōnāausgabe; s. d.

= Homiliae selectae Mar Jacobi Sarugensis ed. Bedjan. Paris 1905. 
Isaac Antiochenus ed. Bickell.

Ken

Lal.

Lbd. v. A m.

Lieder

Lieder äg. Bau. = H. Schäfer, die Lieder eines ägyptischen Bauern. Leipzig 1903.

Malt. Märch. $=$ H. Stumme, Maltesische Märchen. Leipz. semit. Studien I 5.

Malt. Stud.

Märchen

Marokko

Neuar. Gesch. = Meissner, Neuarabische Geschichten aus dem Iraq.

Neuar. Volksp. = Neuarabische Volkspocsie, gesammelt von E. Littmann.

Nik.

Op. sel.

Pal. Diw.

$\mathrm{Phil}$.

Săhdōnā

Šar đ̣a Dengel

S ok.

Sonneng.

Takla $\mathrm{H} \bar{a} \mathrm{jm}$.

Tales

Tlemcen

Trip. Bedl.

U $\operatorname{mar}$ Beitr. z. Assyr. u. semit. Sprachw. Bd. V. Abh. d. Gött. Ges. d. Wiss. N. F. Bd. V 2.

$=$ H. Stumme, Maltesische Studien. Ebenda I 4.

$=$ H. Stumme, Tunisische Märchen und Gedichte. Leipzig. 1893.

- A. Socin, zum arab. Dialekt von Marokko. Abl. d. sächs. Ges. d. Wiss. phil. hist. Cl. Bd. XIV 3.

Chronique de Jean évêque de Nikiou ed. Zotenberg Not. et. extr. Bd. XXIV 1.

= Ephraemi Syri aliorumque opera selecta ed. Overbeck. Oxford 1865.

$=$ Palästinischer Diwan. hrsg. v. Dalman. Leipzig 1901.

$=$ The discourses of Philoxenus ed. Budge. London 1894.

$=$ S. Martyrii, qui et Sahdona, quae supersunt omnia ed. Bedjan. Paris 1902.

= Historia regis Sarṣa Dengel ed. Conti Rossini. Paris 1907. (Corpus script. christ. orient.; Script. aeth. II 3.)

= Die Mehri- und Soqoțrisprache von D. H. Müller. (Südar. Exped. Bd. IV. VI. Wien $1902-5$. )

- Knudtzon, Assyrische Gebete an den Sonnengott. Leipzig 1893.

= Il "Gadla Takla Hāymānot". Atti d. Acc. d. Lincei

$=$ Modern Arabic Tales. By E. Littmann. Leiden 1905 (Publications of an American Archaeological Expedition to Syria Bd. VI).

= Le dialecte de Tlemcen p. Marçais. Paris 1902.

$=$ Tripolitanisch-Tunisische Beduinenlieder von $\mathrm{H}$. Stumme. Leipzig 1894 (nach Versen zitiert).

- Umar ibn Abī Rabía ed. Schwarz. Serie V. scienze mor. 1894 Vol. II S. $98 \mathrm{ff}$. 


\section{Einleitang.}

\section{Die Verwendung der Paronomasie.}

\$ 1. Wesen der Paronomasie. 1. Unter Paronomasie wird im Folgenden verstanden eine syntaktische Beziehung zwischen zwei oder mehreren stammverwandten Wörtern von gleicher oder verwandter Bedeutung. Es sind Wendungen wie "Der Fluß fließt" "die höchste Höhe" „ein Grab graben" „der schrecklichste der Schrecken" "Helfershelfer" „so knüpfen ans fröbliche Ende den fröhlichen Anfang wir an" „von Enkeln zu Enkeln sei's nachgesagt" „hei@e Magister, heiße Doktor gar" „am Ganges, am Ganges nur gibts Menschen" „dort klang es lieb und lieber" „und Alles ward erquickt, mich zu erquicken" "es herrscht und ist auch des Ichs Beherrscher" "ich singe wie der Vogel singt" usw. Die Bezeichnungen figura etymologica, schema etymologicum werden gewöhnlich nur auf den inneren Objektsakkusativ angewendet (,vitam vivere") und haben den Nachteil, da@ von ihnen keine Ableitungen bildbar sind. Die paronomastischen Wörter einer Verbindung drücken also die gleiche Grundvorstellung durch gleiche Laute aus; "Fluß" ist in dem obigen Beispiele das paronomasirte Wort, "fliebt" das paronomasirende.

2. Auch sonst geschieht es fortwährend, daß ein Wort die Erinnerung an ein vorangegangenes wachruft; so das anaphorische Pronomen, oder Verba wie "tun", wenn sie eine im Vorangehenden gemachte speziellere Angabe verallgemeinert wiederaufnehmen, oder beide vereinigt („das hat mit ihrem Singen die Lorelei get an"). Es mag sein, daß hierbei öfters mit der Vorstellung auch der Klang der vorhergegangenen Worte wieder auftaucht; in der Paronomasie aber wird dieser Klang geradezu noch einmal hervorgebracht. 
Ferner kommen Umschreibungen und Synonyma in Betracht.

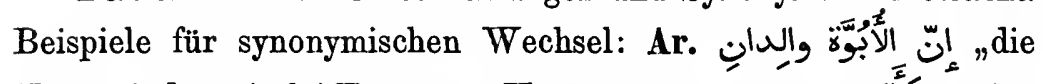

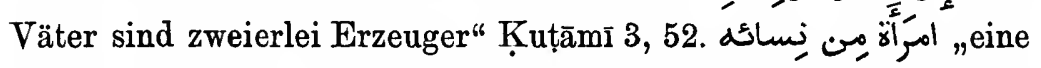
Frau von seinen Weibern" („eine seiner Weiber") I. H̦anbal

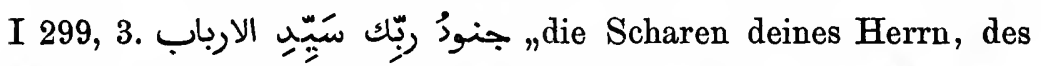

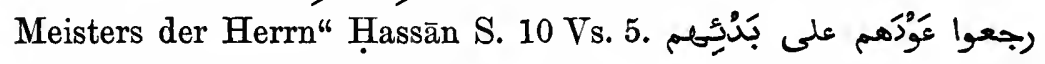
"sie kehrten zurück ihr Wiederkehren zu ihrem Anfangen" = "sie fingen wieder von vorn an" Tab. I4 1973, 2 und sonst. [in ihm [sc. in Arabien], (nämlich) in seiner

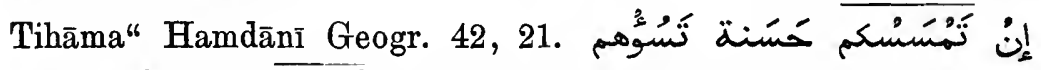

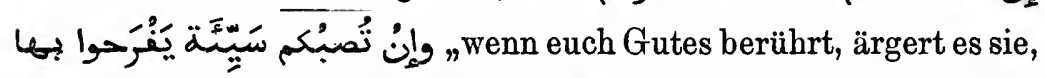
und wenn euch Böses trifft, freuen sie sich darüber"1 Kur. 3,116. So wechseln ferner جاء "kommen" Kur. 7, 126. 19, 44.

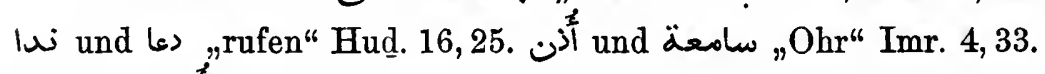

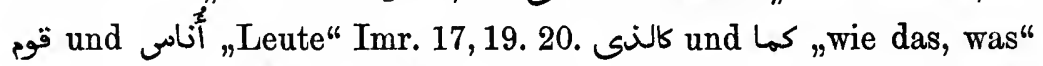

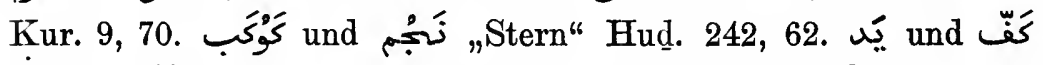

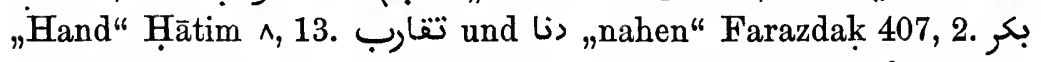
und صبع "leben" Mutalammis 4, 12. Die Negation $ل ا$ als Fortführung anderer Nega-

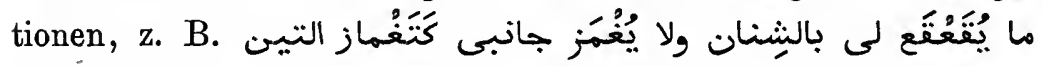
"Nicht knarrt man mir mit den Schläuchen, und nicht preßt man meine Seite wie man Feigen preßt" Kāmil 216, 7. بهاءٍ غيرِ طَرْق ولا „ كِبر usw. vgl. meine Synt. Verh. S. 499 ff. Der Akkus. nach generellem لا

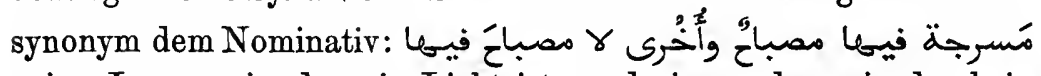
„eine Lampe, in der ein Licht ist, und eine andere, in der kein Licht ist" Găḥiz Buh. 17, 13. Und so noch anderes bei Negationen. Das die Indetermination umschreibende o und das einfach inde-

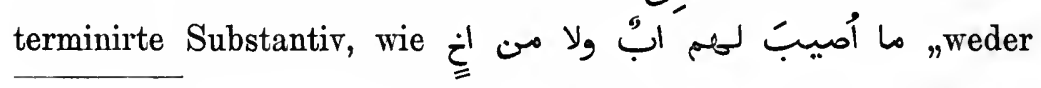

1 مسّى wird auch von Schlimmem gebraucht (Kur. 3, 168 und öfters), und andrerseits اصاب auch von Gutem (Kur. 4, 80; vgl. überhaupt 9, 50. 4; 80 sowie noch 10, 107). 
ein Vater noch ein Bruder von ihnen wurde getroffen" Hiam. 120 Vs. 2. Die Verbindung synonymer Ausdrücke wirkt bisweilen verstärkend, z. B. ich hoffe und harre" Bānat Sư

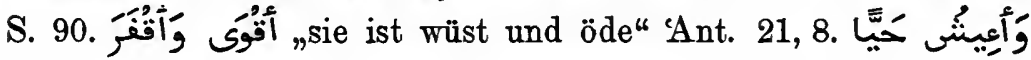
"und soll ich als lebendiger weiterleben?" I. Kut. Kitāb aššír 346,11 . 1.

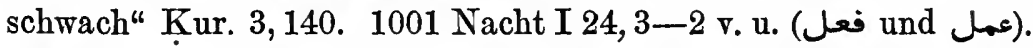
وقفت خيل ونا die Reiter der Benū Hāni standen auf einer Seite, und die der Benū Kašcam auf der andern" Beduinengesch. 11,23. Tales 179, 23. Jā lèt išsōk mā kān ulā ganbar „O wenn doch die Dornen nicht wären und nicht aufschössen" Pal. Diw. S. 5 Mitte. țamān sin̄in w'ām ,acht Jahre und ein Jahr" Arabia petr. 445, 11. Tales 25, 19-20. usw. ÄG. Spitta Gr. § 197 b. Mar. umnāin íḡì

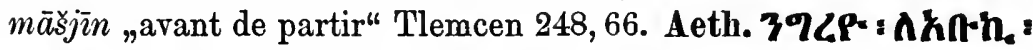
Hhon: hla n.: "Rede mit deinem Vater wie ich mit dir ge-

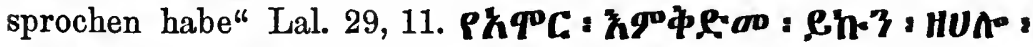
Ch=7: "er wußte, ehe es geschah, was geschehen würde" Lal. 29, 14. Wechsel der Fragepartikeln $n \bar{\imath}$ und $h \bar{u}$, s. Dillm. Gr.

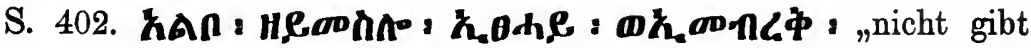
es etwas, was ihm gleicht, weder die Sonne noch der Blitz".

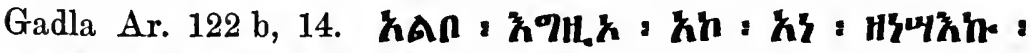

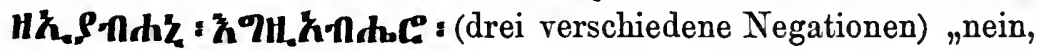
Herr, ich habe nicht genommen, was mir Gott nicht erlaubt hat"

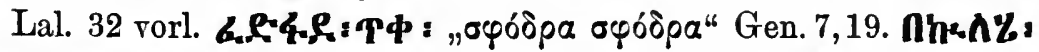
mIh-A : KUT-C: "überall und in allen Landen" Gadla Ar. 58b, 5 .

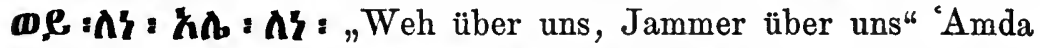
Ș. 410, 3. HehA : h.

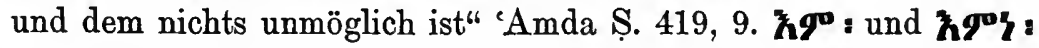

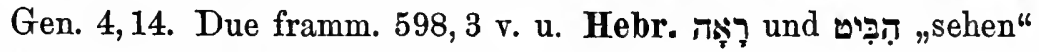

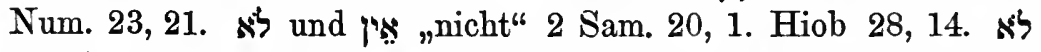
und 1 Sam. 2, 24. לַ (?) 1 Kön. 12, 16, (2 Chron.

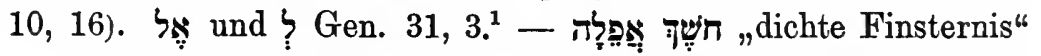

1 Vgl, auch den Wechsel von Aktiv und Passiv and die Tautologie in 


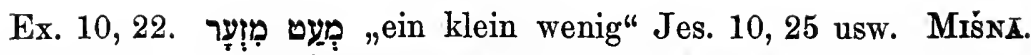

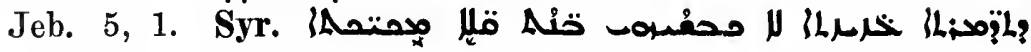
• הحص: Aden gewaltige Wunder nicht unterwarfen, den knechteten

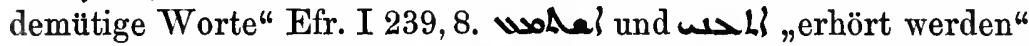
Afr. II 21,5-6. en en "schicken" Addai 5, 21-22. 37,

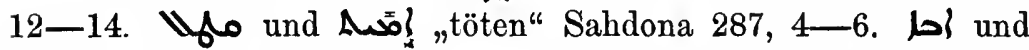

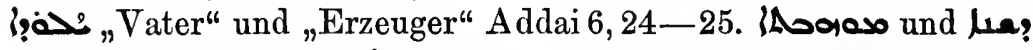

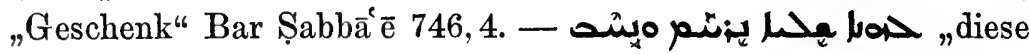
Ruhe mögen und lieben wir" = "lieben wir sehr" Sahdona 93,8

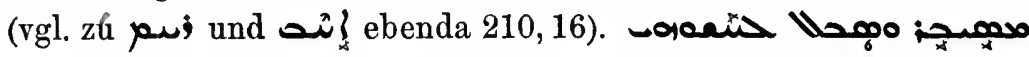
„er erträgt. und erduldet seine Leiden" = „erträgt geduldig"

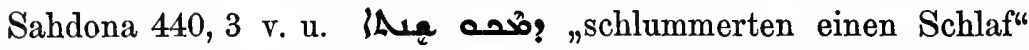

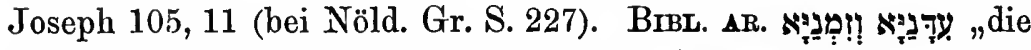

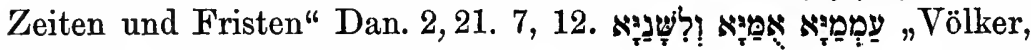
Nationen und Zungen" Dan. 3, 4 usw.

Wechsel der Paronomasie mit anderen Ausdrucksweisen: dab hervorgebrachte Wesen hervorgebrachte anbeten und Geschöpfe ihre

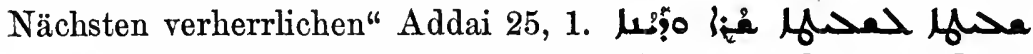
,ein Beamter läßt den Beamten durch, und ein Richter spricht seinen Nächsten frei“ Op. sel. 119, 25. (3)

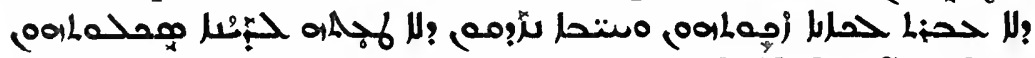
"die Unschuldigen bekennen, daß ihre Unschuld den Gerechten nicht entgangen ist, und die Schuldigen müssen zugeben, daß ihre Sünde dem Richter nicht verborgen geblieben ist" Efr. I 161, 11.

3. Die Elemente der Synonymien weisen wie die der Paronomasien Bedeutungsverwandtschaft auf, sind aber klangverschieden. Wir werden die Synonymien nicht weiter berücksichtigen, ebensowenig die Homonymien; deren Elemente weisen zwar wie die der Paronomasien Klangverwandtschaft auf, sind aber bedeutungsverschieden. - Aus differierenden Wurzeln lassen sich ähnlichlautende oder gar gleichlautende Wörter bilden: Ar. slg > _ _ اءs

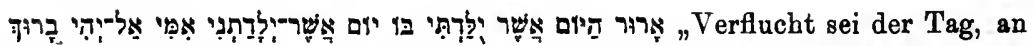
dem ich geboren wurde; der Tag, an dem mich meine Mutter gebar, sei nicht gesegnet" Jer. 20, 14. 
"Heilmittel - Krankheit" 'Umar 129, 6. أخًَا إخُوانٍ (= خِوان) „einen Tischgenossen". Tab. I6 3176, 14. Vulg. Srr. ja min min hejbetku jinhāb „o wer wird durch eure Würde eingeschüchtert?"

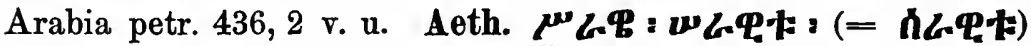
"die Vernichtung seines Heeres" Šarḍa Dengel 53, 25. Die Syr. stellen gerne Formen von "stark sein" dem Part. "مسّل (von "schwach" und seinen Ableitungen gegenüber, z. B. Efr. I 261, 10. Afr. I 655, 19. II 96, 17. 100, 6. usw. Vgl. ferner

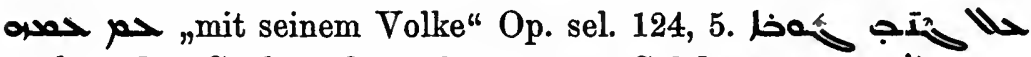
"neben der Grube“ Op. sel. 325, 14. Sahdōnā 245,6 (iLم@ u.

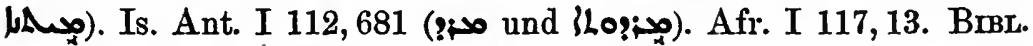

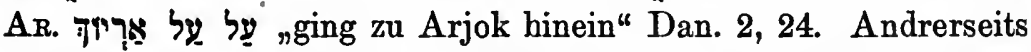
kann sekundär eine Bedeutungsdifferenzierung verwandter Wörter

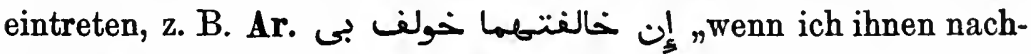
folge, führt man mich ab" Tab. I5 2751, 9 (vgl. de Goeje, selection

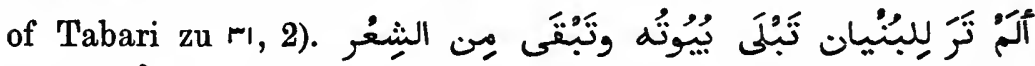
Sahst du nicht, wie beim Bauen seine Häuser vergehen, während vom Gedicht die schneidenden Verse bleiben?“ Ḳuțāmī 14, 30. sie erkennen Wohltaten“ Sỉb. I 189 ult. لdaß meine Verwandtschaft nahe ist" Tab. I6

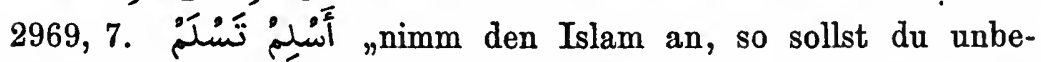

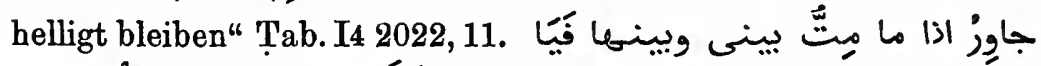
,bringe uns, wenn ich tot bin, in Nachbarschaft zu einander; denn wie köstlich ist mein Tod, wenn sie meinem Grabe benachbart ist!" A g. ${ }^{2}$ VII 102, 4 v. u. $\left(={ }^{1} 108,18\right)$. in der Entfernung der Entfernung" = „in großer Entfernung". (Hier ist بعد zuerst in absolutem Sinne, dann als vox

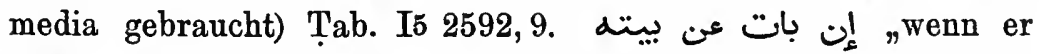
außerhalb seines Hauses übernachtet" ab. TII1 83 ult. من لّ

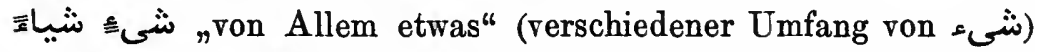
Kāmil 409,5. die Könige aus den beiden Stämmen Mālik" Farazdak I Irq, 2. Ein Wort als Ausrufewort und zitat-

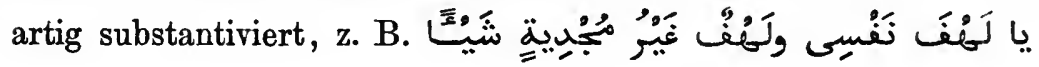


"O Schmerz meiner Seele! Aber ,o Schmerz" nützt nichts"

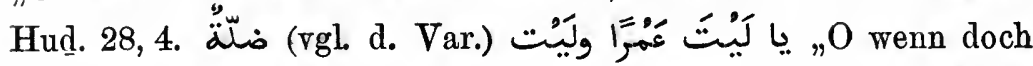
Amr - aber ,o wenn doch" ist Wahn" Hud. 227, 11. 229, 1, Andere Stellen bei Nöld., Zur Gramm. § 54. Die arab. Verba der Bewegung bedeuten in Verbindung mit der Praep. $ب$ bekanntlich häufig nicht mehr "sich mit einem Gegenstande bewegen" sondern "den Gegenstand bewegen" ". Daher heißt es denn auch , رجعت ورجعت بك ,ich bin zurückgekehrt und habe dich mitgenommen" Tab. I4 1967, 10. Vulg. ÄG. fatah kalboh had elkalb(e) "er öffnete sein Inneres und nahm das Herz heraus" Con-

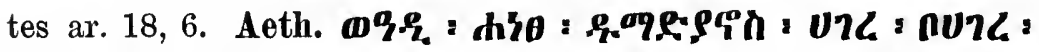
Zh-C:P a "darauf erbaute Domitian eine Stadt im Lande Isaurien“

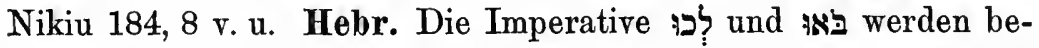
kanntlich in der verblaßten Bedeutung "Auf!" gebraucht; nun

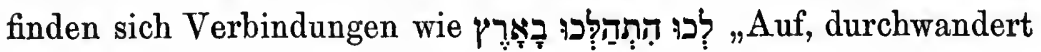

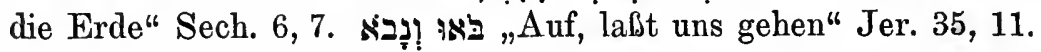
קוּן "Auf, laßt uns aufstehen" Ob. 1,1 usw. Vgl. ferner

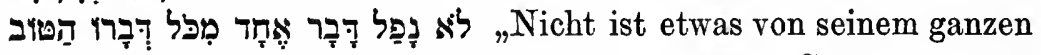
guten Worte zu Boden gefallen" 1 Kön. 8,56. 1 Sam. 3, 17. בְָּּ die Söhne Elis waren nichtsnutzige Leute" 1 Sam. 2, 2. usw. ${ }^{2}$ MIŠñ̄a "bei 100 und mehr; und dieses ,mehr" hat kein Maaß" Terum. 4, 7. Syr. sich erneuern" und „erneuert werden" Phil. 52,13. in "beschneiden" und „beschnitten sein" Is. Ant. I 108, 566. NAB. מלכו מלך נבטו "Maliku, König der Nabatäer" CIS. II 182, 3. Ass. Belu belu „der Herr Bel" Hamm. 26, 89. - Vgl. noch manches in §4. Strenggenommen müssen von unserer Darstellung ausgeschlossen bleiben: 1. Stämme, die in verschiedenen Bedeutungsnüancen gebraucht werden, 2. etymologisch verwandte Wörter, die ihren Bedeutungs-

1 Daß das nicht nur in der deutschen Ausdrucksweise liegt, sondern daß sich im Arab. ein Bedeutungswandel vollzogen hat, ergibt sich aus Stellen wie der nahm ihn mit sich hinaus" Ham. 229, 16. So ferner Buh. III 24, 7. I. Hiš. 88, 9. I. Sacd Gesdsch. 47, 26. Ḥātim S. 84, 14.

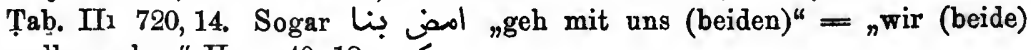
wollen gehen" Ham. 40, 12.

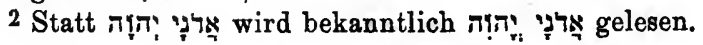


zusammenhang verloren haben, 3. etymologisch unverwandte Stämme, die Klangähnlichkeit besitzen, 4. klangähnliche Wörter, die Bedeutungsähnlichkeit besitzen.

Während in der Homonymie (S. 4) die Wurzelverschiedenheit verhüllt ist, zeigen Fälle wie die folgenden deutlich die bloß partielle Klangverwandtschaft: Ar. عُموم - عَماعم -geeinte - getrennte Stämme" Labīd 51,2 usw. usw. Vgl. zuletzt Nöldeke-Festschrift

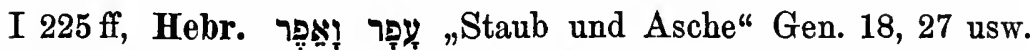
Vgl. Casanowicz, Paronomasia in the Old Testament, Journal of bibl. lit. XII 105-167 (Paronomasie ist da nicht in dem Sinne gebraucht wie bei mir, sondern bezeichnet Assonanzen usw.) Aeth.

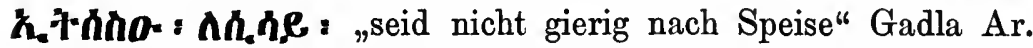
118b, 20 usw. Syr. مة صة - Dornen - Ertrag" Jak. Ser. 767, 4. usw. Ass. līti - lītu „Geißeln - Macht" Ann. 192, 4 (und sonst) usw.

Homonymien sind weit seltener als Paronomasien und nicht von deren großer grammatischer Wichtigkeit. Die Paronomasien sind wohl meist durch ein festeres Band zusammengehalten als die Homonymien, selbst wenn durch die Wortbildung und Flexion weitgehende Lautdivergenzen der paronomastischen Wörter entstanden sind. Auch die Laut- und Akzentgesetze haben Differenzierungen der paronomastischen Wörter bewirkt, z. B. Ar. سأل -

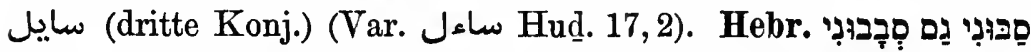

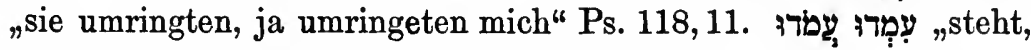
stehet!" Neh. 2,9. Ferner Gen.43,14. Deut. 25,13. Richter 5,7.1 Sam.

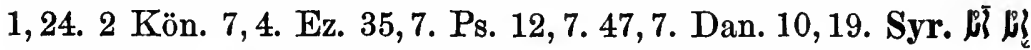
„ich bin es" Marc. 6,50 usw. Endlich seien noch die Verschieden-

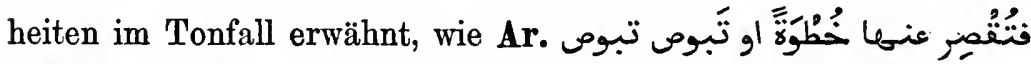

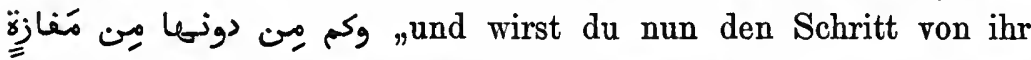
wenden oder (ihr) vorangehen? (Ihr) vorangehen?! - aber wieviele Wüsten trennen dich von ihr!" Imr. 34, 1.

4. Während in anaforischen Prononima und anderen Ersatzwörtern eines wiederauftauchenden Begriffs sowie in der völligen Unterdrückung seiner erneuten Verlautbarung das subjektive Verhältnis des Sprechenden zur Geltung kommt, ist die Paronomasie 
stark objektiv, und Reichtum an Paronomasien, z. B. bei Dichtern, hebt die Deutlichkeit. Aber doch nicht in jeder Hinsicht; denn der wiederkehrende Begriff (das paronomasierende Wort) hat meist eine Veränderung seines Inhalts erlitten, die nicht selten unbezeichnet bleibt, vgl. z. B. die kontrastierenden Nomina in $\S 7$. Subjektiv und beziehungsreich ist die Paronomasie auch insofern schon das bloße Wiedererklingen der gleichen Wurzel ein Bindemittel für die betreffenden Glieder des Satzes bildet und öfters sogar das einzige. Da sie nicht nur eine frühere Vorstellung, sondern auch deren Klang reproduziert, erleichtert sie durch Einprägung des Klangs das Merken des Inhalts und macht die Einheit des Gedankenablaufs im Satze eindringlich. Bei Schriftstellern, die in Paronomasien schwelgen, ist, ganz abgesehen von der künstlerischen — oder unkünstlerischen - Wirkung, dieses Dominieren eines Klangs im Ablauf des Satzes rein sprachlich von Bedeutung. Ihre folgenschwerste und universalste Anwendung aber hat die einigende Wirkung der Paronomasie in der Kongruenz erhalten, denn diese ist zunächst eine Paronomasie gewisser Formantien; nuntius bonus hat Paronomasie der Formantien, opus bonum Synonymie.

Ferner ist zur Charakteristik der Paronomasie zu bemerken, dah in den meisten Fällen durch sie ein und derselbe Wurzelbegriff in verschiedene grammatische Kategorien gebracht ist. Die im Semitischen häufigen Wendungen wie "Er schlug ein Schlagen", "Ein Schlagender schlug" usw. zeigen den Begriff des Schlagens als Verbum finitum und als Verbalnomen, als Prädikat und als dessen Objekt bezw. Subjekt. Es wird sich herausstellen, daß diese grammatischen Verhältnisse, wenn sie paronomastisch sind, einen reicheren Inhalt haben als sonst. Das Verhältnis der Wörter im Satze ist nämlich von viererlei Art: 1. Die Wörter sind weder lautverwandt noch bedeutungsverwandt, 2. lautverwandt aber nicht bedeutungsverwandt, 3 . bedeutungsverwandt aber nicht lautverwandt, 4 . bedeutungsverwandt und lautverwandt. Die letzteren, die Paronomasien, bezeichnen nun meistens überdies, daß das eine Wort eine Entfaltung des anderen ist, und die bedeutungsgeschichtlichen Wirkungen dieses Umstandes werden uns auf 
Schritt und Tritt begegnen; sie dürfen ein sprachwissenschaftliches Interesse beanspruchen, das anderen Ausdrücken nicht zukommt, in denen sich zwar gleichfalls Bestimmungen aus der Natur des Bestimmten ergeben, ohne daß aber ein etymologischer Zusammenhang vorhanden ist; letzteres sind Sätze wie „Die Sonne scheint", "Das Eis ist kalt" usw. Die dem Semitischen ganz geläufigen Sätze wie „Es schlug ein Schlagender" sind der klassischste Ausdruck dessen, was Kant analytische Urteile nannte. Die Paronomasien in ihrer Vielgestaltigkeit, die scheinbar nichts aussagen und doch oft so ausdrucksvoll sind, den Inhalt steigern, scharfe Gegensätze bergen, gehören zugleich zu den lehrreichsten Belegen für die Bedeutung, die dem Konventionellen im Verstehen zukommt.

§ 2. Freie und gebundene Paronomasie. 1. Man würde irren, wenn man in der Paronomasie ein überwiegend poetisches oder rhetorisches Hilfsmittel erblicken wollte. Wenngleich die poetische Literatur die Hauptfundstelle für gehäufte Paronomasien ist, so hat die Paronomasie doch auch in der nüchternen Sprache des alltäglichen Lebens ein breites Anwendungsbereich, denn sie ist unentbehrlich. Wenn wir sie durch sämtliche Kombinationen, in denen sie im Semitischen auftritt, hindurchverfolgen, so wird sich herausstellen, daß sie nicht bloß ein freies Spiel mit Klängen ist - diese Seite ihrer Natur wird sogar fast unberücksichtigt bleiben — sondern sie wird sich als ein notwendiges grammatisches Hilfsmittel erweisen, das Begriffsverhältnisse wiedergibt, für die andere Ausdrucksweisen im Semitischen vielfach überhaupt nicht vorhanden sind. Wenn gehobene Rede vielfach an Paronomasien besonders reich ist, so schöpft sie da nur aus den Gebrauchsweisen, die auch in der einfachen Rede üblich sind; es ist also ein quantitativer, kein qualitativer Unterschied.

$\mathrm{Zu}$ den freien Paronomasien gehören z. B. auch die Etymologien, wie seiner (Geistes)gewandtheit" "Umar 188, 24. Namentlich sind, auch außerhalb der wissenschaftlichen Sprache, Etymologien von Eigennamen beliebt. Sie sind dazu bestimmt, Beziehungen der Eigen- 
namen zu Gattungswörtern des wirklich oder vermeintlich gleichen Stammes aufzustellen. Dadurch werden aber in den meisten Fällen am Träger des Eigennamens Merkmale aufgesucht, die nicht in Wirklichkeit einst zur Verleihung des Namens geführt hatten, sondern erst nachträglich gefunden werden. Ist ein Wort einmal echter und vererblicher Eigenname geworden, so hat er keine begriftliche Beziehung mehr zu den etymologisch verwandten Wörtern; diese Beziehung wird in der Paronomasie künstlich hergestellt, indem der paronomasierte Eigenname ad hoc aus der Kategorie der Eigennamen herausgehoben wird; so entsteht die oft sehr ernst genommene Spielerei des nomen et omen, z. B. Ar. stelle den

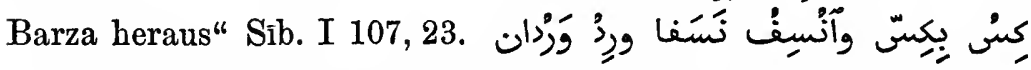
"sei gegen Kiß schlau, rotte Nasaf aus und falle über Wardän her"

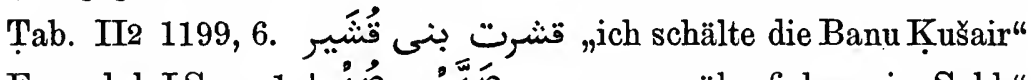

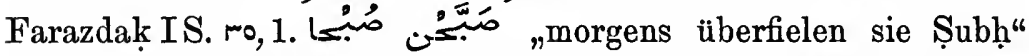
Labīd 42, 13. Vulg. Srr. 'Atāba 'attabatni „Atāba machte mir Unruhe" Pal. Diw. 88, 1. 301 Mitte. Neuar. Volksp. 17 Vs. 26. Sor. I 172 Ged. 27. Hebr. s. Ed. König, Stilistik usw. S. 296. — So wird die freie Paronomasie vielfach zu einem sinnvollen Spiel mit Klängen, das in seinem nachahmenden Verfahren manchmal an die Onomatopoiesie erinnert, nur daß diese außersprachliche Klänge nachahmt, die Paronomasie sprachliche Klänge. Im Grunde beruhen die Wortspiele, gleich dem nomen et omen, auf der ernsthaft oder scherzhaft gemachten Voraussetzung, daß ein direkter kausaler Zusammenhang zwischen zwei Benennungen bestehe, und die eine im Hinblick auf die andere erfolgt sei.

Es ist natürlich nicht möglich, eine strenge Grenze zwischen freier und notwendiger Paronomasie $\mathrm{zu}$ ziehen, und es soll hier überhaupt darauf verzichtet werden, den ästhetischen Motiven für den Gebrauch der Paronomasien nachzugehen. Wenn die Zahl der Paronomasien eines Schriftstellers das in seiner Sprachgemeinschaft, in seiner Zeit und in dem betreffenden Genre vorherrschende Durchschnittsmaß überschreitet, kann man hierin einen Anlab ästhetischer Art erblicken. Dagegen ist es unstatthaft, ganze Sprachen in Bezug auf die Häufigkeit ihrer Paronomasien 
ohne weiteres $\mathrm{zu}$ vergleichen und in dem größeren Paronomasienreichtum der einen Sprache ein vergleichsweise stark wirkendes ästhetisches Prinzip zu finden.

2. Hierzu kommen noch die bloß zufälligen Gleichklänge, wie

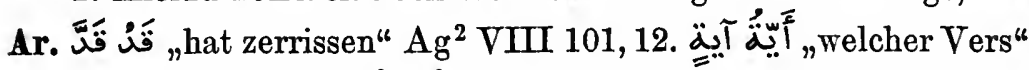
Buh. III 174 vorl. "أمر أميَ "befahl dem Befehlshaber" Tab I4 1880, 5. Die Kakophonie ف ف in dem Munde" Tab. I5 2259, 9. 2423, 9 (vgl. die Var.). Buh. III 177, 15. Farazdak I S. II, 7. Gāhiz Buhalā 97, 3 usw. Zahlenverbindungen wie ألُْف ألٍْف ,eine Million" passim. Adrei

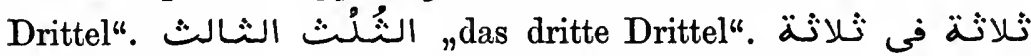

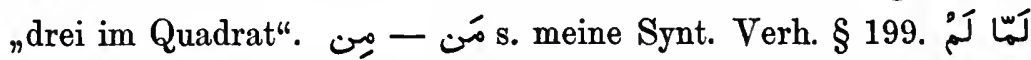
"nachdem nicht" passim. Eine Präpos. vor dem Relativsatz, die vor dem Rückweisepron. ('â'id) wiederholt ist, wie في اليوم الذیى في "an dem Tage, an dem ich den Islam annahm" Buh. III 23, 5 usw. (vgl. Synt. Verh. 621). Ferner Kur. 20,49. 74, 9. I. Hiš. 21, 11. 22, 12. 342, 4-5. Tab. Ш1 298, 14. Ruk. 12, 10. Appellativ und Eigenname: الذى ابوه ابو العاصى ,dessen Vater Abul'āṣī ist" Ruk. 1, 16. Tab. I5 2325, 5. Vulg. Srr. مثل ما قال المثل

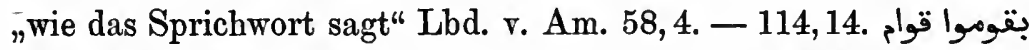
„sie machen sich rasch daran" Tales 2,13. ف ف Tales 4,1 (,im Innern") 6. $61,2.71,4.244,10$. ÄG. wala lā "oder nicht" Contes ar. 6,4 v. u. - 39, 2. MaLt. Stud. 49, 18 („laß mich hierlassen"). - 11, 12. MAR. därilha wahed dār „er ließ ihn ein Haus bauen"1 Houw. 58, 28. bwilli lli „daß derjenige, der" Houw. 50, 5.

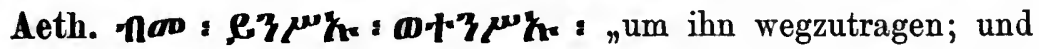
es erhoben sich gegen sie Leute" Chrest. 32,16. — Lal. 2 vorl.

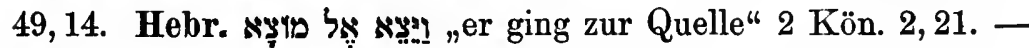
Lev. 26, 32. Num. 16, 27. 21, 9. Deut. 3, 25.-26. 5, 28. 31, 15. Jos. 22, 19. 1 Sam. 6, 20. 8, 3. 2 Kön. 10,6. 11, $14=2$ Chron. 23, 13. Jes. 53,11. Ez. 17, $16=2$ Chron. 6, 10. Prov. 26, 17. 2 Chron.

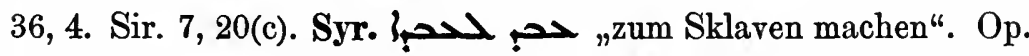
sel. 275,18. und oft. Ferner Luc. 2, 17. Matth. 4,1. Addai 36, 10.

1 dār bedeutet überhaupt „hinsetzen" „machen“. 
Op. sel. 53, 4. Spic. 10,5. 11, 25. Efr. I 243,6. II 463, 2, 10. 466, 6, 10. Afr. 117, 13.604, 25-26. Phil. 77, 19. 350, 2. 382, 12.385, 11. 407, 6-7. Bar Șabbāēe 803, 19. Bibu.-Ar. Dan. 7, 10. Ass. šanūte šañ̄tu „das zweite Mal" Ann. 225,27. ana șit šamšim uși "nach Sonnenaufgang zu kommt er heraus" Lpz. sem. Stud. I1 38, 3. kī kitti „dem Rechte gemäß" KB V No. 50, 19.

3. Für die Anwendung der freien Paronomasie in der Dichtung waren ersichtlich öfters Gründe des Metrums oder Reims maßgebend. Es wird also öfters in der Dichtung paronomastische Ausdrucksweise gewählt, wo ein Ersatzwort genügen würde, z. B. mein Bestes gehört dem, der mein Bestes

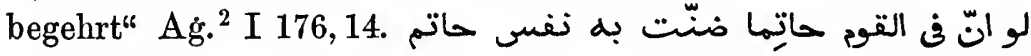
„wenn Ḥātim unter den Leuten wäre, so würde die Seele Ḥātims mit ihm (sc. dem Wasser) geizen" Kāmil 133,20. أَثيم مَماب المُّْْ ich beobachtete die Entleerung der Wolke, wo die Entleerung erfolgen würde" Imr. 20,26. - Ḥam. 205 Vs. 4.326 vorl. Kuțāmī 2, 51. Hud. 15, 1. 252, 27. 279, 6. Ruk. 11, 1. Usw. Vgl. Kap. III. Im Koran: لَعَلِّل أبلغ الاسبابَ اسباب السموات "vielleicht gelange ich zu den Pforten, den Pforten des Himmels" 40, 38 - 39 (es mußte vermieden werden, daß der status cstr. an den

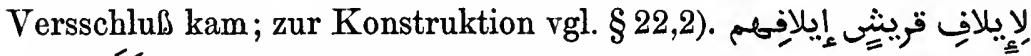

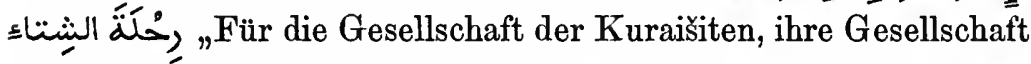
für die Kárawane im Winter" 106,1 - 2 (ähnlich; der Akk. konnte nicht über den Versschluß hinweg von ايلاف abhängen).

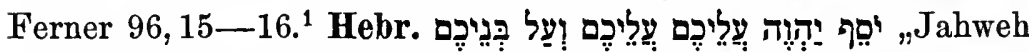
mehre euch, euch und euren Kindern" Ps. 115, 14. - 136, 21-22. Sonstige Einflüsse des Verses: Ar. Nab. 5, 35 wird des Metrums wegen neben حسب حسّب angewendet;

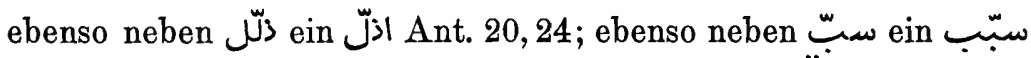
(in der Bedeutung "schmähen") Kumait S. 35e. (Über sonstigen Wechsel synonymer Konjugationen s. § 12). Vulg. Sxr. jā ḩabībi $j \bar{a} h a b \bar{\imath} b$ „O mein Freund, o Freund!“ (Reim). Pal.Diw. 166 No. 1.

1 An den Stellen 2, 122. 14, 17. 22, 13. 35, 32 hat Mohammed das Verbum wiederholt, um einen volleren Versschluß zu erzielen. 


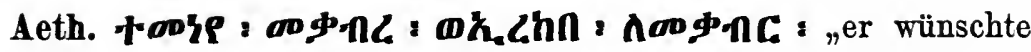
Gräber, aber er fand keine Gräber" (Reim). Kenē VUI ult. Das paronomasirende Wort hat natürlich einen stärkeren Gefühlswert als das vertretende Pron. oder Ersatzverbum. Wenn also

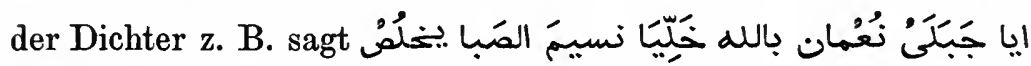
O ihr beiden Berge Nuimāns, bei Gott, laßt das Wehen des Westwinds entströmen, so wird mich sein Wehen treffen" A $\dot{g}^{2}{ }^{2}$ I 170, $8\left({ }^{1} 176,21\right)$, so ist er dem Zusammenhang stärker entrückt — während das Pron. an die augenblickliche Situation fesselt - und schwelgt in der Erinnerung oder im Vorgefühl.

4. Als künstlerisches Ausdrucksmittel greift die freie Paronomasie weit über das Anwendungsgebiet der gebundenen Paronomasie hinaus. Es gibt Schriftsteller, bei denen die Paronomasie üppig entwickelt ist, und es gibt ein ganzes arabisches Genre, für das die Häufigkeit der Paronomasie charakteristisch ist, nämlich die didaktische Dichtung. Man wird das z. B. sofort gewahr, wenn man beim Durchlesen der Mu'allaka Zuhairs an die didaktische

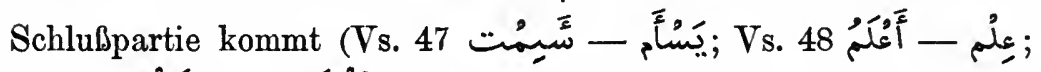
Vs 51. يُشُشتَم - الشَّتُ - usw.). Áuch wo sich die Paronomastik in bescheideneren Grenzen hält, ist sie in der Übersetzung oft unnachahmbar und hat selbst der Kunst Fr. Rückerts gespottet. Was im Original elegant und einschmeichelnd war, wird in der Übersetzung plump und aufdringlich. Am wenigsten hat die gebundene Paronomasie des Semitischen das Gewicht, das ihr durch wörtliche Übersetzung beigelegt wird; "es schlug ein Schlagender" ist einfach "es schlug Einer" $(\S 19,5)$, „er schlug ein heftiges Schlagen" ist einfach "er schlug heftig" (§ 23), und so noch Vieles. Öfters genügt uns schon eine starke Betonung; „er schlug ein Schlagen" = "er schlúg." Eine Übersetzung kann infolge ihrer Genauigkeit ungenau werden. Ohnehin liegen den Paronomasien des Originals vielfach stereotype Bedeutungsbeziehungen zu Grunde, während die Sprache der Übersetzung keine Paronomasie gebraucht, z. B. Wf "töten" - Nomen

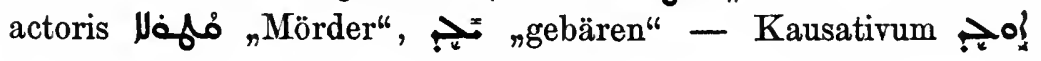


"zeugen", אכל אוכלין "Netz" טמאים ושתה משקין טמאים unreine Getränke trinkt" Mikw. 2, 2.

5. Nicht selten kommen gar drei oder noch mehr Ableitungen einer Wurzel in nächste Nachbarschaft zu stehen, und zwar nicht nur auf getrennte Sätze verteilt, sondern innerhalb des gleichen Satzes oder auf Haupt- und Nebensatz verteilt. Die folgenden Beispiele bieten nur solche Fälle, in denen sich die paronomastischen Wörter entweder berühren oder doch nicht allzu beträchtlich von einander abstehen. Übrigens wird auch bei Kontaktstellung zweier Glieder ihre Verteilung auf Haupt- und Nebensatz eine gewisse Fuge hervorrufen, wie tiberhaupt die Stärke der Trennung in verschiedenen syntakt. Verhältnissen verschieden sein wird; sie wird, z. B. im Allgemeinen bei Subj. - Präd. stärker sein als bei Subst. - Attribut usw.

a Dreifache Paronomasie. Ar. Alle drei in Distanzstellung: ich treibe mich herum, und sähe ich nicht die Umm Gafar in euern Häusern, ich würde mich nicht herumtreiben, wo ich mich herumtreibe" Ag. ${ }^{2}$ IV 48, 22 (und 23). I 170, 20. Tab. I4 2073, 4, I5 2548, 3.

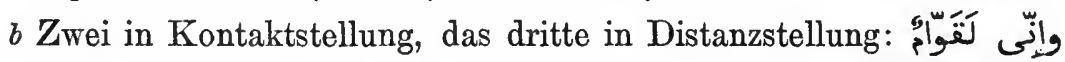

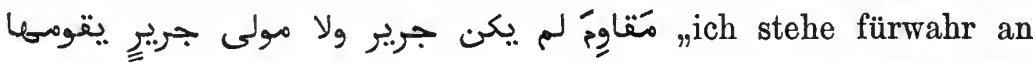
Stellen, an denen weder Garīr noch Garīrs Klient stehen" Ahțal 13,5. Ag. $^{2}$ X 71, 7. Hud. 158, 2. Tab. I4 1859, 3. 2066, 7. 2157, 13. I5 2687,2. Das dritte nur schwach getrennt: ما ترى كرأُ "du hast nicht die Ansicht, die wir haben" Zuhair 15,17. Bānat Sưād S. 185. Labīd 27, 12. 'Ant. 12, 5. Imr. 11, 1. 40, 9. I. Hanbal I 176, 2 v. u. Kur. 5, 115. 26, 18. I. Hiš. 21, 4. 117, 15. I. Sa`d Gsdsch. 31, 8. Tab. I4 1716, 12. I5 2281, 3. 2444, 1. 2479, c 15-16. II1 240, 16. II2 909,11. 1100, 1. Alle drei in unmittel-

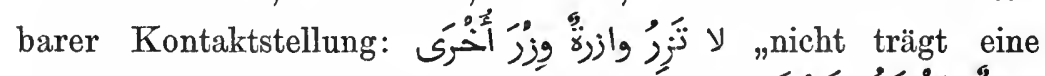

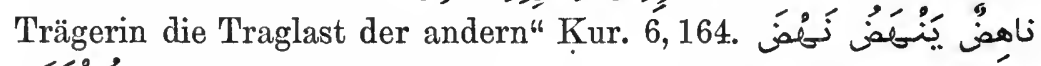
"ein sich erhebender, der sich erhebt wie das sich ér-

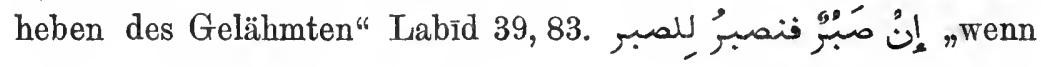


(es auf) Geduld (ankommt), so gedulden wir uns bei Geduld" Sib.

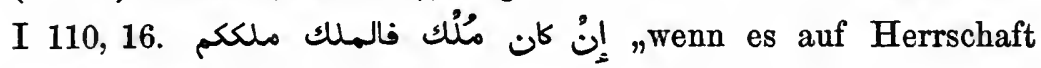
ankommt, so ist die Herrschaft eure Herrschaft" (= gebührt sie euch). Tab. I4 1912,4. Vulg. Srr. (a) Jä wanneti mā wann ${ }^{e} h a$ kiull wannān "o mein Seufzen, nicht seufzte so irgend ein Seufzender“ Pal. Diw. 37 Mitte. (b) بدل مكتوبو بمكتوب كان هو كتبو ,er vertauschte sein Schreiben mit einem Schreiben, das er geschrieben hatte" Tales 75, 16. Lbd. v. Am. 24, 14. Neuar. Volksp. 39 Vs. 63. ÄG. (a) libist kuhli 'ala kuhlī baḳa kuhlī „ich kleidete mich in kuhlfarbiges auf kuhlfarbiges, ganz und gar kuhlfarbig" ZDMG 33, 621, 13. Contes ar. 30,6. MAR. (b) wahed ligdera ligedrurržāla ġdirtūni ,ihr habt einen Verrat an mir begangen, wie ihn nur schlechte Männer begehen" Houw. 64,11. Maxt. Vgl. die eigentümliche Erzählungsform Malt. Märchen S. XV (z. B. Malt. Stud. 12, 33. 19, 36. 20 ult. 26, 26. 27, 34. 28,6.), wodurch die Handlung hinausgezogen wird und dadurch spannender wirkt.

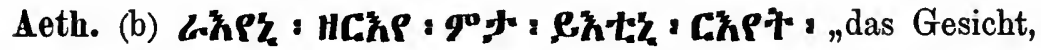
das ihr Mann gesehen hatte, sah sie ebenfalls" Lal. 39, 7. Gadla

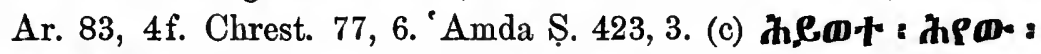
Hh९Q3, "lebe das Leben der Lebendigen" Kenē XLV, 1.

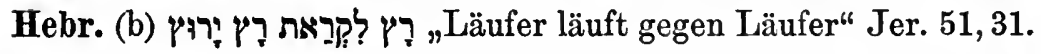
Lev. 11,37. 44. 25,39. Num. 3, 38. 18,21. 1 Sam. 3,17. 1 Kön. 13, 31. 2 Kön. 23, 19. Jes. 29, 14. Jer. 11, 7. Ez. 34, 11-12. Koh.

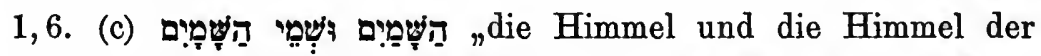
Himmel" Deut. 10,14 (= 1 Kön. 8, 27. 2 Chron. 2, 5. 6, 18. Neh. 9,6.). die Fähre fuhr über um die Familie des Königs hinüberzufahren" 2 Sam. 19, 19. Jes. 10,16. 22,18. 24,16. 27, 7. Jer. 50, 34. 2 Chron. 26, 15. Sir. 51, 12 n. MršNa. der Räucherer pflegte nicht zu räuchern, bis der Vorsteher zu ihm sagte: Räuchere" Tamid 6, 3. Jeb. 1, 3. Syr. (a) صå?: "weil sich die von ihm Getauften nochmals mit der Taufe der Apostel taufen ließen" Efr. I 105, 5, 3. Is. Ant. I 26, 28. Addai 6, 11. Afr. II 32,13-14. Op. sel. 32, 23. Efr. I 43, 3, 4. 155, 8. 167, 18. 229, 8. Carm. Nis. 2, 51. Phil. 52, 14. 
(c) I 569,5,1. ich versammelte mich mit der Versammlung, um von ihren Vorteilen zu sammeln"

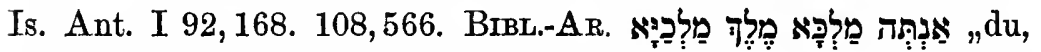
o König, König der Könige" Dan. 2, 37. Ass. (b) teteršanni erištum la ereši „du hast von mir einen Wunsch gewünscht, den man (sonst) nicht wünscht" KB VI 88, 22. 138,35. (c) Bel bel bele „Bel, der Herr der Herren" KB I 192, 5. summa daianum dinam idin „wenn ein Richter einen Prozeß geleitet hat" Ham. 6,6.

Vier- und mehrfache Paronomasie. Wiederum geordnet nach dem zunehmenden Grade des Kontakts. Ar. يا حَتَّ ما حُشتُّ ,Wie herrlich ist die Liebe zu Katūl, obwohl die Liebe zu ihr etwas Aussichtsloses ist; also quäle dich eine aussichtslose Liebe nicht" Hud. 154, 4. Tab.

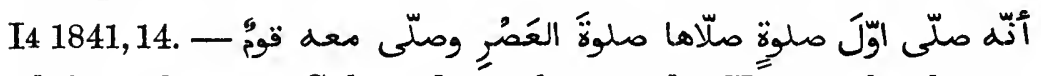
„daß er als erstes Gebet, das er betete, das Vespergebet betete, إن الربّ لَبَرتضِى فيرضَى . فآرضً عنى رضى الله عنك "Wahrlich der Herr läßt sich begütigen, so daß er wieder gut ist, so sei auch du mir wieder gut; möge Gott

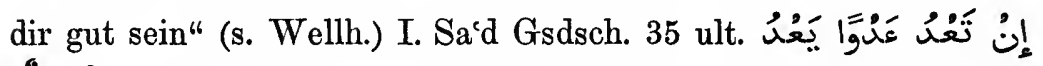
"wenn sie ein Stürmen stürmt, stürmt ein über Fels-

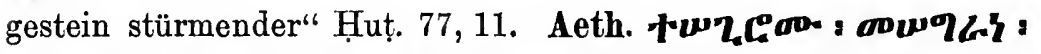

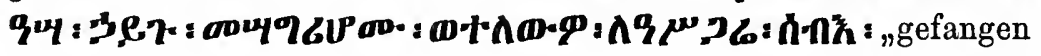
in den Schlingen verließen die Fischer ihre Netze und folgten dem

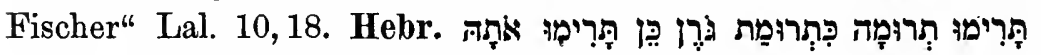
„sollt ihr als Hebe erheben; wie die Hebe von der Tenne sollt ihr sie erheben" Num. 15,20. Gen. 49, 19. Lev. 19, 9. Richt. 16, 30. un zu verrichten das Verrichten der Verrichtung und das Verrichten des Tragens" Num. 4,47. Syr.

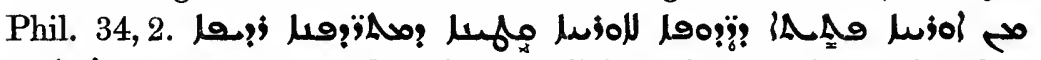

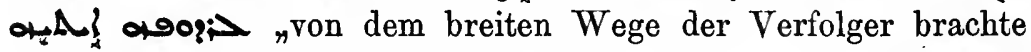
der Verfolgte seinen Verfolger auf den schmalen Weg der Ver-

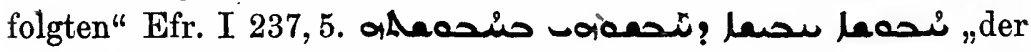
Einschließer ist ein Eingeschlossener, den sie in seinem Gefängnis 
eingeschlossen haben" Carm. Nis. 129,104. - Carm. Nis. 174, 2106 (sechsfach). 67, 10 (sechsfach, darunter vier in Kontakt). Is. Ant. I 172, 2102 (siebenfach). Efr. I 257, 5 v. u. (unter 74 Wörtern 19 paronomastische, wovon zweimal drei in Kontakt). Ass. ša... Marduk mušim šimāti ana kiššsuti mātāti ebešu išimu šimatsu "dessen Bestimmung Marduk, der Bestimmer der Bestimmungen, bestimmte, die Eroberung der Länder zu vollbringen" KB III2 70 No. 1, 6 .

Schließlich können noch verschiedene Paronomasien aneinander gereiht oder in einander verschlungen sein, wie Syr. loa $N$ "er gebar die Eva nicht, sondern sie ging ohne Geburt aus ihm herror" Jak. Ser. 858, 2. bei Weisen wirst $d u$ nicht schlecht werden und bei Schlechten nicht weise" Ahikar 35,10. Ass. hubtu ma'du sallatu kabittu ihabbatu išallalu „große Plünderung, schwere Beute plündern sie, erbeuten sie" Sonneng. No. 35, 9. usw. usw. Indes soll all das nicht weiter verfolgt werden.

6. Die Paronomasie zeigt je nach dem Zusammenhang, in dem sie auftritt, und je nach der Individualität der Schriftsteller einen verschiedenen Charakter. Sie ist bei den einen scherzhaft, ja burlesk, bei den andern erhaben. Die Neigung zu dem Gebrauch ihrer mannigfachen Gestalten wechselt selbst bei ein und demselben Schriftsteller. Z. B. kommen Infinitive des inneren Objekts ohne nähere Bestimmung $(\S 23,7)$ bei Mohammed in den frühesten Korankapiteln fast gar nicht vor, werden dann aber häufiger, um in seiner späteren mekkanischen Zeit wieder auszubleiben; auch in seiner medinischen Zeit begegnen sie verhältnismäßig selten. Er verwendet solche Infinitive der zweiten Konjugation, weil er Reime auf $-\bar{\imath} m$, -iेl, -ìr usw. braucht. Er hat auch den Inf. كِنّ (78, 28). Aber selbst in solchen Fällen ist die Paronomasie, vorab die freie, infolge ihrer Klangwirkung ein künstlerisches Ausdrucksmittel, da sie neben Vorstellungen auch Gefühlswerte hervorbringt. Es wird für uns schwer sein, die Wirkungen der paronomastischen bloßen Klangkombinationen - abgesehen selbst 
von ihrem Inhalt - voll zu begreifen, die im Orient ganze Völker und ganze Jahrtausende entzückten. Diese Freude am Klang hat ihren eigenen künstlerischen Wert und darf nicht gering geachtet werden. Die Paronomasie verleiht offenbar dem Satze Resonanz, ihr Forttönen hält die Stimmung fest; sie wird vorübergehend durch andere Klänge überdeckt um dann, sobald diese verstummt sind, wieder vernehmbar zu werden. Dies sozusagen dynamische Mittel, das ebenso sehr auf die Sinne wie auf den Verstand wirkt, sollte demgemäß ebenso sehr mit dem Ohr als mit dem Verstand aufgenommen werden. Sie hat für unser Empfinden etwas Überladenes, und wollte man alle Paronomasien übersetzen, so würden selbst schlichte Erzähler, z. B. im alten Testament, diesem Vorwurf nicht ganz entgehen. Aber gewandt bewegen sich darin auch Schriftsteller mit üppigster Paronomasie, und es ist für die Beurteilung des Ganzen eben doch ein Unterschied, ob Paronomasien mit Not und Qual, durch Verrenkung und Verzerrung des Sinnes zu Stande kommen, oder ob sie leicht und mit ungezwungenem Ablauf der Gedankenfolge hervorströmen. Die bis zu einem gewissen Grade notwendige Paronomasie hat dem weitgetriebenen Gebrauche der freien Paronomasie vorgearbeitet und an ihn gewöhnt. Bei der Abwägung der Paronomasien haben wir strenggenommen das abzuziehen, was schon der allgemeinen Sprache als Usus angehört. Und wenngleich ferner, wie schon oben bemerkt, der Paronomasie zu Liebe selbst Worte neu gebildet werden, so ist das doch etwas recht Vereinzeltes. Im allgemeinen ließ man sich nicht von Klangassoziationen dahintreiben, sondern verfügte frei über den einer paronomastischen Verwendung fähigen Wortvorrat.

7. Es liegt nicht in meiner Aufgabe, der ästhetischen Seite der Paronomasien nachzugehen, und es soll nur noch allgemein bemerkt werden, daß mancher Geistesblitz in ihnen aufleuchtet, und feine, selbst uns verständliche Effekte durch sie hervorgebracht werden. Ich habe mich hier um so mehr gedrungen gefühlt, den adrocatus diaboli zu machen als mein Stoff im Ü̉brigen Texten mit mäßigen Paronomasien entstammt. Ich bin weit davon entfernt, persönlich Geschmack an dem Paronomasienreichtum zu empfinden, muß aber doch feststellen, daß man den 
Schriftstellern nicht gerecht wird, wenn man ihre Paronomasien lediglich als äußeren Aufputz oder müßigen Zeitvertreib ansieht. Wenn die Paronomasie zu einem durchgehenden, gradezu beherrschenden stilistischen Mittel erhoben ist, wird sie für uns allerdings ungenießbar, mögen sich auch die Araber an ihr berauscht haben. Wir können auch das unangenehme Gefühl nicht los werden, es möchte diesen Worten oft an der realen Grundlage fehlen, den Klängen möchten die Gedanken erst nachträglich, wenngleich sofort, eingehaucht sein. Und dann ist es wieder ein wohlfeiles Grübeln über ein und denselben Begriff, das notwendig immer wieder zu ähnlichen Wortkörpern greift. Hier konnten sich die Tüfteleien namentlich Solcher entfalten, denen es schwer ward, durch Kombination entlegenerer Vorstellungen etwas Neues zu schaffen, und die es darum vorzogen an der gleichen Wortwurzel zu zerren. Nicht zu vergessen der Wortwitze mit ihren äußerlichen Mittelchen.

Wir verlassen hiermit definitiv die freie Paronomasie als künstlerisches Mittel.

\$3. Wechselbeziehung der paronomastischenWörter. 1. Angesichts der engen lautlichen und begrifflichen Beziehungen, die zwischen wurzelverwandten Wörtern bestehen, könnte man versucht sein anzunehmen, beim Aussprechen eines Wortes müßten wurzelverwandte Wörter in stärkerem Grade als andere Wörter ins Bewußtsein treten, d. b. also, paronomastische Wörter müßten die größte Assoziationsfähigkeit besitzen. Wir besitzen keine Untersuchungen darüber, wie es auf semitischem Sprachboden hiermit bestellt ist. Die Beobachtungen, die im Abendlande angestellt worden sind, lassen aber eine solche Annahme keineswegs als selbstverständlich ercheinen. Prüft man z. B. die Tabelle XXIV bei Thumb u. Marbe, Experimentelle Untersuchungen(Leipzig 1901), auf Paronomasien, so ergibt sich folgendes: Unter 640 Reaktionen von 8 Versuchspersonen auf 80 Reizwörter (Infinitive) ist nur $1 / 10$ paronomastisch, dazu kommt $1 /{ }_{15}$ mit partieller Wurzelverwandtschaft ohne Bedeutungsverwandtschaft, zusammen also $1 /{ }_{8}$. Allerdings verhalten sich nun die Versuchspersonen verschieden. Es ist eine darunter, die unter ihren 80 Reaktionen sogar ${ }^{2} / 4$ parono- 
mastische und $1 / 6$ mit partieller Wurzelverwandtschaft aufweist, zusammen also $5 / 12$; auf diese Person kommt gegen $1 / 3$ aller paronomasierenden Reaktionen der 8 Personen. Ich selbst machte folgenden Versuch. Ich schlug ein Buch auf und reagierte auf das letzte Wort rechts unten. Nur selten war die Reaktion paronomasierend, und, was bezeichnend ist, selbst wenn infolge von Umbrechen der Zeile die Seite mit einem Wortfragment schloß, wurde nicht mit dem Gesamtwort reagiert, also z. B. auf "körper-" nicht mit „körperlich" (oder auch "lich"), sondern mit „Geist" usw. Dagegen kommen wieder zahlreiche Reaktionen mit der gleichen Wurzel vor in den Tabellen von Friedrich Schmidt, die bei Thumb, Indogerman. Forschungen XXII (1907) $36 \mathrm{f}$, abgedruckt sind. Indes berechtigt das alles nicht zu Schlüßen auf die semit. Sprachen.

2. Soweit die Paronomasien dem gleichen Satze angehören, sind ihre Elemente dreifach verbunden: Durch die Gemeinsamkeit der Bedeutung, des Klangs und durch ihr syntaktisches Verhältnis mit allem, was zu ihm gehört. Die Klangverwandtschaft kann auf bloßer Wurzelgleichheit beruhen oder außerdem auf engerer Formenverwandtschaft (verschiedene Kasus eines Subst.; verschiedene Tempora eines Verbums usw.). Nun erhalten viele Wörter dadurch, daß sie zu bestimmten andern Wörtern in dauernde Beziehung treten, eine spezialisierte Bedeutung („eine Wunde schlagen" — "eine Brücke schlagen"); welches diese Bedeutung ist, läßt sich aber nur von Fall zu Fall durch Beobachtung des Sprachgebrauchs feststellen. Für die Beziehungen paronomastischer Wortverbindungen dagegen läßt sich schon auf Grund der grammatischen Kategorien, denen die Bestandteile angehören, ein bestimmter Sinn ableiten, der sich also nicht aus der Sachbedeutung der Bestandteile ergibt. Auf dieses Erzeugnis der Beziehung wird in den einzelnen Kapiteln zu achten sein.

3. Eine durchgängige Eigentümlichkeit der paronomastischen Beziehungen ist die folgende, die aus der Natur der Paronomasie entspringt. Betrachten wir Ausdrücke wie „der Mann tötete ein Töten" (§23,7) „ein arabischer Araber" ( $\$ 20,1)$, so scheinen das auf den ersten Blick Binsenwahrheiten zu sein. Einem Mann, der 
tötete, wird sich, wo nicht mehr, so doch zum allermindesten das nachsagen lassen, daß er hierbei als Wirkung die Handlung des Tötens hervorbrachte, und es scheint darin nicht einmal eine $\mathrm{Be}$ lehrung oder doch Formulierung zu liegen wie in Sätzen von der Art „das Eis ist kalt". Ebenso ist von einem Araber die Eigenschaft „arabisch" unzertrennlich. Und umgekehrt: wäre nicht bekannt, welche Handlung der Mann, der tötet, durch den Akt des Tötens eo ipso hervorbringt, so würde es auch nichts nützen, wenn man zur Erklärung dieses unbekannten Wurzelbegriffs den Wurzelbegriff selbst heranzöge. Dennoch ist das Ergebnis solcher Denkübungen nicht $=0$, sondern besitzt einen positiven Wert, unter Umständen sogar einen sehr starken.

Den Wörtern ist nämlich im Gebrauch häufig eine gewisse Spielweite gelassen, und sie dürfen nicht immer auf die Wagschale gelegt werden; sie werden z. B. nachlässig oder hyperbolisch angewendet. Daher fügen wir im Deutschen nötigenfalls das Wort „wahr" oder dgl. hinzu („das ist ein wahrer Unfug") und wollen damit sagen, daß das Hauptwort reiflich überlegt ist und alle seine Kennzeichen im vorliegenden Falle zutreffen. Dasselbe leistet im Semitischen in zahllosen Fällen die Paronomasie. Das eine Element der paronomastischen Verbindung ist das Ergebnis einer Prüfung des andern; es soll damit einer Anzweiflung begegnet werden. Es ist also ein Neuschaffen, und zwar dient es der Erhöhung der Gewißheit; es ist alsdann die Existenz oder Lückenlosigkeit oder Eindentigkeit festgestellt. Tatsächlich ist also eine Bereicherung des Satzinhaltes erfolgt, wenn sie auch nicht verlautbart wurde, und wir haben eine Form der Ellipse. Denn wie in der Ellipse bedeuten hier die ausgesprochenen Wörter mehr als ihr konventioneller Gebrauch verlangt, nur liegt dieses Plus bei der Paronomasie der Natur der Sache nach nie in einem Einzelwort, sondern stets in der Wortbeziehung.

Aber noch mehr. Durch die Paronomasie entsteht bisweilen sogar eine Wertunterscheidung. Wenn es z. B. heißt „das Lied der Lieder", so ist das strenggenommen wieder nur eine taube Nuß; denn ein Lied gehört natürlich von selbst zur Gattung der Lieder. In Wirklichkeit bedeutet es aber das Lied, das im hö chsten 
Grade Lied ist (s. Genaueres $\S 31$ ), und die übliche Übersetzung "das ho he Lied" ist noch nicht einmal stark genug.

4. Es kann hier noch ein anderer Fall besprochen werden, der uns ebenfalls den auf psychologischen Grundlagen beruhenden Sprachgebrauch in Widerstreit mit der Logik zeigt. Eine doppelte Negation kan n zwar im Sprachgebrauch eine Affirmation ergeben,

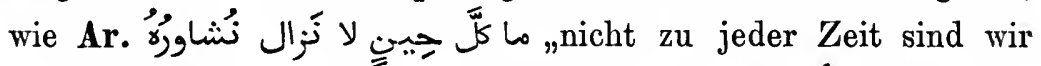

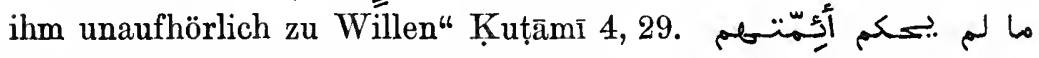
„nie richteten ihre Lenker nicht" Nöld. Zur Gramm. § 70 (I. Hiš.

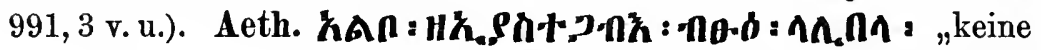
war, die der sel. Lālībalā nicht gesammelt hätte" Lal. 13,2. Syr. loov "wir wollen nicht ungehorsam sein" Sāhdōna 318,3. usf. Allein häufig bildet sie eine Verstärkung der Negation: MišNā man zündet nicht an weder mit Weidenbast noch mit Werg" Sabbat 2,1. Ferner Bēṣā 4, 7. Syr. er weiß auch nicht, wo und wie er enden soll" Phil. 10,7. (Weiteres bei Nöld. Syr. Gr. $§ 330$.) Vgl. unten $\S 35$.

5. Neben der Bedeutungsentwicklung der Paronomasie, die $\mathrm{zu}$ einer Steigerung führt, läuft jedoch eine andere Bewegung, die zu einem Verblassen der Bedeutung des einen Elements führt. Z. B. sind Sätze wie „es kam ein Kommender" (§ 19) soviel wie „es kam Einer". Das Neue, das hier durch das paronomasierende Wort hinzugefügt wird, sind seine kategorialen Bestandteile (Partiz.; Mask.); seine Sachvorstellung ist nichts weiter als der Träger für seine Form. Man könnte nun fragen, ob "es kam ein Kommender" wirklich bedeutet „es kam Einer", oder ob es bedeutet "seine Tätigkeit übte ein Kommender aus", ob also die Verarmung beim paronomasierten oder beim paronomasierenden Worte erfolgt. Man darf indes wohl annehmen, das der Sachbegriff der Wurzel in voller Stärke nur beim ersten Auftauchen des von ihr abgeleiteten Wortes zur Geltung kommt, d. h. im paronomasierten Wort. In den darauffolgenden Wiederholungen des Wurzelbegriffs - den paronomasierenden Wörtern - wird der Wurzelbegriff selbst wohl mehr in den Hintergrund treten, während die 
formalen Beziehungen in gleicher oder vermehrter Stärke erscheinen. Da aber in solchen Fällen das eine Wort zu einem Hilfswort degradiert ist, bei dem der Inhalt verarmt, ja fast völlig ausgeschöpft ist und alles Wesentliche in der Flexion liegt, so ist hier vielleicht überhaupt eine Anbahnung für die Scheidung der Redeteile gegeben.

\section{Das Wort in der Paronomasie.}

\section{Das Nomen in der Paronomasie.}

\section{§ 4. Wurzelverwandte bedeutungsverschiedene Nominal-} formen. 1. Die Bedeutungsverschiedenheiten unterschiedener Nominalstammbildungen werden zwar manchmal als Gegensätze einander gegenübergestellt, indes gewöhnlich nicht mit so markanter Wirkung wie die verschiedenen Verbalstammbildungen. Man bemerkt das, wenn Verbalnomina, die dem System der Verbalstammbildung angehören, in Gegensatz treten; der Kontrast ist hier gleich auffälliger. Die Wechselbeziehungen zwischen den Nomina verbi verschiedener Konjugationen werden denn auch passender bei den Beziehungen zwischen den Konjugationen mitbehandelt (s. Kap. IV).

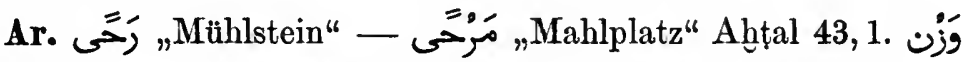

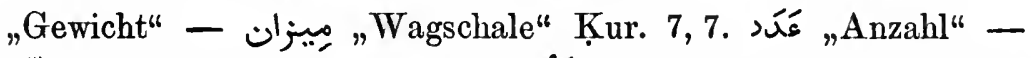

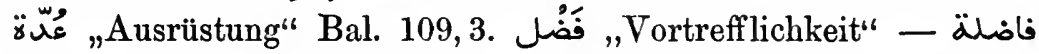

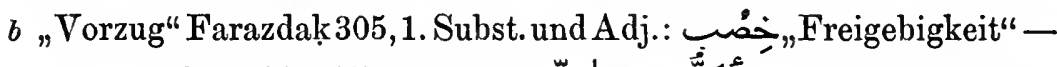

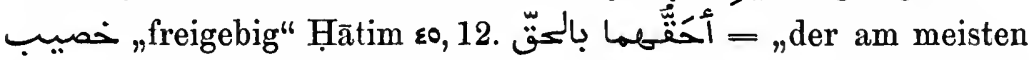
c Rechtsanspruch hat" Far. 307, 11 usw. Positiv und Kompar.

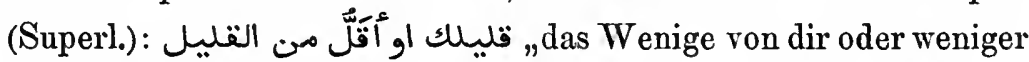
als das Wenige" Ag. ${ }^{2}$ VII 81 ult. ('

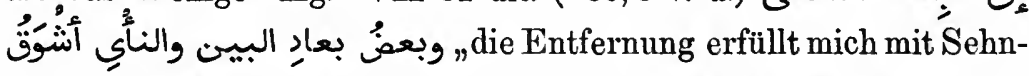
sucht; manche Entfernung der Trennung und Verabschiedung erfüllt aber mit noch größerer Sehnsucht" Ag. ${ }^{2}$ VII 100, 4 ( $\left.{ }^{1} 105,20\right)$. Ferner Nöld. Poesie 79 Vs. 2. Sīb. I 134, 6. Kur. 2, 214. 216. 
$d$ Grundwort und Intensivum: $e$ Erzkauderwelscher" Ag. ${ }^{2}$ V 156, $24\left({ }^{1} 165,11\right)$. Öfters ist erweislich das eine Subst. eine Ableitung des andern, wie فِيــ "Elefant"

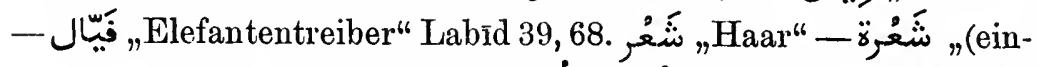

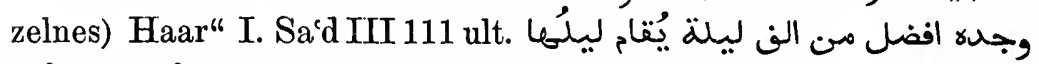
er fand ihn vorzüglicher als 1000 Nächte, die man bei $f$ Nacht steht und am folgenden Tag fastet" I. Hanbal I 61, 16. Mask. $g$ und Fem.: Kur. 24, 3. Hātim $\varepsilon \varepsilon, 19$. usw. Nisbe und Attribut zu ihr, s. $h \S 20$. Grundwort und Diminutivum: 'Umar 197, 44-45 (Eigenname). eine große, überaus große Staubwolke“ 1001 N. III 323, 3 v. u.

Vulg. Srr. (a) "Braut" - "Bochzeit" Lbd. v. Am.

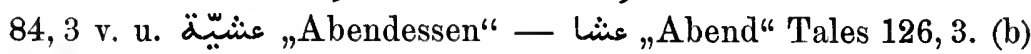
hamra "rot" - humra "Schminke" Neuar. Volksp. 21 Vs. 65. (c)

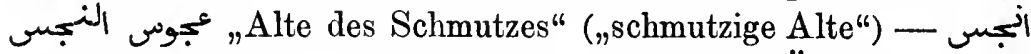
"schmutziger" Libd. v. Am. 42,4 v. u. (e) zètîn "Ölbaum" - zêt "Öl" Neuar. Volksp. S. 20 Vs. 61. tabl "Trommel" - tabbāl "Trommler" Pal. Diw. S. 201 Str. 3. الليلة تعلى عندى في البليل "Komm heute Nacht zu mir bei Nacht" Tales 135,10. (h) ḳalbi $j \bar{a}$ lklejbi „mein Herz, o mein Herzchen“ Arabia petr. 444, 6 .

Südar. (f) התרוהמו ואחררתהמו ,ihre freien Männer und Frauen" CIS IV 80,8 .

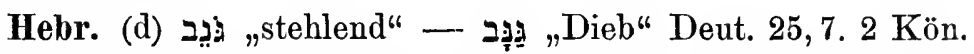

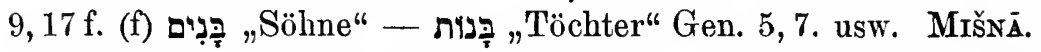

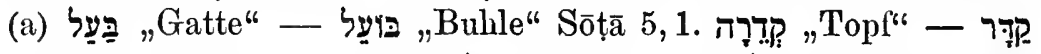
"Töpfer" Bābā k. 5, 2. (e) ל ת "Sand" - Sandschicht" Kēl. 5, 10. מצט "kroßeine Tragstange" Bēṣā 3, 3 .

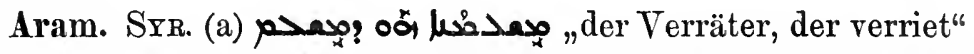

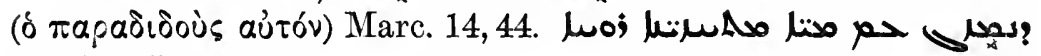

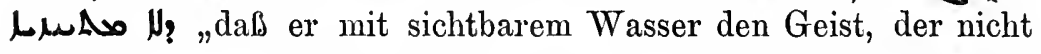

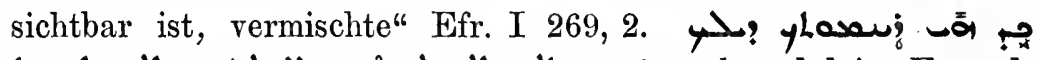

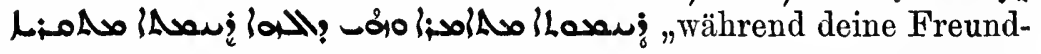
schaft Freundschaft genannt wird, wird die Gottes Liebe genannt"

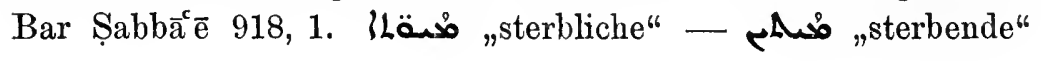




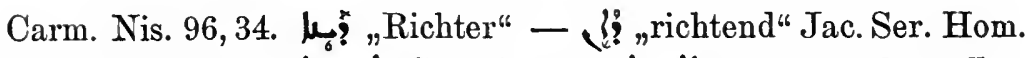

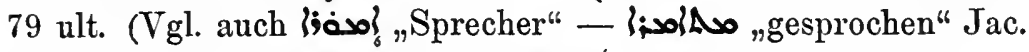

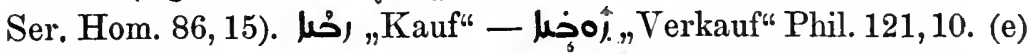
"bitter" — ILo; "Bitterkeit" Jac. Ser. Hom. 54, 10-11.

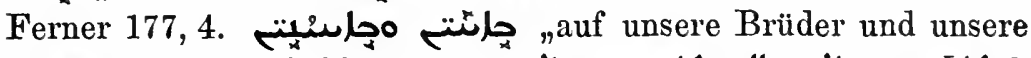

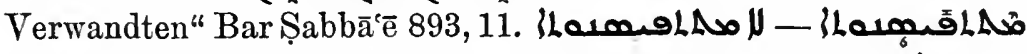

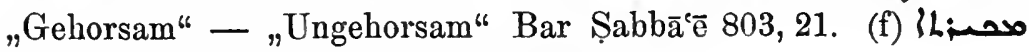
"Braut" - مصن: "Bräutigam" Afr. 1004, 17.

Ass. (b) marșu „krank" - murșu „Krankheit" Lpz. semit. Stud. I1 44,46. (f) šikilu "Schekel" - suluıltu "Gewicht" KB V No. 21,34. kittu „Recht" - kinnu „wahr" KB V No. 50,19. ina paniti ina pan sarri akțibi „früher habe ich vor dem Könige gesprochen" BA 4, 520, 7 .

Weiteres in $\S 20.31$.

2. Paronomasien zwischen Eigennamen entstehen öfters, wenn Angehörige einer Familie den gleichen Namen oder Namen von der gleichen Wurzel haben. So kommt es z. B. im Ar. vor, daß der Name eines Mannes das Dimin. des Namens seines Bruders

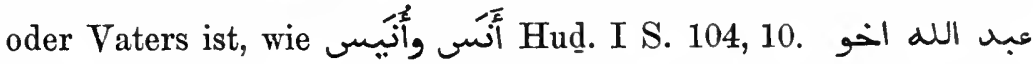

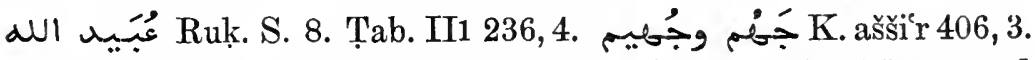
So ferner Utba und 'Utaiba, die Söhne Abū Lahabs; Hasan und Ḥusain; 'Abdallāh und 'Ubaidallāh, die Söhne des 'Abbās usw. -

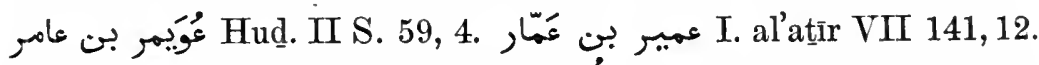

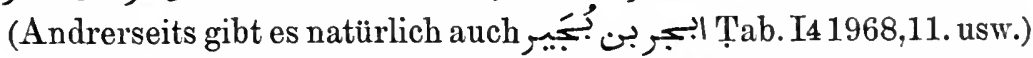

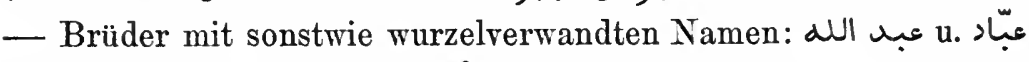
Tab. II1 392,10. خالد u. نَ fünf Brüder العُوَيص und hießen "die 'A jāạ", I. Duraid 45, 17 u. sonst.

1 Für Brüder kommen auch Duale und Plurale a potiori vor, wie „die

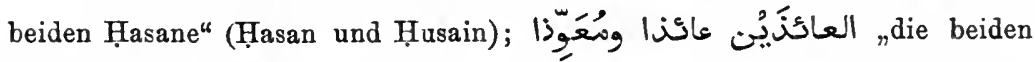
'̄'ide, 'Ā'id und Mu'awwid" Hud. II S. 26, 11; die Karite sind die Brüder Karīt, Kaurṭ und Kuraiṭ (I. Duraid 32, 9). Vgl. endlich den überflüssigen Plural in Tưnisisch femma râzel 'andu tlât ülâd uttlâta esmhum muhammedât „es war ein Mann, der hatte 3 Söhne, und der Name der 3 war Mohammed(e) * Märchen 73, 31. 


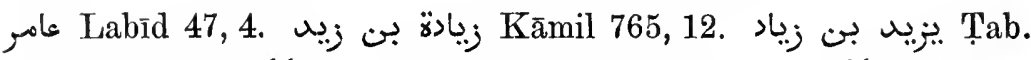

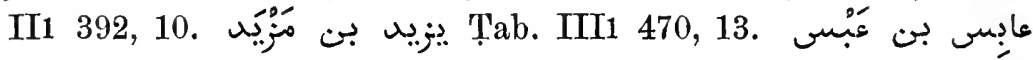
TA IV 184. usw. - Vater und Sohn gleichen Namens : Nāb. 10, 22. I. Hǐ̌ $127,16.881,1-2$. Tab. Is 2634, 17. III3 1754,4. I. Sa'd VIII 343, 25. Mas'ūdī Tanbīh 205, 3. Bal. Ansāb 292, 10 usw. Häufig ein Name und die damit gebildete Kunja, wie الارقم بن ابى الارقم I. Hiš. 162 vorl. Labìd 36, 1. Ağ. ${ }^{2}$ XII 81,19. I. Sacd VIII 60, 21 usw. Gābir Bruder des Gabr, Bed. Gesch. 4, 16. Vulg. 'Ammār Sohn der 'Amra, Pal. Diw. 13 Vs. 1. Sa'dijje Tochter des Saîid, Pal. Diw. 152 No. 4. Südar. Zaid und Zaid'il" CIS IV 37, 2. הלפעד וסעדאל "Ilsa'd und Sa'dil" 102,1.

$\S 5$. Wurzelverwandte synonyme Nominalformen. Die Bea deutungsverschiedenheit, die mit der Formverschiedenheit verbunden war, ist oft ganz oder nahezu geschwunden, und es sind auf diese Weise wurzelverwandte Synonyme oder doch Homoionyme entstanden, die z. B. aus metrischen Gründen miteinander wechseln; auch mag gelegentlich bloß nachlässiger Weise vom Verfasser oder Abschreiber bei der Wiederholung des Begriffs eine andere Wortform gebraucht sein. So wechseln: Ar.

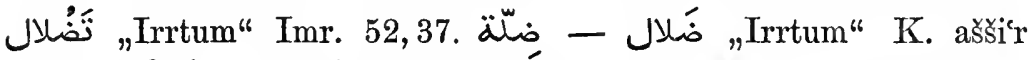

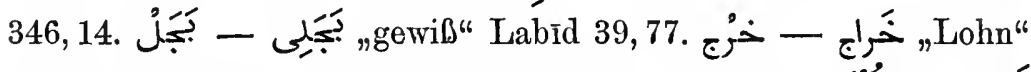

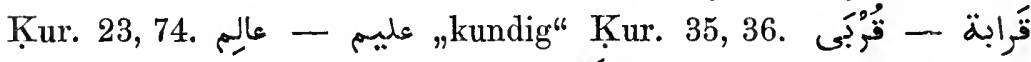

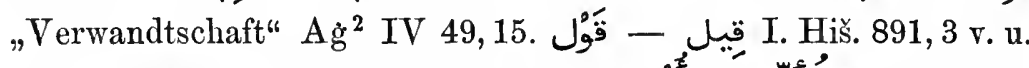

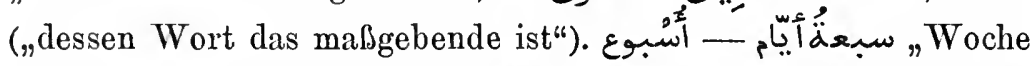

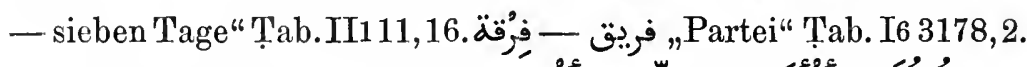

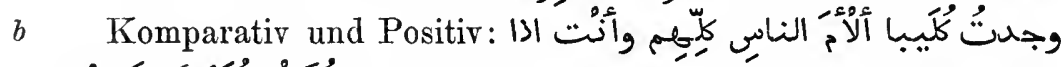
,ich habe die Kulaib als die niedrigsten aller Menschen befunden, und du bist, wenn die Kulaib aufgezählt $c$ werden, ihr niedrigster" Abtal 15, 1. Wechsel synonym gewordener

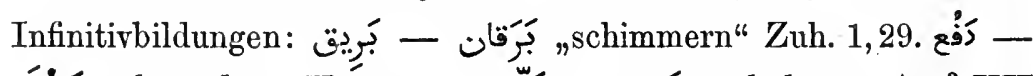

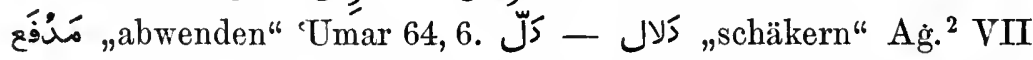
101, 20 (1 107,6). سِياق - "treiben" Ağ. ${ }^{2}$ VII 93, 73 ('98 ult.). Hud. 59, 1. Vgl. hernach $f$. Auch die Unterschiede in den Be- 
$d$ deutungen der Plurale treten zurück, z. B. ع - Gewohn-

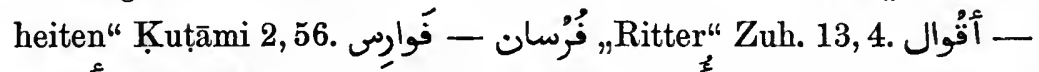

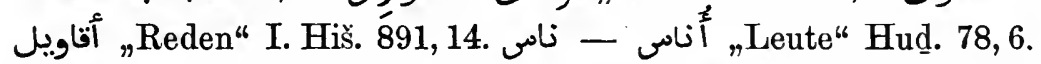
Tab. I6 2961,11. Auch der Unterschied zwischen den plurales paucitatis und multitudinis wird nicht immer strenge festgehalten,

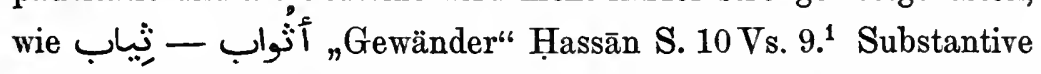
$e$ mit und ohne Femininendung lösen gelegentlich einander ab, ohne dab eine wesentliche Bedeutungsverschiedenheit vorhanden ist, wie wie vielerlei Taten haben sie zu ver-

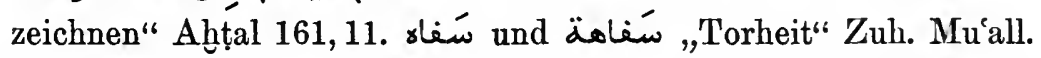
$f$ 63; häufig besteht hierbei zugleich Verschiedenheit der Nominal-

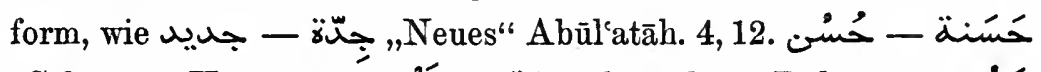

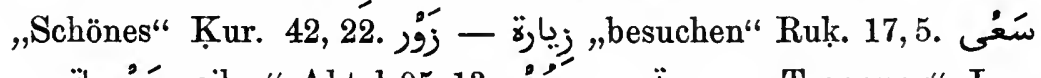

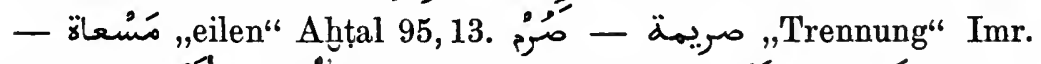

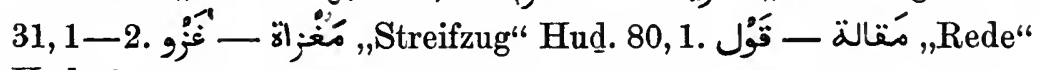
Hud. 72,3 .

$g \quad$ Wechsel des Numerus ist natürlich häufig, vgl. folgende Ausdrucksweisen ein einmaliges Sterben ist mir gleichgültiger als (viele) Sterben, die ich täglich erleide“" Tab. I4 1859,3. den besten aller Dubai'as, den Dubai'a von Kais“ Kāmil 276, 6. den Weg für den Besitz - (viele) Wege“" Hātim 17, 19. ich werde dieses Feuer in (viele)

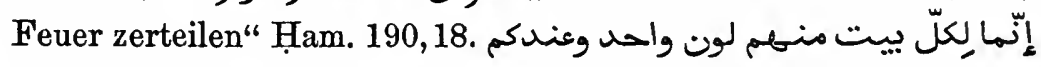
الوان

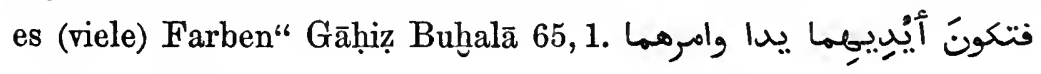

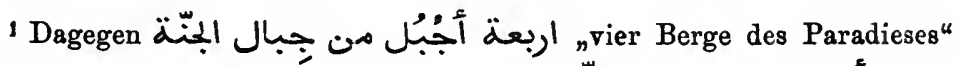

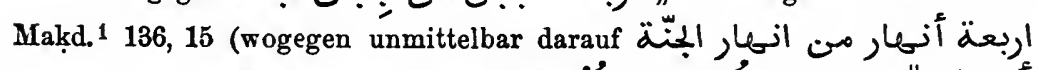

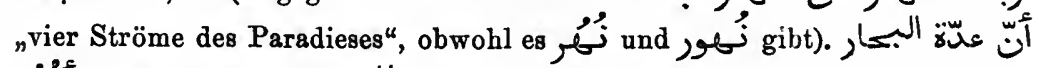

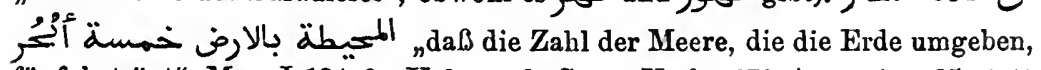
fünf beträgt" Mas. I 184,6. Vgl. noch Synt. Verh. 670 Anm. (wo 35 statt $356 \mathrm{zu}$ lesen). 
اح , so daß ihre Hände eine Hand seien und ihre Sache eine“ h Bal. 103, 3. usw. Infolge der Konstruktion der Zahlwörter: العشإ ,die Zahl der Monate bei Allāh

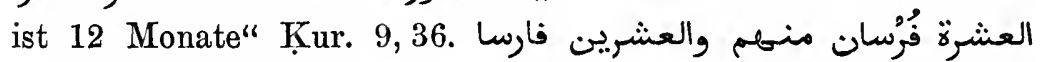
„ein Stücker 10 Reiter von ihnen und ein Stücker 20 Reiter“ $i$ Tab. II1 56,6. Singular und Dual: mit einer Hand und nicht mit zweien" Gāhị Buhalā 60 ult. Ferner Buh. $\Pi$ 41, 16.

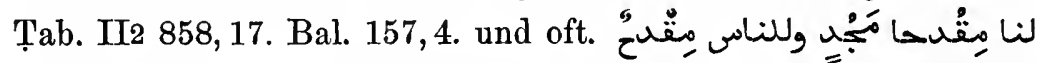
"wir haben zwei Schüreisen des Ruhms und die Menschen

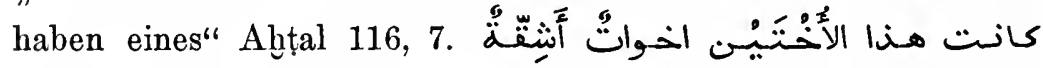
„diese beiden Schwestern waren Schwestern von derselben Mutter" (letzteres ist als stereotyper Ausdruck unverändert im Plural geblieben) 1001 N. II 206 ult. ein, zwei Tage“ Beduineng. 5, 16.

k Die Zusammenstellung synonymer Nominalformen kann den Ausdruck für die Mannigfaltigkeit, Menge, Gründlichkeit bilden und auf diese Weise die Gewißheit oder Totalität verstärken (vgl. § 35), wie ةالنُصْع والنصيحة "Ehrlichkeit und Redlichkeit" I. Hiš. 343,10 vgl. oben $e$.

Vulg. 'IRẠ̄̆. (f) sīratčenn mesâr tuffag „eure Art ist die eines Gewehrs" Neuar. Ged. II S. 92 Z. 4 Syr. (a) alohra - alāllıe "die andere" Arabia petr. 193, 14-15. (d) laḩaḳha šubbāni min šabāb "ḥsenni "es folgten ihr junge Männer Hisēns" Pal. Diw. 14,4 v. u. (i) șaḥhtên ușaḥha „zwei Gesundheiten und eine“ Neuar. Volksp. S. 23, 95. Pal. Diw. 53, 4 v. u. (k) hațātī uhutțär "Vorübergehende jeder Art" Pal. Diw. 13 Ged. 4 Vs. 7. $z \bar{a} d i$ uzuwwādi „meine Zehrung und mein Proviant" ebenda 168 Mitte. ما تعرف شغل ولا شغله "kennst du nicht irgend ein Handwerk?" Tales 28, 13. حولكى ولى rings um dich" Lbd. v. Am. 48, 3. ḩabâjj(i)bī waḥ(a)bèbât $\bar{\imath}$ "meine Freundinnen, liebe Freundinnen!" Neuar. Volksp. 50, 55. Zentralar. (d) wuṣūfin — auṣāfe „Merkmale" 12, 14 usw. TrIP. (e) reffa - reff "Blumenart" Trip. Bedl. 264.

Sïdar. (k) נכיתם ונבים "Leiden jeder Art" CIS IV 82, 9. 


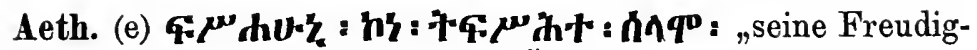
keit war die Freude über den Sieg" Šarḍa Dengel 83, 31.

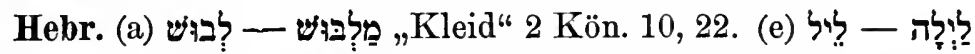

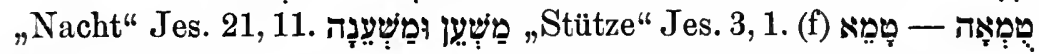

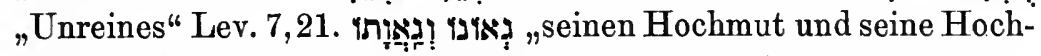

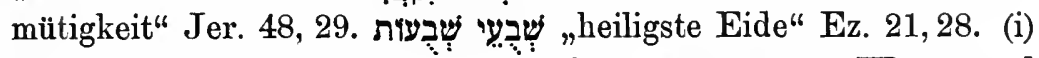

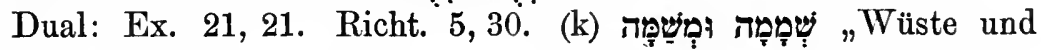
Wüstenei" Ez. 6, 14 (= 33, 28. 39. 35, 3). Ferner Nah. 2, 11. Zef. 1, 15 (= Hiob 30, 3. 38, 27). Klag. 2, 5. Jos. 6, 1. Jes. 29, 14. Ez. 35, 7, und s. oben Jes. 3, 1. Jer. 48, 29. Mršsà (i)

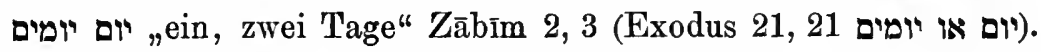

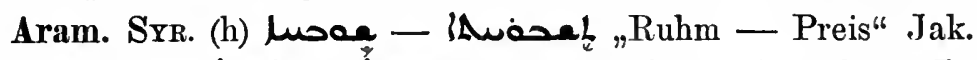

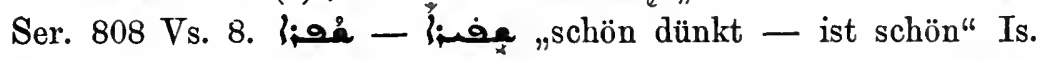
Ant. II 22, 57. Status abs. und emph. gleichbedeutend: عجمعا Fer.641,

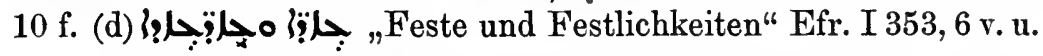

Ass. (f) kullat kalǐšnu "sie alle miteinander" KB VI 48, 15 (vgl. andrerseits 68,5). (k) lu'u lu'ùta „irgend eine Unreinheit" Sonneng. 147,15 u. sonst.

§ 6. Die Determination paronomastischer Nomina. 1. Ein indeterminiertes Substantivum kann im Semitischen keinen determinierten Genitiv regieren, da die Bestandteile der Genitivkonstruktion entweder beide determiniert oder beide indeterminiert sein müssen. Die paronomastische Ausdrucksweise bildet eine der Möglichkeiten, ${ }^{1}$ durch die das Semitische ein determiniertes und ein indeterminiertes Substantiv in ein Verhältnis zu einander setzen kann, das dem der Bestandteile einer Genitivverbindung (*,ein Haus des Mannes") analog ist. Man hat nur nötig, das unbestimmte Substantiv („ein Haus" „Häuser"), d. h. den Einzelfall, als Teil der Gesamtheit dieser Substantive (,,von den Häusern") zu bezeichnen, die ihrerseits der Sphäre des determinierten Substantivs (,des Mannes") angehören und daher innerhalb dieser Sphäre einzig in ihrer Art, d. h. determiniert sind.

1 Das Üblichere ist indes einfache Umschreibung des Genitivs durch eine Präposition. 
Ar. ein Stamm von den Stämmen der Araber" = „einer der Stämme der Araber" oder ,ein Stamm der Araber" Tab. II1 34, 19. ein König Himjars" Kāmil 541, 5. an einem

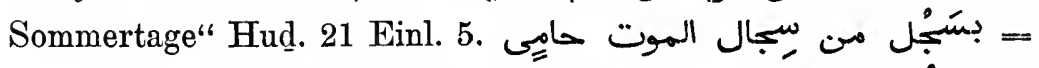
على حِصٌن مرتفع من .mit einem heißen Todeseimer" Hud. 49, 6. auf einer hohen jener Burgen" Tab. I4 1867, 9. II1 107, 12. Ham. 68 ult. ${ }^{1}$ usw. einer der schwarzen Sklaven" 1001 N. I 7, 7. einer der Könige“ I 93, 3 v. u. شئ شى من الاشياء ,irgend etwas" II 244, 9. Das indeterminierte Substantiv ein Dual: آيتتان من آيات السياء $=$,zwei der Zeichen Allāhs" Buh. I 271, 3. Ferner Kāmil 217,4 (,zwei seiner Rippen“). Kur. 66, 10. I. Hanbal I 258,8 v. u. Das

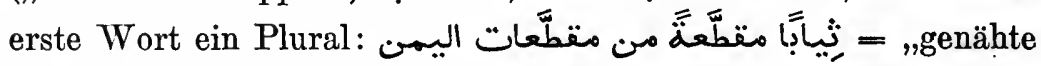

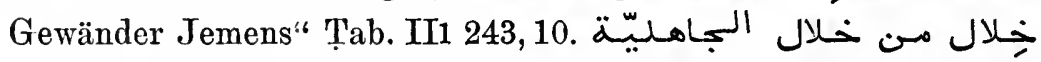
"Eigentümlichkeiten der Heidenzeit“ Buh. III 21, 1. بيضة من مئل b بيض = ,eins seiner Eier“ 1001 N. IV 11,6. Während es sich hier um Individualbegriffe handelte, enthalten folgende Beispiele je zwei Massenbegriffe: : viel Besitz Allāhs" Hud. 245 Einl. 3. تُ تُber viel Land ron ihnen" Tab. II2 1036, 18. Reiterei c der Syrer" Tab. II1 10, 4. - Auf diese Weise läbt sich auch die Indetermination von $\breve{~}$ vor einem determinierten Ausdruck wahren, z. B. كلّ طريق من الطُرُق الثلاثنة

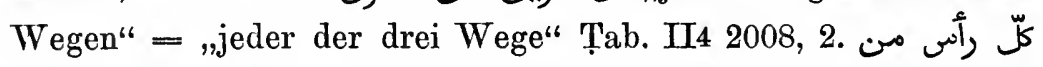

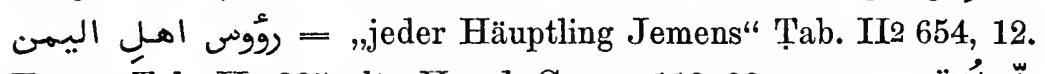
Ferner Tab. II1 385 ult. Hamd. Geogr. 119, 22 usw. usw. لُّلى لُّلة .jede Sprache der.Tiere" 1001 N. I 19, 10.

Vulg. Srr. (a) einer der Bäume des Gartens" Tales 24, 16. 51, 1. 121, 19. 137, 12. (b) šubbāni min šabāb ẹsēeni „Jünglinge Ḥsēn's“ Pal. Diw. 14,4 v. u. maijē min

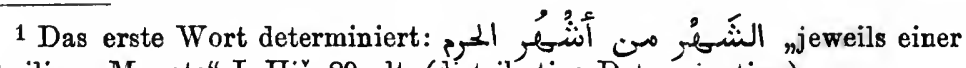
der heiligen Monate" I. Hiš. 29 ult. (distributive Determination). 
maijit čānūn „Wasser des Januar“ Neuar. Volksp. S. 38 Vs. 64 . hinle min hijal enniswān = „eine Weiberlist" Damas 112,7. HADr. (a) rabîa min ribấat 'Ali, ,einen der Schützlinge Alis" Dat. 11,5. ÄG. (a) ḳahfe min kiutü Spitta Gr. 482 Z. 16. walad min îladha "eins ihrer Kinder" Contes ar. 90, 10. (b) 'adm min "adm essamak = "Fischgräten" Spitta Gr. S. 484 ult. Contes ar. 55, 2. (Über den Grebrauch von betā s. Spitta Gr. §119c). Tunss. (a) žâria mižžwârī žūbâda ,eine der Sklavinnen Zubaidas" Märchen 19, 29. Mar. (a) șeifa min șêfet elādami = ,eine Menschengestalt" Mar. 194, 11. kursì min kurāsa lmulūk = „einen Königssitz" Mar. 196, 13. (c) kull gāima men gıuāimha ,jedes ihrer Glieder“ Tlemcen $270,85$.

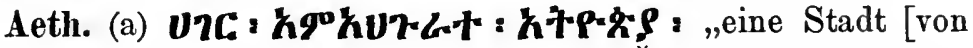
den Städten] Aethiopiens" Lal. 12,1. 51, 9. Šarḍa Dengel 132, 16.

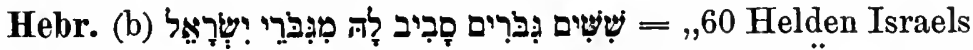

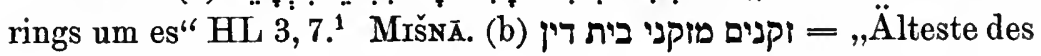
Gerichtshofs" Jōmā 1, 3.

2. Diese Ausdrucksweise ist oft die Form für eine verstärkte Indetermination, die dann allerdings manchmal wieder abgeschwächt

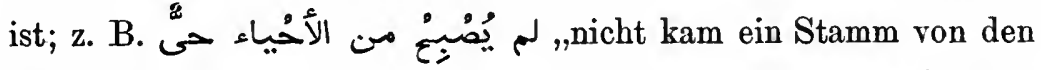

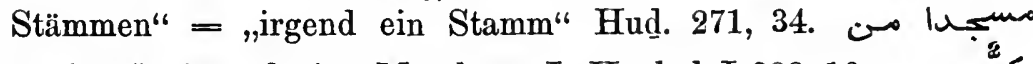

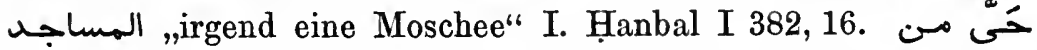
سَواحل من السواحل .irgend ein Lebendiger" Hud. 1, 18, الحَيَوات ميسات „eine Anzahl der Küstengebiete“ Tab. I4 1855, 6. Ferner Tab. I4 1967, 11. 2082 ult. I6 3317, 6. Vgl. ferner bei Zeitausdrücken an irgend einem Tage" Tab. I3 1329, 1. Schon mehr abgeschwächt in einer Nacht von den

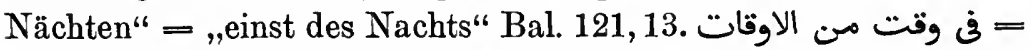
,jemals" Mas. VII 347,6 usw. ${ }^{2}$ So wird auch die in bedeutsamem

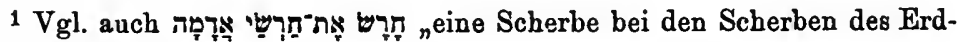
bodens" Jes. 45, 9 .

2 Auch einfaches $\overline{\ddot{\alpha}}$ ist $=$ "einst des Nachts" oder einfach ${ }_{n}$ einst" (Nöld. Poesie 118, 3). 崩 bedeutet „bei Nacht“ (Kur. 10, 25. I. Hiš. 553, 3).

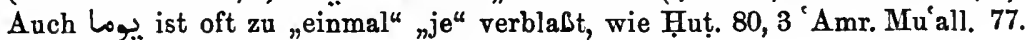
Ḩam. 68, 4. Negirt: Nöld. Poesie 80, 1. 103, 7. 111, 2. 
Sinne gebrauchte Indetermination (s. meine Synt. Verh. S. $163 \mathrm{f}$.) verstärkt, z. B. eine gewisse Sache" Ham. 256, 15. ,Leute ron Menschen" = ,gewisse Menschen" Hud. 78,6. - -einst des Nachts“ 1001 N. I 350, 7. II 6, 2. III 208,8. bis zu einem gewissen

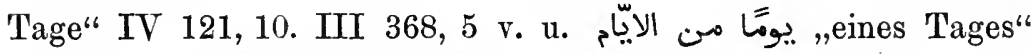

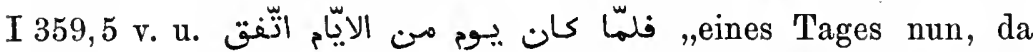

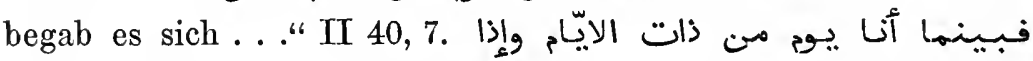
„eines Tages nun, da gewahrte ich . . “ IV 132, pänult. جارِيَة من الجِوارى

Vulg. (c) IRĀK. jōm min elijām, ,eines Tages“ Neuar.Gesch. 8, 21 und oft. Srr. بيوم من الآيام ,eines Tages" Tales 1,3 und oft. 2,3 (ليّ). beled min elbuldān, ,eine der Städte“ Damas 74,10. ÄG. lijōm min zāt elījām, ,eines Tages“Spitta Gr. S. 448, 9. 481, 11 v.u. Contes ar. 1,2. garje min elguwār = „eine Sklavin“ Contes ar. 114,4 v. u. Ferner 52,4 v. u. 156,3 v. u. Tusis. żân mižženûn „(irgend) ein Geist" Märchen 9,8. 10,14. 38,2 usw. jūm millaijam „,eines Tages" 15, 3 usw.

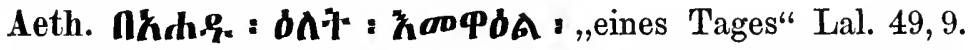

3. Das regierende Wort erhielt manchmal steigernde Bedeutung; eigentlich ist es dann als ein Exemplar der Gattung bezeichnet, das seine Benennung mit Recht trägt; vgl. S. 21 Mitte. (Determiniert finden wir dies Verhältnis im Genitivus partitivus, § 31.) مِّلَّ من ein Irrtum von meinen Irrtümern!“ = ,ein schwerer Irr-

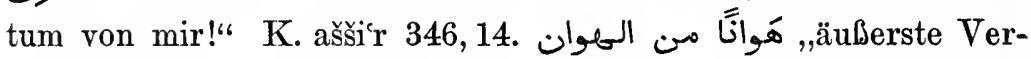

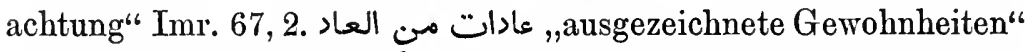
Ķuțāmi 2,56. ein schweres Unglück“" Ham. 801,2. ,eine glückliche Zeit" Farazdak I S. ^r, 2. ال三َ من الداء . „eine heftige Krankheit" Tab. II1 485, 2. eine schwere Prüfung“ I. Hiš. 551, 8.ein unerhörtes Wunder“ I. Hiš. 257 ult. ein ausgezeichneter Reiter" Beduineng. 4,8. 
4. Soferne aber in der Indetermination des regierenden Wortes die vollendete Gleichgültigkeit gegenüber den Besonderheiten der einzelnen Exemplare einer Gattung liegen kann, erhält der ganze

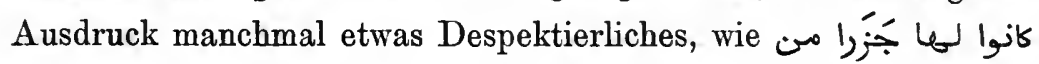

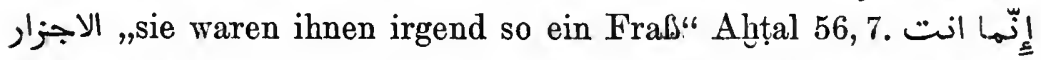
du bist doch nur so ein Schädel“" Ag. ${ }^{2}$ II 7, 13

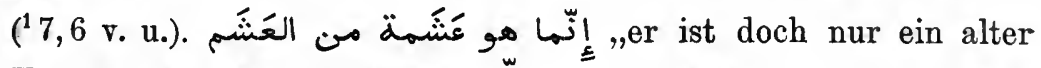

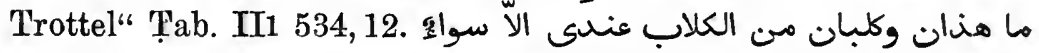
,die zwei da und zwei beliebige Hunde sind in meinen Augen doch

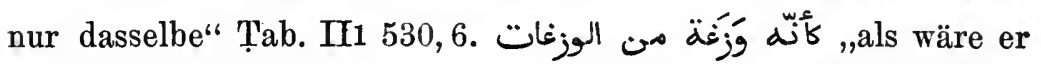
so eine Eidechse“ I. Hanbal I 59,4. als wären sie Stücke Viehs" Tab. I5 2446, 1.

5. Natürlich kann nun statt der Paronomasie auch eines der allgemeinen und geradezu indefinit gewordenen Substantive stehen, لرجل من .einer der Befehlshaber“ Bal. 124,8

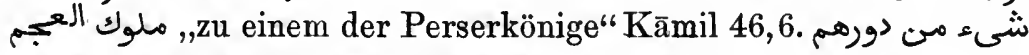
„,eines ihrer Wohnhäuser" Bal. 121,11 usw.

$\S$ \%. Paronomastische Nomina in Kontrast. 1. Es ergibt sich aus vielen der obigen Beispiele, daß zwischen den paronomast. Nomina ein besonderes begriffliches Verhältnis entstanden ist. Die syntaktische Funktion wechselt, der Sachbegriff bleibt zwar scheinbar der gleiche, in Wirklichkeit ist aber die Bedeutung des einen der beiden paronomastischen Substantive verblabt oder gesteigert oder sonstwie modifiziert. Eine Reihe von weiteren Verwendungen der Paronomasie wird nun zeigen, wie jeweils ein Element seine volle Bedeutung besitzt, während das andere neben seinem kategorialen Inhalt nur noch den allgemeinen Nominalbegriff (Personen- oder Sachenbegriff) enthält, d. h. zu einem Indefinitum oder Relationswort verallgemeinert ist und dabei innerhalb der gleichen Gattung einen Gegensatz zum ersten Substantiv bildet. Wenn „ein Mann“ zu „einem Manne“ etwas sagt, muß letzterer dem Zusammenhange nach „ein Anderer" sein. Sehr oft ist das Verhältnis der paronomastischen Glieder symmetrisch.

Ar. Halbblut, das Halbblut seinesReckendorf, Paronomasio. 
gleichen kennt" I.Hiš. 28, 7. wenn dir eine Seite unbequem ist, so wende dich einer (andern) Seite $\mathrm{zu}^{\text {“6 }}$ Ham. 151 Vs. 4. ein Heer und ein (anderes) wachsames Heer" Mutalammis 12,6. . ein Herr von uns dahinscheidet, tritt ein (anderer) Herr an seine Stelle" Ham. 53,12. يوما تسعا ويوما عشرا ,einen Tag neun und

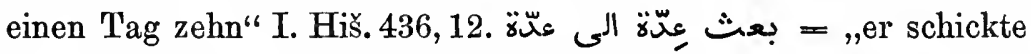
eine Anzahl zu einer andern" I. Sacd Gesdsch. 6,19. عركت فيها ich habe unter ihnen Brust an Brust gerieben“ Hudِ. II S. 6, 15. Ferner Ḥam. 132 ult. Hud. 85, 5. 6. 92,13. 112, 21. 238, 4. Farazdak 263,4. 556,1 usw. مِيلا في ميل ,eine Meile auf eine Meile" = „eine Meile im Quadrat" Kāmil 768,4. So auch $b$ Ham. 107, 8. Tab. II2 1148, 6. Bal. 234, 12 usw. Das paronomasierende Substantiv mit einer näheren Bestimmung, die einen Gegensatz zu einer nicht ausgesprochenen Bestimmung des parono-

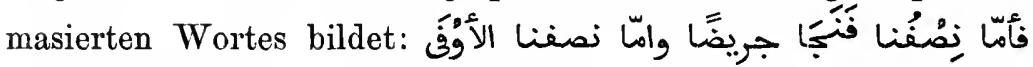
ein Teil von uns - er ist in atemlosem Lauf entkommen; $c$ der größere Teil aber - er ist umgekommen" Hud. 1, 12. Und so wird häufig ein Substantiv wiederholt, beziehungsweise muß wiederholt werden, um nochmals als Leitwort eines Attributs oder attributiven Satzes zu dienen, z.B. قام قياما طويلا وهو دوت القيام الاوّل ,er stand ein langes Stehen, aber doch kürzer als das erste Stehen" = ,lange, aber doch kürzer als das erste Mal" I. Hanbal I 298, 17. بis mein verlorenes Auge meinem gesunden [Auge] half" Bal. 99, 3. متى في Burg außerhalb der alten byzantinischen Burg" Bal. 133,18. ف ,in einem Jahre wie diesem" Ag. ${ }^{2}$ II 33 vorl.

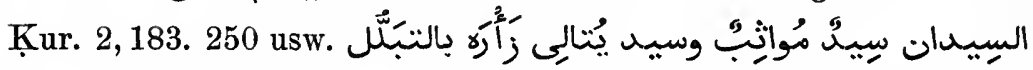
$=$ „die zwei Löwen, ein losfahrender [Löwe] und einer [eig. ein Löwe], der dessen Brüllen mit wütendem Scharren folgt" Hud. 98,18. Im Genitiv nach Superlativen كانت الحالَ بينهما ألُطَغَ حال „das Verhältnis zwischen ihnen war [ein] sehr freundlich[és Ver- 


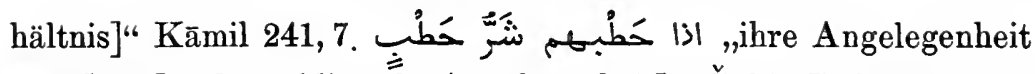
war [eine] sehr schlimm[e Angelegenheit]" Ğâhiz Buhalā 102,8. Stützen, die zu den festesten [Stützen]

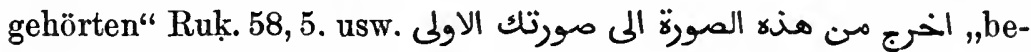
gib dich aus dieser Gestalt in deine erste Gestalt" 1001 N. I 65, 2.

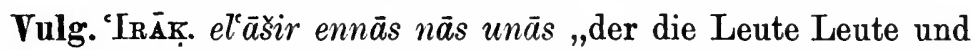
Leute liebt" (- nach zwei Klassen) Neuar. Ged. II 90 ult. min beled libeled „von Ort zu Ort" Neuar. Gesch. 4 ult. 104, 28. Srr. , von dir ein lustiger Einfall, von mir einer" Lbd. v. Am. 10, 2 v. u. 'abid mâ jąț ‘ 'abid „ein Mensch kann dem andern nichts verleihen" Neuar. Volksp. 22, 83. Tales 121, 2. Zentralar. jithūn 'addahan dahan "die das Feuer mit Feuer erwidern" 2,9. Soк. tey lenasf wutey lenasf "die eine nach der einen Seite, die andere nach der andern" II 131, 29. ketetamah lo'rim fidehon befidehon wagehi begehi „Wenn du imstande bist einen Berg mit einem andern zu vertauschen und ein Tal mit einem andern" II 244, 18. Maxt. ubedauwitīn bičča minau ubičc̆a minem, ,sie begannen aufzufliegen, ein Teil hierhin, ein Teil dorthin" 41,33. Tonss. mimblâd liblâd „, von Land zu Land" Märchen 25,13. 45,34. Mar. kahwa merra ... ukahwa mûz „einen bittern Kaffee und einen leichtgezuckerten“" Tlemcen 258, 54 .

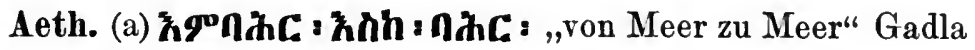
Ar. $122 \mathrm{a}, 13$. Lal. 32, 11 usw.

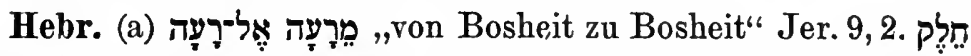

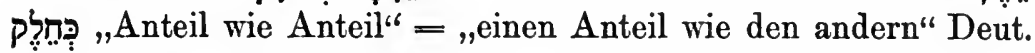

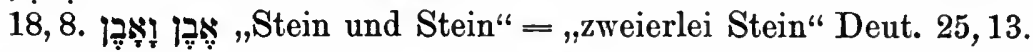
2 Kön. 10,21. Ps. 84, 8. 144,13, usw. usw. גרון על גלון ,Hacke auf

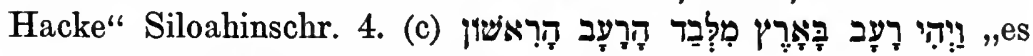
war eine Hungersnot im Lande, abgesehen von der früheren" Gen. 26,1. Ferner Ex. 4,8. 18,22. 25,12. 26,10. MišNā: ממדינה עמצה

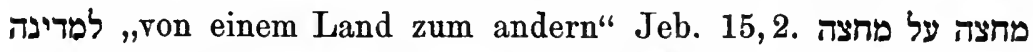
"Hälfte auf Hälfte“ = ,gerade in der Mitte" Giṭ. 8, 2. ממה על שמה אמה ,eine Quadratelle" Sōṭā 2, 2. Ferner Kil. 1, 8. Jeb. 6, 1. Ket. 5, 8 usw. 
Aram. Srr. (a) von Zeit zu Zeit" Addai 49, 15.

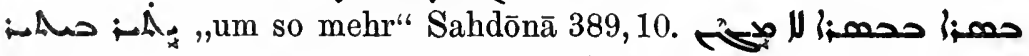

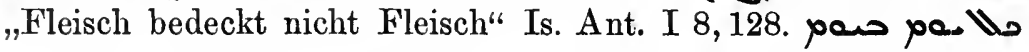

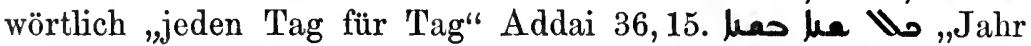
für Jahr" Barșaumā Briefe 101,9. I إ "wenn die eine Partei die andere nicht lieben kann" Op. sel. 55, 10. Ferner Is. Ant. 2, 104, 32. Afr. 168, 2. 181, 13. Phil. 189, 13. 408, 16. Jak. Ser. Hom. 135 ult. Sahdōnā 3, 10 usw.

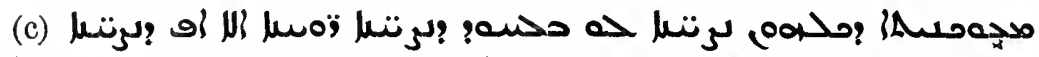
, die Verhindererin aller Siege, nicht nur der geistigen sondern auch der körperlichen" Phil. 355,10. Ferner 80,19. 274, 12. 354, 12 usw. Inschr. (c) er machte die zerstörten Städte zahlreicher als die bewohnten" Panamu 4.

Ass. bìta ki bìti „ein Grundstück für das Grundstück" KB IV 158,10. VI 66, 9 f. usw.

2. In dieses Verhältnis treten nun auch Wörter, die ihrer Natur nach zum Indefiniten neigen, also z. B. Ar. واحصا بعد وأحد

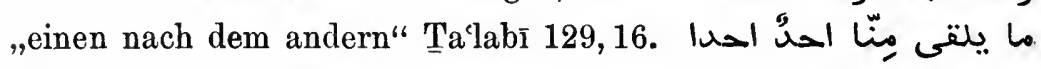
إ| اكلتم .,nicht traf einer von uns den andern“ Tab. III4 2398,

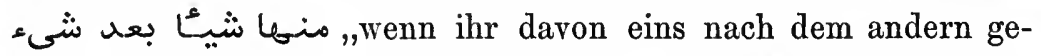
gessen habt" (= es zu Ende gegessen habt) Tab. I4 1850, 14.

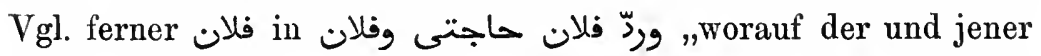
meinen Bedarf verweigerte" Ag. ${ }^{2}$ X 157,9 ((165, 14). Kāmil 3, 20. Buh. I 95, 17 usw. So auch das dem Verbum fin. inhärente Subjekt, wie sie [= die einen] sagen drei, und sie [= die andern] sagen vier" Kāmil 717,9. Häufig und

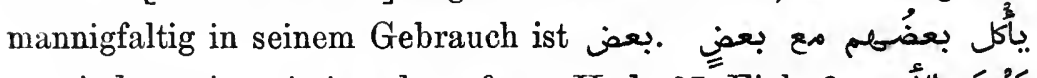
= بَعْضَ الأمبر

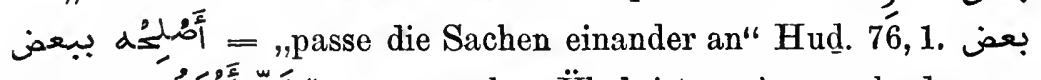
,manches Übel ist geringer als das an-

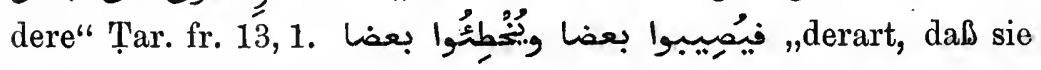
manches treffen, und manches verfehlen" I. His. 132, 9. Tab. I4 2156, 8. 2187, 1. II2 726, 12. 794, 6. Buh. I 145, 5 usw. البعض ein Teil saß, während ein Teil stehen blieb“ 
1001 N. IV 156, 4. Die reziproke Verbindung dieses Wortes konnte auch attributiv gemacht werden und ein reziprokes Verhältnis

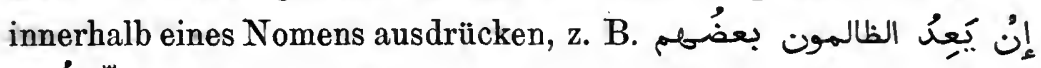

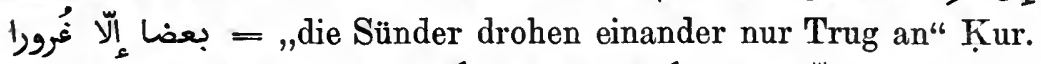
35, 38 (45,18). als wir die Nabhölzer aufeinander geschlagen hatten" Ham. 71 Vs. 2. (die Leute gingen hinter einander

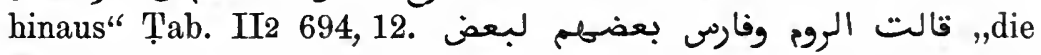
Byzantiner und die Perser sagten zu einander" Tab. I4 2074, 9. Ferner Kur. 2, 252 (=22, 41). 8, 38. Tab. II1 32, 1. II2 978, 14 usw. Noch weiter geht der Gebrauch von بعض im späteren Arab. und in den heutigen Dialekten, vgl. زعتوا الرجال على بعضهم da schrieen sich die Männer einander zu“ 1001 N. III 312, 10. usw. ${ }^{1}$ (Vgl. noch G. Graf, Sprachgebr. der ältesten christl. ar. Lit. S. 62); vgl. S. 38. A. 1. - Zeitsubstantive wie

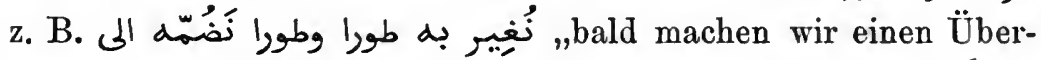
fall mit ihm, bald schließen wir ihn an . .."Labīd 47, 26. حِينً ,bald einen fetten, bald verliert er das Fett des Höckers" Hud. 92, 83. Auch يوما - يومًا ist oft verblaßt (,bald - bald“) z. B. Hud. 1, 2. 92, 77. 108, 8. Öfters ist hier die Wortstellung chiastisch, wie in obigem Labidverse, so auch Zuh. 15, 32. Nāb. 29, 11. Hud̃. 75, 14 usw. $^{2}$

1 Sogar mit Unterdrückung des einen بعض (vgl. Anm. 2). Z. B. die übrigen Kaufleute sammelten sich"

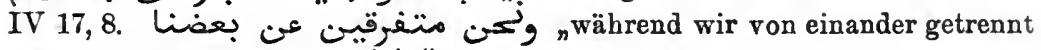
waren" IV 27, 6. فالوا لبعضكم sie sagten zu einander" IV 110, 4. Ferner Beduineng. 6 uit. 8, 26 usw.

2 Nicht selten ist das eine der korrespondierenden Zeitsubstantive unterdrückt (vgl. Anm. 1), sei es im ersten sei es im zweiten Gliede, z. B. بجور

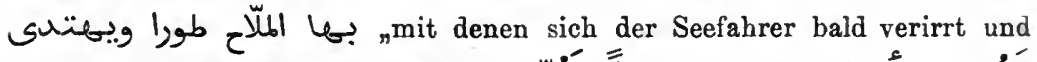

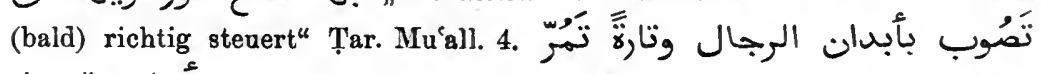
sie treffen die Leiber der Männer (bald), und bald fahren sie außen über die Panzer" I. Hiš. 615, 1. Ferner Nöld. Poesie 69, 4. Lāmijja 66. Kumait 2, 7. Far. 277, 38 usw. Auch kann im zweiten Gliede 
Vulg. 'IRÀK. zemân̄̄ nôb 'agg unổ șâh (mit) Staub (bedeckt), bald klar" Neuar. Ged. II No. 31, 1. Sxr. $n \bar{a} s$ - nās ,einige - andere“ Neuar. Volksp. 14 Z. 20. wahad - wahad „einer - ein anderer" Pal. Dīw. S. 33 Mitte. 169 No. 2 g. E. Tales 123, 21. Lb. v. Am. 66, 5. bei Einem erinnert man sich des Anderen" Lbd. v. Am. 88, 4 v. u. Datinar. hadd - hadd "manche - manche" 20, 14. Sor. tad - tad ,eine - eine andere“ I 188,68, 2. śs — śi „ein Teil ein anderer" II 49, 23. Ferner 52, 3. 98 ult. MeHRI. tait-tait „eine - eine" I 74, 18. 183, 32. 141, 12. ÄG. Spitta Gr. \$ 150 c. Tonis. wâheda - wâheda - wâheda ,eine - eine andere eine andere" Märchen 18 ult. 45, 34. trîk ka - trîka - trîka -

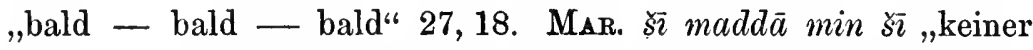
gewann einen Vorteil über den andern" Mar. 182, 11. 16. 198, 4. Houw. 46, 21. Tlemcen 252, 103. Zum Gebrauche von بعض: 'IRĀK. gâlan ba'dhum ba'd „sie sagten zueinander" Neuar. Gesch. 54,11. SYR. sie trennen sich voneinander" يفارفوا بعضهم البعض, Tales 104, 7. Lbd. v. Am. 110, 11. Damas 66, 1. Hạp. jiţohin fog bacadhin el-bacad ,er legt sie aufeinander“ 267, 8 396, 12.

Aeth. hh-t: : - hht: ",die eine - die andere" Lal. 3,1.

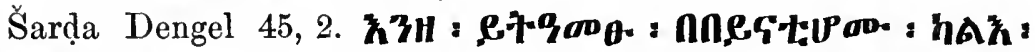

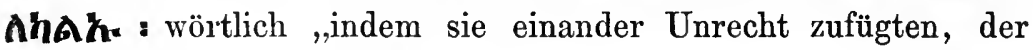
andere dem anderen" (= einander)" Journ. as. 1894 I 349, 14.

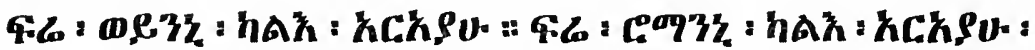

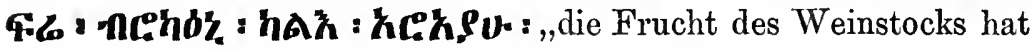
ein andres (= ihr eigenes) Aussehen, die Frucht des Granatbaums hat ein andres Aussehen, die Frucht des Mandelbaums

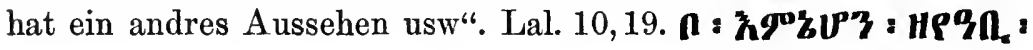

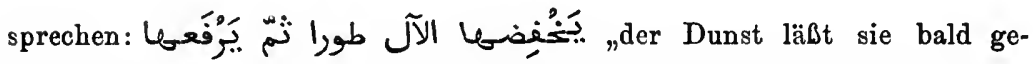
duckt erscheinen, dann wieder hoch" Delectus 106, 8. Nöld. Poesie 175, 3.

1 Zum Gebrauche von einfachem بعن (s. S. 37 Anm. 1) Syr. بتحتوا "unterhielten sich mit einander" Tales 42, 2. 3. 181, 14. 187, 7.

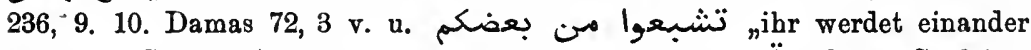
genießen" Lbd. v. Am. 86, 9. 12, 3. 96, 2 v. u. 120, 3 v. u. ÄG. Spitta Gr. \$ 149. MAR. gābedīn fĩd bådhum „einander die Hand reichend“ Mar. 186, 14. 


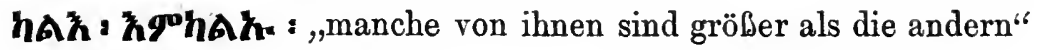
Lal. 22, 9 .

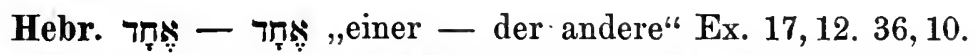

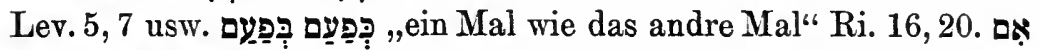
אִ "wenn einer gegen den andern sündigt" 1 Sam. 2,25. Mıšnä: את - את - die eine - die andere" Jeb. 4, 11. Ket. 12, 1 usw.

Aram. SYr. sie stiegen auf dem einen (Wege) hinauf und auf dem andern herab" Jac. Ser. Hom. 135, 13.,nachdem sie sich von einander ge-

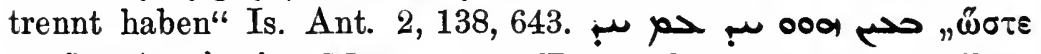

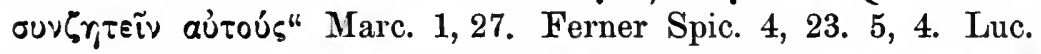
2, 15. Jak. Ser. 668, 10. usw. Vgl. Nöld. Gr. § 319. • eine andere ist nämlich die Zeit der Prüfung, eine andere die des Lehrens, eine andere die des Lesens" Phil. 9, 12. Is. Ant. 2, 136, 570. Spic. 6, 24.

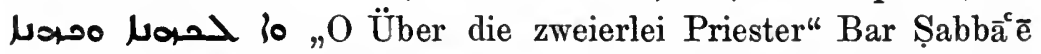

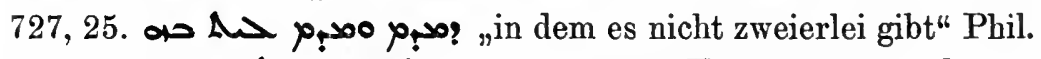
54, 8. er sagt statt Etwas etwas anderes" Jak. Ser. 643, 13. Ferner Phil. 37, 11. Spic. 3, 25. 9, 15.

Ass. amilum mala amilim "einer wie der andere" KB IV 40 No. 4, 17. 42 No. 2, 7. manma itti manma la idabubu „einer wird gegen den andern nicht klagen" KB IV 120 No. 10, 7. isten rabi išten șihir „einer groß, einer klein" Lpz. sem. Stud. I1 38, 4.

3. Es sei auch die Verbindung korrelater Begriffe (Brüder, Freunde usw.) erwähnt, wie Ar. كَلَّل أخخ مُفارِقه أخوه , von jedem كلّ خليل رلوَوصُل . Bruder trennt sich sein Bruder" Sīb. 323, 16

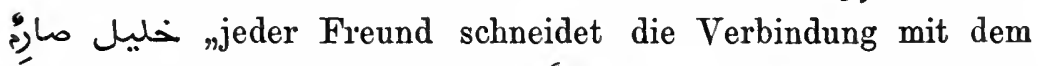
F́reunde ab" Sib. 323, 18. ein Nachbar soll den Andern nicht hindern" Buh. II 102, 13. 129, 6 v. u.

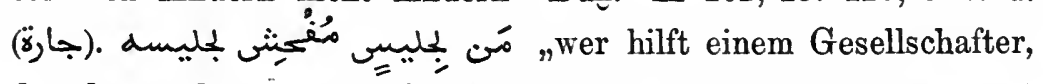
der den andern "schmäht?" Nöld. Poesie 175 Vs. 7. انصرفت له sie wendet sich ihm zu mit einer Hälfte, während unter mir ihre andere ist" Imr. Mu'all. 17. Vulg. 'IRĀr 
girne dihen ugirne dibs "eine Hälfte Mais und die andere Dattelhonig" Neuar. Gesch. 32, 10. 56, 18. Sxr. الجبار بالجار "der Nachbar (war) auf den Nachbar (angewiesen)“ Lbd. v. Am. 10,

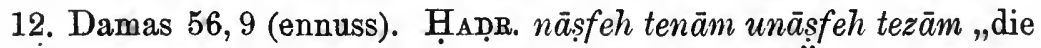
H.̈̈lfte schläft, und die Hälfte wacht" 367,7 v. u. ÄG. ihnne 'nnuṣs weintu 'nnuṣs „wir die Hälfte und ihr die Hälfte" Spitta Gr.486, 8 v. u. Tonss. qtel minhum ștar ušsțar lâhor harab, ,er tötete eine Hälfte von ihnen, und die andere entfloh" Märchen 3,13. Aeth.

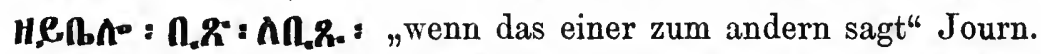

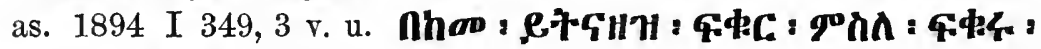

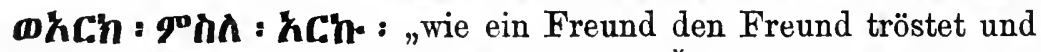
ein Gefährte den Gefährten" Lal. 34, 26. Šarḍa Dengel 32, 1-2. Hebr. MIššā. מחצה חולין ומחצה תרומה ,die Hälfte ist profan, und

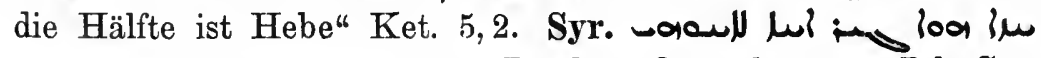
„denn der Bruder sah seinen Bruder" Op. sel. 298, 3. Jak. Ser.

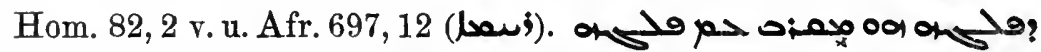
„dessen (eine) Hälfte mit der andern kämpft" Op. sel. 34, 16. 35, 14. Ass. inniṣ̌̌u ahȳ $a h \bar{\imath}$ "sie küßten sich, der Bruder den Bruder" KB VI 20, 132. mišilši ra'im ana māri Abdaširti u mišilši ana bet̄̄a, ihre (eine) Hälfte hängt den Söhnen Abdaširtis an und ihre (andre) Hälfte meinem Herrn" KB V No. 91, 72. $(151,56)$.

4. Beispiele für Substantive im Plural: Ar. نجُوم على آثنارهيّ "Gestirne, hinter denen (andere) Gestirne kommen“ Huṭ. 83, 4.

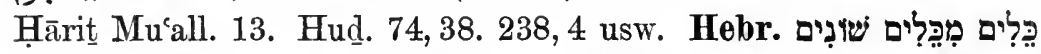
"Gefäße waren von Gefäßen verschieden" Ester 1, 7. MišnĀ. man vermengt nicht Früchte mit Früchten“" Bābā M. 4,11. פעמים - פעמים - פעמים - פanchmal - פanchmal - manchmal" Mikw. 8, 3. Syr. der zwischen Gebeinen und Gebeinen scheidet" Carm. Nis. 133, 74. خهمبر نحف خهمار, ,Tafeln statt der (ersten) Tafeln"Efr. II 730,21, 2. Ass. eli nišeša niše luraddi ,zu seinen Einwohnern fügte ich Einwohner hinzu" KB I 18, 59. Singular - Plural, worin nicht selten

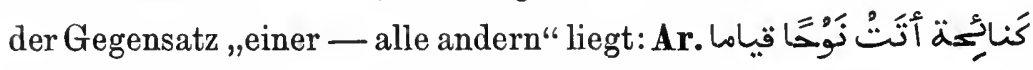
„wie ein Klageweib, das zu stehenden Klageweibern kommt" Hud.

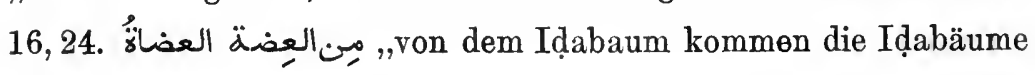




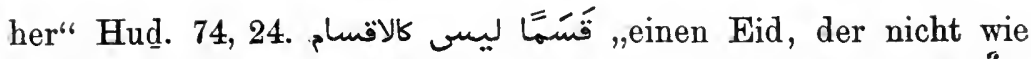

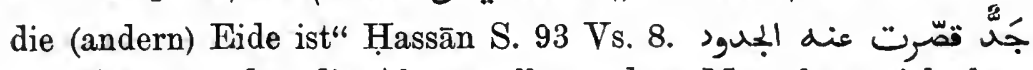
„ein Ahn, an den die Ahnen (aller andern Menschen) nicht heranreichen“ Ahțal 135, 7. ${ }^{1}$ "eine Schar,

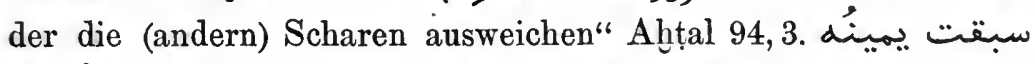
seine Rechte eilt den (andern) Rechten voran" Kuțāmī 3,50.eine (dritte) Partei, die den Kampf mit den beiden (andern) Parteien nicht für recht hielt" Tab. I6 3178, 2. يوزّ بأيّاٍِ "ein Tag für (gewisse andere) Tage" I. Hiš. 622, 19. Ferner 'Alk. 3, 5. Hud.. 2, 9. 16, 23. 66, 12. 237, 8. 244, 5. Kumait 2, 57. 3, 116. Ag. ${ }^{2}$ IV 48 ult. Tab. I5 2281, 4. usw. هذا البيت فى أبياتِ له dieser Vers steht unter (andern) Versen von ihm" I. Hiš. 6, 3 v. u. und oft. Aeth. himan : in.\&:

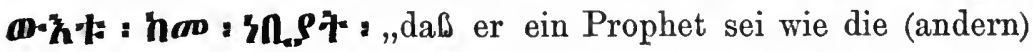
Propheten" Gadla Ar. 121a, 17. Hebr. Mršsā. גיד הנשה שנתבשל die Spannader, die mit den (andern) Adern gekocht wurde" Hul. 7,5. מביא גדולה שבגדולות ,er bringt eine große unter den (andern) großen" =, đie allergrößte"Kēlim 17, 6. Bābā M. 1,8. Syr. von den Völkern trennte er das Volk“" Efr. I $29,4,1$. Jak. Ser. 623,6 v. u. $698,10$.

5. Was die Determinationsverhältnisse kontrastierender Nomina anlangt, so ist Indetermination beider Bestandteile sehr häufig auch dann, wenn eigentlich das paronomasierende Wort dadurch deter$a$ miniert ist, daß das paronomasierte Wort ausgesprochen ist; $\mathrm{vgl}$.

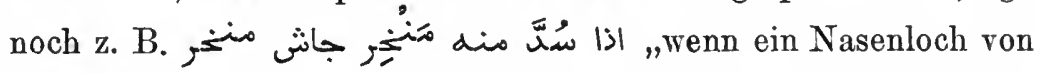
ihm (= sein eines Nasenloch) verstopft ist, schnaubt ein Nasenloch (= das andere)“ Hịam. 33 vorl. der seine (eine) Hand abhaut mit einer (andern) Hand von sich"Mutalammis b 1,11. Ḥātim ^, 13. - Beide Teile determiniert: يُعُ „,indem sie ihr (eines) Bein an ihrem (andern) Bein reibt" "Ant.

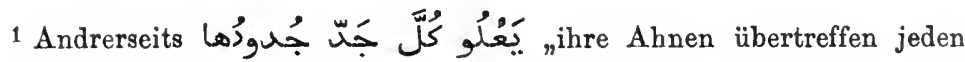
Ahn" Farazdak 433, 10. 
Múall. 19. كَفَنْفنا البُبوت بالبيوت, wir verbanden die [= unsere]

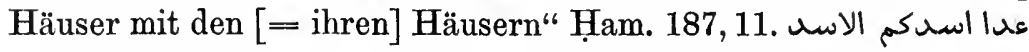
„euer Löwe hat den (andern) Löwen angegriffen" Tab. I4 2037, 8.

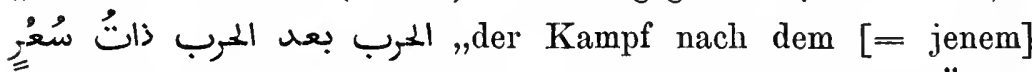
c Kampf war voller Brand" I. Hiš. 581, 6. Hud. 141,6 usw. Öfters mit genereller Determination: der Edle ist

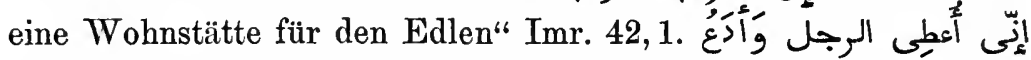
,ich beschenke den einen und übergehe den andern" Buh.

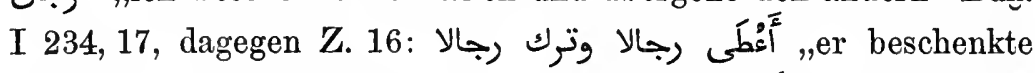
einige und überging andere“. den Traurigen regt das Weinen des Traurigen auf" "Umar 125, 10. mit der (einen) Sache wird die (andere) Sache erstrebt" Ham. 198, 2. Buh. II 41, 13. Kumait 1,97. Tab. d II2 876,9. Kur. 2,173. - So stehen sich auch gleiche Demon-

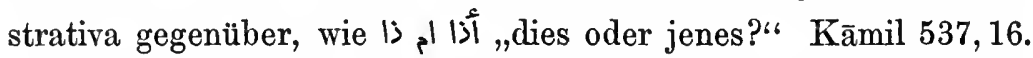

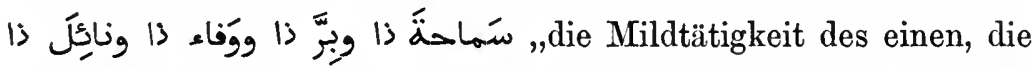
Lauterkeit des andern, die Zuverlässigkeit des dritten und die Freigebigkeit des vierten" Imr. 17,17. إن قتنل هؤلاء هؤلاء وهؤلاء هؤلاء ,wenn diese jene töten, und jene diese" Buh. II 169,5. (Weitere Beispiele für هذا Synt. Verh. 413 u.) تخنُكم بتلكم ,das für das" $e$ Labīd 1, 15. ${ }^{1}$ Das erste indeterminiert, das zweite determiniert:

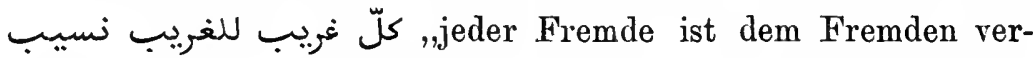

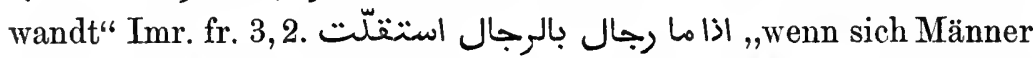

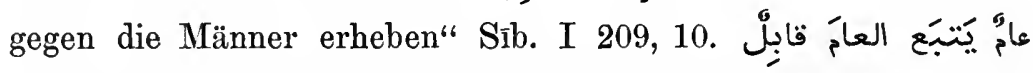
„ein kommendes Jahr, das dem Jahre folgt" Labīd 41,52. usw. $f$ Das erste determiniert, das zweite indeterminiert: للماحب المتروك

1 Demonstrativische Adverbien: فعل قومبك يومَ كنا وكنا كنا وكنا ndeine Leute haben an dem und dem Tage so und so gehandelt" Buh. III 4, 6 . فعل كيت وكيت . so und soviel hundert" I. Kat. Adab 4, 8.

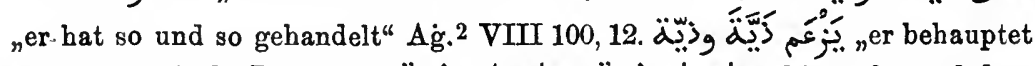

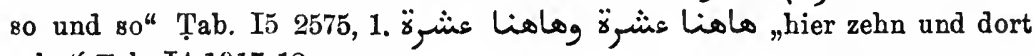
zehn" Tab. I4 1917, 12. usw. 
أبَ für den verlassenen Gefährten besteht das اتبع . ,er ließ den Boten (andere) Boten nachfolgen“" Tab. I4 1871 ult. usw.

1001 N. (a) (der König schlug die Hände zusammen" III 208, 2. (bon der (einen) Augenbraue bis zur (andern) Augenbraue" II 90, 8.

Vulg. 'IRĀḲ. (a) fürd mečân biggezîre ubîh dûd umečân bîh dibbân welmečân bîh haššřs ,,eine Stelle in der Wüste, an der sich Ameisen befanden, und eine (andere) St., an der sich Fliegen befanden, und die (andere) St., an der sich Gras befand" Neuar. Gesch. 32,6. Sxr. (a) sie schlägt die Hände zusammen“ Tales 24, 10. Ar. petr. 180, 8 v. u. (b) hott illkadam 'alkadam ,setze Fuß vor Fuß" Pal. Diw. 230 M. 335 ult. Ar. petr. 212 M. (d) تلاته من 172 (d) drei von hier und drei von dort" Tales 172, 7. Happr. (b) min esseneh ila esseneh "von Jahr zu Jahr" 433,11. (d) illi jigätạ uh biljām uilla biššher, ,die einen machen mit ihm ab per Tag, die andern per Monat" 329, 8. DАт. (b) mițel ennās uennās „wie die Leute untereinander" 7, 5. Sok. (d) hic - ha $\bar{a}$ — h. $\vec{a}$ „da - dort - dort" II 71, 27. ÄG. (a) binti tinhatța fi kaffe weddahab fi kaffe "meine Tochter soll in die eine Wagschale gelegt werden und das Gold in die andere" Contes 33, 13. (b) 'ēnoh fi'lganne weénoh fi' 'nnār "sein eines Auge war im Paradiese, sein anderes in der Hölle" Contes 10, 1. elbāb łịsș̣a $e l b a \bar{b} b$ „die eine Tür ist der andern gegenüber" Spitta Gr. 490, 3 v. u. (d) elli baka jekiul - welli bakia jekiñl ,die einen sagen die andern sagen" Contes 62, 10. Tunis. (d) messha minhûn̄ messha minhûn

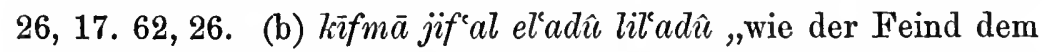
Feinde tut" 29, 32. errâžel 'obâru 'rrâžel „des Mannes Gegner soll der einzelne Mann sein" 45, 18. hū râžlī 'ž min halwalit elhalwakt $=$ „der Bruder meines Mannes kommt gewöhnlich um diese Zeit" 54, 8 usw. Mar. (b) ml'eid ll'eid "von Fest zu Fest" (an jedem Fest) Houw. 18, 13. 22, 27. (d) min häd ezinka lhādi „von einer Straße zur andern" Mar. 176, 9. Tlemcen 258, 44. hakka 
uhakka ,hierhin und dorthin" Houw. 39, 12. 47, 18. Mar. 182, 19.

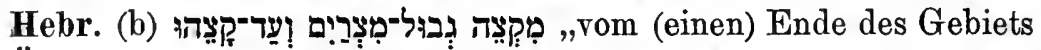
Ägyptens bis zum (andern) Ende" Gen. 47, 21. Deut. 4, 32. Ferner Ex. 18, 3-4. Deut. 28,64. 2 Sam. 14, 6. 18, 2.1 Kön. 3, 25.

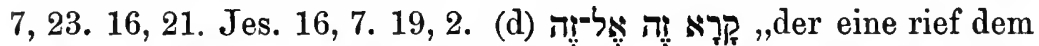

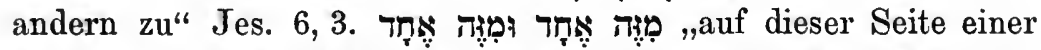
und auf jener einer" Ex. 17, 12 usw. drei hier und drei dort" Ez. 40, 10. Ferner Ex. 2, 12. 1 Kön. 14, 5. Jos. 8, 20. 1 Kön. 2, 36 usw. (e) (ein (jeder) Knochen zu seinem [= dem zu ihm gehörigen] Knochen" Ez. 37, 7. eine (Taube) als Sündopfer und die andere

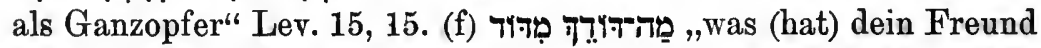
vor irgend einem (andern) Freunde (roraus)?" HL 5, 9. Mišná (d) dieser kann den von jenem vorgeschlagenen Richter ablehnen, und jener diesen" Snh. 3, 1. Ned. 3, 4 usw. ממכאן ,auf dieser Seite und auf jener Seite" Bābā B. 1, 2. Jeb. 4, 7 usw. Aram. Bibu.-Ar. (d) א? sie werden nicht aneinander haften“ Dan. 2, 43. 5, 6 usw. Srr. (a) bo, \

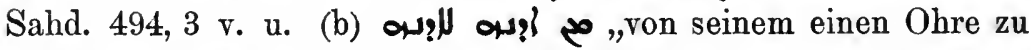
seinem andern" Op. sel. 278, 20. (d) (? Jow lua "dieser richtet jenen" Op. sel. 119. ult. 13, 2. 129, 19. Jak. Ser. Hom. 97, 1.

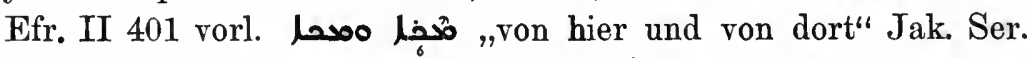
Hom. 139, 2. Op. sel. 309, 26. Sahd. 336, 6 v. u. Afr. I 397, 11. II 28, 24. Ass. (a) šatta ana šatti „Jahr für Jahr" KB VI 168, 47. (d) anute - anute, ,die einen - die andern“ KB I 66, 90. 70, 117. annum $u$ annutu ,diesen und jene" BA V 420 No. 10, 9. kĩam - kīam „hierhin - dorthin" KB V No. 214, 11. (e) $u l$ immar ahu ahašu, „nicht sieht ein Bruder seinen Bruder" KB VI 236, 12.

6. Der Kontrast läßt sich durch Wörter, die "Anderes" bezeichnen, verstärken, also z. B. Ar. أَخْرَى , auf einer Seite - auf der andern Seite“ Tab. III 302, 3. eine Schar eine andere Schar - eine andere Schar" Hud. 155, 5. أن لای 


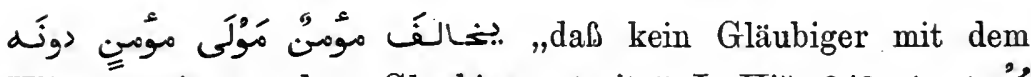
Klienten eines andern Gläubigen streite" I. Hiš. 342, 4. ,einen andern Speer als den deinen" Hud. 97, 26. Ķur. 24, 27. I. Hišs. $718,6^{1}$. Vulg. ÄG. feirfum inn ilfellāh kāan

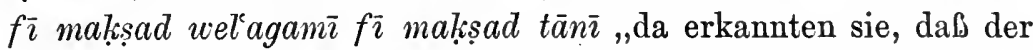
Fellache eine Absicht gehabt hatte, und der Perser eine andere" Spitta Gr. S. 484, 21. lïinn elwāhhid j̈ğ fi-llēl walwāhnid tām jigī fi-nnahār „weil der eine des Nachts kommt und der andere

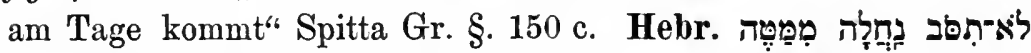

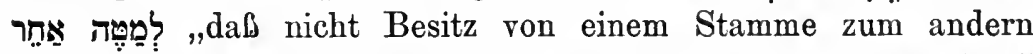

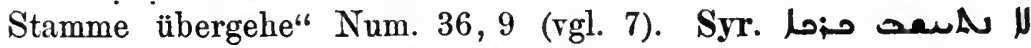
die Stadt wird nicht wie alle andern Städte angesehn" Op. sel. 11, 22. Jak. Ser. Hom. 93, 6 v. u.

7. Das Begriffsverhältnis der Nomina kann das von etwas Vorhandenem zu etwas Neuhinzugekommenem sein, wie Ar.

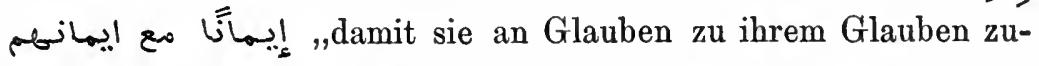

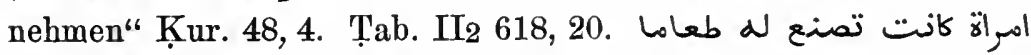
eine Frau, die ihm Speise zu der Speise zu bereiten

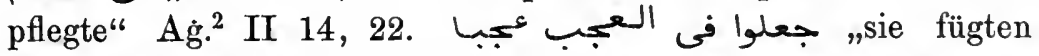
Wunder zu Wunder" 1001 N. II 344, 8. اعمل على ابوابها ابوابا فيا „,ich bringe au@er ihren Toren weitere Tore an" III 51, 7. Aeth.

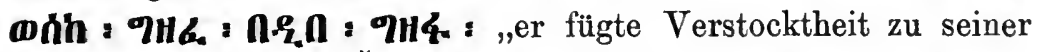

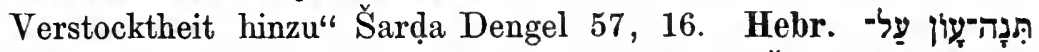

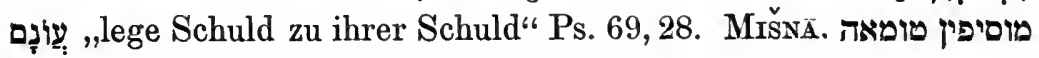
, „ל על עומאתו Ass. ina put hitị̌u hitṭi emessu ,gegenüber seiner Sünde hat er ihm Sünde aufgelegt" KB IV 144, 51. - Weiteres § 7, 4. Verwandt ist dann der Ausdruck der Steigerung oder Totalität

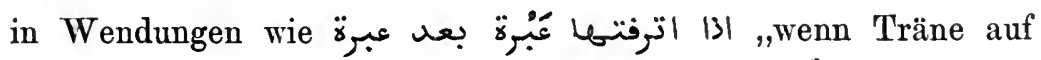

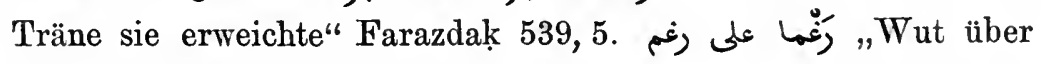

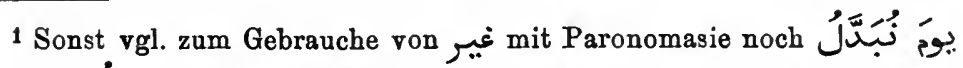
“am Tage, da die Erde in eine andere Erde verwandelt wird“" الارضٌ غيَّ الارض

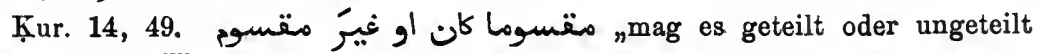
sein" Buh. II 75, 5 usw. 
Wut!" A hțal 76, 2. Ferner Kur. 31, 13. 'Umar 56, 6. Nāb. 1, 4. Zuh. 15, 21. Mueall. 'Amr 39. Huṭ. 13, 3. 53, 2. Ruk. 60, 4. Kumait 4, 23. Ham. 13, 22. 1001 N. I 362, 7. حرام فن حرام = „ein großes Verbrechen" ZDMG. 33, 6283 (Antarroman). Vulg. "IRĀK. zèn "ala zèn "schön auf schön" = „um so besser" Neuar. Gesch. 58, 3. 62, 3. Sxr. tiswa sūg ilbelistān dikkān enbatar dikkān "sie ist den Markt von Belistan wert, Laden für Laden" Pal. Diw. 287, 5. ÄG. jitkallim hadūta kidbe f $\ddot{\imath}$ kidb ,er erzählt eine Geschichte, Lüge auf Lüge" Spitta Contes 48, 10. TrIP. reffa baede reff "Blumenart nach Blumenart" Trip. Bedl. 264. Tonis. hažra "ala hažra „Stein um Stein" (= „alle Steine")

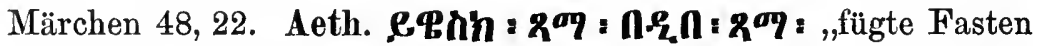

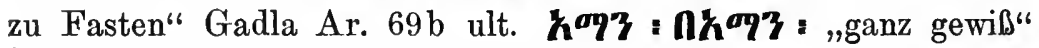
Šarḍa dengel 79, 3. Hebr. בְּי "Tag für Tag" 1 Chron. 12, 22. חֶדר

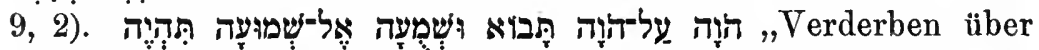
Verderben wird kommen und Gerücht auf Gerücht entstehen“" Ez. 7, 26. Jer. 9, 2. Ps. 69, 28. 84, 8. 144, 13. Aram. Srr. :

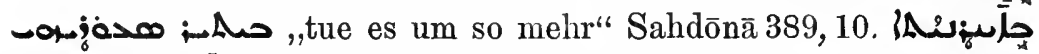

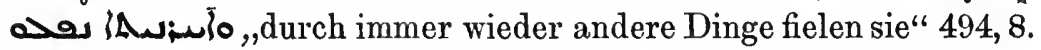
مخه ,sie wird ganz vollständig besiegt" Phil. 193, 18. Tag für Tag“ Is. Ant. 2, 56, 276. Verstärkt durch No:Tag für Tag“ Addai 36, 15 u. sonst.

8. Die Beziehung der Nomina ist ferner einseitig oder wechsel-

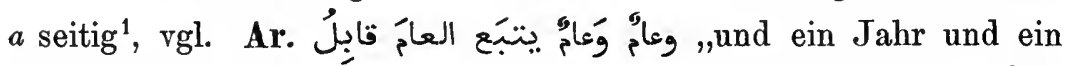
kommendes Jahr, das dem Jahre nachfolgt" Labīd 41,52. الامكر mit der einen Sache wird die andere erstrebt"

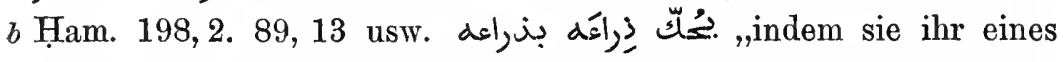
Bein an ihrem andern reibt" 'Ant. Mu'all. 19. Hud. II S. 6, 15. usw. Vulg. Syr. (b) الناس بالناس والبار بالجار (der Mensch ist an den Menschen und der Nachbar an den Nachbar gewiesen" Lbd. v. Am. 10, 12. Mar. (b) gūg begūg = ,parweise" Marokko 196, 16.

1 Es kommt hier darauf an, ob an der einzelnen Textstelle die Beziehung einseitig oder wechselseitig ist, nicht darauf, ob die Beziehung überhaupt so oder so gedacht werden kann. 


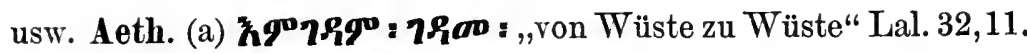

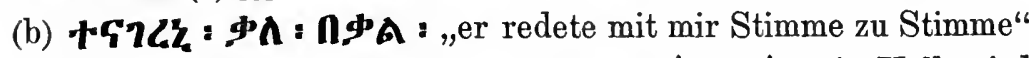
Gadla Ar. 122 b, 15. Hebr. (a) ein Volk wird

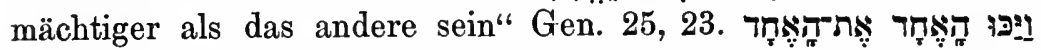

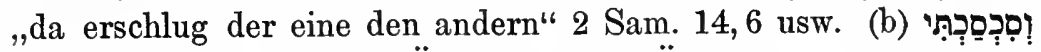
ich wiegle Ägypten gegen Ägypten auf" Jes. 19, 2. die Steinhauer schlugen in der Richtung aufeinander, Hacke auf Hacke" Siloah 4. usw. MIŠNĀ. (a) מחללים אותו כסף על כסף, מחון (ban entheiligt es, Silber durch

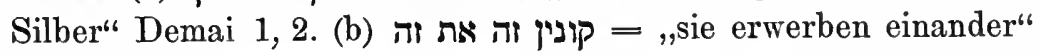
Bābā M. 4, 1. נתערבו ", sie haben sich miteinander ver-

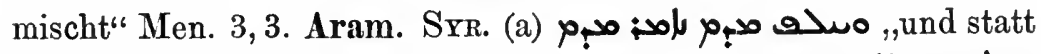

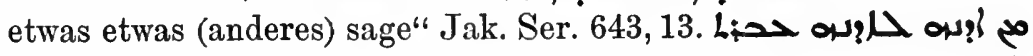
,sie geht von seinem einen Ohre zu seinem andern" Op. sel. 278, 20 usw. (b) indem ein Körper dem andern nahe ist" Sahdōnā 244, 9. ihr Lämmer gleicht Lämmern" Ephr. I 41, 26, 3. usw. Ass. (a) išten Kāraššurnașiraplu šumšu abbi išten Nibartiaššr šumšu abbi „der einen gab ich den Namen K., der andern gab ich den Namen N.“ KB I 102,49. (b) ul immar ahu ahašu ,einer sieht den andern nicht" KB VI 236, 112.

9. Die Zahl der ausgesprochenen Nomina entspricht entweder der wirklichen Anzahl der Glieder oder bildet die Abkürzung für eine größere, gewöhnlich unbestimmt große, Anzahl, z. B. Ar. $a$ eine Heerschar ruft eine andre zum Kampfe" Nāb. 27, 23. deine beiden Hände — was die eine Hand anlangt, so ist sie übervoll . . . und die andre Hand gibt zu trinken . . ." Hāâtim ^, 13. Imr. Múall. 17.

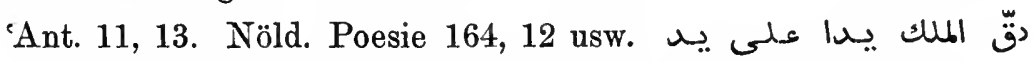
„der König schlug die Hände, zusammen" 1001 N. III 208, 2. فمرّت فمكرّ da zog eine Kamelherde an ihm vorüber, dann wieder eine; so oft eine Kamelherde zur Tränke ging, fragte er ..." Hud. 41 Einl. 17. يخلون لهم عن ارض ,sie räumten vor ihnen ein Land nach dem andern“ Tab. II2 1037, 1. فال سورةٌ كنا وسورة كنا لسور سمّاما 
,Die Sure (habe ich bei mir) und jene Sure' mit Bezug auf Suren, die er nannte" Buh. III 430,1. الا اكلتم منه شيث بعد شيء = „wenn ihr es allmählich eßt" Tab. I4 1850,14. Bānat Súād S. ı^9.

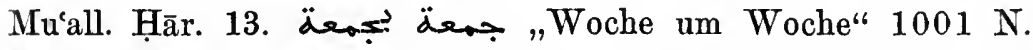
II 5 ult. III 373, 4 v. u. IV 116, 7. Vulg. Srr. (a) بتضرب كف عاكف, sie schlägt die Hände zusammen" Tales 24, 10. ÄG. (a) rikib hüwa ḥușān welbinte husşān ,,er bestieg ein Roß und das Mädchen eines" Spitta Contes 5, 3. habat kaffe 'ala kaff „er schlug die Hände zusammen" 6,5. Damas 68,12-13. Sor. (a) 'arumk 'ase béase, ich tauschte einen Herrn um einen andern aus" II 83, 17. Mar. (a) milludel luden, „von einem Ohre zum andern" Houw. 34, 8. Tlemcen 262, 23. 'IRAK. (b) rumh 'agd min fudde u'agd min deheb = ,eine Lanze, deren Glieder abwechselnd aus Silber und aus Gold bestehen" Neuar. Gesch. 88,12. Srr. (b) (Nacht für Nacht" Tales 74, 18. dallatni 'abīr ubìr $=$,sie zeigte mir den Weg zu verschiedenen Brunnen" Pal. Diw. 16,1. 32 M. $185,6.189,6.9 .12 .210$ M. Tales 63,9 . HADR. (b) min belād lablād "von Land zu Land" 367,7 . Sок. (b) men șabh id șabh „von Morgen zu Morgen" II 59, 5. min temonī id temoni „von acht zu acht Tagen“ 65, 2. 67, 26. I 151,4. 170 Ged. 22, 3. 171 Ged. 25, 3. MaLt. (b) peljet fü peljet "Matte auf Matte" Stud. 69 No. 14. TrIP. (b) lèle 'ala lēle „Nacht für Nacht" Lieder

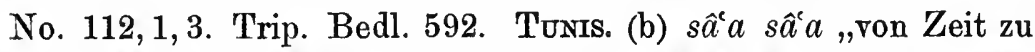
Zeit" Märchen 73, 17. 93 Ged. 36, 4. Mar. (b) wimešši șab'o 'alīhum harf ebharf ,und führt ihm den Finger-darüber, Buch-

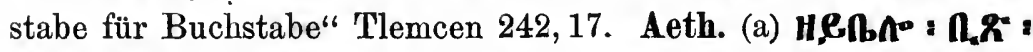
$\mathbf{A} \mathbf{\Omega} \boldsymbol{R}^{*}$ : ,wenn das einer zum andern sagt" Eskender 349, 3 v. u.

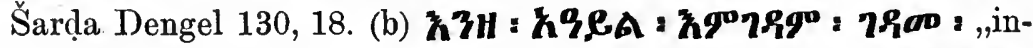

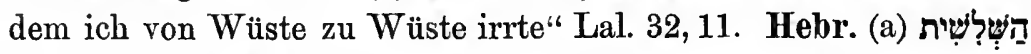

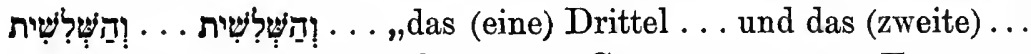
und das (dritte) Drittel" 2 Sam. 18, 2. Gen. 25, 23. 32, 31. Ex. 17, 12

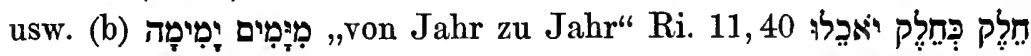
„Anteil wie Anteil sollen sie verzehren“ Deut. 18, 8. Ex. 13,10. 32, 27. Lev. 25, 53 usw. Pнöx. (b) ים מד "Tag für Tag“ Larnax Lap. 11. 12. Syr. (a) ein König und ein (andrer)

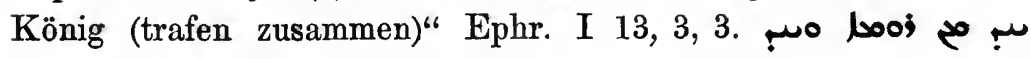


"einen aus der Höhe und einen aus der Tiefe" Jak. Ser. 668, 10. Op. sel. 55, 10. 198, 17. Sahdōnā 3, 10. 389, 10 usw. (b) von Ort zu Ort" Sahdōnā 494, 3 v. u. Is. Ant. 2, 28, 98. 56, 276. Afr. I 260, 20 usw. NAB. (b) אצדק באדצי = ,die Berechtigten der Reihe nach" CIS 201, 5 und sonst (Entlehnung aus dem Arabischen). Ass. (a) šumma amelum eli amelum še’u $i s ̌ u$ „wenn jemand an einen andern eine Forderung an Getreide hat" Hamm. fr. Rs. 2 a, 75. H్Hamm. 18, 88. (b) šatta ana šatti „Jahr für Jahr" KB VI 168, 47. Ferner BA 4, 539, 15.

\section{Nomen und Pronomen.}

\$ 8. Allgemeines. Das Personal- und Demonstrativ,,pronomen" vertritt nicht nur - wie sein Name vorgibt - ein Nomen, sondern umfabt auch den Zusammenhang, in dem sich das betreffende Nomen befindet. Gerade der Zusammenhang aber ist es, der das Nomen für die Folge zu einem bereits bekannten Worte stempelt, d. h. determiniert; daher ist das Personal- und Demonstrativpronomen determiniert und kann nicht stehen, wenn von jenem determinierenden Zusammenhang abgesehen werden soll. Aber noch mehr: Unter Umständen wird durch das Pronomen überhaupt nicht auf das Nomen, sondern ausschlieblich auf den Zusammenhang hingewiesen. Ein substantivisches odieser" nämlich kann zwar ein vorher ausgesprochenes رجلَ منا "ein Mann“" vertreten, aber das adjektivische هذا الرجل in هieser Mann“" kann, wenn zufällig kein Adjektiv vorangegangen ist, natürlich keines vertreten.

Wir haben es hier mit dem Gegensatze von Nomen und anaphorischem Pronomen im engeren Sinne zu tun, dem anaphorischen Pronomen also, das ein wirklich ausgesprochenes Nomen vertritt; denn die Frage ist für uns, wann statt der üblicheren Anwendung des Pronomens, das zwar die Vorstellung aber nicht die Lautgestalt des vorangegangenen Nomens wiederaufnimmt, das Nomen selbst wiederholt wird. Bei ihrer Wiederaufnahme steht nämlich die Vorstellung in verändertem Zusammenhange, und die Verbindung mit ihrem ersten Auftreten ist hierdurch dermaßen gelockert, 
$\mathrm{da} ß$ sie nicht mehr bekannt genug ist, um durch ein anaphorisches Pronomen ausgedrückt werden zu können (§ 9). Oder die Anwendung des Pronomens ist aus grammatischen Gründen, infolge seiner Natur, ausgeschlossen ( $(10)$. Zur Verwendung von Nomen und

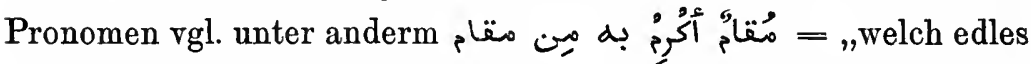
Verhalten!" Labīd Hुālidī S. 12 Vs. 2. Vgl. andrerseits Pronomen

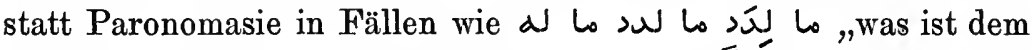
Dad? was ist dem Dad? was ist ihm?" Kāmil 206, 17. Daß ein Pronomen mit einem andern in Paronomasie tritt, ist beim Personalpronomen häufig, aber gerade hier, infolge der geringen Lautfülle des Personalpronomens, wenig sinnenfällig. Vgl. noch هذا - هذا $\S 7,5 d$; ferner den Kongruenzartikel des Attributs (المَكك العظيهم), wozu auch der im Relativpronomen الّنى enthaltene Artikel gehört.

§ 9. Freier Gebrauch des Nomens. 1. Nach dem oben Bemerkten wird im allgemeinen der Grad der Lockerung des $\mathrm{Zu}$ sammenhangs den Ausschlag dafür geben, ob ein mehr oder minder starker Einschnitt gemacht und das Bedürfnis empfunden wird, das Nomen $\mathrm{zu}$ wiederholen, was oft schon nach 1-2 Worten in dem gleichen Satze geschieht, oder ob ein Pronomen angewendet wird. Ferner besitzen manche Wortverbindungen, wenn sie auch noch nicht formelhaft geworden sind, doch schon eine gewisse Stärke des Beharrens, so daß ihre nominalen Bestandteile nicht so leicht durch Pronomina ersetzt werden. Manche Schriftsteller haben die Neigung, das Nomen tunlichst zu wiederholen, so daß die Wiederkehr des gleichen Klangs bei ihnen nicht in dem Maße eindrucksvoll ist wie sonst. ${ }^{1}$ Wir können unmöglich den Motiven für die Wiederholung des Nomens im einzelnen nachgehen und müssen hier, wie so häufig, darauf verzichten, eine Gesetzmäßigkeit für den Eintritt einer stilistischen Erscheinung aufzuzeigen, und uns vielmehr begnügen, da, wo sie eintritt, eine Erklärung für sie bieten zu können. Natürlich wirken auch hier öfters metrische Gründe. Fast ausnahmslos steht Pronomen, wenn

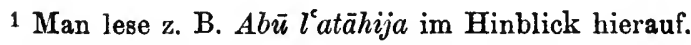


es Rückweisepronomen im Relativsatz oder nach einem isolierten Subjekt ist; vgl. indes S. 54 Anm. 2 und Kap. XV.

Zunächst eine Auswahl verschiedener Beispiele : Ar.

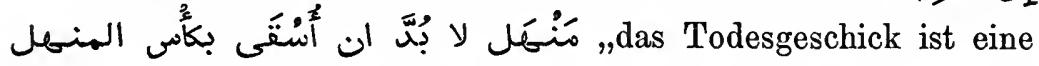
Tränke; ich muß unvermeidlich aus dem Becher der Tränke

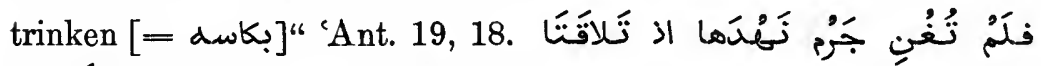

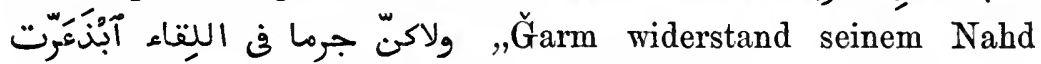
nicht, als sie zusammenstießen, sondern Ğarm zerstob beim $\mathrm{Zu}$ -

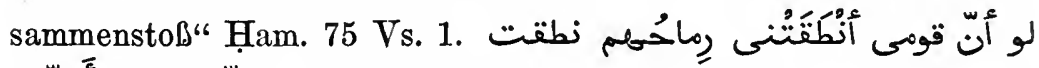
,hätten mich meiner Leute Lanzen reden lassen, so hätte ich geredet, allein die Lanzen haben mich zum Schweigen verurteilt" ebenda Vs. 3. العشر ونصف العشر, der Zehnte und die Hälfte des Zehntens" Balād. 225, 3. Ferner Kur. 5, 14. 'Ant. 19, 17. 22. Ham. 142, 7. Hāătim 19, 5. Hud. 255, 7. 279, 20. Kumait 5, 7 usw. nachdem er das Wort seines Vaters gehört hatte, ergriff er die Hand seines Vaters" Beduinengesch. 4, 6. 5, 18 usw. Vgl. § 2,3. Vulg. 'IRĀḲ. lāčin eddarb gerīb eddarb 'alēhinn mugdār sāंa, ,der Weg war nicht weit, der Weg war für sie ungefähr eine Stunde" Neuar. Gesch. 40, 27. 'iftahi șşand $\vec{u}$ uhallì sirrik bișșand $\vec{u}$,öffne die Truhe und laß dein Geheimnis in der Truhe" Neuar. Volksp. 30, 75. Mar. ahuwa itțāma līha filsanha olktā̄leha lsanha, ,und er packte ihre Zunge und riß ibre Zunge heraus" Houw. 48, 17. Aeth. hng'h-:

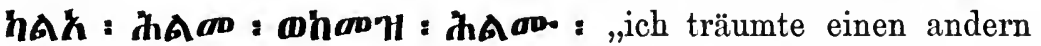
Traum, und dies ist sein Traum" (= der dabei in Betracht kommende Traum) Gen. 37, 9; s. Dillm. Gr. § 172, 1 b, vgl. ZDMG.

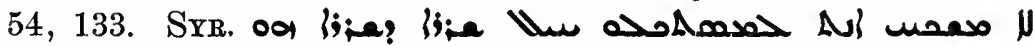
„du kannst nicht an der Kraft der Wahrheit erkennen, daß es die

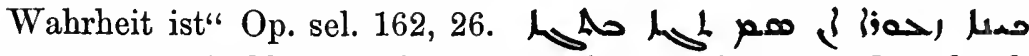
$\rightarrow$, ,wenn ein kleines Wesen eine Krone aufsetzt, wird es durch die Krone groß" Efr. II 507, 13. 335, 18. Afr. II 29, 2-4. Op. sel. 163, 9. Phil. 34, 14. Ass. Ištu șît šamši adi erib šamši ,vom Aufgang der Sonne bis zum Untergang der Sonne" Annals 184, 4. nudunnu mala nudunnu innamdinšu = „die Mitgift, soviel sie 
betrug, soll ihr gegeben werden" Winckler, Gres. Hammurabis, Anhang S. 90 IV 13.

2. Eine Unterbrechung des Zusammenhangs findet namentlich $a$ durch Parenthesen statt, die schon syntaktisch den Zusammenhang $b$ mit einem Ruck unterbrechen; ferner, wenn in die fortlaufende Darstellung eine Erklärung zu einem einzelnen Teile eingeschoben $c$ wird; wenn ein Teil aus einem anderen Zusammenhang entnommen $d$ ist, also z. B. ein Zitat bildet; wenn er ein Sprüchwort oder ein $e$ sentenziöser Ausspruch ist. Überhaupt, wenn er verallgemeinert ist und auch ohne Rücksicht auf den augenblicklichen Zusammenhang ein selbständiges Dasein besitzt und eine geläufige Verbindung bildet. Durch die Anwendung des Nomens statt des Pronomens in solchen Sätzen tritt auch deren objektive Gültigkeit stärker hervor; denn das Pronomen enthält immer irgendwie, unmittelbar oder $f$ mittelbar, eine Beziehung auf den Sprechenden. So tritt denn anderwärts der Darsteller, indem er das Nomen setzt, der Sache fremder oder in größerem Abstande gegenüber.

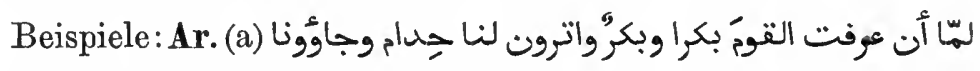
,als ich die feindlichen Bekriten erkannt hatte — und die Bekriten waren ha@erfüllt und zornglühend gegen uns - und sie auf uns

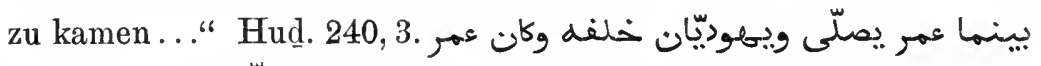
während Omar betete, als gerade zwei Juden hinter ihm standen - und Omar pflegte, wenn er sich niederwerfen wollte, den Leib einzuziehen - , da sagte der Eine von ihnen" Tab. I2 538,6. Hud. 148,15-16. (b) نه "

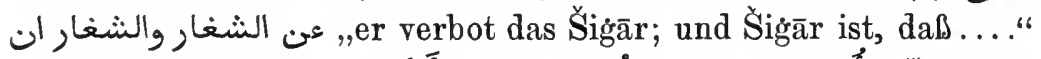

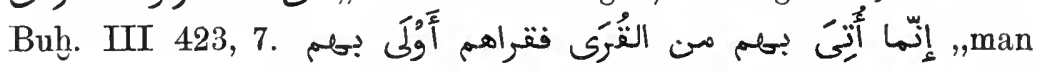
hat sie nur von den Dörfern geholt, und ihre Dörfer sind doch ان قلتتم من مَذُخحج إنّ . إِّو إيّاكم والكنب فإنّ الكنب (d) (d) . "hütet euch vor der Lüge, denn die Lüge steht weit ab vom Glauben" I. Hanbal I 5, 15 v. u. (dagegen Z. 12 v. u.:

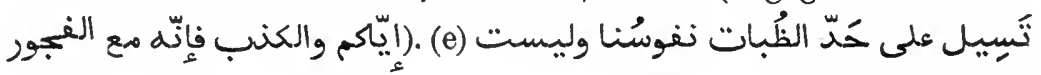


unsere Seelen fließen über die Schneide der Schwertspitzen, und sie fließen über nichts anderes als über Schwertspitzen" Ḥam. 52, 8. 107, 2. Kur. 2, 223. 'Alk. 2, 8. I. Sa'd

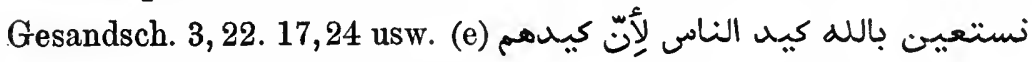
wir nehmen unsere Zuflucht zu Gott vor der List der Menschen, weil ihre List gro@ ist" 1001 N. I 15,4. Hebr.

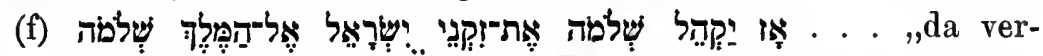
sammelte Salomo die Ältesten Israels zum Könige Salomo"

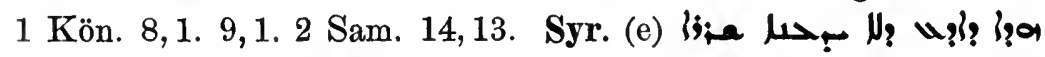
ierier Umstand, daß ich weiß, daß ich die Wahrheit nicht kenne, ist noch nicht Erkenntnis der Wahrheit"

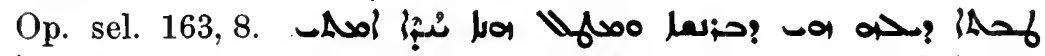
iA freut er sich, wenn er das Gute tut" Spic. 6, 11. Phil. 274, 4. Sahd. 54,9. Ass. (f) lutira mät šarri ana šarri "damit ich das Land des Königs dem Könige zurückbringe" KB V No. 183, 20.

Bisweilen ist es die Symmetrie, durch die die Wahl des Nomens herbeigeführt wird; so namentlich in Gegensätzen, wie das Schicksal hat unser vertrautes Verhältnis hergestellt, und so hat uns auch das

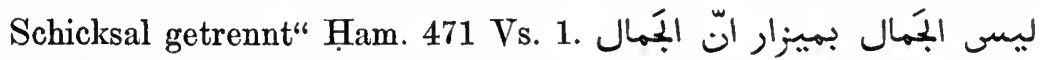
dé ,die Eleganz besteht nicht in Gewändern, die Eleganz besteht in edeln Eigenschaften" Ham. 81 Vs. 1. 2. I. Sa'd 21,16. 'Ant. 2, 19.

Es wäre irrig, wollte man all diese Erscheinungen aus dem Streben nach Deutlichkeit erklären, wiewohl natürlich auch das unter Umständen den Ausschlag für die Wahl des Nomens gibt,

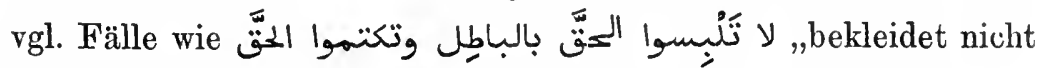
die Wahrheit mit dem Nichtigen, so daß ihr die Wahrheit verbergt" Kur. 2, 39. 171. 5,100. 7,51 usw.

$\$$ 10. Gebundener Gebrauch des Nomens. 1. Das Demonstr. und Personalpron. ist oft infolge der grammatischen Natur dieser Wortarten ausgeschlossen, und daher die Wiederholung des Nomens erforderlich. Also z. B. wenn das Wort indeterminiert 
bleiben soll, wie es u. a. bei $\breve{J}^{5}$ vorkommen $\operatorname{kann}^{1}$; z. B. Ar.

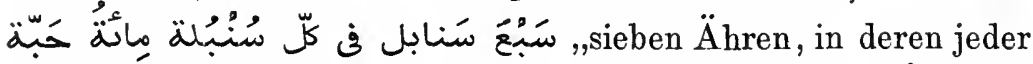

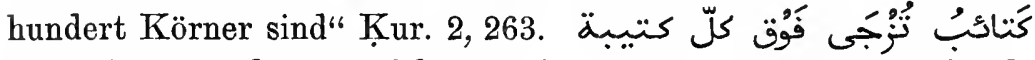
,Scharen, die vorgeführt werden, über deren jeder ein Feldzeichen schwebt" "Ant. 4,5.'

2. Das Demonstr. kann ursprünglich keinen Genitiv regieren ${ }^{3}$ (arab. و), syr. ? usw. mit Genitiv sind nicht mehr reine Demonstr.), daher heißt es vor der Rabīas" I. Hiš. 12 ult., und so zahllose Fälle, z. B. nach

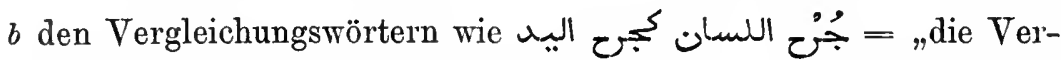
wundung der Zunge ist wie die der Hand"Imr. 14, 4. Hud. 96, 10.

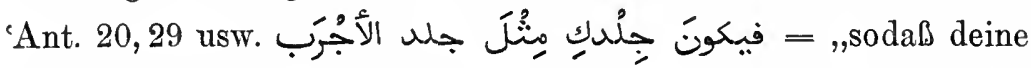
Haut wie die des Krätzigen wird" "Ant. 5, 1. Hud. 95, 10 usw. euer Gefangener hat einen besseren Vater als der eure (ist)“" Ant. 9, 1. das Gleichnis Jesu ist wie das Adams" = „Jesus gleicht Adam" Kִur. 3,52 und sonst.; in Sätzen nach Vergleichungswörtern, wie

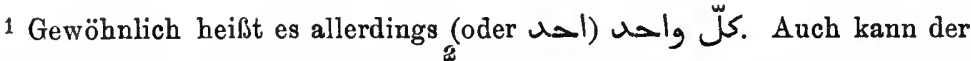
Genitiv überbaupt wegbleiben, und كلّ steht dann auch im Sinne ron (Ag. ${ }^{2}$ XI 111, 13 [=1 116, 14]. Ḥam. 122, 4 v. u. Ḥătim 19, 19).

2 In diesen Sätzen ist also das Nomen gleichwertig einem Rückweisepronomen (' $\overline{\mathrm{A}}$ 'id).

3 Der Genitiv wird aber alsdann oft durch o umschrieben, wie in |\rangle $\mid$ تِّك ... . ¿dies sein (Benehmen) bietet keine Gewähr dafür, daß ..." Ham. 64 Vs. 1. dies (Verbalten) Nu'mās war keine Belohnung" Ahital 18, 12. ein ähnliches Wort wie dieses" A ${ }^{2}{ }^{2}$ XVI 13, 1. I. Hiš. 83, 17. 565, 17. Tab. I4 2072, 14. Ag. 2 XIII 73, 7 usw. Vulg. ÄG. lōno zēj üläd elfallăhīn „dessen Farbe wie (die) der Bauernsöhne war" Spitta Contes 53, 8. - In solchen Sätzen liegt bisweilen die Gefahr nahe, den mit ${ }^{-}$gebildeten präpositionalen Ausdruck auf ein falsches Wort zu beziehen; ersetzt man aber das Demonstr. durch das erforderliche Substantiv, so wird der präpositionale Ausdruck Genitiv; also in dem ersten Beispiele تأخي (nicht etwa ist zu verbinden obio sl, ner sah an ihnen“). 


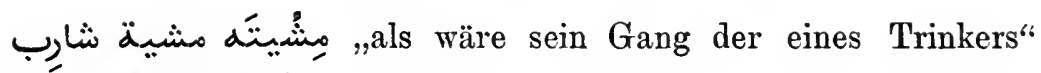
'Ańt. 20,30 usw. '.

Vulg. 'IRĀK. (a) ḥfaret lah gabr jemm gabr abūh „sie grub ihm ein Grab neben dem seines Vaters" Neuar. Gesch. 22,15. wilein 'ein ennugīd „und das Auge ist das der Gazelle" Neuar. Ged. S. 126 No. 4. Sxr. (a) min 'èn̄i weèn hal' allā ,vor meinem Auge und dem der Menschen" Neuar. Volksp. S. 18 Vs. 42. S. 16 Z. 14. S. 20 Prosa Z. 10. Pal. Diw. 53 vorl. ÄG. (a) aṭlub serāje gambe serājet ibn elmelik ,ich verlange einen Palast neben dem des Königssohns" Spitta Contes 109, 1. 154, 4. (b) huêroh ketīr zijāade "an hyerr abüje "seine Schätze sind größer als die meines Vaters" Spitta Contes 64,9. serāje zè serājet abūh ,einen Palast wie den seines Vaters" Spitta Contes 94 ult. 26,6. TRIP. (a) wagha wagh brēs „deren Gesicht das eines Falken ist" Lieder No. 81, 7,1. (b) 'ainiti liema 'ain 'alī mtāara, ,dein Auge ist wie das des hochfliegenden" Lieder No. 16,1. SüDar. (a) קניהו וקני אמבהו ,seine Güter und die seines Vaters" CIS IV 37, 2. Ferner 2,5.

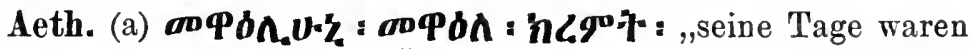
die des Winters" Lal. 46,11. Šarḍa dengel 30,12 usw. (b) noC.T :

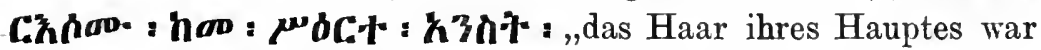
wie das von Frauen" "Amda șejon 401 pænult. Šarḍa dengel 3, 2.

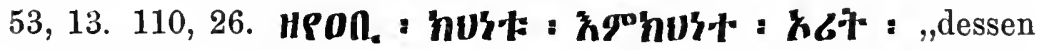
Priestertum größer ist als das des Gesetzes" Chrest. 97, 5 v. u.

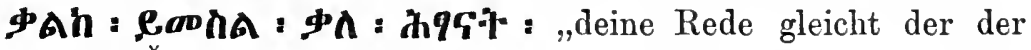
Kinder" Šaṛ̣a Dengel 46, 29.

Hebr. (a) der Name der einen

1 Bisweilen ist die Vergleichung durch Unterdrückung des gemeinsamen

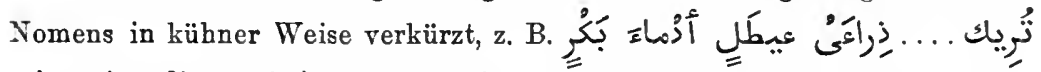
„sie zeigt dir zwei Arme (wie die) einer langhalsigen, rötlichen jungén

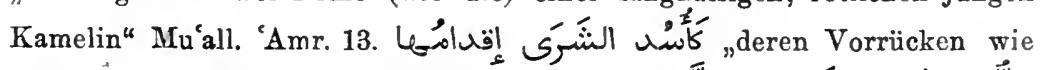

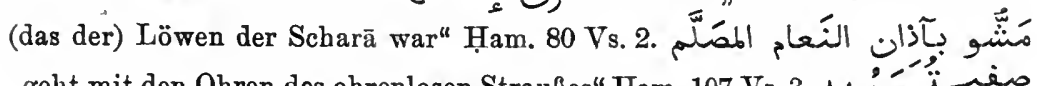

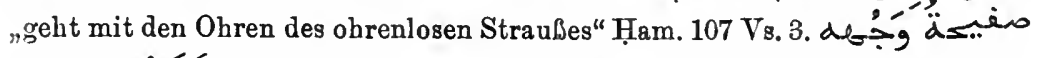

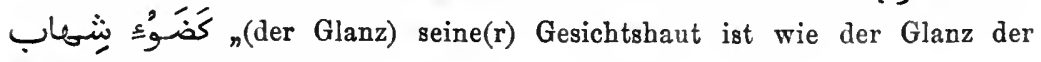
Flamme" Ḥam. 208, 14. 


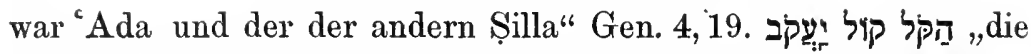

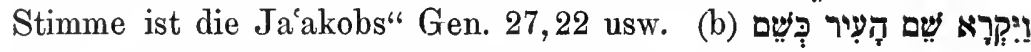
"er nannte den Namen der Stadt wie den seines Sohnes" Gen. 4, 17. 19, 28 usw. Mišnā. (a) מכבילתו ואכילת חבירו, seine Speise und die seines Nächsten" Me îlā 5, 5. usw. (b) פהה כח הבעל מכח האב „die Kraft des Gatten ist besser als die des Vaters" Ned. 10, 2.

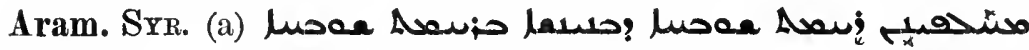
lall!, "wir ersetzen die Sucht nach Lob der Menschen durch die Sucht nach dem Lob Gottes" Sāhdōnā 143, 10. W „deine Geburt war die Aller" Efr. II 465,5,9. I 157,15. Afr. 488, 22. Phil. 56, 17. 357 ult. Is. Ant. I 128, 1038. Spic. 7, 22. Sāhdōnā 203, 3. 494,2. (b) wir haben seinen Ruhm wie den des Eingeborenen gesehen" Is. Ant.

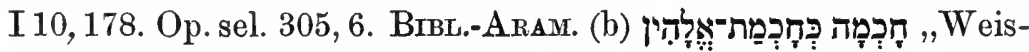
heit wie die von Göttern" Dan. 5,11. 7,8.

Ass. (a) ana balațišu u balaṭ aplišu ,für sein Leben und das seines Sohnes" KB I 2 No. 3,9. Sonneng. No. 1,4. Amarna 44, 15. 122,1. 138,8. (b) kibitsu lima kibit Anim ,seinen Befehl wie den des Anu" KB VI 92, 2.

3. Neben dieser Ausdrucksweise steht allerdings in mehreren semitischen Sprachen eine andere, die den paronomastischen status constructus durch ein allgemeines Vertretungswort, meist pronominalen Ursprungs, ersetzt. Vulg. Äg. Zum Gebrauche von betā vgl. Spitta Gr. § 119. 120. MaIr. nofsom ta šädīn ,ihre Person war die eines Affen“ Stud. 41,3. MaR. žuž hıžlāt... an nakul ta't binti, ,zwei Rebhühner .... ich werde das meiner Tochter essen" Houw. 14, 4. 22, 11. Aeth. Fovch : He.t.6n:

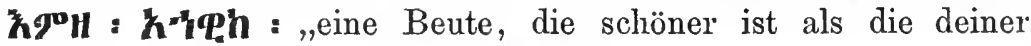

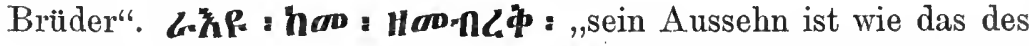
Blitzes" Dillm. Gr. § 186 . Hebr. Mišnä. שלה של יד אינה מעכבת der Gebetsriemen der Hand schließt den des Kopfes

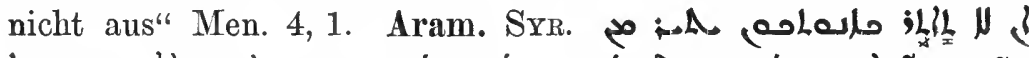

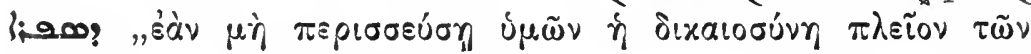

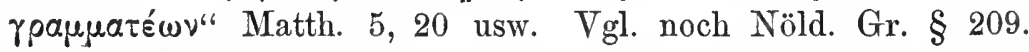

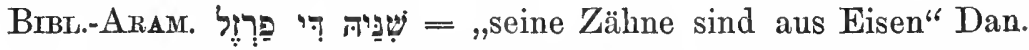
7, 19. Ass. tabka ša šèim ana ša ab̄a luttiv ,,eine Aufschüttung von 
Getreide zu der meines Vaters machte ich" KB I38, 103. minusunu kima ša maršit șini ma lu ammu, ,ich zählte ihre Zahl wie die von Schafherden" KB I 40,11. madattu ki ša Ašsuri emidsunuti „Tribut wie den der Assyrer legte ich ihnen auf" KB II 40, 16.

4. Auch das ursprüngliche Fehlen eines substantivischen Possessivums machte paronomastische Ausdrucksweisen erforderlich. Ar. لا ياكل احل .die Habe ist eure" "Ant. 16,4 المال مالكم ,keiner ißt Speise außer von der deinigen"

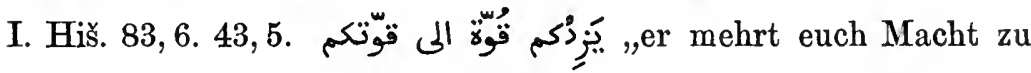
eurer (bereits vorhandenen) [vgl. § 7, 7.]" Kur. 11, 55. 9, 126.

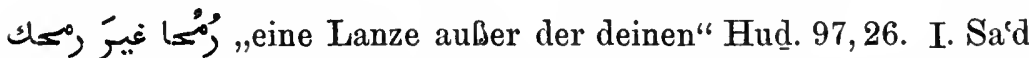
VIII 131, 2 usw. I. Hiš 718,6 (ني). Kur. 24, 27 usw. 1001 N. IV 60,5 v. u. Beduinengesch. 7, 17. Vulg. 'IRĀK. mítadil lōnak ulōni șufar „deine Farbe ist gut, aber meine ist gelb" Neuar. Ged. II S. 94. No. 8,3. SYr. ich gebe mein Auge für das ihre" Lbd. v. Am. 10, 14. 110, 7. Pal. Diw. 50,7 v. u. bèt mitl bètak, ,ein Haus wie das deine“ Damas $110 \mathrm{Z} .6$. Lbd. v. Am. 128, 14. wādine ahsan min wādìtum, ,unser Tal ist schöner als das eure" Lieder e. Bauern No. 54, 2. 68,2. Mar. hăda wuldkum uwuldi „das ist mein Kind und das eure" Tlemcen 280, 60. Houw. 42, 11-12. Tunis. fi 'ašăh u'ašăha „für sein

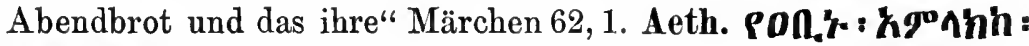

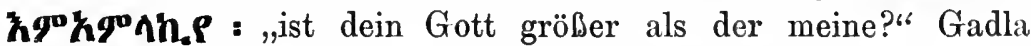

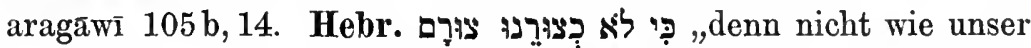
Fels ist der ihrige" Deut. 32,31 usw. Mršnā. mein Mund ist wie der seine" Nãzir 4,1. לא יתפור אדם בור סמוך לבורו של חבירו „,man grabe keine Zisterne neben der des andern“ Bābā b. 2, 1. Syr. unsern vermischt" Jak. Ser. Hom. 11, 7. Efr. I 43, 2, 4. II 339, 13. Is. Ant. I 4, 56. 108, 546. 146, 1475. Afr. I 341, 16. 412, 1. Phil. 76,9. Op. sel. 120, 11. Ass. šumka itti šumia šuțur ,schreibe deinen Namen neben den meinen" Annals 165 Rev. 6. 166, 13. KB III a 198, 29. - Vgl. übrigens oben No. 3.

5. Ein Teil der semit. Sprachen besitzt nur in beschränktem Um- 
fange ein eigentliches Korrelativum. ${ }^{1}$ Paronomastische Ausdrucksweisen wie die folgenden sind im Ar. nicht nur möglich, sondern unvermeidlich: dieses unser Haus

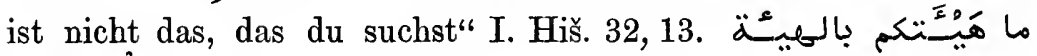
ما

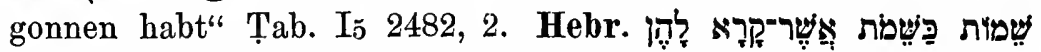
Nאוֹבְיו 26, 18. - So im asyndet. Relativsatze: لا اخرج بعد يومى هنال ich werde nach diesem heutigen Tage nie wieder zu einem Manne hinausgehen, außer zu einem, den ich

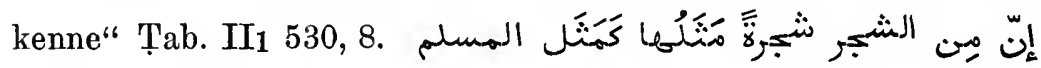
„unter den Bäumen gibt es einen, der dem Gläubigen gleicht" Bub. I 30, ich habe keine Leute getroffen, wie solche, die ich unter den Persern ge-

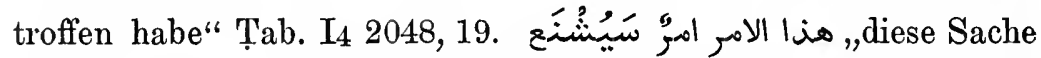
ist eine solche, die für abscheulich gehalten werden wird" "Umar 55, 18. Ḥātim 4, 8. Nāb. fr. 24,4 . So hält sich überhaupt der Gebrauch der Wörter, die zu thetischen Indefiniten geworden sind, in gewissen Grenzen ${ }^{2}$, und Paronomasien sind hier dem-

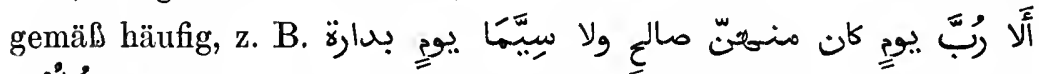

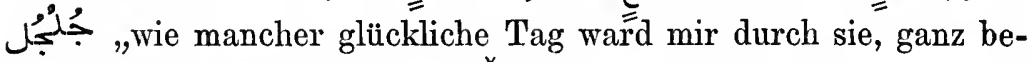

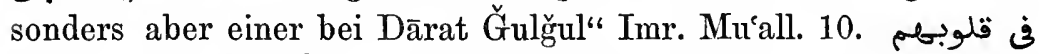

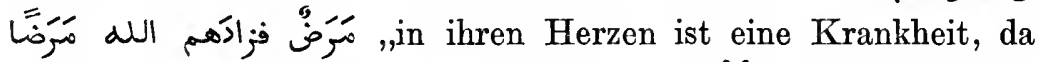

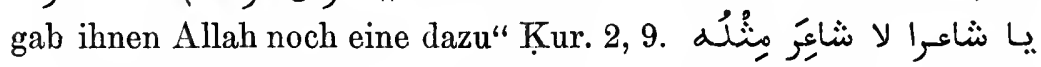
„o über einen Dichter, dessengleichen es keinen gibt" K. aššír 315, 14. sie begrüßen ihn als Trottel, wenn er auch keiner ist" Hud. 261, 9.

6. Im Dialog werden oft statt eines allgemeinen Bejahungsoder Bestätigungswortes die Worte des Vorredners noch einmal

1 Vgl. dagegen z. B. zum syrischen Korrelativum Nöld. Gr. § 236, wiewohl natürlich auch im Syrischen die paronomastische Ausdrucksweise vorkommt.

$2 \mathrm{Mehr}$ oder weniger gilt das überhaupt für alle Sprachen. 
ausgesprochen, z. B. sie sagten: Bist $d u$ Josef? Er antwortete: Ich bin Josef" Kur. 12, 90. Oder Bejahungswort nebst Wiederholung: أرَجوت أث يكون Hofftest du, er werde Chalife werden? Er antwortete: Ja, ich hoffte das" Tab. II2 1111, 8. - Auch außerhalb der Frage, wie قال قل شاع في الناس عنكما الخبر قاعت Er sagte: Die Geschichte über euch hat sich unter den Leuten verbreitet. Er antwortete: Sie hat sich verbreitet" Ag. ${ }^{2}$ XII 81, 1. Vulg. MaLt. 'andek ši ftìd żbeiniet ta 'audeš 'andi „Hast du einige von den kleinen Gozokäsen? - Ich habe" Malt. Stud. 45, 14. Mar. galtlih waš t'aḳkel 'al trīk galliha n'aḳl 'al trīk „Sie sagte zu ihm: Kennst du den Weg? Er antwortete ihr: Ich kenne den Weg" Houw. 36, 7. Südar. Sor. 'emor selobk tos emor selobk ,Er sprach: Hast du es geschlachtet? Er antwortete: Ich habe (es) geschlachtet" Sok. II 58, 28. 78, 24. 90, 3 usw. MEHRI ṫaaurib salīt di šlīt senīn amōr heh ajaurib „Kennst du dreijähriges Öl? Er antwortete ihm: Ich kenne (es)" Mehri I 66, 28.

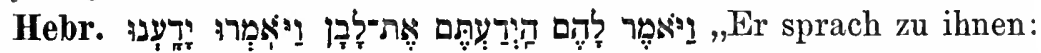
Kennt ihr den Laban? Da sprachen sie: Wir kennen (ihn)" Gen.

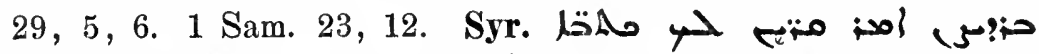
Bardaișan sprach: Hast du die Bücher der Chaldäer gelesen? "Awīda sprach: Ich habe die Bücher der chaldäischen Lehre gelesen" Spic. $13,8-11$.

\section{Das Verbum in der Paronomasie.}

\section{$\$$ 11. Wurzelverwandte bedeutungsverschiedene Verbal-} formen. 1. Tempuswechsel: Ar. النى كان ويكون ,was gewesen

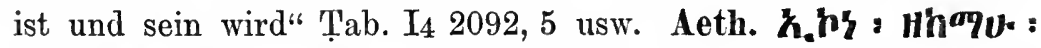
" wird keines geben" Rendiconti d. A. d. Lincei 1893, 816, 4 v. u.

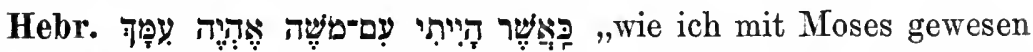

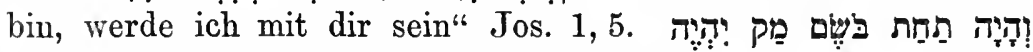
,,und es wird geschehen, statt Wohlgeruch wird Moder sein"

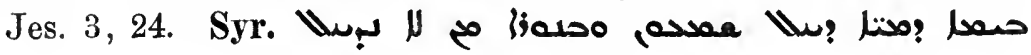


„im Wassermeere hat sich Simeon gefürchtet, und wer sollte sich nicht im Feuer fürchten" Efr. II 421, 5 v. u. Usw. So gibt es mannigfache Kombinationen mit Partiz., Imperativ, Subjunktiv usw.

2. Wechsel von Aktiv und Passiv: Oft sind Aktiv und Passiv so verbunden, daß mit ein und demselben Subjekt sowohl die Ausführung als das Erleiden einer Handlung verbunden wird, wie z. B. Ar. der nicht besucht und nicht besucht

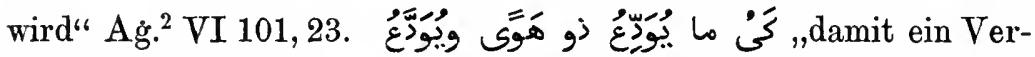
حتّى ,bis ihr eilt, oder mit euch geeilt wird" Hud.

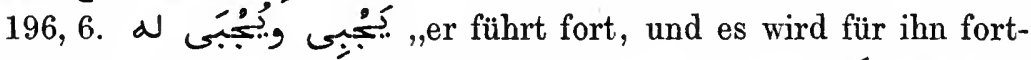

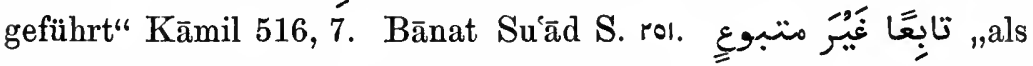
ein Nachfolgender, dem nicht nachgefolgt wird" Tab. I4 1843 ult. K. aššír 277, 15. 436, 9; vgl. noch § 36. Vulg. SYr. ja lèt kattālu katīl „o wäre doch sein Mörder ein Gemordeter“ Pal. Diw. 327 pänult. Neuar. Volksp. S. 31 Vs. 81. Ar. petr. 27, 11. Aeth.

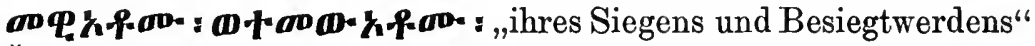
Šarḍa Dengel 81, 29. Gen. 4, 15. Inschr. Bent III 26f. = IV

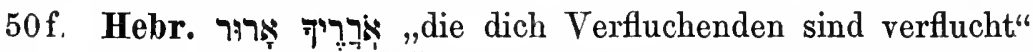
Gen. 27, 29. Jes. 33, 1. Mršnā. כל הנושא ונישאיו',Alles, was trägt und getragen wird" Zābìm 5, 3. כסורין ואוֹסרין ,sie sind verboten und machen verboten" 'Abōdā z. 5, 9. Gițțīn 5, 7. 'Arāk̄̄n 1, 1. Kēlìm

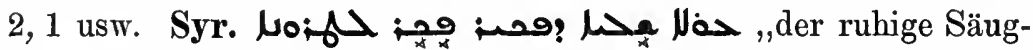
ling, der gebunden war, band den Tyrannen" Jak. Ser. 776, 15. Spic. 13, 22. Phil. 41, 4. 80 ult. Op. sel. 21, 9. 24, 22. Spic. 1, 19. Efr. II 465, 7, 9. Afr. I 89, 4. Efr. I S. 41, 26, 4. Vgl. noch unten No. 4. Da der Täter der Passivhandlung in suspenso bleibt, und daher das Passiv z. B. gebraucht wird, wenn der Täter sehr allgemein ist, so wird das Aktiv mit dem Passiv unter anderm dann in Beziehung gesetzt, wenn das Aktivsubjekt etwas Spezielles ist, das einer höheren Gattung subsumiert werden soll, so z. B.

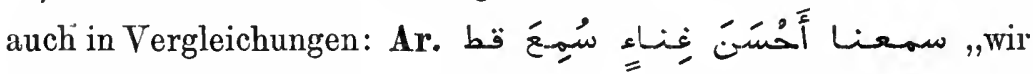
haben den schönsten Gesang gehört, der je gehört worden ist"* 
Ag. ${ }^{2}$ V 36, 7. ich habe einen Verächtlichen unter euch verächtlich behandelt, wie die Klippdachse verächtlich behandelt werden" "Ant. 12, 5. Vulg. 'IRĀK. Iōn jïnbāg haddak labuget minna ,wenn deine Wange gestohlen werden könnte, würde ich von ihr stehlen" Neuar. Gesch.

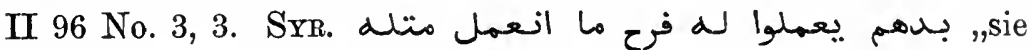
wollen ihm eine Hochzeit richten, derengleichen noch keine gerichtet worden ist" Lbd. v. Am. 94, 3. 1083 v. u. MAR. šadd mā itšadd „er schnürte, was geschnürt wird“ Mar. 182,13. Südar. Soḳ. al etmah lenfah de nefặ waīhe al išnefah ,ich kann diese Arbeit nicht machen und sie kann (überhaupt) nicht gemacht werden"

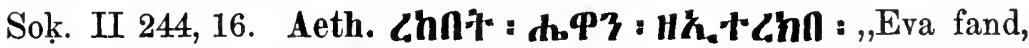
was (sonst) nicht gefunden worden ist" Kenē XX 4. Hebr. אִ לִיא ליא wenn er das Feld nicht einlöst, kann es

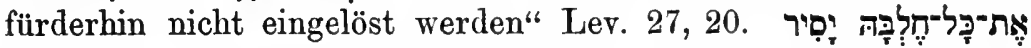

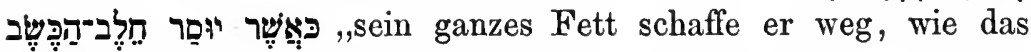
Schaffett weggeschaft wird" Lev. 4, 35. Deut. 12, 22. Richter 16, 9. Sach. 4, 1. So wechselt auch die zweite Person des Ak-

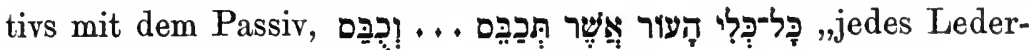
gerät, das man wäscht, soll gewaschen werden" Lev. 13, 58.

Die Verbindung von aktiver und passiver Ausdrucksweise ist auch ein Mittel, den Täter beim Passiv anzugeben, was sonst be-

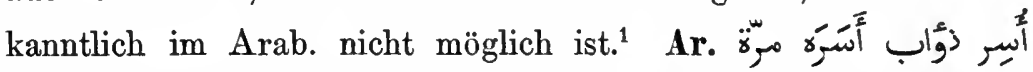
"Du'āb wurde gefesselt, es fesselte ihn Murra" $>$ "Du’āb wurde von Murra gefesselt" Ag. IX 6, $10\left(={ }^{2} 6,2\right)$. إنّ رجلا مِن صُصاء

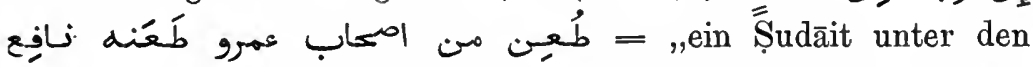
Leuten Amrs wurde von Nāfi durchbohrt" Tab. II 113,9 . لِ (ب) er wurde deswegen von einem Landsmann getadelt" Hud. II S. 4, 1. Diese Konstruktion kommt besonders oft mit قتّل vor, z. B. Hud. II S. 12, 1. Ṭab. I4 1951, 16. 2069, 4. II 1 386, 7. Kāmil 129, 18. Balād . 306, 16. Balāḍ. Ansāb 98, 4. Ag.. II 159,6 v. u. $\left(={ }^{2} 154,15\right)$ usw. Noch zutreffender

1 Ein anderes Verfahren den Täter beim Passiv zu bezeichnen, s. Syntaktische Verhältnisse S. 785 Mitte. 
würde man übersetzen ,er wurde gefesselt, und zwar von ..." usw. Als eine solche nachgetragene nähere Bestimmung erscheint das Aktiv namentlich dann, wenn es durch einen längeren Ausdruck

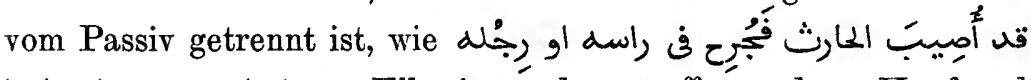
"Elhạrit wurde getroffen und am Kopf und Fuß verwundet von einem unserer Schwerter" I. Hiš. 552, 13.

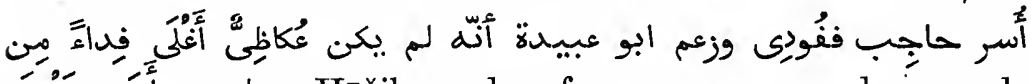
Hب̣ăğib wurde gefangen genommen, dann wurde er ausgelöst, und Abū Ubaida behauptet, kein Ukāẓit habe ein höheres Lösegeld erfordert als Ḥāğib; und zwar nahm ihn Zahdam gefangen" Kāmil 273, 11. - In den Dialekten kann man den Täter beim Passiv durch w bezeichnen; natürlich kommt aber doch auch die obige Wendung vor, z. B. Vulg. Syr. wana 'alhānn indellēt dallüni ḥusn ilbanāt, „und ich wurde zum Chan gewiesen, die schönsten Mädchen wiesen mich" Pal. Diw. 139 No. 3 Vs. 2. Südar. Soк. jehuton h̆amed wajeḥatenoš h̆sein = „Hamed wurde von Hisein beschnitten" Sok. II 293, 2. Das Gleiche gilt für andere

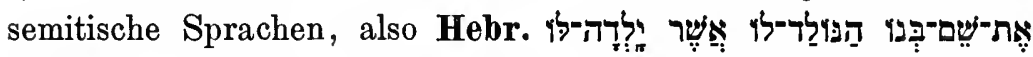
שֶׁ = "den Namen des ihm von Sara geborenen Sohnes" Gen.

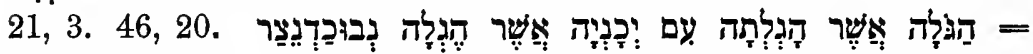
„die Gefangenen, die mit Jekonja von Nebukadnezar weggeführt wurden" Est. 2, 6. Vgl. auch Jer. 20, 14.

3. Der Wechsel verschiedener Konjugationen ist natürlich mannigfaltig ${ }^{1}$; in den allermeisten Fällen ist es das Wechselverhältnis einer Konjugation mit einer davon abgeleiteten, also vor Allem der Konjugation katala mit einer anderen. Die folgenden Beispiele enthalten nur die selteneren und z. T. mehr auf zufälliger Parono-

1 Im Folgenden werden auch die Verbalnomina berücksichtigt, soweit sie an den Eigentümlichkeiten ihrer Konjugation teilnehmen; auch Adjektive sind nicht ausgeschlossen, soweit sie mit Partizipien gleichgesetzt werden können, vgl. Ausdrüicke wie Ar. [= I] an einem Morgen voll Wetteifers um die Zabl [III]" Farazd. 465, 50. Syr. ui is

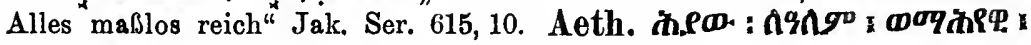
"lebendig auf immer und belebend" Clirest. 98, 10. 
masie beruhenden Fälle, in denen die beiden Konjugationen nicht im Ableitungsverhältnis zu einander stehen, also auch mit Ausschluß von katala, für dessen Kombination mit allen möglichen Konjugationen ich zahlreiche Belege geben könnte:

kattala und taktala. Ar. I. Hiš. 24, 16. Buh. III 444 ult. (خار). Tab. Is 2689 ult. (غبطh)

kattala und astaktala. Ar. Kur. 10, 12 (عجل). Ruk. 33, 6. Tab. Is 2803, 7 (بدل). Tab. II1 11, 16 (اجل). Buh. III 177, 6 (خلف; ,zum Vertreter machen - zurücklassen“).

kattala und naktala. Ar. Abū Nuwās (ed. Ahlwardt) 7, 9

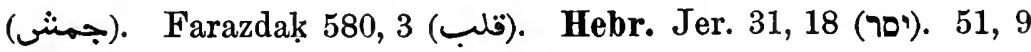
(נפר). Richt. 16, 9 (נתק). Num. 22, 25 (קדש).

kattala und kātala. Ar. Hāatim ro, 18 (لطم). Țab. I4 2033, 8 (ع) (s).

kattala und takātala. Ar. Abtal 146, 3 (هع).

kattala und 'aktala. Ar. Nāb. 27, 22 (نبش). Buh. II 302, 4 (بشن). Hebr. Mršsā. Ned. 5, 6 (קדש). Syr. Op. sel. 179, 7 (;A).

kātala und taktala. Ar. Tab. I3 1196, 12 (باع). I4 1890, 9 (فتل). I6 3378, 8 (خلف).

$k$ ātala und takattala. Ar. Tab. I5 2730,1 (هج)

kātala und astaktala. Ar. Ag.. XI 112, 23 (عتب).

kātala und 'aktala. Ar. Hamad̄āni Rasāil S. 17, 2 (>),). Kumait 2,112 (بلع). Tab. I4 2191, 17 (بهِل).

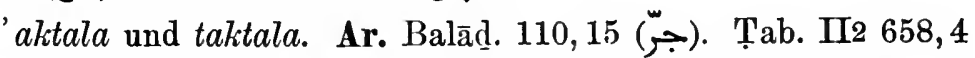

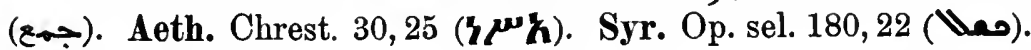
Phil. 32, 5 (ح).

'aktala und takattala. Ar. Imr. 30, 13 (لبس). Mutalammis 1,7 (ق)). Aeth. Gen. 7,17 (nON).

'alctala und (h)atkattala. Hebr. Gen. 42, 7 (נכר).

'aktala und naktala. Ar. Abțal 88, 15 (נج) Hebr. Ez. 38, 7 (כון). Jes. 7, 9 (אמן). Mršnā. Bābā k. 1, 2 (נמן).

takattala und takātala. Abulḳāsim 1,8 (نفسى).

Weitere Belege im Folgenden passim, und namentlich in $§ 12,2$.

4. Während in obiger Zusammenstellung nur das formale Verhältnis der paronomastischen Konjugationen ins Auge gefaßt 
war, sollen nun einige der zugrunde liegenden Bedeutungsverhältnisse dargestellt werden.

Die eine Verbalform bezeichnet z. B. eine größere Intensität

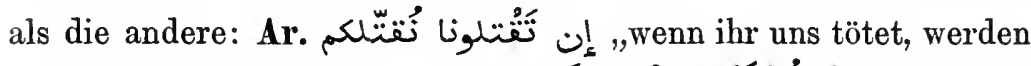

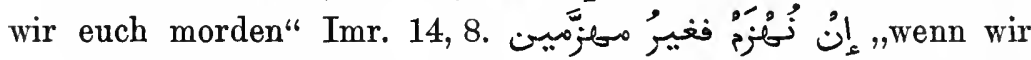
in die Flucht geschlagen werden, werden wir doch nicht in wilde

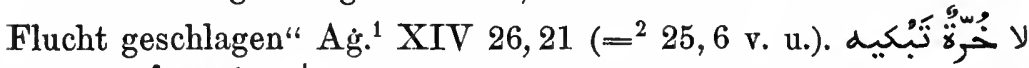
nicht eine Edle beweint ihn, sondern Klageweiber stimmen ihr Geheul über ihn an" Tab. II2 1108, 17.

Oder das eine Verbum steht zum andern in Kausativverhältnis, (vgl. § 12, 2), gleichviel welches das vom andern formal abحمل . حمّل - das Geheimnis bewahren - es anvertrauen" Ahțal 10, 13. gereizt sein — reizen" Ham. 236, 20. sich in Acht nehmen — warnen" Tab. II2

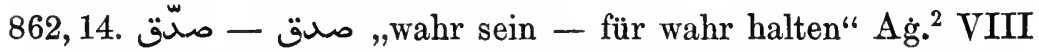

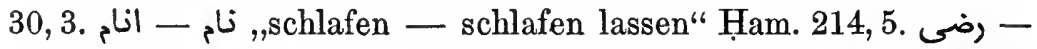
تدفع - دفع . gnädig stimmen" Balādِ. 231,2.

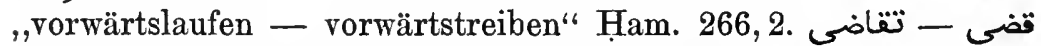

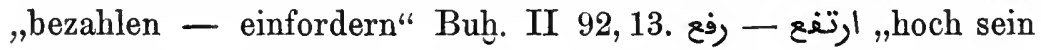
- erheben" Ahțal 40,1. sich erniedrigen -

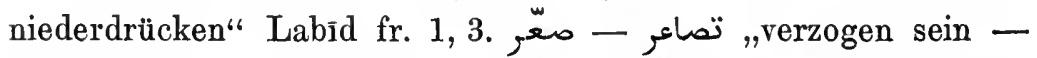

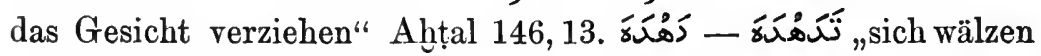
— wälzen“ Ṭab. Id 1874, 14. منغ - fliehen - zur Flucht auffordern" Tab. I4 2081, 8. سال - استهال - geneigt machen" Ahțal 134,12.trinken - um

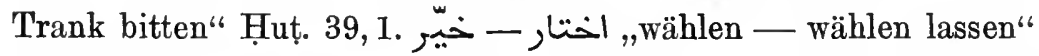
I. Hiš. 24, 16. beschleunigen -um Beschleunigung

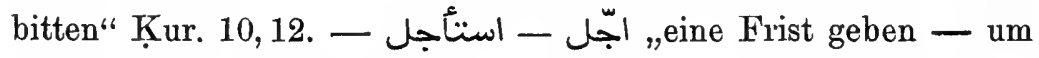
eine Frist bitten“ Tab. II2 11, 16. Nachricht geben — um Nachricht bitten“ K. aššír 233, 7. aufrecht

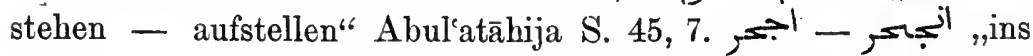
Loch eilen - ins Loch treiben" Ahțal 88, 15. اعان - استعان 
"helfen - um Hilfe bitten" Ham. 208 Vs. 3. الطعم - استطعى -

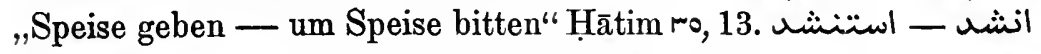

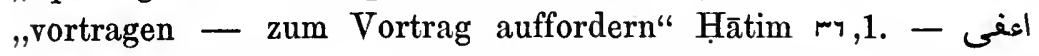
entheben - um Enthebung bitten" TTab. I5 2635, 3. إستراح - ruhig werden — Ruhe verschaffen" 1001 N. III 54,5.

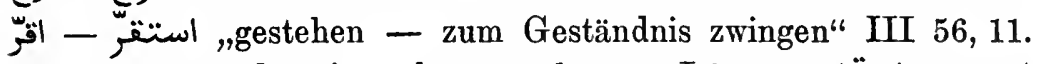

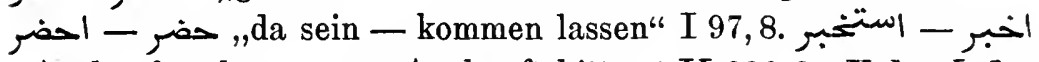
„Auskunft geben - um Auskunft bitten“ II 286, 3. Vulg. IRĀK. طاب - sitzen lassen - sitzen" Neuar. Gesch. 18, 4. قعد - ثعَّد bersten -

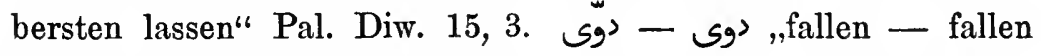

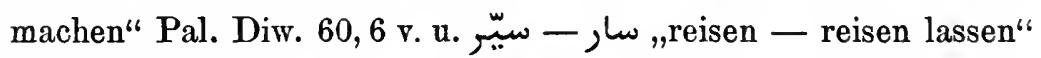

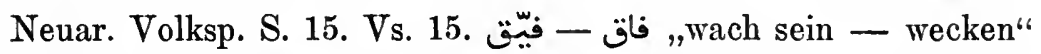

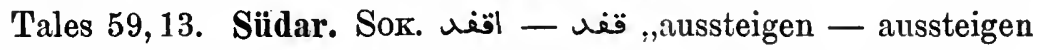

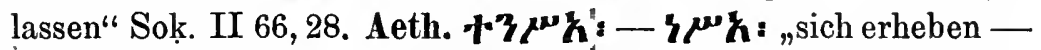
mitnehmen" Gen. 19, 15. - nUn : - Kin : ,sagen - sagen machen"

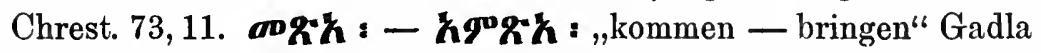

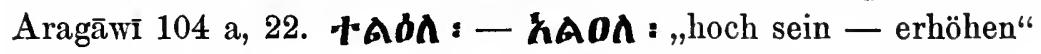

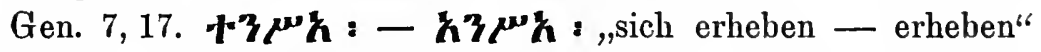

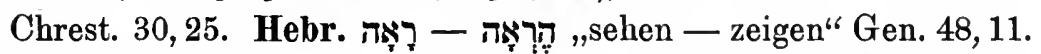

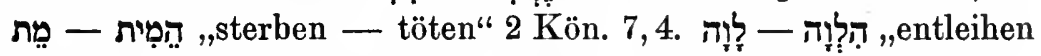

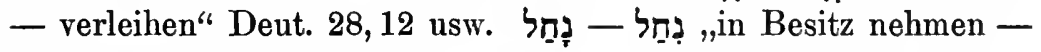
als Besitz geben" Jos. 14, 1. "kinderlos sein -

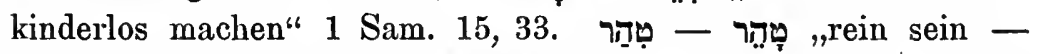

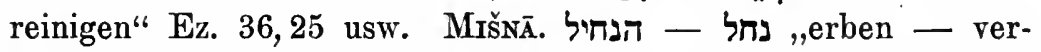
erben" Bābā b. 8, 1. הדלק - דלק - "Feuer fangen - anzünden" Bābā k. 6, 5. Syr. iAl - iA , ,reich sein — reich machen" Addai 46, 22. ;all - ;al, ,verwundert sein - in Verwunderung setzen" Jak. Ser. 700, 6. احصم - "tun - zu tun veran-

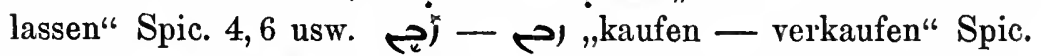
19, 21. Aram. Ezra 7, 25 (ידע). Ass. izziz - ušeziz ,,stehen - aufstellen" KB I 68, 105. idbud - ušadbib "klagen - klagen lassen" KB III1 160 Col. V 34 f. und sonst. KB IV 62 Col. 3,16 (nkr). 76 Col. 1,36 (pkr). 37 (tbl). 
Die eine Konjugation bezeichnet die Simulierung der von der andern bezeichneten Handlung: unwissende

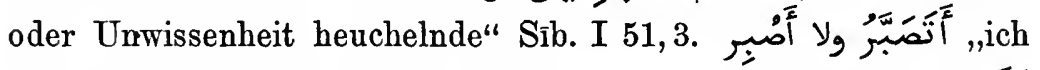
stelle mich geduldig, bin es aber nicht" Tab. II1 274,18. عَ"َّى Blindheit oder simulierte Blindheit" Kumait 1, 89. vollzieht die Hedschra, und tut nicht bloß so!“،

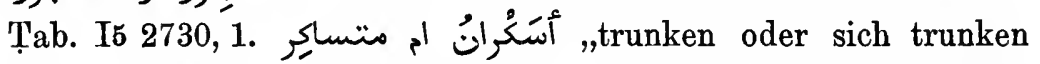

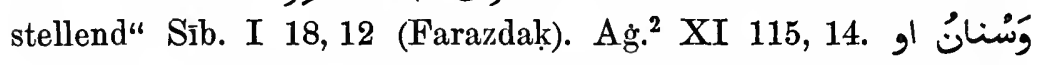
,schlafend oder sich schlafen stellend" Hud. 78, 10. 277, 12 (نضب). Ag. ${ }^{2}$ XVI 16, $17={ }^{1} 17$, v. u. (مرو).

Die eine Konjugation bezeichnet die Reaktion auf die andere: sie sprangen auf Mackil los, da wehrte

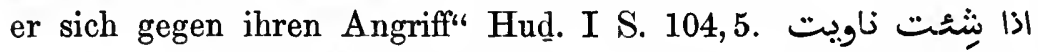

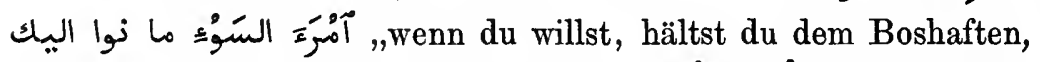

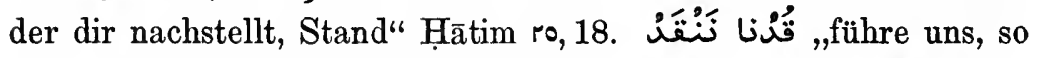

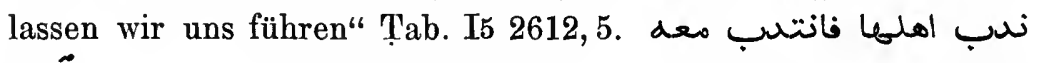
نr rief ihre Bewohner auf, da folgten 10,000 seinem

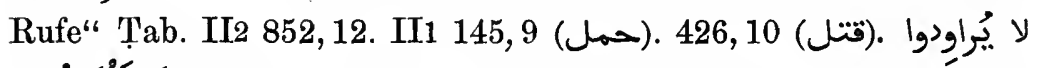
= ,sie suchen bei Gott nichts als seinen Willen

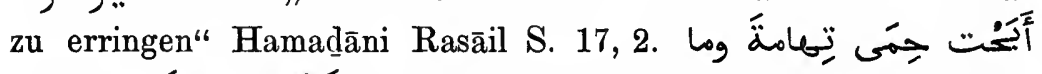

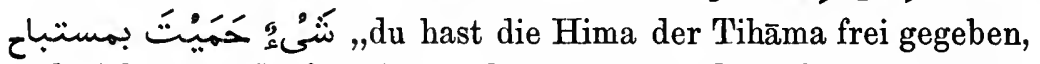
und nichts was du für Hima erklärt hast, wird als frei angesehen" Sīb. I 34, 15. Vulg. 'IRĀK. jerīd jefukkhā mä tinfakk, ,er versuchte sie zu öffnen, sie ließ sich aber nicht öffnen" Neuar.

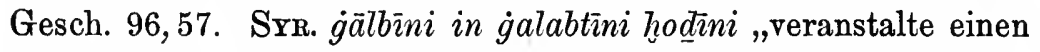
Wettstreit mit mir, und wenn du mich besiegst, nimm mich" Pal. Diw. 205 No. 8, 1.

Dem Verhältnis der Handlung zur Reaktion auf sie liegt also unter Umständen das Verhältnis des Versuchs zu seinem Erfolg zugrunde. So ist es auch in folgenden Fällen: Ar. ,als sie ihn niederzustrecken suchten, da wehrte er sich dagegen niedergestreckt zu werden" Labid 34, 6 . 
ich habe mit ibnen disputiert und sie besiegt" Kāmil 645,6. سابَقطم فسبِقهم ,er suchte sie zu überholen, da überholte er sie" Tab. I4 1899, 14. Kur. 2, 8 (خد). مت = so oft wir mit Pfeilen um die Wette spielten, gewann ich es ihm ab" Ag. ${ }^{2}$ I 165, $6\left(={ }^{1} 171,14\right)$.

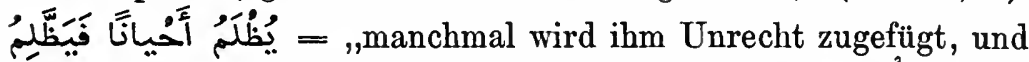

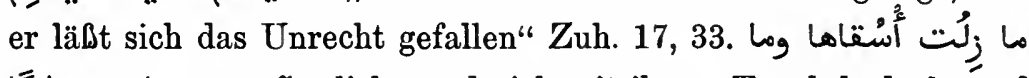
(unaufhörlich wurde ich mit ihrem Trunk bedacht und trank ich" Farazdak 330, 3. der Mensch wird nur belehrt, damit er weiß" Mutalammis, 1, 8.

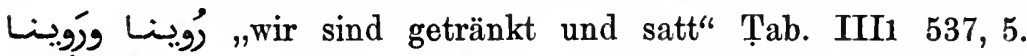
sie würden sich bereit erklären, ihr Leben für mich hinzugeben ${ }^{1}$, wenn sie ihr Leben hingeben könnten" Ag. ${ }^{2}$ II 4, $14\left(={ }^{14}, 20\right)$. سَّ spitzen - hören“ Hud.. II S. 41,9. zu erkennen suchen - kennen". Sïb. I 27 ult.
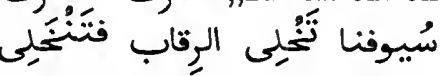
„unsere Schwerter hauen die Nacken durch, und sie sind durchhauen" 'Ant. 20, 16. ich treibe es fort, aber es läßt sich nicht forttreiben" Nöld. Poesie 78,4. عدلنا wir haben die Biegung von Bedr wieder gerade gèrichtet, so daß sie gerade ist" I. Hiš. 616,19. Vulg. SYr. jalli bithöbb issamra bhazz issamra ma tinh.öbb „Der du die Braune liebst — beim Glück der Braunen! sie wird nicht geliebt" Pal. Diw. 296, 4

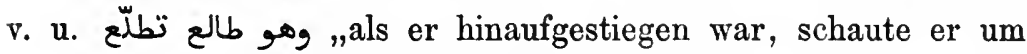
sich" Tales 90,1. MAR. ma 'allimtin̄ ma ntéallem „du hast mich nichts gelehrt, so lerne ich auch nichts" Mar. 160,10. Aeth. ith :

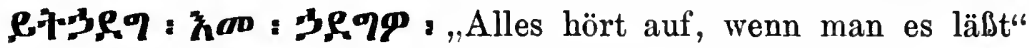

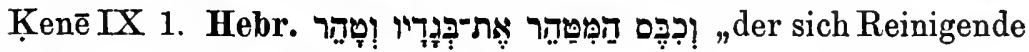
wasche seine Kleider, so ist er rein" Lev. 14, 8. Ez. 24, 13.

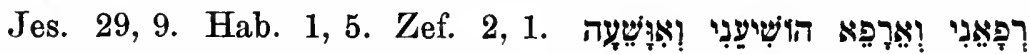
„heile mich, so werde ich geheilt; hilf mir, so wird mir geholfen"

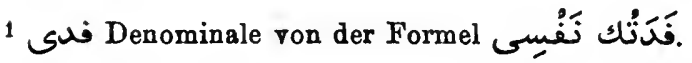


Jer. 17, 14. wir heilten Babel, aber es

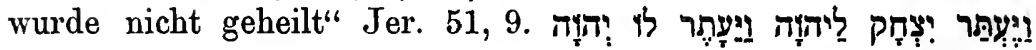
"Isak flehte $\mathrm{zu}$ Jahveh, und Jahreh ließ sich von ihm erflehen“" Gen. 25, 21. Jes. 66, 13. Jer. 31, 18. Gen. 27, 33 (vgl. Num. 22, 6. 24, 9). 1 Sam. 1, 28. Gen. 6, 12. Deut. 21, 8 usw. Syr. حإحب ا

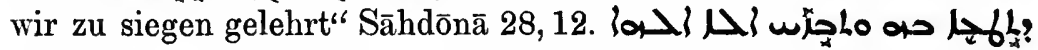

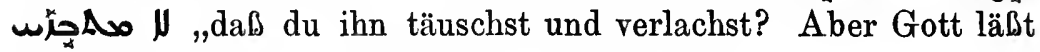
sich nicht täuschen" Sāhdōnā 435, 9. Spic. 2, 23.

Wie das Subjekt des Passivs mit dem des Aktivs öfters identisch ist (s. oben No. 2), so kann auch das Subjekt, das sich in einem gewissen Zustande befindet, mit dem Subjekt identisch sein, das den Zustand hervorruft. Ar. Lيَ

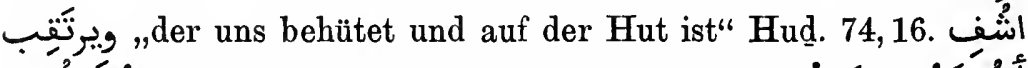

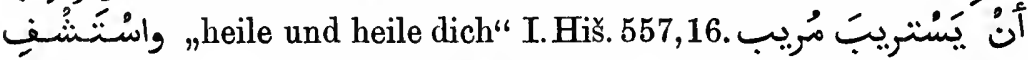
„daß einer, der Verdacht einflößt, Verdacht schöpft" Ag. ${ }^{2}$ I 181, 10. , hört von mir, was ich sage, und laßt mich hören, was ihr sagt" Buh. III 20, 16.

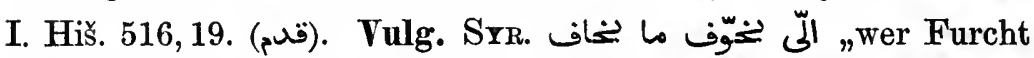
einflößt, fürchtet sich nicht" Lbd. v. Am. 34,2 v. u. Aeth. goqvC.

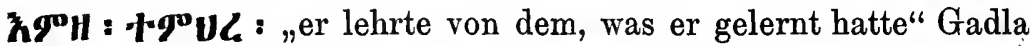

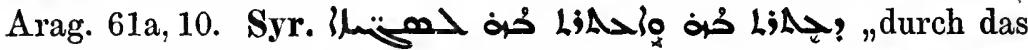
ich reich wurde und viele reich machte" Addai 46,22. كمب حتملح !), "لاج , wir wollen unsere Schlechtigkeiten zugrunde richten, da-

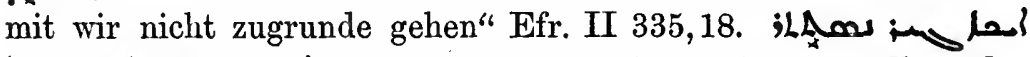

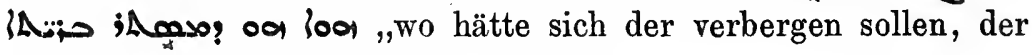
die Geschöpfe verbirgt" Efr. I 351, 12.

Andrerseits stehen sich gegenüber der Zustand und seine Entstehung (vgl. S. 70), z. B. Ar. الناعِ المتتِعِّم ,dem es gut geht, und der es sich wohl sein läßt" Múall. Zuh. 9. تَغََََّمى من (1u wirst verständig, nachdem du keinen

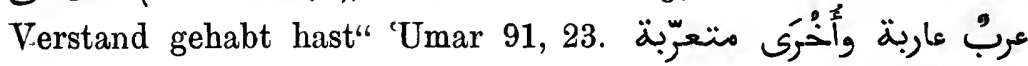
„echt arabische und andrerseits arabisierte Araber" Tab. I4 2041, 6. Vulg. MAR. mā jąlem mā jitsalem ,der kannte niemand 
und wollte auch niemand kennen lernen" Houw. 24, 9. Hebr. MIšNĀ. ילודים - נולדים, geborene - die erst noch geboren werden sollen" Ned. 3,9. Ferner Jeb. 4,10 (נשא , ארם (נשאה). Pārā 8,11, "sich verändert haben - von selbst anders sind"). Syr. oor ح oo9 dich, den Verehrungswürdigen verehrten die Starken, die verehrt wurden" Ephr. II

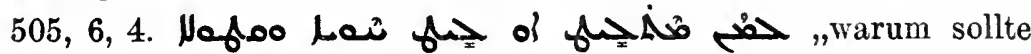
Schlange und Mörder verflucht werden oder verflucht sein" Carm.

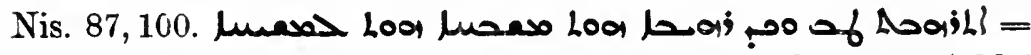
"sie erschrak sehr und in ihrem Schreck pries sie Christus" Addai 15,4. was geschrieben ist oder geschrieben werden soll" Phil. 24, 20. 122, 11. Afr. I

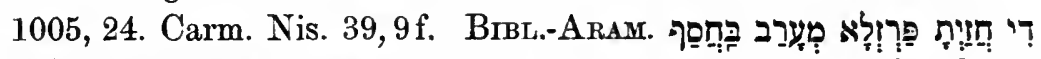

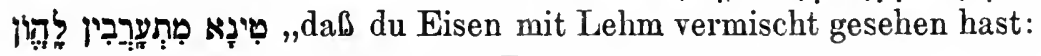
sie werden sie vermischen ..." Dan. 2, 43.

\$ 12. Wurzelverwandte synonyme Verbalformen. 1. Per-

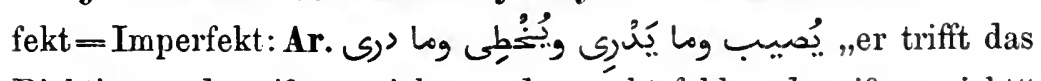
Richtige und weiß es nicht, und er geht fehl und weiß es nicht" Ag. ${ }^{2}$ 106, 12 (111, 3): Öfters in Vergleichungen: ,sie eilt, wie der Esel eilt" Huṭ. 10, 14. Ferner I. Hiš. 613,17 . Hud. 169, 4 usw.

| Perfekt = Apocopatus nach lā: اخخذ من الصدقة ما فيمكا sobald er die Armensteuer in natura und nicht ihren Geldeswert erhebt" Kāmil 222, 15. I. Hiš. 579, 9. 961, 18 usw.

Imperativ = Imperativus energicus: laß zu 'Āmir gelangen oder laß zu seinem Bruder gelangen" Ag. ${ }^{2}$ II 25,7 v. u. $\left(={ }^{1} 27,8\right)$.

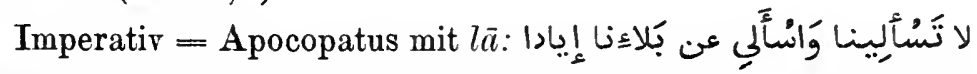
"Frage nicht uns, sondern frage nach unserer Bewährung Ijād" Labīd 40, 77.

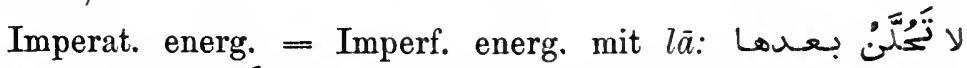
,wohne nachher ja nicht im Winkel, sondern in der dichten Menge" Hud. 210, 2.

2. Verschiedene Konjugationen eines Verbums können in 
ihrer Bedeutung völlig oder doch nahezu zusammenfallen. Gewiß bestehen aber vielfach noch feine Unterschiede, die uns entgehen oder doch in der deutschen Übersetzung nicht ausdrückbar sind. Aus grammatischen Gründen ist der Konjugationswechsel geboten z. B. in Ar. als mein Vermögen zurückkehrte, kehrten sie zu mir zurück" Nöld. Poesie 67 Vs. 4.

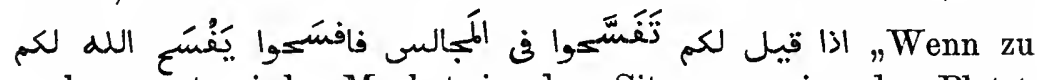
euch gesagt wird: ,Machet in den Sitzungen einander Platz', so machet Platz, dann wird Gott e uch Platz machen" Kur. 58, 12 (hier ist von der reziproken zur nichtreziproken Form übergegangen im Hinblick auf das folgende "wird euch Platz machen"). Reflexivkonjugationen werden, wo sie mit den zugehörigen Grundkonjugationen synonym zu sein scheinen, mehr auf den Effekt weisen, der dem Subjekt infolge seiner Tätigkeit zufällt. Ferner ist das Passiv einer Kausativkonjugation oft nur scheinbar bedeutungsgleich dem Aktiv einer intransitiven oder transitiven Konjugation desselben Stammes (vgl. S. 64.) und bezieht sich mehr auf die Entstehung der Handlung (vgl. S. 68.) Deutlich ist

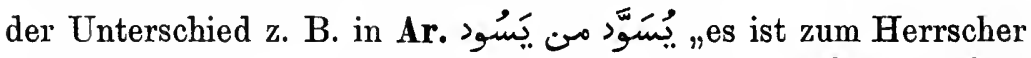

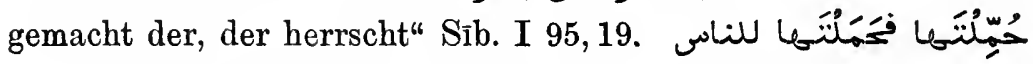
$=$,das dir übertragen worden ist, und das du für die Leute

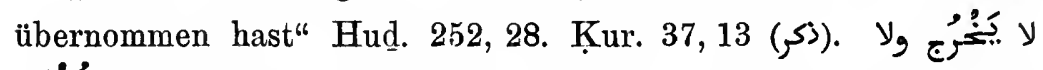
يُغْ = "er geht nicht hinaus und wird nicht hinausgejagt" Buh.

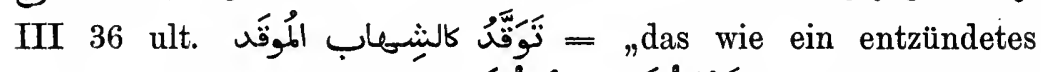

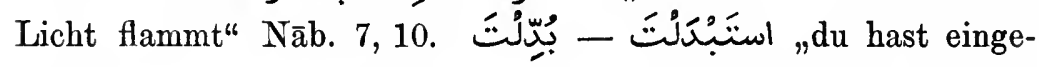
tauscht - es ist dir in Tausch gegeben worden" Ruk. 33, 6. - Synonyme ${ }^{1}$ oder nahezu synonyme Konjugationen ergeben koordiniert eine Verstärkung oder Verallgemeinerung des Sinns (vgl. § 35), z. B. Ar. erzähle mir nur ja genau die Geschichte“ Imr. 56,2. "wie kann ich

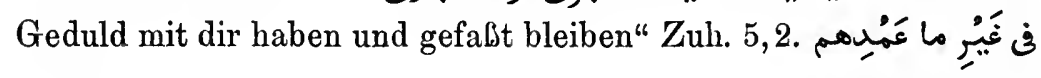

1 Eigentlich geht aber diese Ausdrucksweise von der Unterstellung aus, dab auch die synonymen in Wirklichkeit nicht synonym seien. 
ohne Absicht und ohne es zu wollen“ Hātim ^, 16. كرئم ohne daß ein Aufwiegler

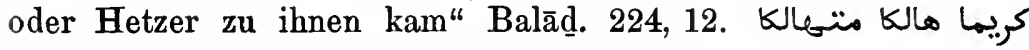
„einen zu Grunde gehenden, schon beinahe zu Grunde gegangenen Edeln" Ruk. 50, 12. Südar. Sox̣. tšemetolen wumetolen „schwatzet, schwatzt" Sok. II 172, 1.

Beispiele für Konjugationen, die sich synonym vertreten:

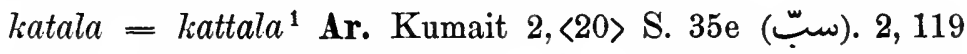
(亏)). Hud. 263, 11; Ag. ${ }^{1}$ II 27, $18={ }^{2} 26,4$ (رجا) Hātim S. 19, 1

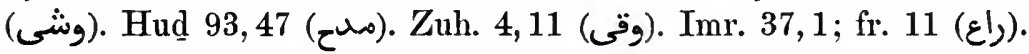
Nāb. 5, 35 (حسب) Vulg. 'IRĀK. Neuar. Gesch. 22,15 (rwḥ). Hebr. Ex. 6, 29 (דבר). ${ }^{2}$

katala = kātala. Ar. Huḍ. 17, 2 (سأل). Farazdaḳ 562, 3 (حف).

katala = (h,̌s,)'aktala. Ar. 'Ant. 17, 2; Labīd Chālidī S. 127 Vs. 3 (سقى). Hud. 254, 9; Kumait 6, 15 (b). Nāb. 5, 11 (س,ى). Ahțal 141, 9 (מג)). Hebr. Ez. 14,5; 18, 30 (שרב). Dan. 9,23 (בין). Ass. KB VI 216, 24 (pšk). Tell el am. No. 17, 65 (mrș).

katala = taktala. Ar. Ham. 14,6 (فلا). Imr. 33,1 (فخر). Imr. Mu'all. 51. Nāb. 10,4 (حمل)). Kur. 2, 286 (كسب) Farazdak 298,

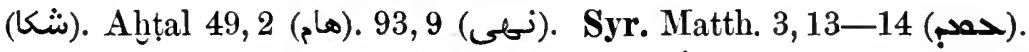
Ass. Sonneng. No. 72, 7 ('mr). ebenda ('šm'). Hamm. 10, 23-29 ('lk). Hamm. fr. Rs. 2a, 21. 29 ('b').

katala = takātala. Ag. ${ }^{2}$ XI 105 ult $\left({ }^{1} 110,21\right)$ (قعس).

katala = naktala. Hebr. Jes. 6, 11 (שאה). Mršñ̄ Jeb. 4, 10 (Nש) Passiv Kal).

katala = astaktala. Ar. I. Hiš. 615, 9 (ان).

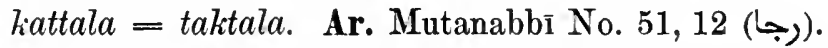

kattala = takattala. Ar. Ḥuṭ. 49, 1 (ولى). Ass. KB VI 147, 47 (ml'). H్Hamm. 17, 47-49 (hpd).

kattala = 'aktala. Kur. 3,2;16,46;47, 22 (نزل) 10,103; 26,

1 An manchen Stellen könnte kattala Intensivbedeutung haben, an andern ist das aber ausgeschlossen.

2 Num. 22, 6. 35, 33. Jer. 20, 14 enthalten nicht Passive zu kattala sondern die bekannten Passive des Kal. 


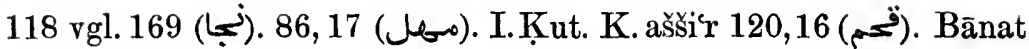
Su'ād S. vv (مسكك). Labīd fr. 40, 1-2; Hud. 110, 8 (بلغ). Múall. 'Amr. 9 (خبر). 'Ant. 20, 24 (ذّ) usw. Hebr. 1 Sam. 1, 6-7 (כעם). kātala = taktala. Ar. Ruk. 61, 14 (نظق) (ن)

$k$ ātala = takātala. Ar. Labīd 29, 2 (ف) (ف) (ف)

kātala = 'aktala. Ar. Ḥātim S. oo, 3 (ش) (ش). Kumait 1, 84 (s).

'aktala = taktala. Ar. Mutanabbí No. 56, 18 (تحصم). Syr. Op. sel. 180, 22 (Ma).)

$($ (s,)'aktala = astaktala. Ar. 'Umar 126, 13 (يقن). Ham. 371, 3 v. u. (جاب).

haktala = naktala. Hebr. Ez. 22, 22 (נת) Hofal).

naktala $=($ ha)takattala. Ar. Sīb. II 260, 16 (b) (b). Hebr. Lev. 18, 24 (טמה). 1 Sam. 7,6 (קבץ).

taktala = takattala. Ar. Kur. 2, 229 (عu). 'Ant. 20, 31 (ع)ى).

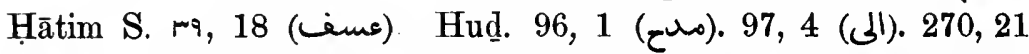
(وقى). Kuțāmī 13, 24 (تبع). Tar. frgm. 8, 2 (ولج). Mutanabbī 56, 18 (صبs).

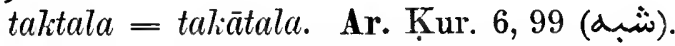

astaktala = takattala. Ar. Ruk. 15, 3 (بدل).

Das Transit. mit ذََّّْْى wechselt mit dem Reflexiv. Ar.

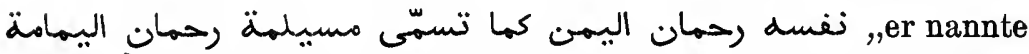
sich den Raḥmān Jemens wie sich Museilima den Raḥmān Jemāmas

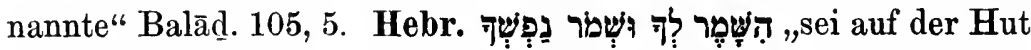
und hüte dich" Deut. 4, 9 (vgl. die Kombination in Vs. 15 und Josua 23, 11 ; vgl. auch 2 Chron. 2, 35f).

Die gleiche Handlung aktivisch und passivisch ausgedrückt: Syr. lall „bald wurden die Gerechten erhört, bald erhörte sie Gott nicht" Afr. II 1, 14. eure Ohren hörten etwas, was ihr noch nie gehört habt" Addai 29, 16. Weiteres hierzu s. oben S. 54 .

\section{Allgemeine Verba.}

§ 13. Für das Verbum gibt es kein Vertretungswort, dessen 
Natur der des Pro-nomens entspräche. Als Seitenstück zu den Darlegungen im Kap. III, das der Lehre von der Paronomasie des Nomens folgte, kommen hier, nach der Lehre von der Paronomasie des Verbums, höchstens allgemeine Verba wie היה ,كان ,עשה , فعل usw. in Betracht. Wie umfassend in der Tat die Vertretungsfähigkeit ron فعل "tun" ist, sieht man daran, daß es — um einen beim Pron. gebräuchlichen Ausdruck anzuwenden - bei "anaphorischem" Gebrauch ein den ganzen vorhergehenden Ge-

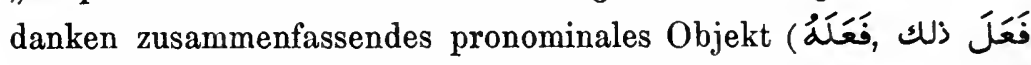
„er tat $e s^{6)}$ ) nicht nötig hat. Hierbei ist allerdings die Leichtigkeit $\mathrm{zu}$ berücksichtigen, mit der überhaupt im Semitischen anaphorische pronominale Objekte unterdrückt werden. ${ }^{1}$ Beispiele für

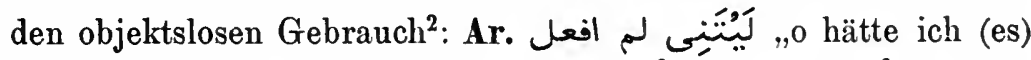

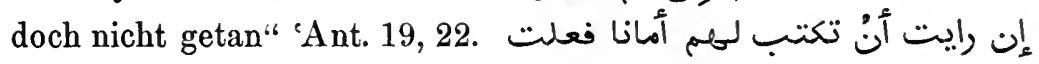
„wenn du geruhen willst, ihnen einen Geleitsbrief zu schreiben, so tue (es)" Tab. II1 316 ult. Tab. I5 2364, 5. Kur. 2, 279. 5, 71. I. Sa'd VIII 9, 17. Mu'all. 'Ant. 75. Zuh. 14, 39. 'Umar 90, 9. So im Dialog, z. B. ما منعك أن تنصر امير المؤمنيت قال فح فعلت „Er sagte: Was hat dich abgehalten, dem Beherrscher der Gläubigen zu helfen? Er erwiderte: Ich habe (es) getan" Tab. II2 855, 4. Sie sagte: ,Hast du Lust etwas zu trinken?" Ich erwiderte: ,Tue (es)"“ 1001 N. I 217, 2. Kāmil 506, 11 usw. Im Bericht über die Ausführung von Bitten und Befehlen, z. B. ارسل المى عاتكة رِّبى المال

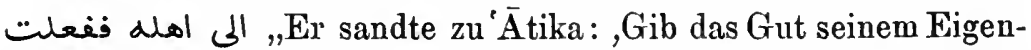
tümer zurück'. Da tat sie (es)" I. Sa'd VIII 194, 24. Kāmil 273,

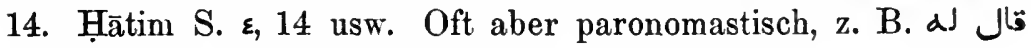
"Er sagte zu ihm: ,Geh geradewegs hinein‘

1 Natürlich kann man auch sagen فe ner tat das mit ihnen" I. Sa'd Gesandsch. 40,10 usw. Sonst vgl. noch zum Gebrauche von فعل mit Objekt Nāb. 8, 3 ( „ảß das Schicksal ihre Absicht ausführe"). Hud. 163, 4 ("einem etwas antun"). "Was macht er" $=$ "wie befindet er sich": I. Hiš. 583, 16. Ag. ${ }^{2}$ III 18,9 v. u. $(118,14$.

2 In einem Satze wie فعل ${ }_{n}$ er handelte wie ich" I. Hanbal I 159, 8 liegt für beide Verba eine nähere Bestimmung in So. 


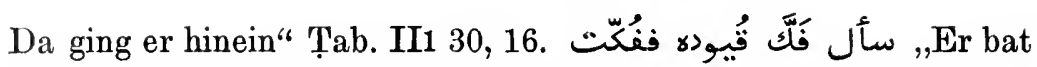
um die Lösung seiner Fesseln; da wurden sie gelöst" Kāmil 767, 19 usw. Weit seltener als فنع ist ond und schließt wohl meist eine geregelte Art der Handlung ein ${ }^{1}$, wie er ging so hinaus, wie er zu verfahren pflegte, wenn er heiraten

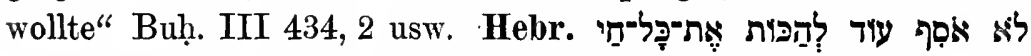
,ich will nicht noch einmal alles Lebendige umbringen, wie ich getan habe" Gen. 8, 21. Zur Objektslosigkeit vgl. z. B. ich will (es) nicht tun" Gen. 18, 29. 30.

\section{Nominalformen und Verbalformen.}

$\S$ 14. 1. Wenn sich Nomen und Verbum desselben Stammes gegenüberstehen ${ }^{2}$, so ist das zugrunde liegende Verhältnis meist das der Handlung zu einem zeitlichen Rückblick auf sie oder aber zu ihrer Ausführung, ihrem Erzeugnis, ihrer Nachwirkung, ihrem Ziel, ihrem berufsmäßigen Vollzieher u. A. Im ersten Falle kommt meist znerst das Verbum, im letzten zuerst das Nomen. Im allgemeinen steht häufiger das Verbum zuerst.

2. Bei dem Wechsel von Verbum finitum und Partizip (Verbaladjektiv) lassen sich Einblicke in das Wesen des Partizips tun; (s. Nöldekefestschrift 255 ff.). Vgl. Fälle wie Ar. أنّى ثائل فيك

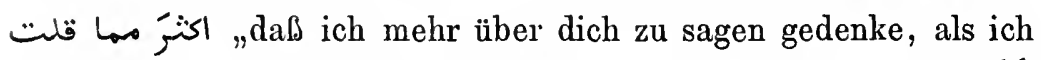

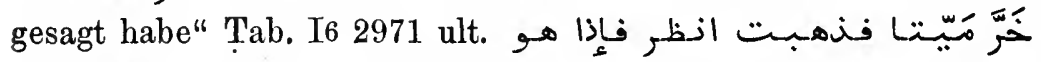
مات sehen, da war er wirklich gestorben" Tab. II2 971, 15. Vulg. Srr. er flog mit ihm immer weiter" Tales 90, 12. Tunis. skit sākit $b \bar{a} l i \bar{\imath}$ „er schwieg und beharrte im Schweigen"

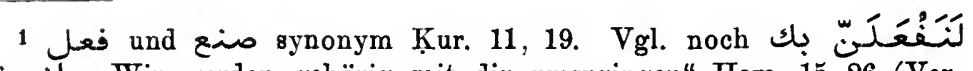
"Wir werden gehörig mit dir umspringen" Ham. 15, 26 (Verstärkung durch Synonyme, vgl. S. 3).

2 Nomen und denominiertes Verbum تَّ تََّّ

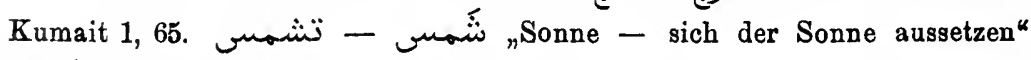
Farazdak 404, 14. دون - Tab. I5 2749, 14.

3 Häufige Konstruktion, z. B. Tales 88 ult. 94, 1. 172, 3. 181, 14 usw. Statt des Part. kann aber auch das Imperf. stehen $(205,6$. 219, 5). 


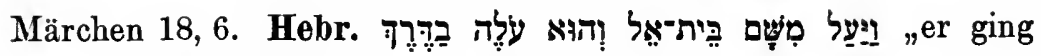
von dort nach Bethel hinauf, und während er unterwegs war ..." 2 Kön. 2, 23. Gen. 25, 28. Mišs̄ā המפריש חטאת ואבדה והפריש wer ein Sündopfer aussondert, und es geht verloren, und er sondert dafür ein anderes aus" Méilā 1, 2. Syr. Vgl.

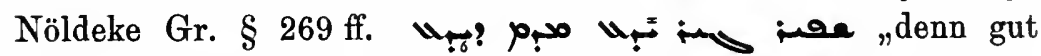
hat er erkannt, was er kennt" Op. sel. 31, 6. Jak. Ser. Hom. 149, 7. Spic. 6, 4. Sāhdōnā 435, 17. Efr. I 227 ult. - 228. Carm. Nis. 87, 120. 113, 23 usw. إلجي "die, die geglaubt haben und glauben werden" Addai 32, 10. Efr. II 477, 11, 10. Carm. Nis. 67, 118. Sāhdōnā 216 paenult. usw. S N loo "es faulte nicht das, was der Fäulnis unterworfen war" Carm.

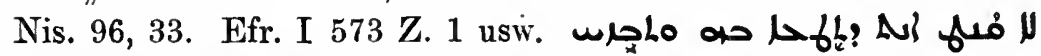
, scheust du dich nicht ihn zu täuschen und zu verlachen? Aber Gott läßt sich nicht verlachen" Sāhdōnā 435, 8. Op. sel. 163, 8. Phil. 24, 20. 56, 18-19. Efr. I 351, 12-13 usw. BiBL.-ARAMr. das Werk des Gotteshauses wurde verhindert und blieb verhindert" Ezra 4, 24.

Verbum finitum parallel einem Verbalnomen, wenn es negiert werden muß: Hebr. beim Aufsteigen der Wolke - und wenn die Wolke nicht aufsteigt" Ex. 40, 36. 2דוsischen dem eßbaren Tier und dem Tier, das nicht gegessen werden darf" Lev. 11, 47.

Aber auch ohne jeden inneren Anlaß wechseln Verbalnomina mit finiten Verben z. B. aus metrischen Gründen. Ar. "ein Wachender, der nicht schlief und Schlafende"

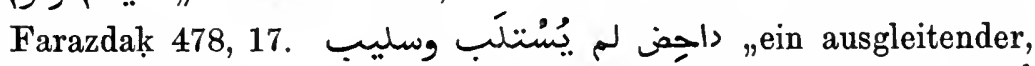
der nicht beraubt wurde, und ein Beraubter" 'Alk. 2, 33. أَّا

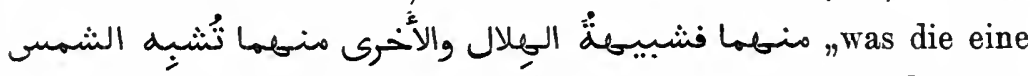
von ihnen anlangt, so ist.sie dem Mond ähnlich, und die andere von ihnen ähnelt der Sonne" Ruk. 11, 3. Kụr. 6, 95 (vgl. 30, 18).

$$
1 \text { غَبْرُ نائم }
$$


109, 2-3. Ham. 586 Vs. 3. Farazdak I S. १, 2. S. r., 2 v. u. Kumait 3, 116.

3. Unter den mannigfachen Bedeutungsverhältnissen, die mit dem Wechsel von Nominalform und Verbalform verbunden sind (vgl. No. 1), sei bloß eines genauer besprochen, nämlich

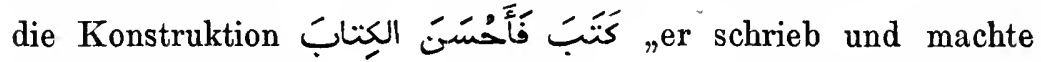
$a$ schön das Schreiben" = ,er schrieb, und zwar schön". Z. B. du wandest dich ab, und zwar lange" 'Umar 430. wir bewirteten euch, und zwar schleunig" 'Amr Mu'all. 33. Ferner 'Umar 18, 11. Ag. ${ }^{1}$ VIII 81, $b 16\left({ }^{2} 78,15\right)$. Buh. I 192, 17. Tab. II2 900, 4. Ist hier das Verbum fin. eine abgeleitete Konjugation, so kann der Inf. in der Grundkonjugation stehen, vorausgesetzt, daß die Sachbedeutung die

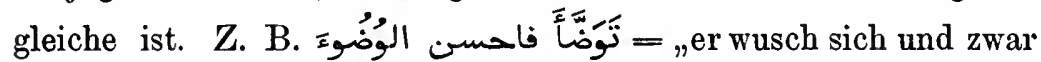

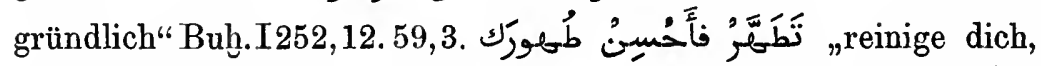

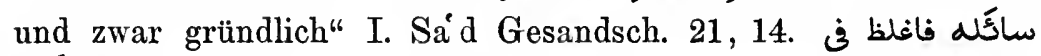
"er fragte ihn, und zwar in grobem Tone“ I. Sacd Ge$c$ sandsch. 34, 15. Inf. in der gleichen Konjug. wie das Verbum fin.: er bildete sie aus, und zwar gut" Buh. I 37,3. sie zogen uns auf, und zwar gut"

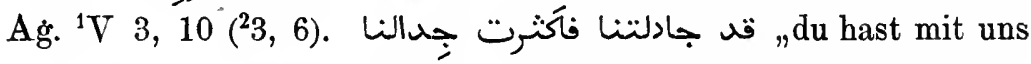
$d$ gestritten, und zwar viel" Kur. 11, 34. Das Nomen ein Konkretum: er gab ihnen Wegzehrungen, und zwar

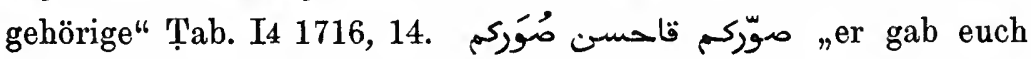
Gestalten, und zwar schöne" Kur. 64,3. Das Nomen hat also entweder den bestimmten Artikel oder ist mittels eines Genitivsuffixes auf das Subjekt des paronomasierten Verbum fin. oder auf ein anderes dazu gehöriges Wort bezogen. Das paronoma$e$ sierende Nomen kann auch zum inneren Objekt gemacht (s. Genaueres § 23) und durch ein Genitivsuffix wiederaufgenommen Bedeutung.

1 L أَ 
werden, z. B. er schwieg, und zwar lange“ $f$ Tab. II1 457, 7. Schließlich kann sowohl Nomen als Suffix fehlen, wie sie unterhielten sich, und machten lange“ = „und zwar lange" Tab. II1 313, 18. Zتكلّم زيد فاحسن "Zaid redete, und

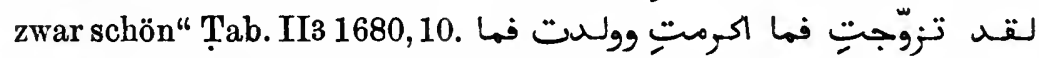
أنجبت du hast geheiratet, aber nicht vornehm; Kinder bekommen, aber keine edeln" Tab II1 185, 12. Ferner Tab. I4 1926, 5. II1 476, 12. Buh. III 433, 9. Mas. I 281, 6. Ag. ${ }^{1} \mathrm{~V} \mathrm{19,} 10\left({ }^{2} 18,9\right)$. $g$ 'Urwa 32, 1. - Eine andere Wendung ist die, dab das Nomen Subjekt ist, z. B. Sağạ̣i wurde اللّ فابهل . ,sie ist liebenswürdig, und zwar ist ihre Liebenswürdigkeit entzückend" Abul'atāh. 309 Vs. 1. I. Hiš. 945, 14.

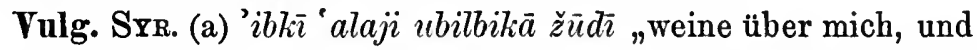
zwar reichlich" Neuar. Volksp. S. 28, 6. 9. 'azamna wačattar fī 'azimitn $\bar{a}$ "er hat uns eingeladen, und zwar viel" Neuar. Volksp. 41,74. (d) ehlub laha zìd elhalīb "melke sie und zwar reichlich" Pal. Diw. 39, 2.

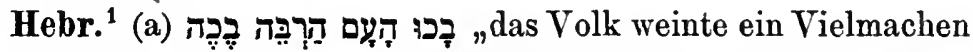

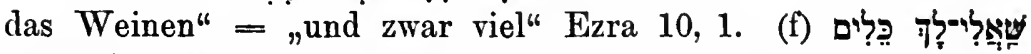
"bitte dir Gefäße aus .... und zwar nicht wenig" 2 Kön. 4, 3.

\section{Die Paronomasie der Syntagmen.}

\section{Nominalsatz.}

\$ 15. Die paronomastischen Bestandteile. Es sind auch die Fälle zu berücksichtigen, in denen abhängige Glieder des Subjekts oder Prädikats paronomastisch sind, die Paronomasie also nur

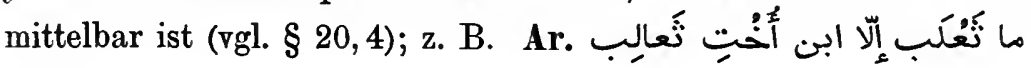

1 Die gleiche Bedeutung hat die Konstruktion אציז „sie aßen Jakob, und zwar vollständig“ Jer. 10, 25. 
„ein Fuchs ist immer ein Schwestersohn von Füchsen" Hud. 98, 5. "rom 'Iḍabaum kommen die 'Iḍabäume" Hudِ. 74, 24. Ferner 98, 3. 247, 5. Ham. 10, 27-28. Labīd 1, 15. Buh.

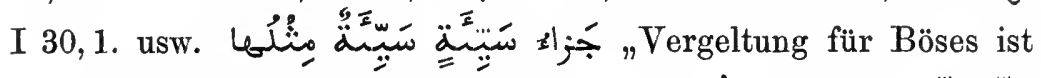
ein ähnliches Böses" Kour. 42, 38.

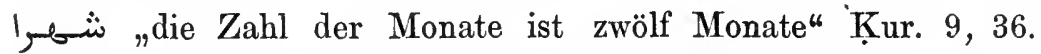
Ferner 24,6. 69,32. Vulg. Srr. al'ejün essüd süd „die schwarzen Augen waren (wirklich) schwarz" Pal. Diw. 139 No. 3 Vs. 3. ilkohl filmiikohle "die Schminke bleibt im Schminkfläschchen" 213

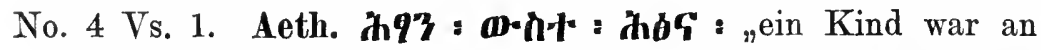

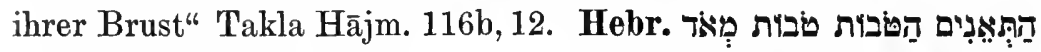

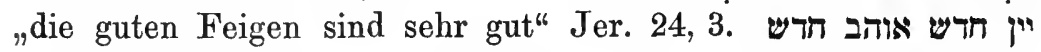

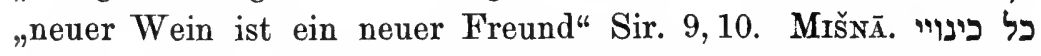
,jede Umschreibung des Enthaltsamkeitsgelübdes ist wie das E." Nāzīr 1, 1. Ned. 1, 1. Šeb. 7, 1. Midd. 2, 2. Ter. 9,4. was zum Passaopfer geeignet ist, wird Passaopfer" Škek. 7,4.

§ 16. Bedentung der Paronomasie. 1. Die Sätze, deren Subjekt und Prädikat identische Substantive sind, scheinen einer Grundforderung, die wir an jeden vernünftigen Satz stellen, zu widersprechen, daß nämlich sein Subjekt und sein Prädikat etwas irgendwie von einander Verschiedenes bedeuten. Genau besehen gehen jedoch solche paronomastischen Nominalsätze davon aus, daß die Unterstellung gemacht werde, ein Wort könne auch einmal etwas anderes bedeuten als es selbst, und wollen einer Misdeutung entgegentreten; denn tatsächlich wird eine Bezeichnung einem Dinge bisweilen per nefas beigelegt. Jene paronomastischen Nominalsätze betonen also, daß das Subjektswort dem damit gemeinten Ding wirklich entspreche. Es wird z. B. die bloß metaphorische Verwendung des Subjektsworts zurückgewiesen. Über das Prädikatswort besteht vorweg Übereinstimmung beim Redenden und Hörenden; über das Subjektswort könnten Meinungsverschiedenheiten bestehen. Die Idendifizierung des Subjektsworts und̆ des Prädikatsworts ist also nicht ein Zeichen für besonders glatten. Verlauf der Prädizierung, sondern dafür, daß sie durch 
eine größere geistige Arbeit erfolgt, durch eine genauere Prüfung des Subjektsworts im Hinblick darauf, ob es den landläufigen Vorstellungen, die man damit verbindet, entspricht; und die Wirkung ist, daß das Prädikat eine größere Gewähr seiner Richtigkeit bietet. Und so bringt denn wirklich das Prädikatswort etwas Neues, nämlich diejenigen zwar nicht ausgesprochenen aber mitgedachten charakteristischen Merkmale, die beim Aussprechen des Subjektsworts etwa noch rermißt werden konnten.

Beispiele: Ar. هُنَى اللهِ هو الهرى „die Leitung Allahs (ist)

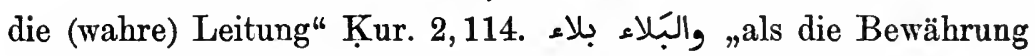
eine (wirkliche) Bewährung (war)" Múall. Ḥār. 82. غزيرما غزير "deren Gabenfülle eine (wirkliche) Gabenfülle ist" Farazdak I S. I v, 6 v. u. Ferner Umar 111, 20. Ahțal 108, 12. Charakteristisch sind auch negierte Sätze, weil sie, wenn man sie logisch und nicht genetisch betrachtet, einen Widersinn ergeben z. B. ما الناس بناسِ "die Menschen (sind) nicht (wirklich) Menschen" Mutanabbī 191, 37.

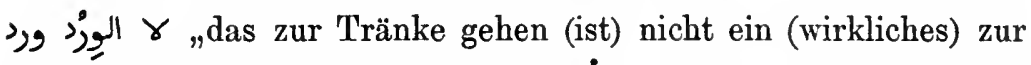

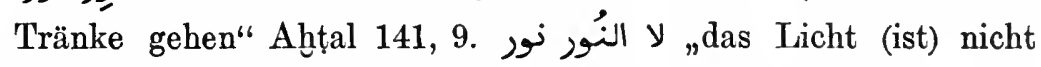

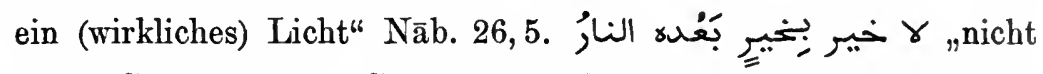
(liegt) Gutes in etwas Gutem, worauf das Höllenfeuer folgt" Tab. I4 1847, 18. . لا كََّّ (möge) deine Belohnung nicht (wirkliche) Belohnung (sein)" $=$,möge dich die Strafe treffen" (Labīd 28, 1. Hud. 232, 2. Ruk. 17, 3. Sīb. I 223, 5 usw.). Hebr. Mršñ. "sein Zeugnis (ist) nicht ein (giltiges) Zeugnis" Jeb. 16,5. Ned. 2, 2. Kid. 4, 9. Ter. 1, 1. 'Erubin 3, 3. Syr. $: \mathrm{loo}_{3}$ ○o $\log _{3}$ ه "ein Fasten (ist) nicht Fasten, wenn ..." Phil. 49, 20. 428, 3. Vgl. andrerseits -a lleseine Nichtweisheit (ist) Weisheit" Op. sel. 31,2. 4.

Prägnanter noch sind Sätze, in denen das Verbältnis in dem Sinne gesteigert ist, daß das Subjekt durch das Prädikat als das im vorliegenden Falle einzig in Betracht kommende bezeichnet

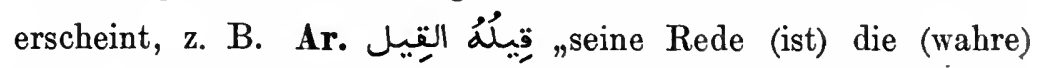
Rede" Bānat Sūād S. INv. يَتُنك البيت لdein Haus (ist) das 


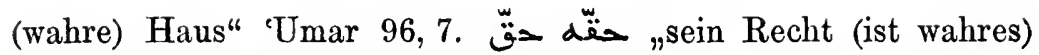
Recht" I. Sa'd Gesandsch. 12, 14.

In andern Fällen wird dadurch das Unabänderliche bezeichnet, wie eure Vereinigung (ist) eure Vereinigung (geblieben)" Tab. I6 3307, 1. الذليل خليل "der Niedrige (ist und

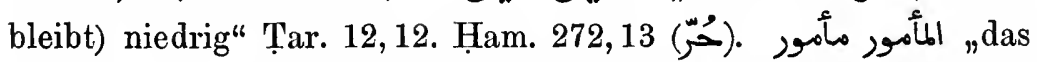
Befohlene (ist) befohlen" Nāb. 14,2. الحروب حروب ,die Kriege (sind nun einmal) Kriege" Ruk. 30,2. da ja die Leute Leute und die Länder Länder (sind)" Jāḳ̄ut I 131, 21. عَ عَهَ "Blindheit (ist eben) Blindheit" 1001 N. II 89, 5. Vulg. MaLT. maut ebmaut "Tod bleibt Tod" Malt. Stud. 54, 21. Hebr. Mišnā. ihr Kauf (ist ein giltiger) Kauf, und ihr Verkauf Verkauf" Giț. 5,7.

2. Oder Subjekt und Prädikat bezeichnen zwei zunächst als verschieden gegebene, mittels des Satzes aber vereinerleite Dinge, z: B.

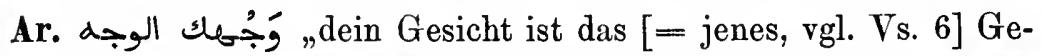

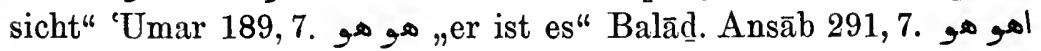

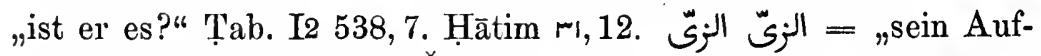
zug ist derselbe" Sūl und Šumūl 37,11. Hebr. Mršnā. שפה שאטר der Mund, der verboten hat, ist der Mund der erlaubt hat" Ket. 2,2. Oder es sind zwei wirklich verschiedene Dinge von gleicher Benennung, wie كَدَّى في أمثالها أمثالها "mir (steht) in ähnlichen (Lagen) ähnliches (Verhalten) (zu Gebote)" Ham. 194 Vs. 1.

3. Das paronomastische Prädikat kann in aktiver oder passiver Gestalt eine Entfaltung der natürlichen Eigenschaften des Sub-

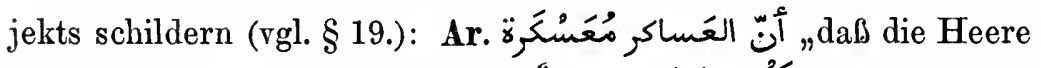

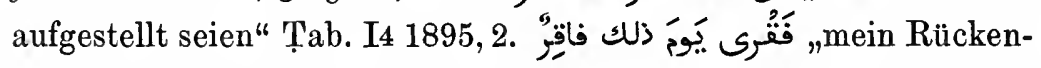

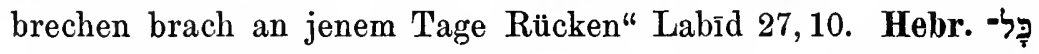

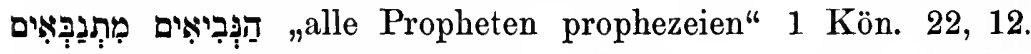

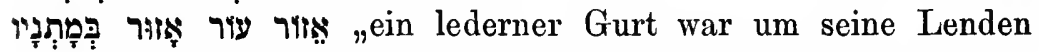

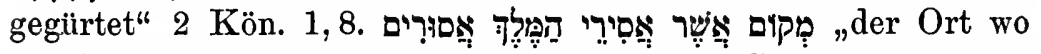

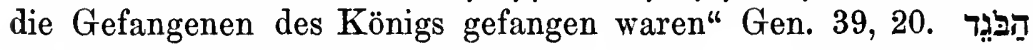
= "der Treulose übt Treulosigkeit" Jes. 21,2. Haggai 1,6. 


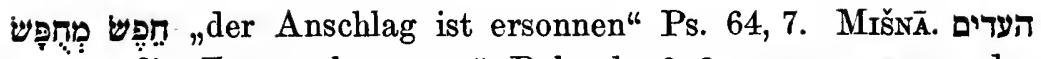

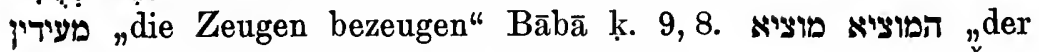
Hinausführende führt bloß hinaus" Bābā m. 10,5. Ferner Šeb.

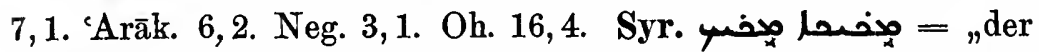
Demütige erweist sich demütig" Afr. I 412,1. تُنْبر "der Barmherzige [Nomen ag.] ist barmherzig [Partiz.]" Efr. I

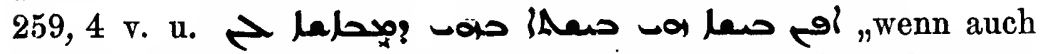
das Böse darin, daß es uns Böses tut, böse ist" Op. sel. 52, 23. "was unser Wollen will" Op. sel. 53,18 usw. , daß der Heilige geheiligt ist" Is. Ant. I 106,518.

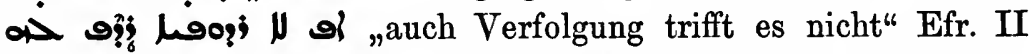

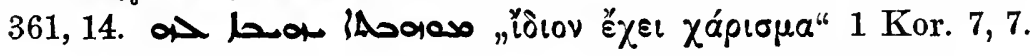

Das Prädikat macht auf eine neue Seite des Subjekts aufmerksam, z. B. Ar. der zu ihm rufende

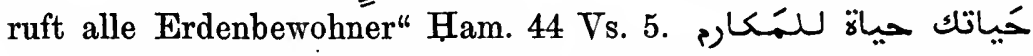
"dein Leben ist ein Leben für edle Eigenschaften" Kāmil 794, 5. "während die Nacht sehr tiefe Nacht war" Lāmijja 56. die Burg ist (nur) ein Bürgchen“ Tab. I4 1954,17. Vulg. Sxr. sabāb zalabījē sabāb $i b l \bar{a} d n \bar{a}$ „schöne Jünglinge sind die Jünglinge unseres Landes" Neuar. Volksp. S. 37,43. Hebr. der euch berührende berührt seinen Augapfel" Sach. 2, 12. MIšNā. מרבה בשר מרבה רמה "der Fleisch

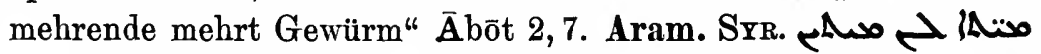

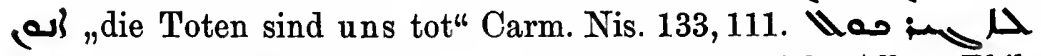
"die Lehre lehrt dich nicht Alles" Phil. 24, 18. denn seine Größe ist über alles Maaß groß" Efr. I 149,10. Ferner II 465,5,9. Spic.

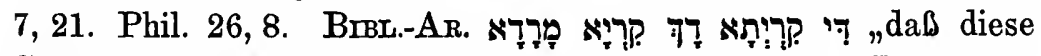
Stadt eine aufrührerische Stadt ist" Ezra 4,15. Ferner Dan. 2,47.

Das Subjekt wird im Prädikat zerlegt, z. B. Ar. الأَّمْنة ,der Jahreszeiten sind es vier“ I. Ḳut. Adab 87, 12.

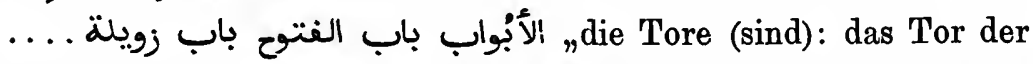
Eroberungen, das Zevilator usw." Makdd. (1. Aufl.) 226,7. مَابئن (waren) 
drei Städte“ Tab II2 1238,6. meine Seele (ist in)

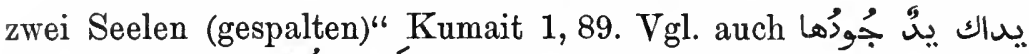

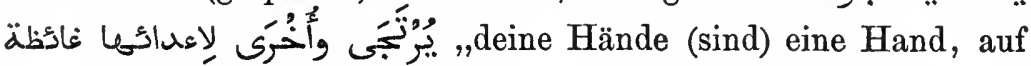
deren Freigebigkeit man hoftt, und eine andere, die ihre Feinde erzürnt" Hut.. 77 Schol. S. 169. Far. 391,66. Delectus 3, 13. Südar. Sok. ber 'alehen tiro 'alini „die Liebe (zerfällt in) zwei Arten von

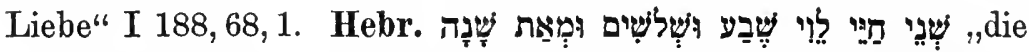
Jahre des Lebens Levis waren 137 Jahre" Ex. 6, 16 usw.

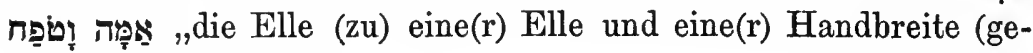
rechnet)" Ez. 43, 13.

4. Subjekt und Prädikat bezeichnen das gleiche Ding, das eine Mal tätig das andre Mal leidend: Vulg. Srr. ja lèt ḳattālu ḳatīl "O wäre doch sein Mörder ermordet" Pal. Diw. 327 pänult.

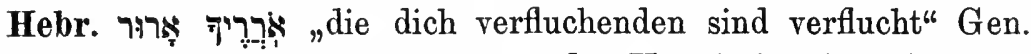

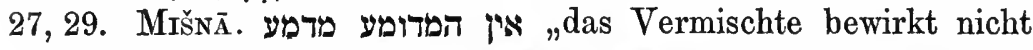

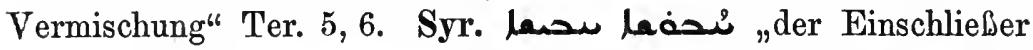
ist eingeschlossen" Carm. Nis. 129, 104. . "denn das Opfer opfert seinen Opferer nicht" Efr. I 259, 2.

§ 17. Zum Gebrauch der Paronomasie im Nominalsatz. 1. Das Subjekt muß oft im Prädikat als stat. cstr. wiederholt a werden. Vgl. Ar. ein Stamm ist ein Stamm der Eide" Ag. ${ }^{2}$ VIII 31, $10={ }^{1} 32,19$; Weiteres in $\S 10$. Mit Perb sonalpronomen (= Possessivum): , das Reich ist das eure" Tab. I4 1912,4. Buh. II 92,2 usw. Vulg. 'IRĀk. (a) țōthā $b t a \bar{l} l$ ed $\underline{d} e r \bar{a}^{e}$ „ihre Länge betrug einen Arm" Neuar. Gesch. 50,9. Sxr. (a) 'ilbēt bèt 'immī „das Haus ist das meiner Mutter" Neuar. Volksp. 30, 54. halāli ḥalāl ga gawärni „meine Herden sind gleich denen von Bewohnern des Gōr" Arabia petr. 182 Mitte. Pal. Diw. 100 No. 3 Vs. 5. 6. 133, 1. Neuar. Volksp. S. 21,64. (b) 'ilfarah farah̄i "die Freude ist die meinige" Neuar. Volksp. S. 38, 67. 18, 33. Lbd. v. Am. 18, 14. ÄG. 'l'awān di 'awān errumān ,ist diese Zeit die der Granatäpfel?"“ Spitta Contes 9, 6. (b) elfigle di figli "diese Rettiche sind die meinen" Lieder äg. Bau. 48, 3. 41, 1. TRIP. (a) wağha wağh brēs, ,sein Antlitz ist das 
eines jungen Falken" Lieder No. 81, 7, 2. Tuxis. (a) hăal ellkda hăl eșsabr ,der Zustand der Prüfung ist der der Geduld“ Märch. 10, 6. 74, 34. MAR. (a) السبت سبت اليهود ,der Sabbat ist der der Juden" Tlemçen 228, 1. Mar. 186, 7. Südar. Soḳ. (a) 'ümes kan kan di 'azeh ,und ihre Gestalt ist die einer Frau" II 64, 13.

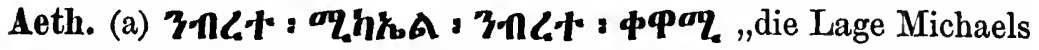

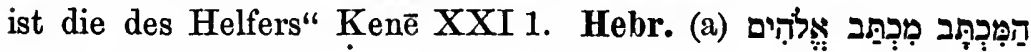

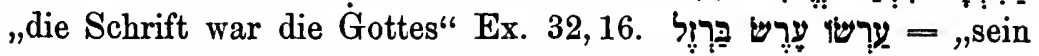
Bettgestell war aus Eisen" Deut. 3,11. 19, 18. 33,17. Num. 32, 1.

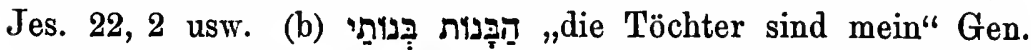

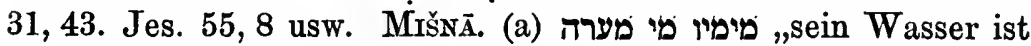
das einer Höhle" Bek. 4, 6. Ābōt 3, 16. Jeb. 8, 3. Ket. 1, 6. Nāzìr 7,1 usw.

2. Da sich die Substantivierung von Adjektiven im Semitischen nicht immer leicht vollzieht (sie ist z. B. selten, wenn es sich um ein indeterminiertes Subst. handelt), so wird dem Adj. in solchen Fällen ein Subst. als Träger gegeben, und das ist beim Prädikatsadj. oft das Subjektssubst. Z. B. Ar. euer Gott

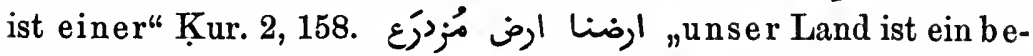

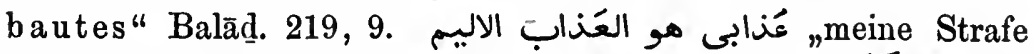

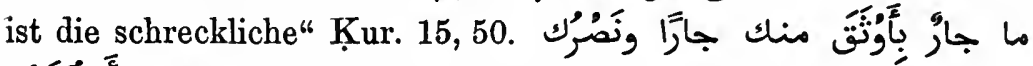
kein Schutzgenosse ist ein zuverlässigerer als du, und deine Hilfe ist dem Vereinzelten die stärkste" Imr. 24, 4. sein Bericht ist der sicherste" Kāmil 284, 1.

Vulg. Srr. elazrag azrag semāui "das Blau ist himmlisches Blau" Pal. Diw. 39 letzter Vs. menğali menğal h.suni „meine Sichel ist

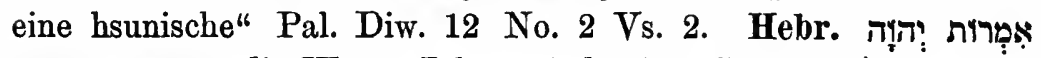
die Worte Jahves sind reine" Ps. 12, 7.1

\section{Verbalsatz.}

§ 18. Die paronomastischen Bestandteile. 1. Beispiele für ${ }_{a} b$ Paronomasie zwischen Verbum und Attribut oder Genitiv des

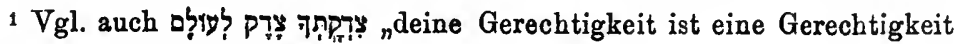
für die Ewigkeit" Ps. 119, 142. 
Subjekts: Ar. (a) eine von der Wahrheit ablenkende Seele lenkte ihn ab" Nāb. 15, 10. ولا عثرت und die (sonst) strauchelnden Glücksfälle straucheln bei uns nicht" Ham. 295 ult. Kur. 69, 12. Hebr. (a)

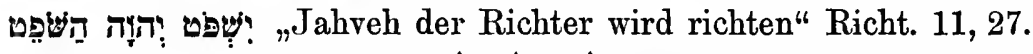

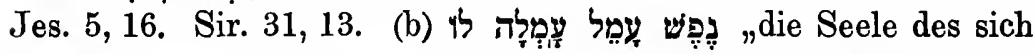
abmühenden müht sich für ihn ab" Prov. 16, 26. Micha 4, 14.

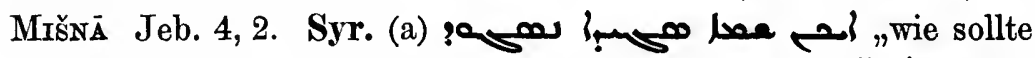
ein angebeteter Name anbeten?" Efr. II 667, 9, 6. N pa Is. Ant. I 26, 28. Efr. II 501, 13, 1. Op. sel. 10, 25. (b) Jes \&

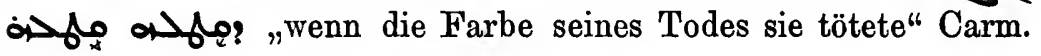
Nis. S. 74, 272. 67, 12. Efr. I 259, 1.

2. Paronomasie zwischen Imperativ und Vokativ. Hier liegt ein Folgeverhältnis vor: Der Angerufene soll das tun, wozu ihn seine Natur verpflichtet. Im streng grammatischen Sinne haben wir übrigens zwei getrennte Sätze; dem Sinne nach ist der Vok. خَنْبِفْ eile herbei, du Herbeieiler!" Ham. 194, 4. Vulg. 'IRẠK. ja șşäig $u$ șìg „o Goldschmied, schmiede...!" Arab. Volksl. S. 25 No. 11, 3. SxR. umm alḡêt $\dot{g} \bar{t} \underline{t} \bar{n} n a$ „Mutter des Regens, beregne uns!“ Pal. Diw. 58, 1. Ferner 74, 3. 141 No. 1, 7. 172, 1. 194, 5, 7. 271 No. 2, 1. 317 No. 3, 1. Neuar. Volksp. S. 14 Vs. 5; S. 17 Vs. 29. 30; S. 28 Vs. 22. Lbd. v. Am. 84, 11. Arabia petr. 221, 8 v. u. 299, 14. 439, 4 v. u. Centralan. 52, 33. ÄG. Spitta Gramm. (Texte) S. 453, 3 v. u. (O Peitsche, peitsche ihn). Lieder äg. Bau. 40, 1. ZDMG. 33, 611, 8. Tunss. äja fettāl elhbāl ftilli ḥbel „o Seildreher, drehe mir ein Seil" Märch. 8, 4.

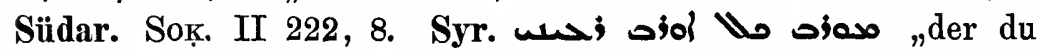
Alles gemehrt hast, mehre meinen Verstand" Efr. II 461, 1, 5. Is. Ant. II 50, 160-162. Afr. I 357, 1. Sāhdōnā 357, 3 v. u. ${ }^{1}$

§ 19. Bedeutung der Paronomasie im Verbalsatz. 1. Im paronomastischen Prädikat entfaltet sich die Natur des Subjekts

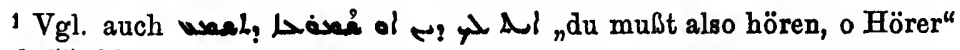
Op. sel. 55, 26. 
$a$ (vgl. $\$ 16,3$ ), z. B. wenn das Subj. eine Berufsbezeichnung u. dgl. ist. Ar. so haben die Genealogen seinen Stammbaum angegeben" Ag. ${ }^{2}$ VIII 101, 24. مكب خطيبهم ihr

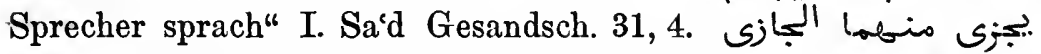
„der Vergelter wird ihnen vergelten" Ham. 191, 27. Ferner b Kur. 2, 282. 26, 197. Hud. 153, 12. Sonstige Konkreta: من لا wen setzt das Wunderbare nicht in Verwunderung?:“ Farazdak 430, 6. طار طأر طo lange ein Vogel fliegt" Ag. ${ }^{2} \mathrm{X}$

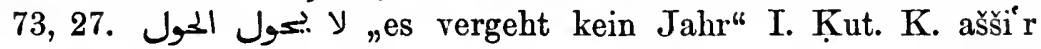
259,4. ein Traumbild besuchte uns" 'Umar 164, 1. eine Gūl hat den Mālik fortgerissen" Ahțal 41, 15. اجتمعت الجِماءة "der Heerbann sammelte sich“ Tab. II2 794, 12 . تبطّحت البطائح „,die Sümpfe versumpften [= entstanden]" Balād. «93, 9. Ferner Kur. 4, 160. 7, 203. 19,60. Labīd 35,5. 40,57. 46,17. fr. 13,6. 31, 6. Zuh. 4, 9. Hud. 8, 2. Ham. 168, 4. 235, 16. Kuț. 1, 1. Tab. I4 1822, 13. Hansā S. 45. ult. "a (a (a) "dein Tamburin klingt"

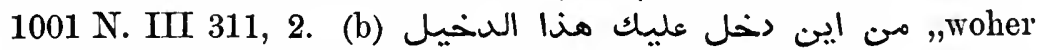
ist dieser Eindringling zu dir gedrungen?" III 207, 5. Vulg. IräḲ. (b) jewaččir elwāčir „der sich niederlassende Vogel läßt sich nieder" Neuar. Ged. I S. 126 No. 5. Sxr. (a) jesūmik assauucām ,der Abschätzer schätzt dich" Pal. Diw. 106 Z. 7 v. u. win kannak ja ḥākim tehkum ,wenn du, o Richter, richtest" Pal.Diw.68 Mitte. FernerLbd. v. Am. 46, 1. (b) ihnull ilhūl „das Jahr vergeht" Pal. Diw. S. 86 No. 14, 3. Ferner Lbd. v. Am. 100, 6 v. u. 108 ult. Hapr. (a) jinfoh 'alēh ennaffāh „der Bläser bläst hinein" 352 M. Ferner

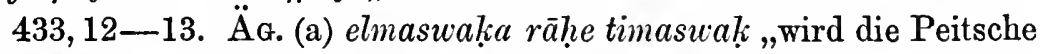
peitschen?" Spitta Gramm. (Texte) S. 453 paenult. ennatara natarat kibrīt „der Regen regnete Schwefel" ZDMG. 33, 612, 3 v. u. Tonss. (a) liașhum mḳas ,eine Nadel hat sie genäht" Märchen

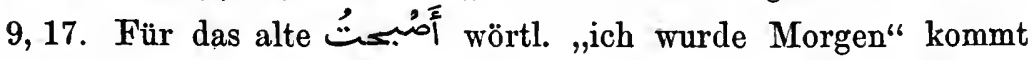
in der jüngeren Sprache auf der Morgen wurde

1 ist wie das gleichbedeutende مريجر konstruiert. 
Morgen" usw., so 1001N. I 358,3 v. u. u. oft. Lسكا liol „es wurde Abend" I 362, 5 usw. "Irāk Neuar. Gesch. 18, 18. Srr. Arabia petr. 113, 6 v. u. Centralar. S. 124, 4 v. u. ÄG. Spitta Contes 77, 6. Trip. Trip. Bedl. 223. Tunis. Märchen 61, 35. Mar. Mar. 162, 8. Südar. Sok. (a) al lehi jeheh inhi ,mein Blöker blökt nicht mehr" II 308, 14. (b) tesbah̆ deš sibeheh "die Schwimmerin

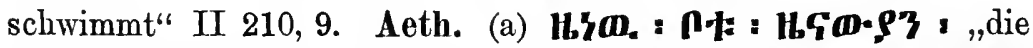
Geschichtschreiber berichten über ihn" Nik. 187, 20. P.: : 9中: : „ein Herold zog herum" 'Amda Ș. 314, 4 v. u. Chrest. 18, 14.

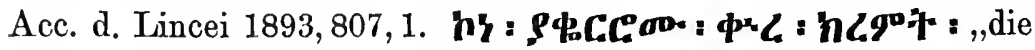
Kälte des Winters machte ihnen kalt" Chrest. 31, 15. @H39\% , HG9" : ,der Regen regnete" 'Amda Ș. 314, 13, 15. 3 Kön. 17, 7

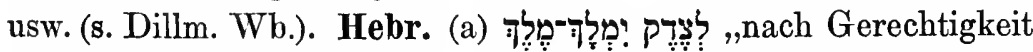

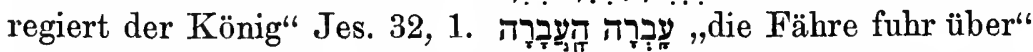
2 Sam. 19, 19. Ferner Num. 9, 14. Jer. 2, 8. Ez. 34, 2. Prov.

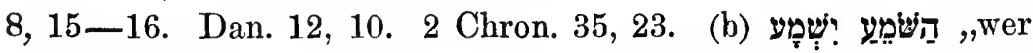

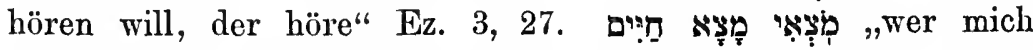
findet, findet Leben" Prov. 8, 35. Ferner Prov. 10, 9. Gen.

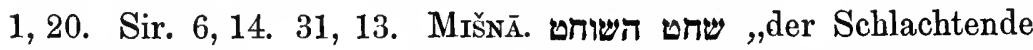
schlachtet" Tām. 4, 1. הובח נובח ,das Opfer wird geschlachtet"

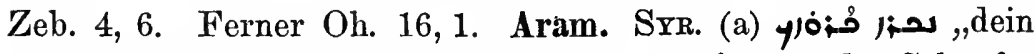
Verkündiger verkündet" Op. sel. 328,5. Dor Schöpfer schuf dich" Phil. 52, 14. Afr. I 709, 2. Matth. 5, 16. 13, 2. Efr. I 27, 1, 3 II 501, 13, 1. Carm. Nis. S. 4, 3-4. Efr. I $615,34,1.35,2.167,18$. BrbL.-Aram. (a) Esra 5, 1. Ass. (b) akti alittu uladuma "wenn die Gebärerin gebiert" KB VI 286, 18. ahizianum ihazama "(wenn) ein Freier heiratet" KB IV 16 No. 2, 5. ibrik birḳu „ein Blitz blitzte auf" KB VI 164, 17.

2. Das Subjekt ein Infinitiv oder ein anderes Nichtkonkretum: Ar. sein Kochen kocht" = "er kocht aus Leibeskräften" Hud. 92, 41. جخّ حخدهم ,es strebte ihr Streben" = ,sie

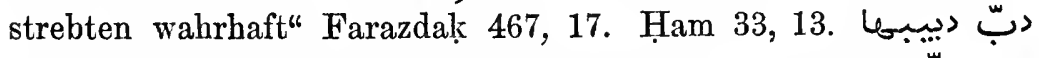

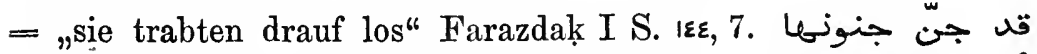

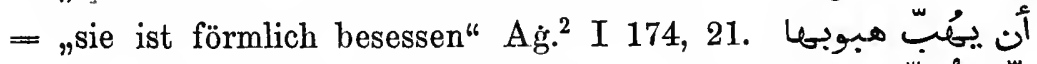

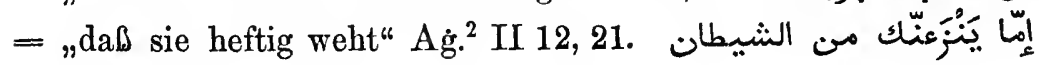




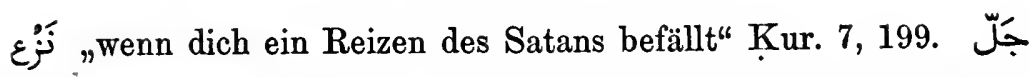
"seine Majestät ist majestätisch" = „ist groß" passim.

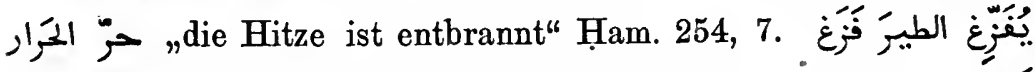
"den Vogel befällt ein Schreck" Abțal 40,3. مَن دارت عليه um den sich die Schicksalswendungen gedreht haben"

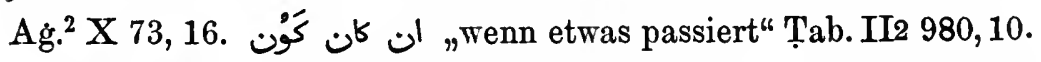
nachdem dies Ereignis eingetreten war" Tab. I4 1910 ult. Ferner Ağ. ${ }^{2}$ VI 99, 10. Nöldeke Beitr. z. Poesie d. Ar. 75 Vs. 4. 103 Vs. 49. Labid Múall. 51. Ham. 25, 6. Huḍ. I S. 94, 1 No. 259,16. Vulg. Syr. بقا يرجع مرجوعنا „es kehre zurück unser Zurückkehren" = „aber wir wollen zurückkehren" Tales 133, 14. العها يعميكى "möge dich die Blindheit blenden" Lbd. v. Am. 94, 8. ̈̈G. jirga margǘna = "wir kehren zurück" Spitta

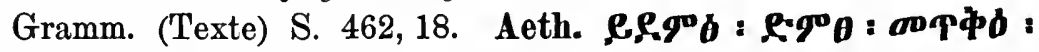

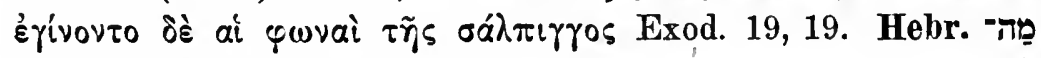
"was weist Zurechtweisen zurecht" Hiob 6, 25. ,ihr Zufall traf das Stück des Feldes" Rut. 2, 3. Koh. 2, 14. Aram. Srr. Awea bawe of ,unser

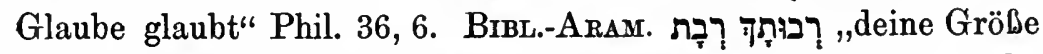
wurde groß" Dan. 4, 19. Ass. raggāt ameluti iraggigki „ist dir das Schlimme der Menschen schlimm?" KB VI 244, 219.

3. Ein selteneres Verhältnis ist, daß das Subjekt selbst in den $b$ Zustand gerät, den es hervorruft, oder daß es den Zustand hervor-

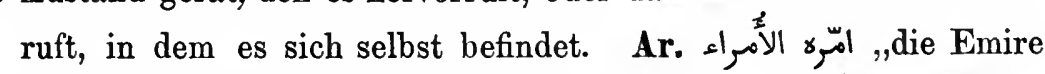
machten ihn zum Emir" Balād. 109, 7. Aeth. (b) how : K.P.' :

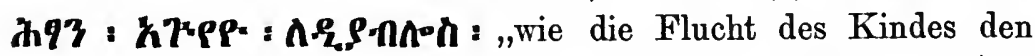

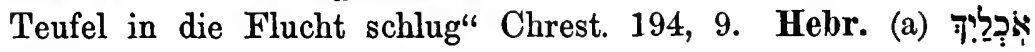

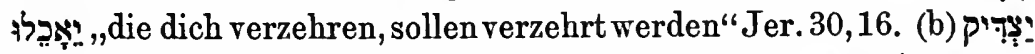

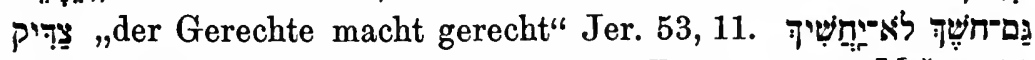
"auch Finsternis macht nicht finster" Ps. 139, 12. Mišrĩ̃. (a) deine Ertränker werden ertrinken" Ābōt 2, 6. Syr. (a) seine Darbringer werden dargebracht" Efr. I 259, 6. 569, 5, 1.

4. Das Subjekt ist das Ergebnis des Prädikats: أَََّّّ مريرها 
„deren Strick fest gedreht ist" Ahțal 34, 2. ein

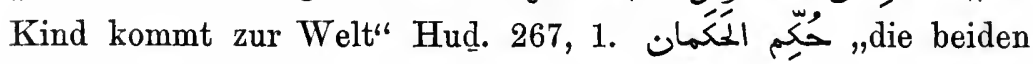
Schiedsrichter wurden eingesetzt" Tab. II1 8, 16. Ferner Kur. 35,

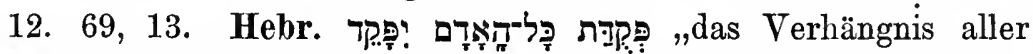

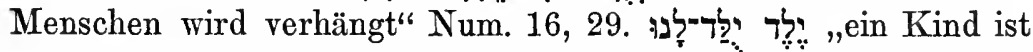
uns geboren" Jes. 9, 5. Ferner Jes. 26, 1. MišnĀ. נהרגו הרוגים ,Erschlagene wurden erschlagen“ Jeb. 16, 7. מפרצו פרצות ,Risse entstanden" Kil. 4, 4. נתרמה תרומה "Hebe wurde gegeben" Šek.

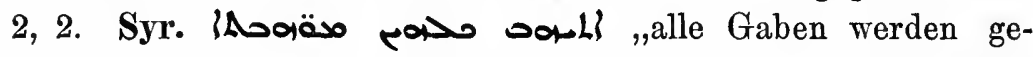
geben" Sāhdōnā 123, 9. Ferner Op. sel. 121, 16. Jak. Ser. Hom. 75, 4. Addai 15, 14. Ass. kunukku ul kanik, ,das Siegel ist nicht gesiegelt" BA II 120. Col. III 7. hubtum ihhabtu ,der Raub wurde begangen" Hamm. 9, 41. šimum išsamu ,der Kaufpreis wurde bezahlt" Hamm. 7, 31. Ferner KB I 52, 3.

5. Im allgemeinen kann die Gattung des Verbalsubjekts mehr oder weniger genau angegeben werden, nötigenfalls, wenn sie nicht eingehender bestimmbar oder gleichgültig ist, in $\mathrm{Ge}$ stalt einer sehr allgemeinen Gattung wie رجى Mann", رجل „Sache“ usw.; denn auch wenn das Subjekt nicht selbst wahrzunehmen ist, kann doch durch die Handlung meist darauf zurückgeschlossen werden. Der extremste Fall dieser Art ist es, wenn zum Aufbau des Subjekts ausschließlich der Wortstoff des Prädikats verwendet wird: قتاتِلَ es tötete ein Tötender“ = ,es tötete Einer", denn jedes Verbum trägt in sich den Hinweis auf ein Subjekt, das mindestens so geartet ist, daß es in der Lage ist, Träger jener Tätigkeit zu sein. (Das gilt auch für die „Impersonalien", denen solche Ausdrucksweisen schon recht nahe stehen; vgl. auch die subjektslosen Verbalformen in Fällen wie Hebr. עַל

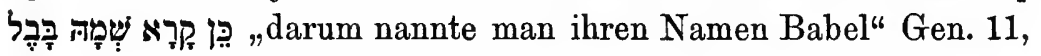
9 usw.) Während also sonst die Benennung des Subjekts ihre Gültigkeit unabhängig von der Benennung des Prädikats behält, ist hier das Subjekt nur im Hinblick auf die Gültigkeit des Prädikats richtig benannt, und das Selbständige an ihm sind nur die grammatischen Formbestandteile wie Femininum, Plural, Indetermination, Nominativ. Aber das Wichtigste - Genus und Numerus 
- könnte zumeist auch ohne selbständiges Subjekt durch das bloße Verbum finitum ausgedrückt werden. Die Determinationsverhältnisse allerdings nicht; ${ }^{1}$ aber sie sind in diesen Fällen belanglos.

Wie hier vom Subjekt nur der allgemeine Gegenstandsbegriff übrig bleibt, so verbleibt andrerseits, wenn man bei der ganzen Erscheinung vom Su bjekt ausgeht, dem Prädikat nur der allgemeine Tätigkeitsbegriff (,ein Tötender war am Werke“); und so wenig wie im ersteren Falle das Prädikat durch das Subjekt, wird im letzteren das Subjekt durch das Prädikat näher bestimmt.

Indeterminiertes Subjekt: Ar. „wenn Einer vergölte“ Ahțal 59,1. "أثنابك مُثنيب "möge dir einer vergelten"

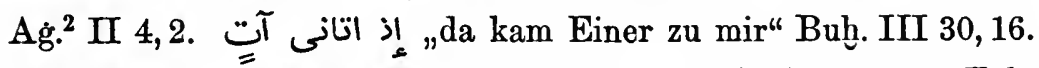
Einer sagt ... . ein Anderer sagt" Tab. I4 2016, 12. keiner wurde getötet" Hudِ. II S.

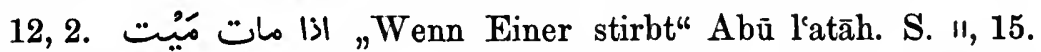

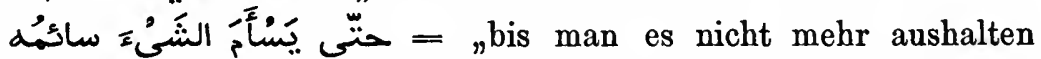
kann" Ahțal 104,5. "wenn dem Etwas

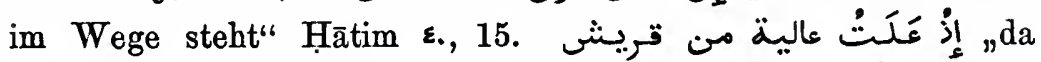

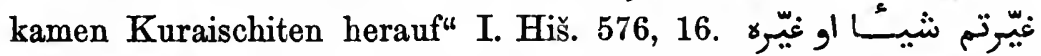
ihr oder irgend jemand von Euch hat etwas ge-

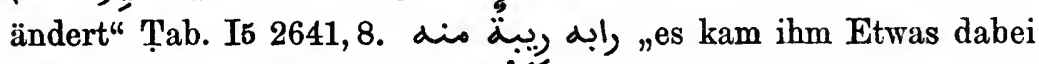

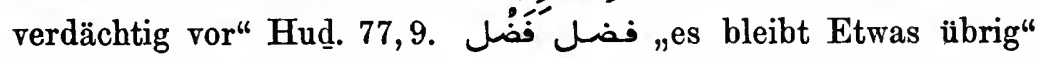
Tab. II1 392,12. wenn Leute unter uns auszögen" Tab. II1 517, 15. man hat nie eine gleich große gesehen" Tab. I4 2366, 9. Ferner Ḥam. 586 Vs. 1. Hud. 113, 7. 245 Einl. 4-5. 257, 12. 279, 5. II S. 6, 18. Kur. 12, 10. 26. Tab. I4 1840 ult. usw.

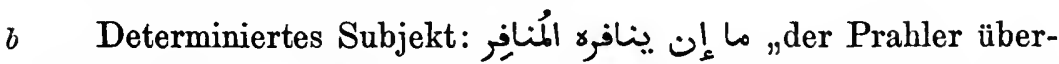

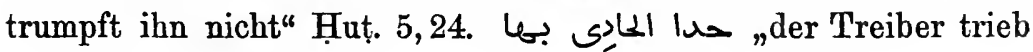

1 Die Verbalformen der 1. und 2. Person enthalten fast immer ein determiniertes Subjekt, die der 3. Person sind hinsichtlich der Determination indifferent. 


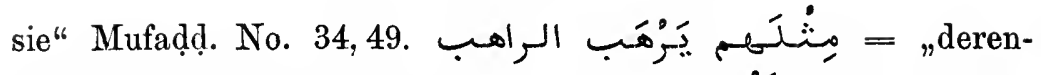
gleichen man scheut" Hud. 56,6. يَمَّرض الهمريض "es kann Einer

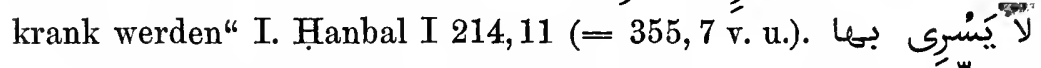

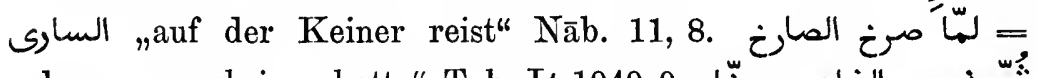
"مُّم ذهب الخاهب منّا . "darauf ging man unsrerseits nach Kubā" Buh. I 147, 16. Ferner Kur. 54,6. Bānat Suēàd S. I9v Vs. 2. Hud. 65, 1.

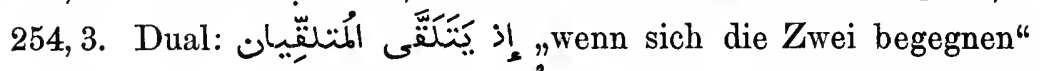

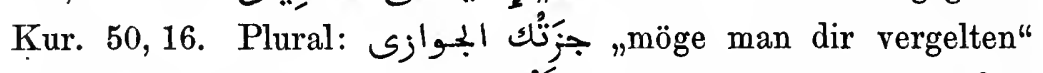
Ag. ${ }^{2}$ VIII 28,5 v. u. möge man weinen" Ag. ${ }^{2} \mathrm{X}$

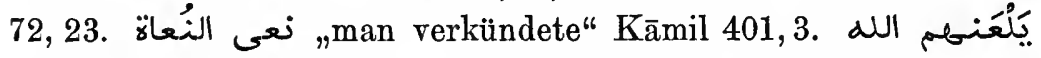
"Gott verflucht sie und man verflucht sie allge-

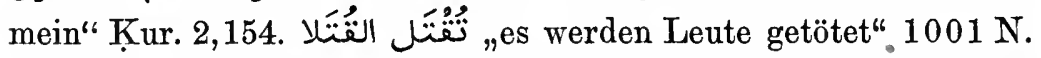
I 352, 10. Ferner Kur. 12,67. 37,59. 83,26. Ahțal 58,16. Ḥārit Mu'all. 44. 'Umar 197, 29. Ḥātim 19, 4. Bānat Su'ād S. 14.

Vulg. Srr. (a) mā wanneha kull wannān "Gar keiner seufzte so" Pal. Diw. S. 37 Mitte. MAR. (a) lōkān uḳa fik ši wāạic "wenn dir etwas zugestoßen wäre" Mar. 198, 13.

Südar. Sok. (a) 'a lahmodhin maḩmid „keiner möge uns tadeln" II 326, 8.9. (b) 'af linher di neher ,bis der Wanderer voriiberzieht" II 280,23. 310,3.

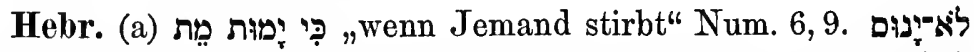

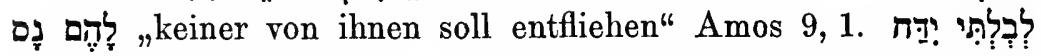
"damit keiner von ihm verstoßen werde" 2 Sam. 14, 14.

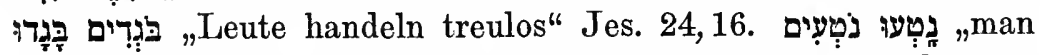

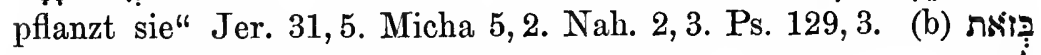

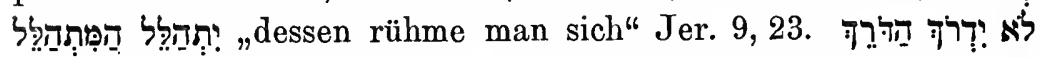
„Keiner keltert" Jes. 16, 10. לִ "es werde Jemand hingerichtet" Deut. 17,6. Ferner Num. 15, 4. Deut. 22,8. 2 Sam. 17,9. Jer. 51,3. Ez. 33, 4. ihre Leute entrinnen"

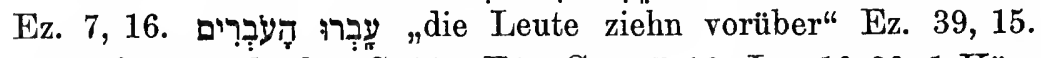
(darauf הูרָ, vgl. oben S. 88 g. E.). Gen. 7, 16. Jos. 10,20. 1 Kön. 8,46. MIšNĀ. (a) מת לו מת "es ist ihm Jemand gestorben" Sanh.

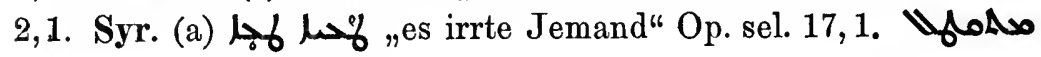




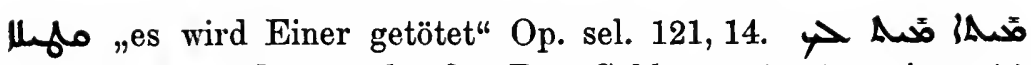
„ist dir Jemand gestorben?" Bar Șabbāēe 751, 12 . Ass. (a) nadinanummi idinam "Jemand hat es verkauft" Hamm. 7, 9. àmiru immar sēmu išimmē „Wird es Jemand sehen? Wird es Jemand hören?" Sonneng. No. 1,16.

\section{Attribut.}

§ 20. Die paronomastischen Bestandteile. 1. Das Attribut ein Adjektiv: Ar. flließende Quelle“ I. Hanbal I 360,10.

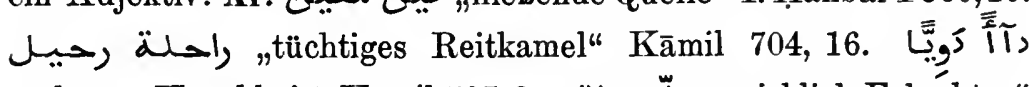

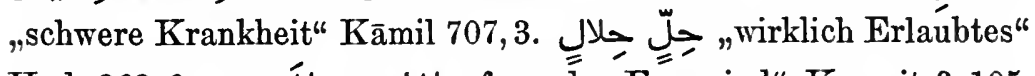
Hud. 262,6. الحاصِب الحَصِب "fegender Fegewind" Kumait 3, 105. الحَكم الحكيم .fürchterlicher Staub“ Kumait 3,106، التُرْب التَّرِب „der weise Richter“ Tab. II2 909,11. einen hören-

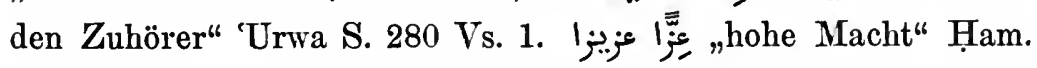

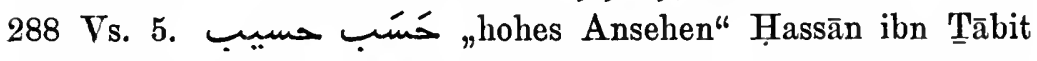

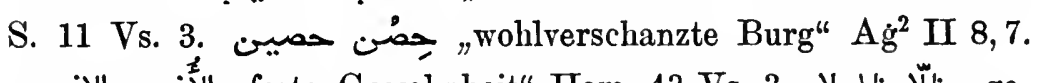
ge-

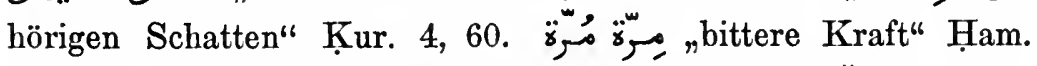

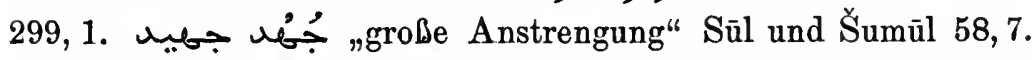
Zahlreiche weitere Beispiele aus Literatur und Grammatikern bei Grünert, Begriffsrerstärkung durch das Etymon im Altarabischen S. 8-36 (Sitzungsber. der Wiener Ak., Band 125).

Das Attribut ein Komparativ; s. Grünert, a. a. 0.17-23.

Vulg. Trip. țêr taijār "kräftigfliegender Vogel" Lieder No. 1,3. Aram. Srr. lic lin taperer Mann" Afr. I

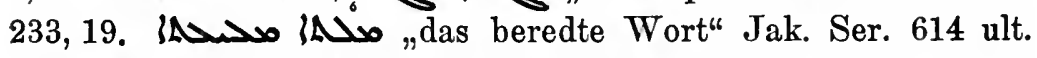

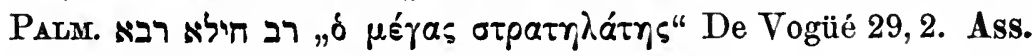
rabū rabium „der große Fürst" Hamm. 26, 98.

2. Das Attribut ein Partizip: Ar. wَ خَبْل خابل,wahrer Wahn-

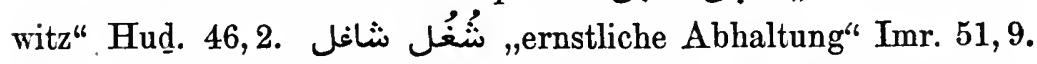

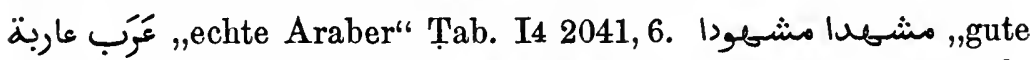
Bezeugung" Ḥam. 1 ult. نفس منفوسة ,neugeborenes Kind" Tab. 
I5 2804, 5. تَغِاليجه المخلموجة , seine hervorgerufenen Schwankungen“" Labīd fr. 26, 1. die Tränke, zu der man geht" Kur. 11, 100. Ferner Ḳur. 11, 101. 19, 23. 25, 24. 55. 33, 38. zum Schlachten geführtes Schlachttier“ 1001

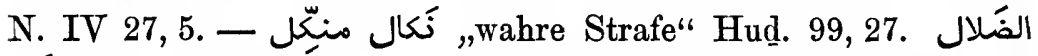
"vollständiger Irrtum" Abū l'aswad Refāíjahandschr. fol. 55b,2. eine aus Holz verfertigte Türe“ Balād. 278, 4. Ferner Kumait 4, 34. Ruk. 54, 6. Kur. 3, 12. أضعافا ,einen beschützenden Patron“" "Urwa 9, 13 جارا مجاورا ,unter Vornahme von Verdopplungen“ Kur. 3, 125. الغَضَب .einschüchternde Furcht" Ag.

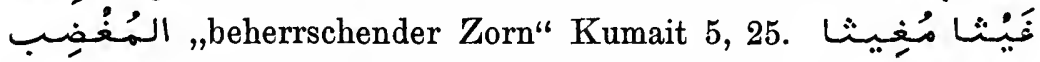

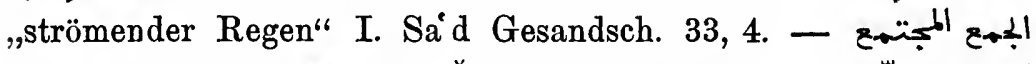

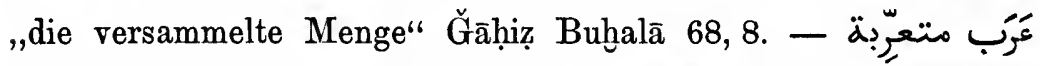
,arabisierte Araber“ Tab. I4 2041,6. - -arabisierte Araber، Ham. 671, 10. ألحتّ المستختّ علينا ,der Anspruch, der an uns gestellt wurde" Tab. II1 240, 16.

Das attributive Partizip wird von dem Leitwort des Attributs ad hoc denominiert, gleichviel ob das Verbum sonst in der betreffenden Bedeutung vorkommt, und ob es überhaupt vorkommt, wie vielbegangene Straße" Kāmil 144,14; so auch ليل لائل, ,tiefe Nacht",

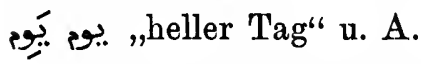

Vulg. Syr. atțawīl almuṭāwil „der Lange, weitausgreifende“" Arabia petr. 252, 5. Centralar. bašita ššătī, im tiefsten Winter“" 6,4. humūmin mehimmātin ,schwere Sorgen" 7, 8. Hebr. הָרצים

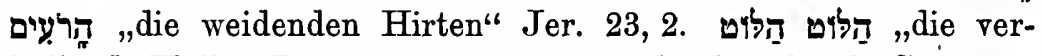

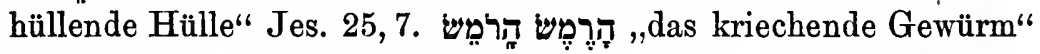

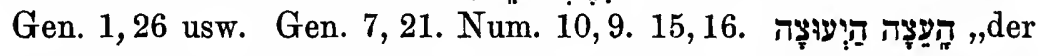
beschlossene Ratschluß" Jes. 14, 26. זֶר : ,Samen der zur

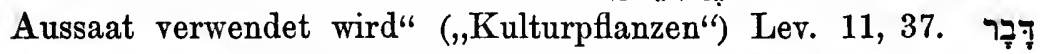

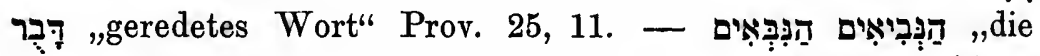

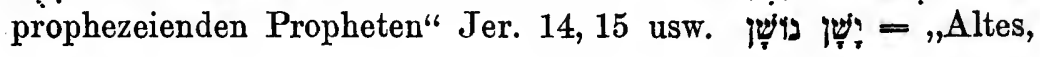




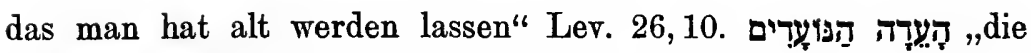
Rotte, die sich zusammenrottete" Num. 27, 3. Ferner Jer. 8, 3.

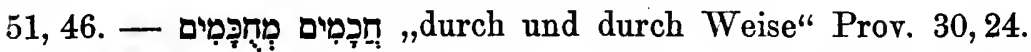

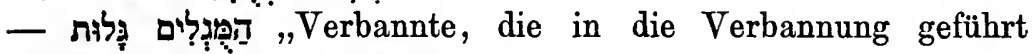
wurden" Jer. 40,1. MIšsā. אפרוחין מפריחין,flügge gewordene Junge" Hul. 12, 3.

3. Das Leitwort ein Zugehörigkeitswort, das Attribut (Apposition) sein Grundwort: الكنانيّى كنانِّة تغلب ,der Kinānit, näm-

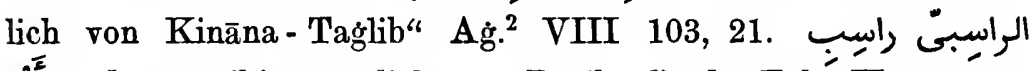

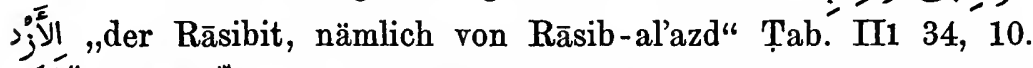

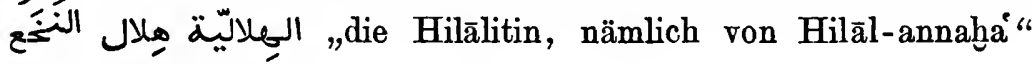
Tab. I5 2364, 3 usw.

4. Mittelbare Paronomasie (vgl. $\S 15,1$ ). Leitwort und Dependenz seines Attributs: Ar. die ihren Häusern benachbarten Häuser" Ag. ${ }^{2}$ VI 52, 1. شابث حسن ein Jüngling von schöner Jugend“ 1001 N. II 138, 4. ,die Schürhölzer, die Söhne der Sch.“

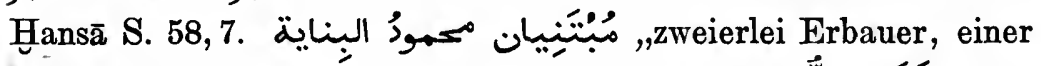

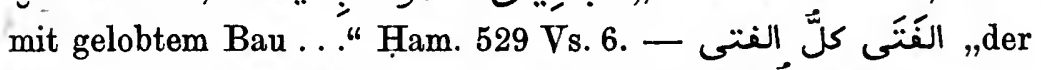

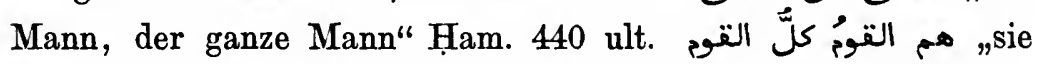
sind Leute, ganze Leute" Síb. I 78 ult. I. Kut. K. aššír 259, 12. den sprachfertigsten der Menschen,

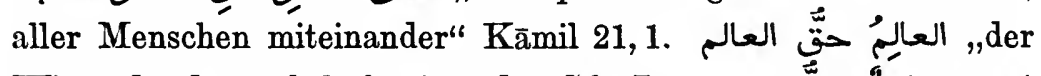

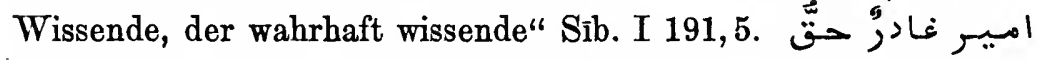
” ein treuloser, wahrhaft treuloser Emir" Tab. U1 389, 5. بيتٍ .andre Häuser als die euren" Ḳur. 24, 27. بُيوتا غَيْرَ بيوتكمٍ eines andern Hauses als das deine" I. Hiš. 718, 6. Vulg. "ТвĀK.: $i \bar{a}$ čelib $i b n$ eččelib „O Hund, Sohn eines Hundes" Neuar. Gesch. 26,18. Srr. ein Fürst, Sohn eines Fürsten" Lbd. v. Am. 52, 8. MAR. ja ĺafrìt iben al'afrīt „O Unhold, Sohn eines Unholds" Mar. 190,3. Aeth. gohch : wCQ : gohc. ",dein Rat, die Wurzel (jedes) Rats" Kenē VIII 4. Syr.

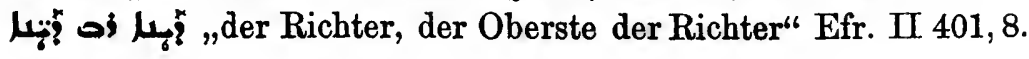


Ass. nudınnu mala nudunnu „die Mitgift, die Fülle der Mitgift" (= „die ganze M.") KB IV 322 Col. 4, 13.

Leitwort und attributiver präpositionaler Ausdruck: Hebr.

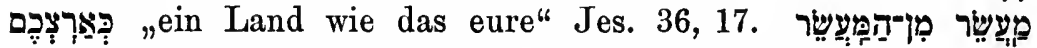
„Zehnter vom Zehnten“ Num. 18, 26 (vgl. Neh. 10, 39). Vgl. ferner $\S 6$.

Status constructus und Attribut seines Genitivs: „Sohn" in Stammbäumen (A Sohn des B, des Sohnes des C).

Vom Leitwort abhängiger Genitiv und Attribut: Ar. في يبتِ . in einem edlen Hause der Ehre" Hansā S. 80 Vs. 3. Hebr. Berg des Verderbens,

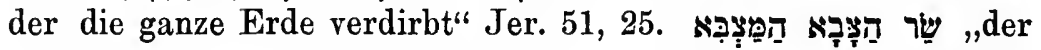

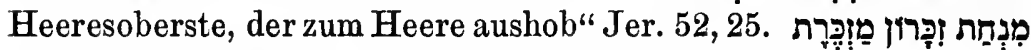
"ein Erinnerungsopfer, das in Erinnerung bringt" Num. 5, 15. Syr. ,das Haupt der Städte, die Stadt Antiochia" Is. Ant. I 90, 151.

5. Oft werdén Worte, die vor dem Leitwort stehen, vor seiner Apposition wiederholt, z. B. Präpositionen; so Ar. أَفِْيْه بكلَ ich gebe für ihn alle Sulaimiten hin, ihre Umherziehenden und Seßhaften" Hansā S. 80 Vs."

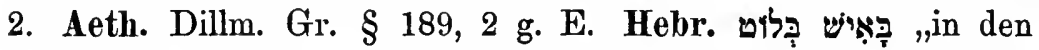

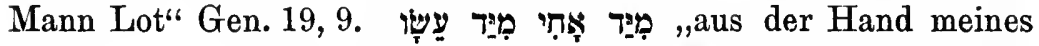

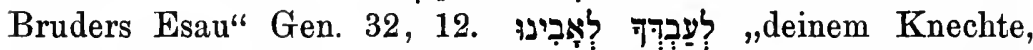
unserm Vater" Gen. 43, 28 usw; das zweite Glied ist meist ein Eigenname. Syr. für mich, den Schwachen“ Carm. Nis. 40 No. 26, 33. - يا حيا محمّف يا ابن . vor dem Vokativ: Ar. o Mohammed ibn Kašǎam" Beduinengesch. 11, 21. Valg. Sxr. jämīrenä jābü 'amīn „o unser Emir, Vater Emins" Neuar. Volksp. S. 83 b. c. So ferner 20, 25f. 39, 45. 46. 49, 37. Tales 144, 3. Arabia petr. 8 Mitte. 177 Mitte. Trip. jā 'abd jāa mēmūin „o Abd, Mëmün" Lieder 20, 5. Mar. a hüija a nșarțal „o Bruder Halbpfund“ Houw. 46, 7. - Hebr. צ̧ vor dem Akk.:

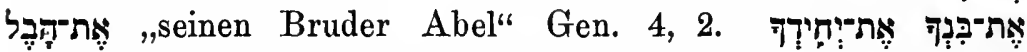
"deinen Sohn, den Einzigen" Gen. 22, 2. Jos. 24, 3. 2 Sam. 5, 2. - Wiederaufnahme des status cstr.: Ass. bit Šamaš bìt 
ili nāṣiri „das Haus Šamašs, des helfenden Gottes" Budge, Annals S. 3, 3.

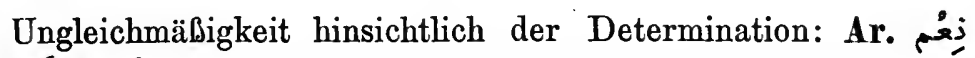
wie trefflich ist der Tote, ein Toter, der Friede gestiftet hat" Ham. 251 vorl. له zu

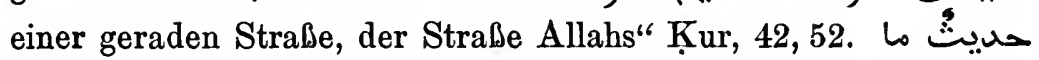
eine gewisse Geschichte, die Geschichte der

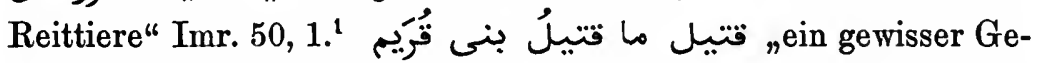
töteter, der von den Banū Kuraim Getötete" Huḍ. 211, 1. ${ }^{1}$ S. noch einige ad hoc gebildete Beispiele bei Sīb. § 76f. Vulg. Syr. $j \bar{a}$ šêhna šêhin tegīl „o unser Häuptling, ein mächtiger Häuptling!“ Pal. Diw. 150 No. 2. vilu ițm ițm eddaba "und es hat ein Maul — das Maul der Hyäne" Pal. Diw. 98, 2.

$\S 21$. Bedeutung der Paronomasie des Attributs. 1. Wie die Beispiele S. 91 zeigen, gibt das paronomastische Attribut oft ein Werturteil ab; s. hierzu $\S 16,1$.

2. Das Attribut (die Apposition) gibt eine Erläuterung, z. B. er ist der Löwe, der Löwe des Dickichts“"

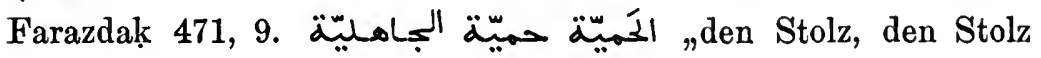

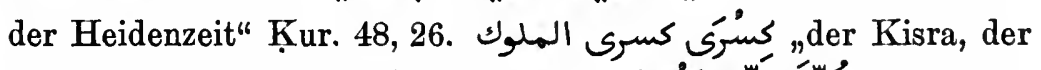

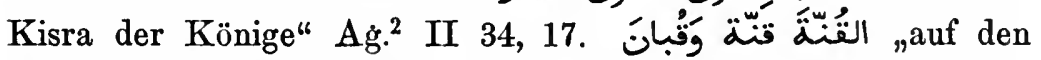
Gipfel und zwar gerade den Gipfel Waḳbān" Jākūt IV 935, 13. Av in jenem Jahre, dem Jahre 87" Tab. II2 1186, 3. Ferner I. Hiš. 851, 1. Buh. I 36, 3 v. u. Tab. II1 297, 15. Imr. Múall. 13. Ruk 1, 22. Kur. 87, 18-19. So mit Eigennamen بَ̣ais, nämlich Ḳais 'Ailān" Ham. 160

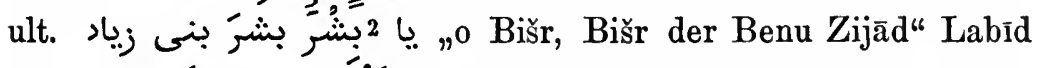
29, 1. Ader Zaid, der Zaid der Schlachtreihen“"

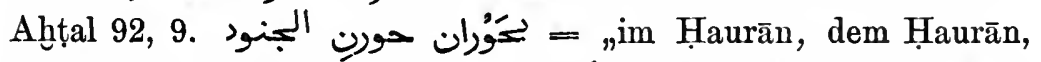

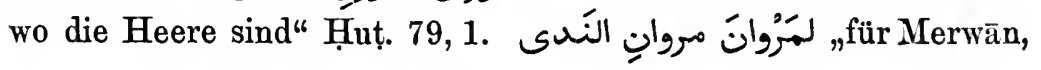

1 "Eine gewisse Geschichte der Reittiere ${ }^{\alpha}$ kann man bekanntlich im Semitischen nicht sagen; vgl. noch $§ 6$.

2 Über die Kasusform des Vokativs in solchen Fällen s. Sīb. § 150. 
den Merwān der Freigebigkeit" Farazdak 610. Vgl. § 22, 3. بعث

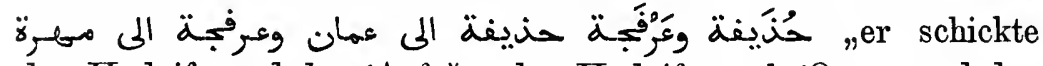
den Ḥudaifa und den 'Arfağa; den Ḥudaifa nach 'Omān und den

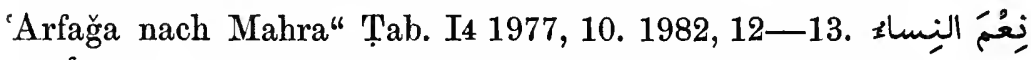
"wie trefflich sind die Frauen, die Frauen der Anșār" = "welch treffliche Frauen sind die Frauen der Anșāir" Buh.I46, 6. نَّقَ ,welch treffliches Volk ist dein Volk" Balāḍ. Ansāb́

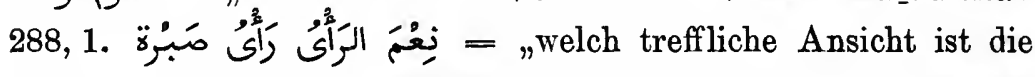
Șabras" Ṭab I6 3455, 8. Farazdak I S. or, 7. IrE, 4 v. u. Vulg. SYr. mit meinen Augen, mit diesen beiden Augen" Lbd. v. Am. 112, 5 v. u. TRIP. lābis miset umiset bșarma "er trug einen Stiefel und zwar einen Stiefel mit Seidenstickerei" Lieder No. 81, 4. 7, 9. No. 104,1-2. Tusis. fïha khul kḥul mtah hikma „in ihr befindet sich ein Pulver, ein Zahnpulver" Märchen 31, 5. Südar. Sox̣. Faḳaz de fakiaz di Momi „Fakaz,

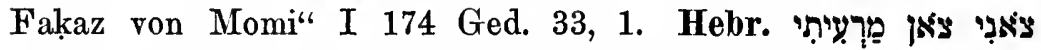

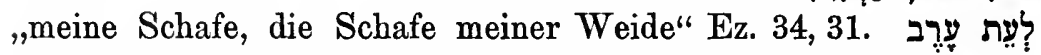
zur Abendzeit, zur Zeit des Herauskommens

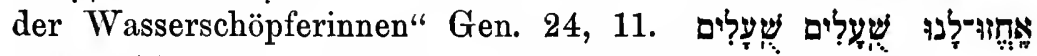

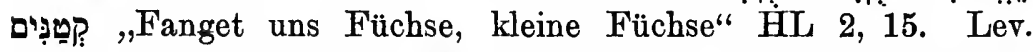
13, 38. Erfindungen, Erfindung des Er-

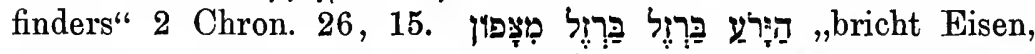
Eisen aus Norden?" Jer. 15, 12. Gen. 49, 22. MišNĀ. עצים הים משרים Hölzer waren dort aufgeschichtet, Zedernhölzer" Pārā 3, 8. ihre Erben, die Erben ihrer Eheverschreibung" Ket. 11, 1. Aram. NAB. למלכו מלכא dem König Maliku, dem König der Nabatäer" CIS 220,3 .

3. Zerlegung eines Duals oder Plurals in die Teile, aus denen

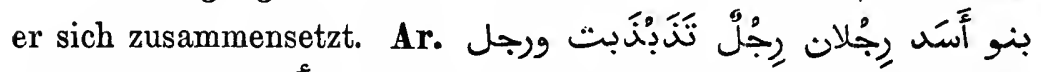
die Benū Asad zerfallen in zwei Füß̉e, einen, ${ }^{1}$ der herumwackelt, und einen, den die Erschütterungen an uns angelehnt haben" Ahțal 76, 12. يومان يوُ مُقاماتِ ويسوُ سَيْرِ

1 Vgl. § 10; ebenso im Folgenden. 
,zwei Tage, einer der Aufenthalte und einer des Losziehens" Mufac̣. No. 20, 50. Zweierlei Kummer, einen verborgenen und einen sichtbaren" Nāb. 8, 1. Ferner Nāb. 1, 6. Ḥātim $r$, 5. I. Hiš. 37, 16. 228, 6. Huṭ. Schol. zu 77, 22 (S. 168 unten und 169). I. Kut. Adab 87, 2-3. Sìb. I 183, 7. جنَو dern" Ag. „sie setzten ihre Monate fest, jeden zu 30 Tagen“ Tab. I4 2032, 8.

Südar. ihren beiden Herren, dem des Königs von Saba und dem des Königs von Hadramūt" CIS IV 155, 3. Vulg. MAr. men ğihtain ğîha uğinha „auf zweiten Seiten, die eine - die andere" Tlemçen 248,

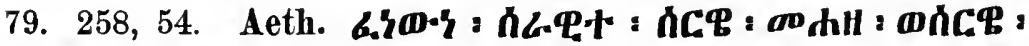

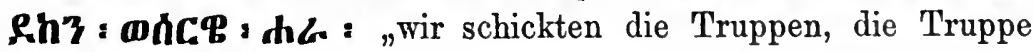
Mahaza, und die Truppe Dakan und die Truppe Harā" Inschr.

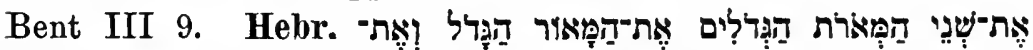

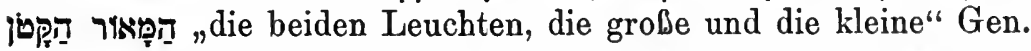
1, 16. für die Ganzopfer, für die des Morgens

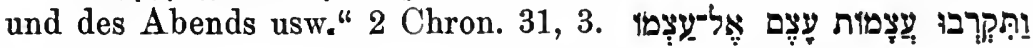
„es nahten sich die Gebeine, eines zu seinem zugehörigen" Ez. 37, 7.

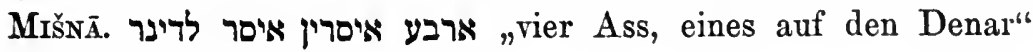
Bābā m. 4, 5.

4. Zwei paronomastische Attribute, deren zweites das erste näher bestimmt: Ar. eine weiße, reinweiße“" Ag.. II 11, 15. Jezid war rot, sehr rot" Ibn Duraid 169, 11. sie war eine lange, auffallend lange Frau" I. Sa“d VIII 126, 3. كان جَواءولة مشنهورا باليُّود kannt" Tab. I5 2866, 1. Ferner I. Hiš. 580, 12. Tab. I5 2736, 15. II1 530, 3. 4 .

§ 22. Zum Gebrauch der Paronomasie des Attributs. 1. Da nichts zwischen das Regens eines Genitivs und den Genitir treten kann, muß das Regens unter Umständen zweimal gesetzt

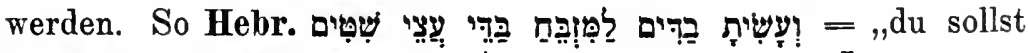


Stangen aus Schittimholz an dem Altar anbringen" Ex. 27, 6. ${ }^{1}$ Ass. dūru rabā dūr irșit gurgurri $=$,die große Mauer des Quartiers der Bronzearbeiter" BA I 302 Col. II 8. So kann denn auch von einem status cstr. nur ein einziger Genitiv abhängen,

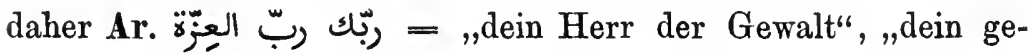

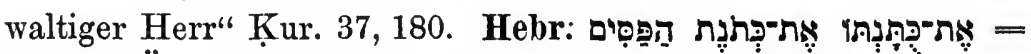
„seinen Ärmelrock" Gen. 37, 23. "meinen

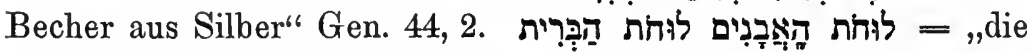

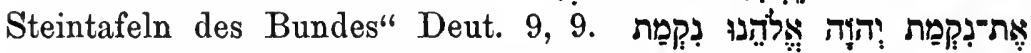
תָיכָלו = ,die Rache Jahwehs, unseres Gottes, für seinen Tempel“

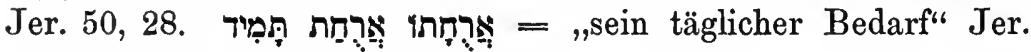
52, 34 (2 Kön. 25, 30).

2. Da das Demonstr. keinen Genitiv regiert (vgl. $§ 10$ ) so ergibt sich die Notwendigkeit das Subst. zu wiederholen in Fällen wie , von dem Hause, dem der beiden Nachbarinnen" Farazdak 564, 2. 2die Sattel-

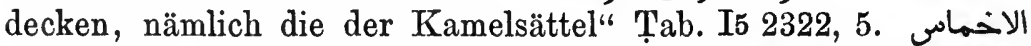
,die Stadtquartiere, nämlich die Madāins“ Tab. I5 2454, 6. Ferner Tab. I4 2049, 15. 2454, 13. I. Hǐ̌. 618, 5. Vgl. oben $\S 21,2$.

3. Eine Schwierigkeit entstand, wenn durch den Sprachgebrauch ein Subst. und der bestimmte Artikel zu einer festen Einheit, nämlich einem Eigennamen, erstarrt waren, und wenn nun ein Genitiv davon abhängen sollte. Denn Adjektive zwar (einschließlich der Partizipien) können, solange sie Adjektivnatur besitzen, einen Genitiv regieren, auch wenn sie den bestimmten Artikel haben, weil es bei ihnen überhaupt keine natürliche Determination, sondern nur eine formale Kongruenzdetermination gibt (s. meine Syntakt. Verhältnisse § 92). Dagegen besitzen die erwähnten Substantive gerade eine sehr starke natürliche Determination. Die unmittelbare Verbindung mit einem Genitiv war hier bei Anwesenheit des bestimmten Artikels ausgeschlossen und wurde auf mittelbare Weise dadurch bewerkstelligt, dab das mit dem Artikel verbundene Wort appositionell in artikelloser Gestalt wiederholt wurde und

1 Noch stärker ist die Trennung Gen. 35, 14. Num. 27, 3. 
$a$ so den Genitiv regierte. Das betrifft erstens Eigennamen mit $b$ festem Artikel und zweitens Appellative, die eine so gebräuchliche Spezialbeziehung auf bestimmte Gegenstände erhalten haben, daß sie gleichfalls beinahe Eigennamen geworden sind. Beispiele: (a)

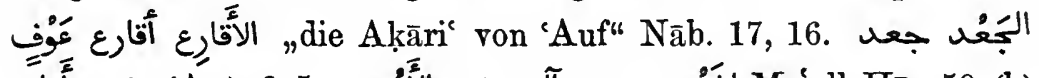

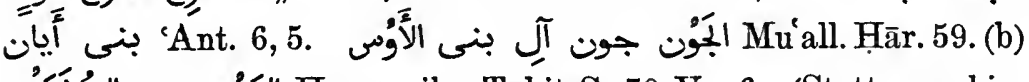

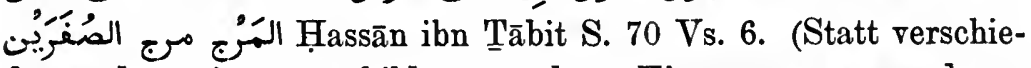
dener der mit gebildeten und zu Eigennamen gewordenen

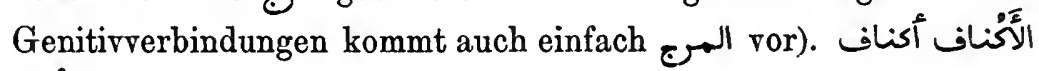
سَلَْْى Tab. I4 1886, 10. (Auch dies Wort ist sowohl Appellativum wie, mit festem Artikel versehen, als Eigenname belegbar; das

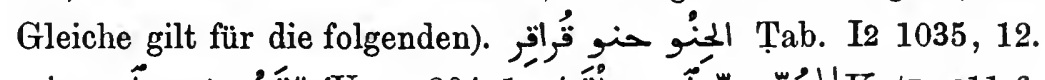
Kuțāmī11,6.

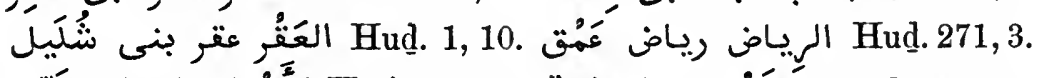

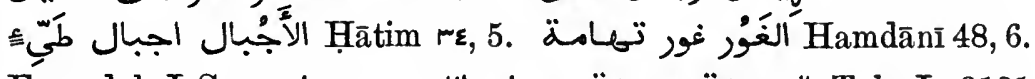

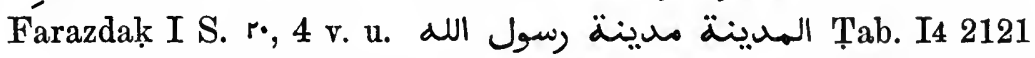
ult. usw. Es sind geographische Appellativa, die ursprünglich an Ort und Stelle $x a \tau^{\prime}{ }^{\prime} \dot{\varepsilon} \xi_{0} \chi \dot{r}_{i}^{\prime}$ gebraucht worden sein werden; der Artikel bezeichnete sie als einzigartig - innerhalb ihrer Sphäre. In diesem Stadium waren sie Appellative. Sobald sie auch bei den ferne Wohnenden für die gleiche Örtlichkeit gebraucht wurden, waren sie Eigennamen.

Die Ortsbezeichnungen, nach denen denkwürdige Tage beيوم الِِسنر جسر nannt werden, haben ebenfalls festen Artikel, also der Tag der Brücke', der Brücke des Abü "Ubaid" Tab. I4 2156, 2. الم الحديقة حديقة الموت ,Garten', dem Garten des Todes" Tab. I4 1943, 11. — Eigennamen ohne Artikel s. oben $\S 21,2$. Vgl. übrigens $\S 20,3$.

Vulg. Srr. ilbaraki barakat rabbi, ,der Segen, der Segen meines Herrn" Pal. Diw. S. 20 No. 5, 2. Centralar. alğenā̆l. ğenāh̆ 'anezeh „Ğenāḥ, Ğenāḥ der 'Anezeh" 97 Einl. 1. Hebr.

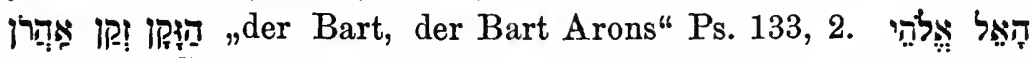
der Gott, der Gott deines Vaters" Gen. 46, 3. Num. 27, 3.

4. Die unvollkommene Ausbildung des thetischen Indefinitums 
(s. $\S 10$ ) ist aus der Übersetzung der Beispiele in $\S 21,3 \mathrm{zu}$ ersehen.

\section{Akkusativ. ${ }^{1}$}

\$23. Effizierte innere abstrakte Objekte. 1. Über das Wesen des inneren Objektsakkusativs s. Syntakt. Verhältn. § 56. Es gibt auch nichtparonomastische innere Objekte, z. B. كركبهم المسلمون die Gläubigen setzten ihnen arg zu ein Töten und Gefangennehmen" = "mit Töten und Gef." Tab. II1 1187, 13.

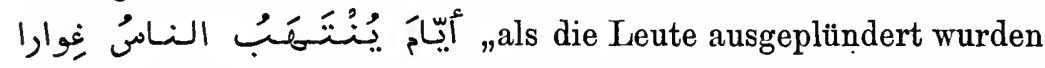
ein zu Felde ziehen" = „auf einem Feldzuge" Muacll. Ḥārit 34. 35. 45. Nöld. Beitr. Poesie d. Ar. 117 Vs. 3. 172 Z. 4.

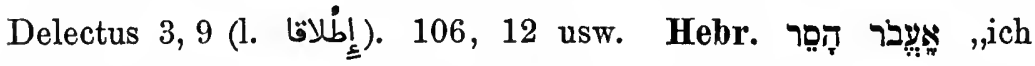
will durchgehen ein Entfernen" = ,und entfernen" Gen. 30, 32.

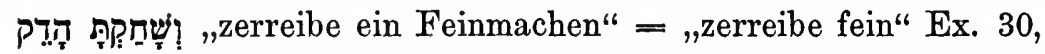
36 usw. Syr. Nöld. Syr. Gr. $§ 298$ erster Absatz g. E. In weitaus den meisten Fällen aber sind die inneren Objekte paronomastisch, und wir erhalten die auf den ersten Blick nichtssagende Angabe, daß ein Ding etwas tut und hierdurch bewirkt, daß das betreffende Tun zustande kommt: "Zaid tötete ein Töten" = „Zaid tötete und brachte dabei ein Töten hervor". In dieser häufigen Ausdrucksweise ist ein und derselbe Begriff nicht nur in zwei von einander geschiedene grammatische Kategorien (Nomen und Verbum) gebracht, sondern er ist in der einen, dem Nomen, geradezu als das Produkt der andern hingestellt. Und zwar ist das bei allen Verben möglich, auch bei solchen, die ihrer Natur nach nichts über die Beziehung ihres Subjekts zu irgend einem Objekt aussagen (,schlafen" ,getötet werden"), und auch Verba, die ihrer Natur nach nur ein affiziertes Objekt regieren (,töten"), regieren hier ein effiziertes Objekt. In jedem Verbum, auch dem starren Zustandsverbum, liegt der allgemeine Gedanke des Produzierens einer Tätigkeit, und er ist es, der das innere Objekt

1 Vgl. die Umschreibung des Akk. durch $l a$ in $§ 33,6$. 
regiert. Es ist die freieste Verwendung des Akkusativs; jedes Verbum kann ihn regieren.

Die Tätigkeit nun ist hierbei völlig von ihrem Subjekt losgelöst, während sie ihm sonst inhäriert, und das Verbum finitum selbst wird $\mathrm{zu}$ einer Art Beziehungsbegriff, der zwischen einem Subjekt und dessen Handlung die Beziehung herstellt.

Indem aber bei dem Vorgang der Abspaltung eines paronomastischen inneren Objekts das Verbum finitum degradiert wird und zu dem allgemeinen Tätigkeitsbegriff verarmt, während der spezielle Tätigkeitsbegriff in das Objekt wandert und dort selbständig herausgestellt wird, wird das Zustandekommen der Tätigkeit lebhaft vorgeführt, sei es, daß hierdurch ihre Tatsächlichkeit, sei es, daß die Vollständigkeit ihrer Durchführung hervorgehoben wird. Indes ist die Kraft der Paronomasie hier wie sonst öfters abgeschwächt; namentlich wenn das Objekt eine nähere Bestimmung hat (s. u.), liegt der Nachdruck meist auf dieser.

Beispiele für inneres Objekt nach "Intransitiven": Ar.

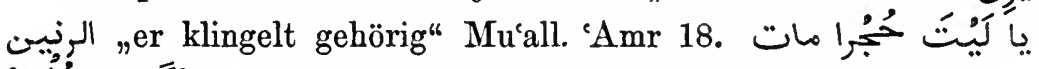
OO Oäre doch Ḥuğr eines (natürlichen) Todes gestorben und nicht abgeschlachtet worden"Tab. II1 146, 17. لمّا غضب غَفْبة "als er in Zorn ausgebrochen war" Tab. II3 1392, 13. Ferner

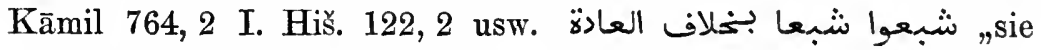
wurden ganz anders satt als sonst" 1001 N. II 102, 1. Vulg. Sxr. lauman tūkaf wakfitha, ,wenn sie ilhre aufrechte Stellung einnimmt" Pal. Diw. S. 120, 6 v. u. nadadet nadedha ,sie machte ihre Toilette" Arabia petr. 438,70 v. u. ÄG. ziilet $z a \dot{a} a l$ šedìd "sie brach in fürchterlichen Zorn aus" Contes 20,3. Aeth. MH:

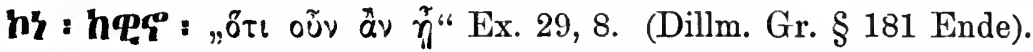

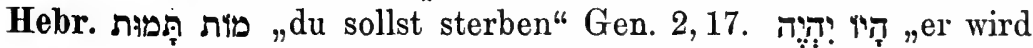

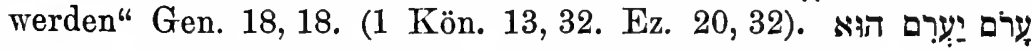
"er ist sehr listig“ 1 Sam. 23,22 usw. Syr.

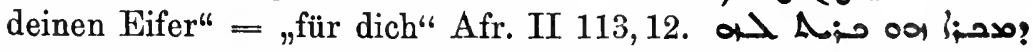
"daß es ihn schmerzte" Afr. II 17, 17. I 396, 23 usw. Ass. edešrı lediš „er soll ganz neu bleiben“ KB VI 248, 262.

Und so steht dieser Akkus. auch bei Passiven (vgl. übrigens 


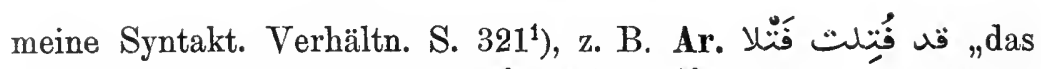

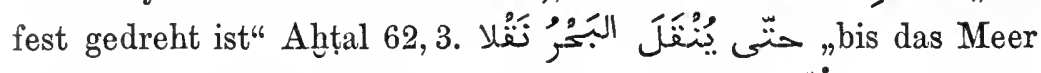

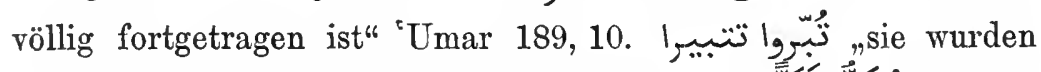
vollständig zerbrochen" Tiab. II2 739,6. indem er in roher Weise geschleift wurde" Tab. II1 125, 1. Ferner Kur. 25, 27. 33,61. 56, 4. 5. 69, 14. 76, 14. 84, 8. 89, 22. Ḥātim ro, 16. 'Amr Múall. 17. Kutạmi 3,22 usw. Hebr. "gestohlen

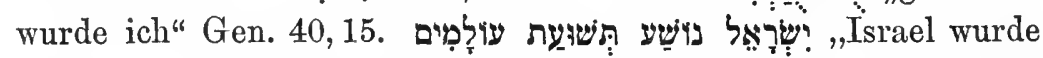
mit ewiger Hilfe geholfen" Jes. 45, 17. Jer. 14, 17. Dan. 11, 34. MIšxī. sie war dem einen wegen Blutsverwandtschaft verboten" Jeb. 3, 2. עשרה נמינות נתנסה אברהם „mit zehn Versuchungen wurde Abraham versucht" Ābōt 5,3. Jeb. 6, 5. Pes. 7, 7. Syr. loa la Ser. 658,11 .

2. Wie nach dem Verbum finitum so steht inneres Objekt auch nach Verbalnomina und verwandten Ausdrücken, z. B.

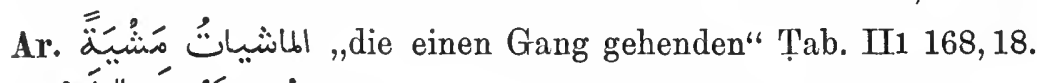
der den breiten Stich versetzt“ Hud.

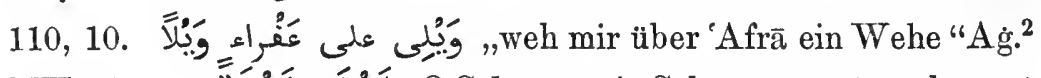

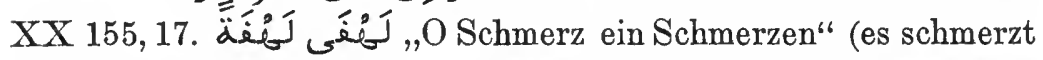

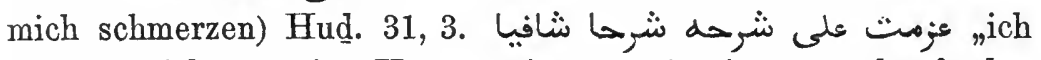
machte mich an seine Kommentierung mit einem erschöpfenden Kommentar" Ḥam. 2, 22. Vulg. SYr. jō näima nōm etțuli ,., der du schläfst den Schlaf des Lamms" Pal. Diw. S. 7 c, 1 ÄG. mesäfir safar jōm „eine Tagereise machend" Contes 120, 9. Hebr. Sich freuend mit großer Freude" 1 Kön. 1, 40. , dies Volk wunderbar zu behandeln, wunderbar und wundersam" Jes. 29, 14. Syr.

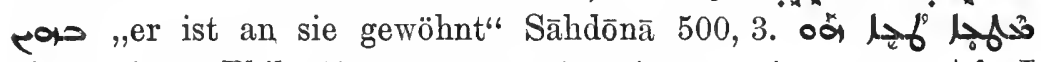

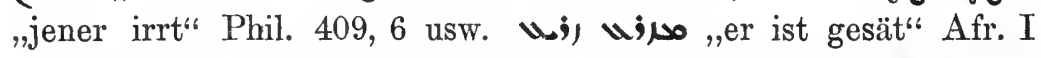

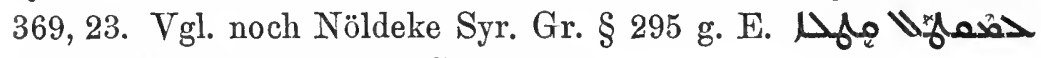
„einen Mord zu begehen" Spic. 17, 20.

3. Inneres Objekt als zweiter Akkusativ neben erstem Akk. verschiedener Art, abhängig von jedem beliebigen Transitivum, 
z. B. Ar. كَ, wer dir diese Wünsche einge-

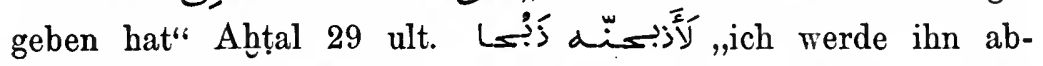
حتّى يطرق دهاقين الانبار طروقا . ,bis er nächtlicher Weile zu den Dihkānen ron Anbār kam" Tab. I4 2203, 9. Ferner Kur. 71, 16. Ḥam. 129, 24. Tab. I 3 1426, 12. I4 2066,5. I5 2314,4. sie sahen einen in zwei Falten gelegten Schurz" 1001 N. I 352, 2. 7. Vulg. Srr. saraḳtu sirāka ,stehlen tat ich" Pal. Diw. $178 \mathrm{Z} .13$ v. u. dibbūha filkabr dabb, ,werft sie im Wurf ins Gras" Pal. Diw. 287 Z. 14 v. u. Lbd. v. Am. 90, 8: 122, 10. ZENTr. jagbed arrụ̄e gabdā ,sie könnte dir wirklich das Leben kosten“ 20,18. Hạ̣R. jitibibhin $\underline{t} l \bar{a} \underline{\underline{a} a} t \bar{u} \bar{b} b$,er ordnet sie in drei Reihen" 263 Mitte. ÄG. bijūga $\bar{c} \bar{u} n \bar{\imath}$ waga "šedì "sie tun mir sehr weh" Contes 20, 8. rașṣettuh raṣs ,ich habe es ausgelegt" ZDMG 33,618, 18. TRIP. lī ğazzartüni tĭgzìr ,wenn ihr mich auch abschlachtet" Lieder No. 37,20. Tunis. dlamnāh dulman, wir haben ihm Gewalt an-

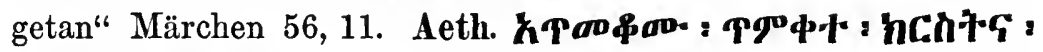
,er taufte sie mit Taufe des Christentums" Chrest. 18, 18.

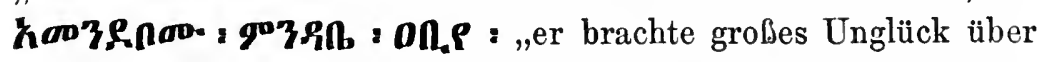
sie" Chrest. 21, 15. 23, 4. Lal. 62, 17. Hebr. înr

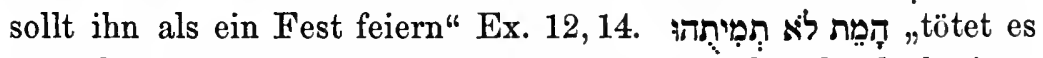

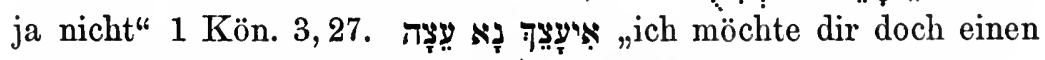

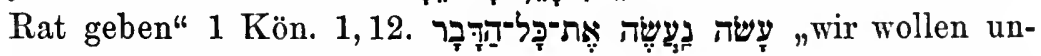

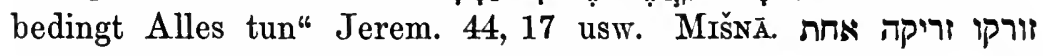

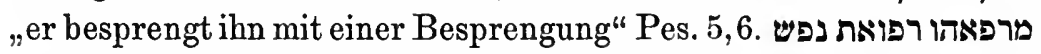
"er heilt ihn persönlich" Ned. 4, 4. אוסרתה איסור עולם "macht sie für ewig verboten" Sōța 6 , 3. Syr. denn der Schöpfer schuf dich zu einer zweiten Schöpfung" Phil. 52, 14. 이

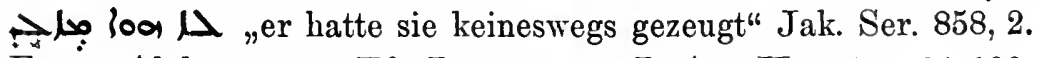
Ferner Ahịkāan 54, 12. Efr. I 259, 5 v. u. Is. Ant. II 60, 122. 64, 100. 116, 174 usw. Ass. arrat la napšuri lirurušu „mit unlösbarem Fluch mögen sie ihn verfluchen" BA II 122 Kante Kol. II. jilammununi lumnum "sie sprengten Böses über mich aus" Tell el Am. No. 146, 6. isḳšsı . . rimutu ul irimi „sein Einkommensrecht wird er nicht als Gunsterweisung zuwenden" KB IV 214, 24. 
4. Der infinitivische innere Akkus. kann von der gleichen Konjugation wie das regierende Verbum gebildet werden, z. B.

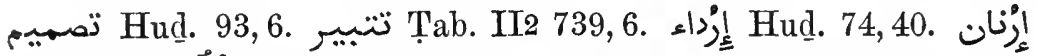

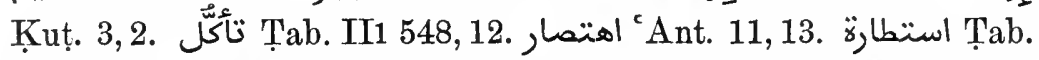
I4 1855,2. Tab. II2 909,14; also auch wo sich längere

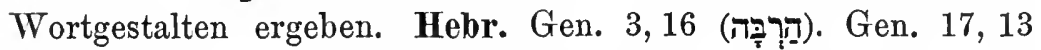
(הט). Gen. 40,15 (ב) usw. Oft aber fällt der Infinitiv in die zugehörige Grundkonjugation, oder über diese hinweg direkt in die erste Konjugation zurück, da der Inf. den bloßen Handlungsbegriff, nicht die den einzelnen Konjugationen eigenen Modalitäten verstärkt. So erscheint z. B. regierendes Verbum und abhängiger Infinitiv folgender Konjugationen verbunden:

kattala - katala Ar. Tab. I4 2072, 13 (بات). Hansā 30 ult. $(-\infty)$.

'aktala -katala. Ar. I. Hiš. 410,17 (حسّ). Kur. 4,63 (نَّ). Kaur. 3, 32 (نبت) Balād. 113, 14 (نبا). Hebr. Gen. 26, 11 usw. (עות Hofal). 1 Sam. 23, 22 (ערם).

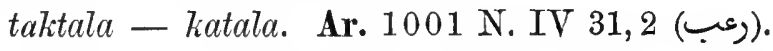

takattala - kattala. Ar. Kur. 73,8 (بتل). Farazdak 407,3 (s).

takattala - katala. Ar. Buh. I 290, 13 (reb).

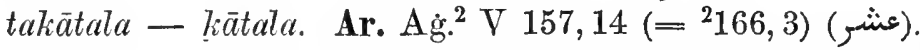

takâtala - katala. Ar. Kur. 17,45 (علا). Ḥātim 17, 14 (عوى). naktala - katala. Hebr. Ex. 19,13 (עקל) 21, 22 (עמשל) usw. astaktala - katala. Ar. Zuhair frg. 26,1 (جنّ).

Und so andrerseits erste Konjug. mit Inf. einer abgeleiteten: Ar. Kuṭ. 13, 33 (بلع VIII). Farazdak I S. r., 2 v. u. (بكر VIII). Kuṭ. 3,41 (ح, V).

Aber auch Konjugationen, die in keiner morphologischen Beziehung stehen, werden verbunden; z. B.

kattala - 'aktala. Hebr. Ez. 16,4 (לת, Pual - Hofal).

'aktala - kattala. Ar. Ham. 187 Vs. 3 (قد). Hebr. I Sam. 2,16 (ר)

taktala - kātala. Ar. قتّ häufig.

taktala - takattala. Ar. 'Ant. 20, 31 (قتحم). Kuṭ. 13, 24 (تبع). 
naktala - 'aktala. Hebr. 2 Kön. 3, 23 (חרב, Hofal). Ler. 19, 20 (פדofal).

takattala - taktala Ar. Kuuṭ. 13, 24 (تبع).

takattala - naktala. Ar. Sìb. II 260, 16 (طوى).

astaktala - 'aktala. Ar. Labīd frg. 38 (بدل).

5. Bei der größeren Ähnlichkeit, die zwischen den mittels des Partic. pass. gebildeten Infinitiven und den andern Verbalformen besteht, kann es nicht wundernehmen, wenn als inneres Objekt gerade diese Infinitivbildung oft begegnet. Z. B. Kur. 34, 7

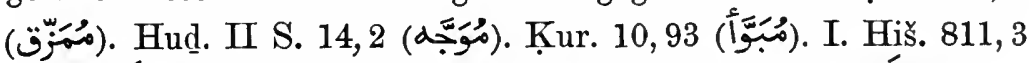

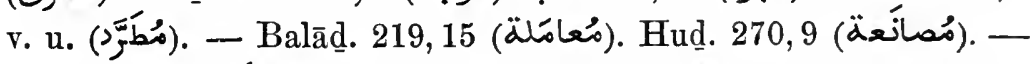

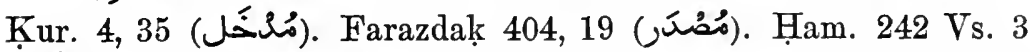

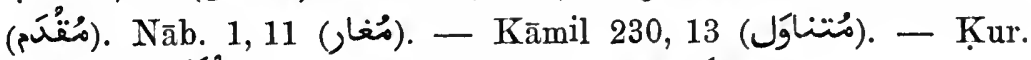

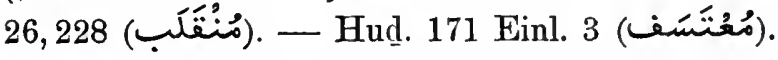

6. Das innere Objekt ein nichtinfinitivisches Abstraktum:

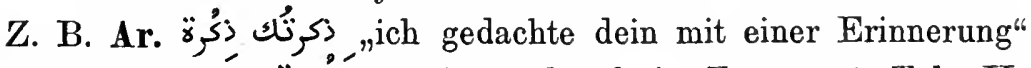

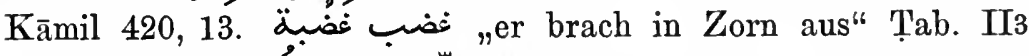

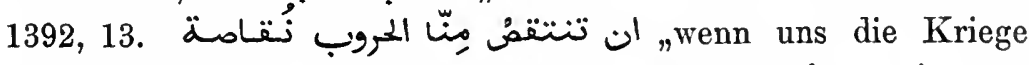
Schädigung bringen" Hud. 78, 22. Vulg. SYr. fá al elfé āl „er hatte die Taten vollbracht" Damas 94 ult. ațlob țulba = "verlange was man gewöhnlich verlangt" Arabia petr. 181,25. Aeth.

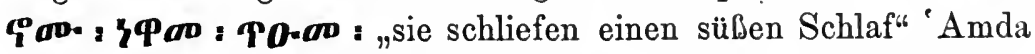

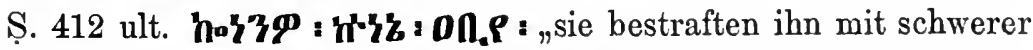

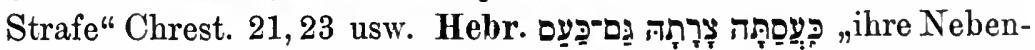
frau kränkte sie gar sehr" 1 Sam. 1,6, Syr.

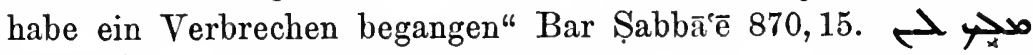
"er gab uns ein Versprechen“ Bar Șabbāê 734, 6. Außerdem ist stets das nichtinfinitivische Abstraktum erforderlich, wenn das innere $\mathrm{Obj}$. eine attributive oder genitivische $\mathrm{Be}$ stimmung erhält, s. Nöld. Syr. Gr. § 298. Ass. mitluk millii „er pflegte Rat" BA V 310, 27. lā hițu dannu ihți "er hat kein schweres Verbrechen verübt" BA IV 514, 3.

7. Wenn das innere Objekt keine nähere Bestimmung hat, bezeichnet es gewöhnlich eine Verstärkung und kann übersetzt werden mit "gehörig", „geradezu“, „förmlich", „wirklich“, „ernst- 
lich", „richtig", „in der Tat", „vollauf" usw., muß aber oft unübersetzt bleiben und durch die Betonungsweise des regierenden Verbums ausgedrückt werden. Beipiele: indem

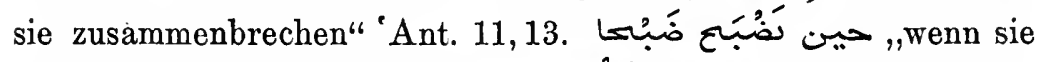

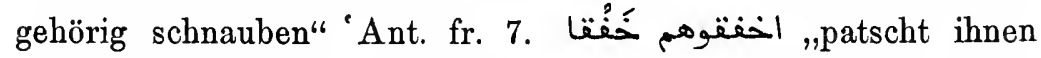
ordentlich drauf" Tab. I4 1850, 16. er packte

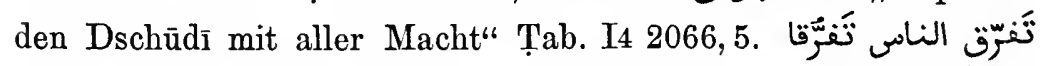

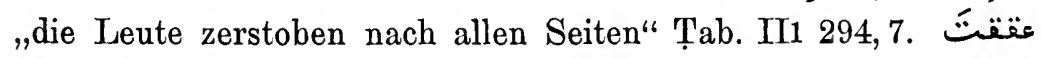
قد .du hast ganz pietätlos gehandelt" Tab. I4 1842, 15. عَفاقِ ihr habt eure reitenden Frauen auf alle

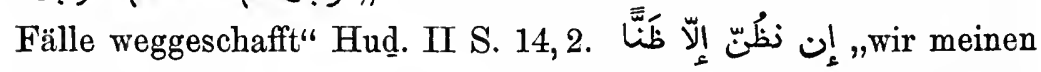
blob" Kur. 45, 31 usw. Der Inf. verstärkt öfters eine Negation, wie treiner von ihnen wurde auch nur verwundet" Tab. Is 2307,8. ich werde nimmer-

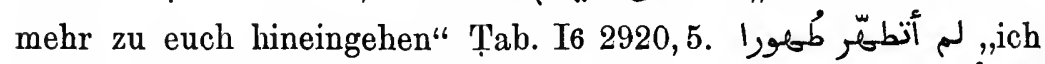

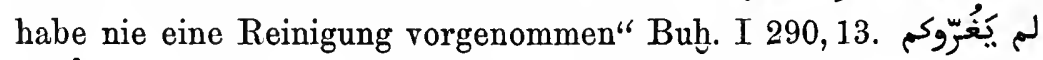

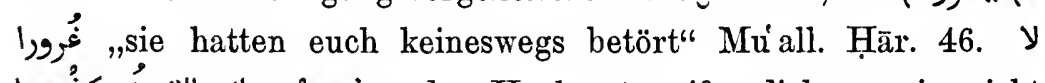
der Hochmut reiße dich nur ja nicht

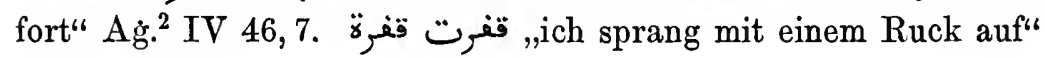
1001 N. I 238, 2.

Vulg. 'IRĀk. arìd ašarriğ tešrīğ ,ich will nach Osten ziehn" Neuar. Ged. S. 112, 4 v. u. ilu'an šwāh saaw̄ „bis er ihn vollständig gebrüht hatte" Neuar. Gesch. 34 ult. 104, 21. Srr. ولو "selbst wenn er sie nur aufs Geratewol hinschlägt" Lbd. v. Am. 100, 3. bārūdtu tirzim razìm „sein Gewehr knallt furchtbar" Pal. Diw. 332 Str. 6. Centratar. jisfir isfār ,es strahlt hell" 12, 12. 23. Hạpr. jibridūn bräd "sie erfrischen sich tüchtig" 367 Mitte. tedwi madwa „du kommst erst Abends" 435, 14. ÄG. mā jikidar 'alkudra ill 'allāh „keiner hat wahre Gewalt außer Allăh" Contes 33, 3. TRIr. kette kettān "sie bricht in Grollen aus" Trp. Bedl. 381. Mar. azga 'alēh zigja „er erhob den Schlachtruf" Mar. 182, 14.

Südar. Sox̣. tișéa ạ șáaḳaneh ,sie erhebt ein Geschrei" II 334,6. 


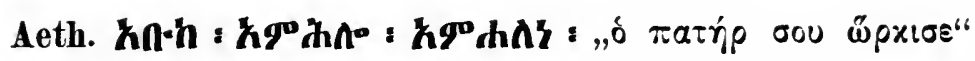
Gen. 50, 16.

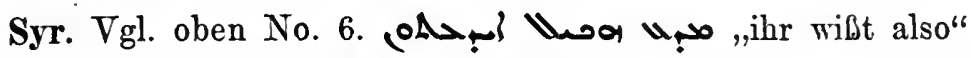

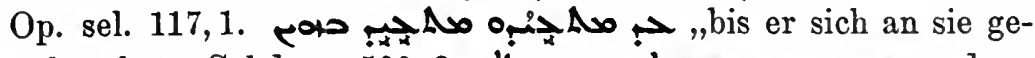
wöhnt hat" Sāhdōnā 500, 3. lLava denn

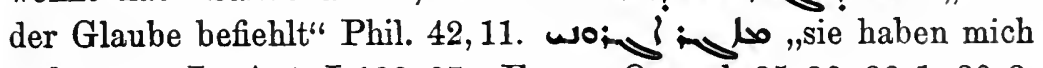
gedungen" Is. Ant. I 182, 97. Ferner Op. sel. 25, 26. 26, 1. 30, 2. 301, 18. Efr. II 595, 19, 1. Is. Ant. II 64, 98. 100. 68, 2. 10. 182, 86. Namentlich oft bei irgendwie verstärkenden Partikeln, wie oo (Spic. 9, 11. Afr. I 305, 21. Carm. Nis. S. 11, 93. جه (Op. sel. 56,22. 128, 15). loo IJ (Ahik. 61,11. Afr. I 301, 21. Is. Ant. II 116, 174. Jak. Ser. 858, 2). lar (Afr. I 369, 23). D (Spic. 2,13). of (Spic. 48,1. Op. sel. 28,9. 174,12. Addai 11,19. Afr. I 88, 7. 348, 23. 396, 23). ححسه (Op. sel. 189, 15. Sāhdōnā 15,6) und anderen.

Ass. ha $a \check{a} \bar{a} l a$ iȟšl „er zerschmetterte vollständig“ KB VI 272, 6. bikîtum ibaki "er bricht in Weinen aus" Bab. Bussps. S. 10,14. zikiltam izakkil ,er begeht eine unüberlegte Handlung" Hamm. fr. Rs. 7a, 39. Ferner BA IV 520, 12. 539, 15. Hुamm. 6, 8.

8. Eine inhaltliche Bereicherung dagegen bringt der Akk. schon dann, wenn er ein Nomen unitatis, ein Dual oder Plural

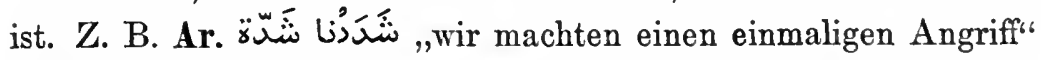

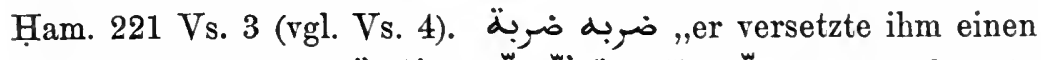
Hieb" Ham. 236, 23. sie sprachen ein Takbirgebet, darauf sprachen sie es zum zweiten Male“ Tab. I5 2388, 2. Deutlicher: daß sie euch mit einem einzigen Überfall überrumpelten" Kar. 4, 103. , sie werden mit einem einzigen Stoß zerstoßen" Kur. 69, 14. Ḥam. 99, 1. - sie ging zweimal herum" Ahțal 15, 7. Hātim rr, 4. er versetzte dem Gefangenen mehrere Hiebe damit" Tab. II3 1338, 15. Eine weitere Bestimmung dabei: ربارَبْوَة شديدة er ächzte einmal schwer" Buh. II 41, 3 .

Vulg. 'IRĀḲ. şăhl şōhèn ,er rief zweimal" Neuar. Gesch. 52, 15. Sxr. dār ilkamar dōra „der Mond machte eine Drehung" Pal. 
Diw. 181, 6. jafenn fenün „es macht viele Kunststücke" Arabia

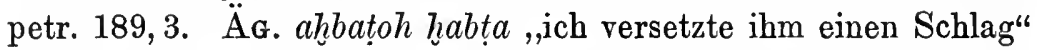
Spitta Gramm. (Texte) S. 482, 3 v. u. bašukki šakka, ,ich mache einen Stich" ebenda 448,4 v. u. tihbato habta wahde „schlug ihn einmal" Contes 17,2 v. u.

Südar. Soḳ. meberote al ba'ar „Nachtmärsche macht er nicht" I 164 Ged. 5, 3. bošik țād boši ,ich weinte einmal" I 188 No. 69,1 .

9. Enthält der Ausdruck nähere Bestimmungen, so kann es, wo kein deutliches grammatisches Beziehungszeichen vorhanden ist, also namentlich bei praepositionalen Bestimmungen, unter Umständen zweifelhaft sein, ob die Bestimmung zum Akk. oder zum regierenden Verbum gehört. Auch die Stellung der Bestimmung bildet nicht immer ein sicheres Kennzeichen, aber wenn z. B. das Verbum zwischen dem Akk. und dem praepositionalen Ausdruck steht, gehört dieser zum Verbum.

Oft steht beim Akk, ein Adj., unter Anderm deswegen, weil die semitischen Sprachen nur in beschränktem Maße Adjektive ohne weiteres adverbial verwenden, $d$. h. substantiviert ${ }^{1}$ und zum inneren Objekt gemacht. Das Gebräuchlichste ist vielmehr, daß das Adj. Attribut eines inneren Objekts wird. Ar. ظلمت نفسى

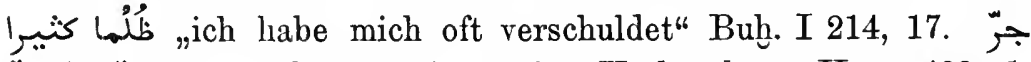
ק,er beging ein großes Verbrechen" Ham. 423, 1.

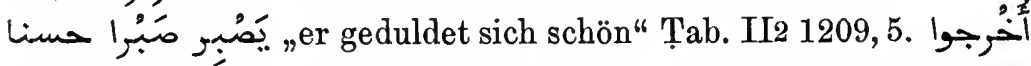
"اخخراجا عنيفا "sie wurden rücksichtslos hinausgetrieben" I. Hiš. 362, 7. er würgte ihn heftig“ Buh. III 22, 16.

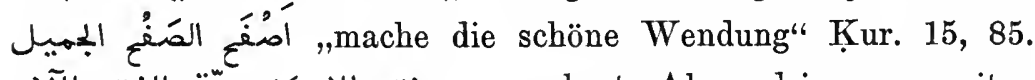
er eroberte Alexandria zum zweiten Male" Balād. 223, 2 v. u. Zum Teil also auch, wo das Adj. unmittelbar adverbial gebraucht werden kann; so in dem vorletzten

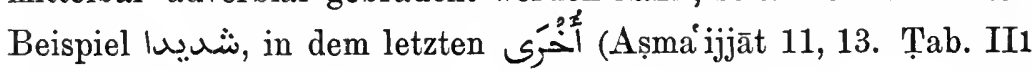
59, 5). - er liebte seine Tochter

1 Überhaupt erfolgt die unmittelbare Substantivierung eines Adjektivs im Semitischen nur unter bestimmten Voraussetzungen. 


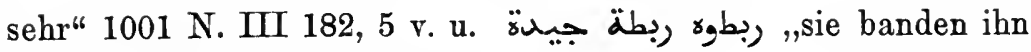
fest" II 303, 7. Beduinengesch. 10, 8. 11, 6.

Vulg. 'IRĀK. 'akram Abunnuwās ikrām zā'id ,er beschenkte Abu Nuwās reichlich" Neuar. Gesch. 72, 36. jehibbhā mahabbe ketīre „er liebte sie gar sehr" Neuar. Ged. I S. 100, 1. Srr. زعق er schreit fürchterlich" Lbd. v. Am. 106, 4 v. u. 26, 8. Arabia petr. 248,6 . 429, 6 v. u. MALt. saffar tisfïra gbīra ,er tat einen langen Pfiff" Malt. Stud. 20, 12. ḩārset leih har ara helwa

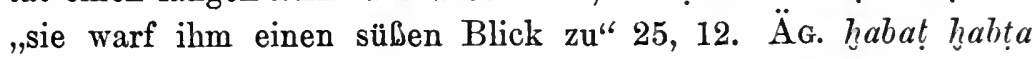
ḳawìje ,er schlug stark" Contes 18, 3. "aijațet 'aijāt šed̄id ,sie weinte heftig" Contes 18,5 v. u. TRIP. rauwah mirwāha maglüba ,er ging einen bósen Gang" Lieder N. 76, 9. Mar. mebni benjān emlīh „schön gebaut" Tlemcen 268, 50. biši mišjā 'aijāna ,sie ging mit gebrochenem Gang" Mar. 180, 7. Aeth. 中w\$:\$av. ,

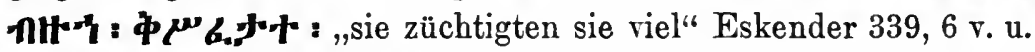

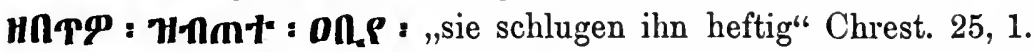

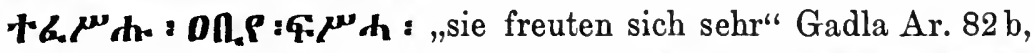

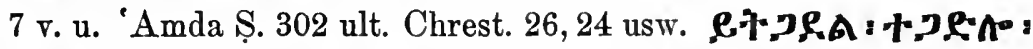
T<.6. ,indem er glänzend kämpfte“ Takla Hājm. 118 vorl.

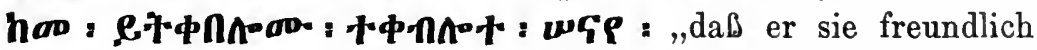
aufnehme" Šarḍa Dengel 105, 7. Hebr. Auch hier öfters innerer

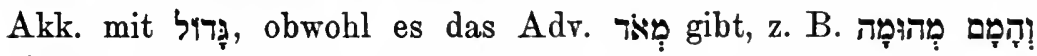

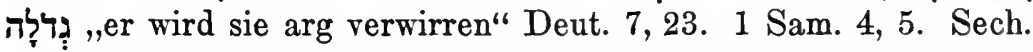

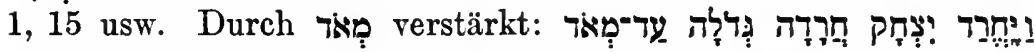

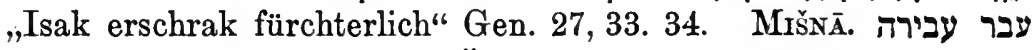
er hat die und die Übertretung begangen“ Sanh. 6, 1.

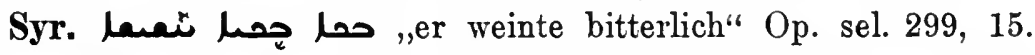

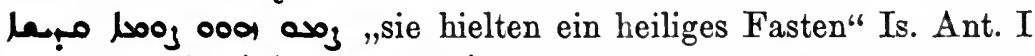
274, 500. 2er wurde zum zweiten Male geboren" Efr. I $14 \dot{7}$ ult. Ass. irrita marušta lirurušu ,mit argem Fluch mögen sie ihn verfluchen" KB I 8, 33. 46, 76. VI 186 Col. 3, 8.

Mوجِع وَجَعَهُ النى . er bekam den Schmerz, an dem er starb“ Buh. I 314, 4 v. u. er wuchs in andrer Weise 
heran als die andern Jünglinge" I. His. 105, 6. Kumait 1, 93. Appositionelle, nichtrelativische Sätze: نذرت نذرا لا يخطبها كريم „sie tat ein Gelübde, kein Edler sollte sie freien“ Hẫtim S. 116 vorl. die Emeser verfaßten unter einander ein Schreiben, sie sollten sich Jezìd nicht unterwerfen" Tab. II3 1826, 12. - Nichtrelativisch sind هزم المسلهون العدوّ هزيمة ماروا الى (die Gläubigen schlugen die Feinde (derart) in die Flucht, (daB) sie bis in ihren Tempel drangen" TTab. II2 1192, 2. Weitere Beispiele bei Nöldeke, Zur Gramm. des klass. Arabisch S. 98 und in meinen Syntakt. Verhältn. S. 509. Vulg. Srr. nāmet nōme $m i m b a^{c} d i h \bar{a} m \bar{a}$ 'àmat ,sie rersank in einen Schlaf, von dem sie nicht wieder aufstand" Neuar. Volksp. 29, 34. تجبمعنا اجتماعا لا فراق sie soll uns mit einer Vereinigung vereinigen, nach der es keine Trennung gibt" Lbd. v. Am. 116, 13. TRIP. derabtū darba bilgerābes $m \bar{a} l$, ,ich versetzte ihm einen Hieb, daß er zwischen den Sattelhölzern wankte" Trip. Bedl. 182. Aeth. §3H : EßG:

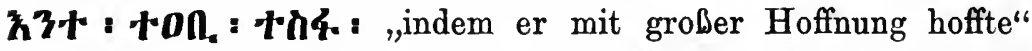
Gadla Ar. 75, 12 (vgl. die Var.) Hebr. Mišñ̄. עבר עבירה שנתחייב er hat eine Übertretung begangen, auf die hin er doppelter Todesstrafe verfällt" Sanh. 9, 4. Syr. Jorjon loo dinll lla Folge derer er aus dieser Welt schied" Addai 40, 15. Is. Ant. I 268,384 . II $48,80$.

Der Akk. durch einen Genitiv näher bestimmt: Ar. مَل مَبْل عدوّك ,er konspirierte mit deinem Feinde“ Tab. I4 1857, 4. ich hätte fröhlich gegrüßt" Ag. ${ }^{2}$ X 77, 3

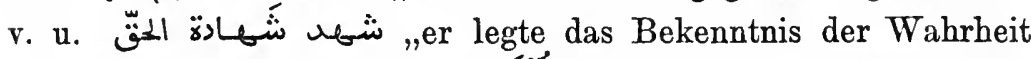

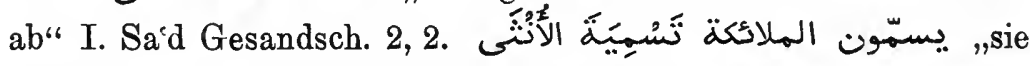
benennen die Engel weiblich" Kur. 53, 28. اعهلوا عملكم , verrichtet eure Arbeit" Ṭab. I4 1859, 5. ich erteilte ihnen meinen Befehl“ Ag. ${ }^{2}$ IX 5, 3. . wenn die Erde in ihre Erschütterung versetzt wird" Kur. 99, 1. I. Sacd Gesdsch. 16, 2. Und so öfters mit einem auf das Subj. zurückweisenden Suffix. Vulg. SYr. asīr sìrāt assrāb „ich wandere 
nach dem Mittagsdunst" Pal. Diw. 95 ult. lauman tükaf wakfitha „,wenn sie ihre aufrechte Stellung einnimmt" Pal. Diw. 120,6 v. u. ÄG. lā betihsib hisāb ezzamān ,du nimmst keine Rücksicht auf die Zeit" Spitta Gramm., Texte S. 485, 11. ištağal šuğloh ,er verrichtete sein Geschäft" Spitta Gramm., Texte S. 459, 5. Aeth.

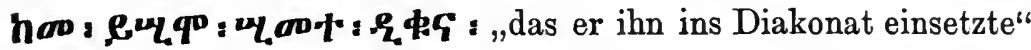

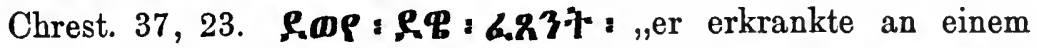

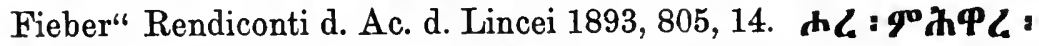

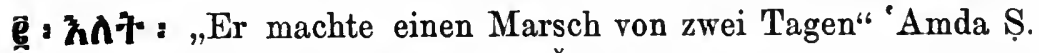
295, 1. Ferner Lal. 4, 4. 43, 10. Šarḍa Dengel 105, 35. 121, 24.

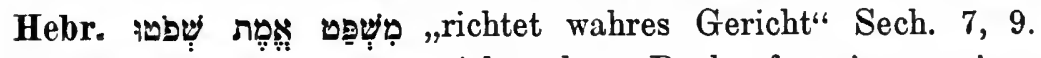
ich nehme Rache für eines meiner

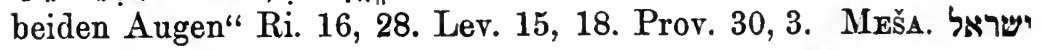
אסר את Israel war auf immer dahin“ 7. MIŠNĀ., אבד אבד עלם schließt die Männer mit ewigem Verbot aus" Jeb. 8, 3. man läbt seinen Viehbesitz

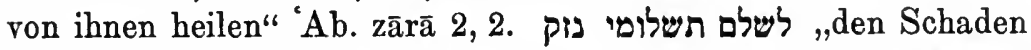
zu erstatten" Bābā k. 1, 1. Jeb. 6, 5. Ket. 1, 5 usw. Aram.

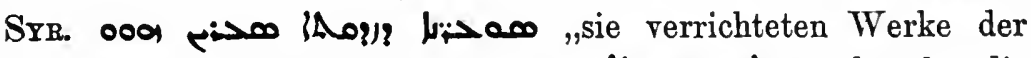

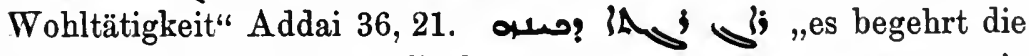
Begierde seiner Natur" Phil. 33, 14. sow ilie besorgten ihre Geschäfte" Is. Ant. I 28, 100. Afr. I 120, 1. 348,

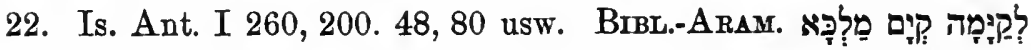

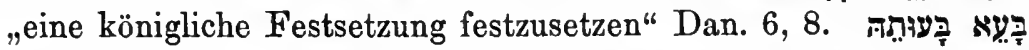
"er betet sein Gebet" Dan. 6, 14. Ass. mutu bubuti u șumi limuta „daß er den Tod des Hungers und des Durstes sterbe" KB VI 106, 29. lidlula dalelešu ,sie mögen sich unterwerfen die Unterwerfungen vor ihm" $\mathrm{KB}$ VI 34, 10. dìn mātim ana dianim "das Recht des Landes zu sprechen" Hamm. 24, 70. mașşartāni itti aḩames ninașșaru „unsere Wache haben wir mit einander gehalten“ BA IV 536, 22. nī̌ ḳäti la inašši „Erhebung der Hände erhob er nicht" Lpz. semit. Stud. III 87 No. 7 obv. 22. Ferner ebenda I6 18, 10. KB IV 60 Col. 4, 6. 142 No. 4, 20. BA II 33 Rev. 18. IV 582, 10.

Der Akk. durch einen praepositionalen Ausdruck näher be-

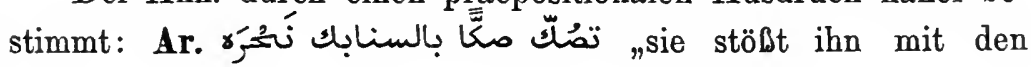


Hufen auf die Kehle" Nöld. Poesie d. Ar. 139 Z. 7. نظر نَظُرته فَى

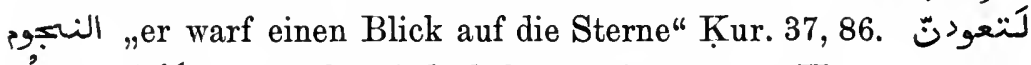
sie soll wiederkehren wie zuvor" Ham. 421, 20. Vulg. Srr. snūnu tilmá lamac bradd „seine Zähne glänzen mit widerstrahlen" Pal. Diw. 132, 2 v. u. Hap̣. jiṣorbūn essubūl şrāb biššerūn „man schneidet das Getreide mit der Sichel" 285, 18. nām nōme bala țōme "er ist in den Schlaf ohne Wiederaufstehen versunken" Spitta Gramm. Texte 478, 3. TRIP. nibki

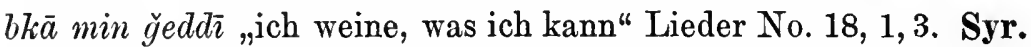

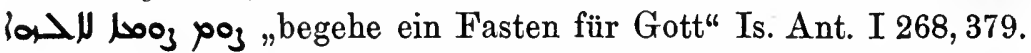
; زحما "erhebt ein Donnern im Himmel“ Efr. II 403, 19. - Meist könnte der praepositionale Ausdruck ebensogut auf das Verbum bezogen werden.

10. Das paronomast. Nomen ist nicht unmittelbar Obj., sondern bildet einen vom Obj. abhängigen Gen.:Ar. يتلونه حَقَّ تِلاوته

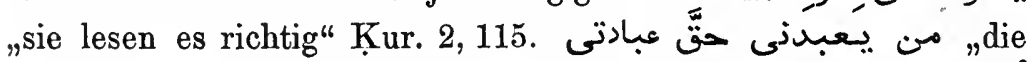

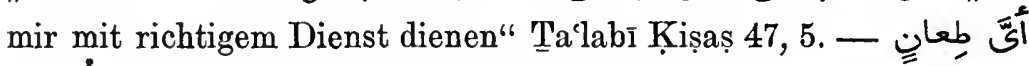
"نُطاعن "welches Durchbohren führen wir aus!" Hud. 78, 22. mit welchem Blick eines Blickenden blickte ich!" Ag. ${ }^{2} X$ 71, 7. So ferner Kur. 26, 228. Kumait 1, 80. Ham.

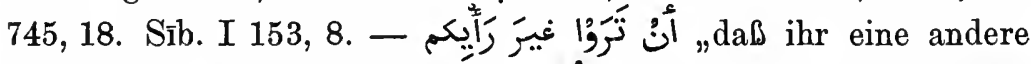

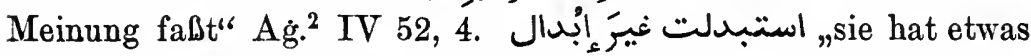
in Tausch gegeben ohne etwas dafür zu erhalten" Labīd fr. 38. Es gibt kein adverbiales

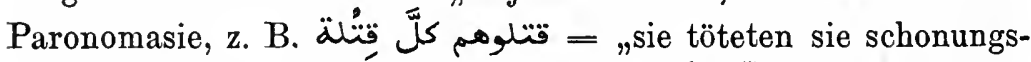

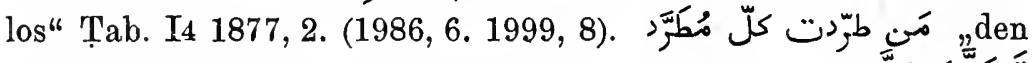

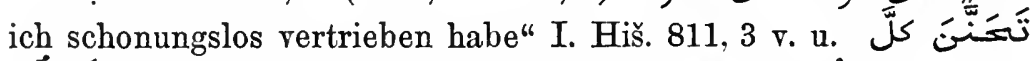
er

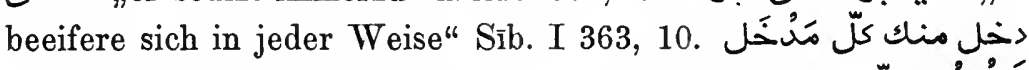

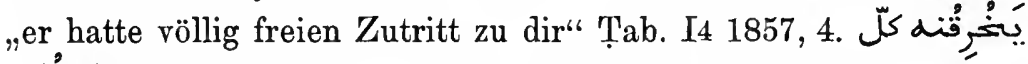
ذهـ optime se gessit“ Tab. I3 1089, 20 (s. Glossar). Kur. 6, 69. 34, 7. 18. Generell determiniert: لا تَمبلوا كلّ الهَيْبل

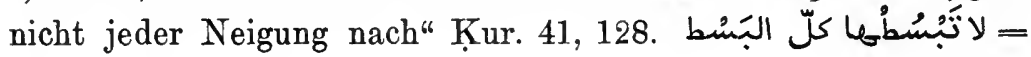


"strecke ihn nicht aufs Geratewohl aus" Kur. 17, 31. داويتـه كبل ich habe ihm jede Pflege angedeihen lassen" Nöld. Beitr. z. Poesie d. Ar. 140 Z. 2. Plural : das in jeder Weise erprobt ist" Hud. 21, 9. Nāb. 1, 20. — In Abhängig-

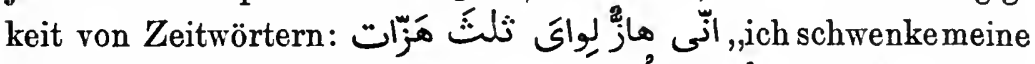

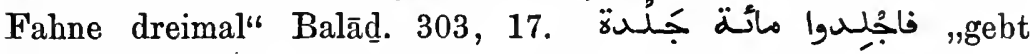
hundert Peitschenhiebe" Kur. 24, 2. - Von einem Elativ ab-

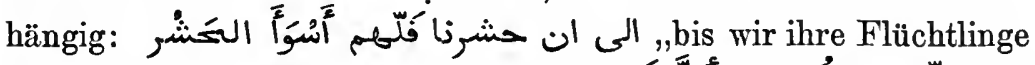

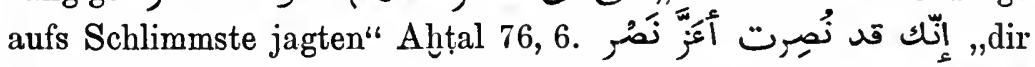
ist die kräftige Hilfe zuteil geworden" Farazdak 546, 17. فاتلماتم er bekämpfte sie aufs Nachdrücklichste“ Balādِ. 115, 10 und oft. Ferner Kur. 12, 3. Buh. III 32, 11. Tab. I2 852, 4. I4 2191, 16. er ehrte mich aufs Höchste“ 1001 N.

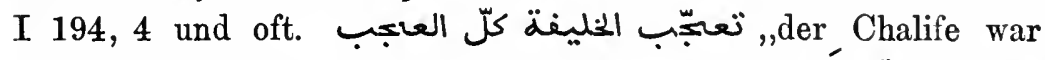

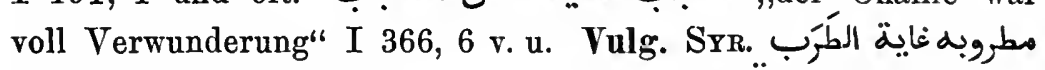
„aufs tiefste betrübt" Lbd. v. Am. 114 ult. ÄG. jeliff elmadne sab́a laffät „er umging das Mināret sieben Mal" Spitta Gramm., Texte 445, 6. Mar. siffeget ger teșfïga, sie schlug mehrmals die

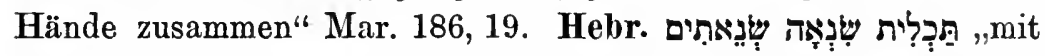

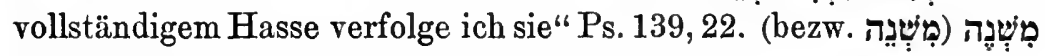
zerschlage sie doppelt" Jer. 17, 18.

10. Trotz der Emphase, die oft auf dem inneren Objekt ruht, steht es im Ar. nur höchst selten vor dem regierenden Verbum,

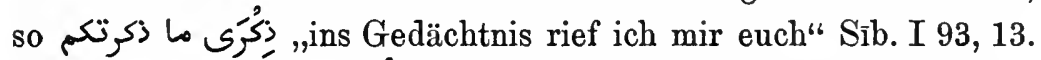
Vgl. töten tue ich nicht" Ham. 25, 21. Im Aeth. steht es dagegen oft voran, s. Dillm. Gr. $§ 181$ g. E. Ebenso stehen im Hebr. die infinitivischen inneren Objekte meist voran, dagegen die nichtinfinitivischen meist nach, s. (Ges.-)Kautzsch § 113, 3; vgl. im РнöN. "אם פתח תפתח עלת ,wenn du über mir öffnest" Tabnit 7. Im Syr. meist voran, s. Nöld. Syr. Gramm. § 296, so auch das innere Objekt zu dem einen von zwei asyndetisch verbundenen Verben (Nöld. § 338 B): 
„,zu neuem Preisen stiegen sie herab" Efr. II 429, 3, 2. BrbL.-Ar. ,Deutungen zu geben“" Dan. 5, 16.

\$ 24. Akkusativ der Vergleichung. 1. Der Akk. der Vergleichung ist ebenfalls ein effiziertes inneres Objekt; das Subj. des regierenden Verbums bringt durch sein Wirken eine Handlung hervor, die (sonst) von ihm selbst oder — und das ist weit häufiger - von einem andern Subj. hervorgebracht wird. Nur selten erscheint er nichtparonomastisch (vgl. § 23, 1), wie Ar. ستطت ihr Blick senkt sich wie das Scheuen von Kamelfüllen“ Sib. I 150, 6. er hat sie entstellt, wie man den Renner mager werden läbt" Sỉb. I 150, 9.

Beispiele für den paronomastischen Gebrauch: Ar. Gleiches a Subjekt: يَنْعُ الإنسان بالنّرّ خُعاءه بالنير der Mensch ruft das Böse,

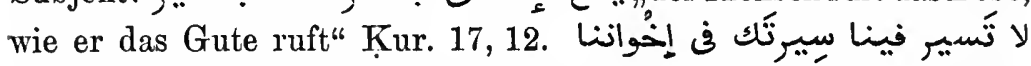
"du wirst unter uns nicht wandeln, wie du unter unsern Brüdern gewandelt bist" Tab. II1 185, 6 (Dagegen Z. 13: فيسير, فينا كما

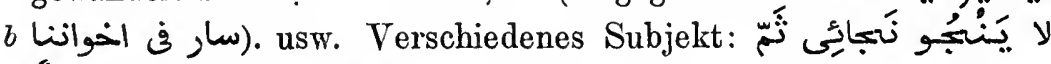
"ح ,kein lebendes Wesen entkommt dort, wie ich entkomme"

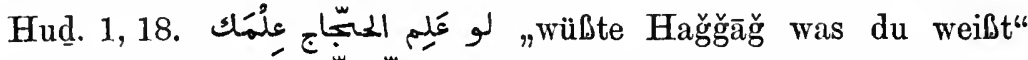

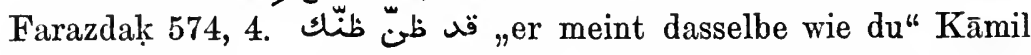
c 532, 8 usw. Oft ist aber das Subj. (Genitivus subjectivus) des Infinitivs garnicht ausgedrückt, ${ }^{1} d$. $h$. es ist ein allgemeines, unbestimmtes Subjekt, z. B. wir trieben Rabīa

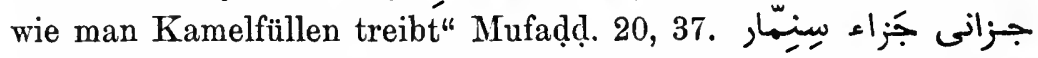
„er vergalt mir, wie man dem Sinimmār vergalt" Tab. I2 852, 4. ich will ihn knechten, wie man die Torheit knechtet" Hud. 171 Einl. 3. Ferner Tab. I5 2786, 12. $d$ Kumait 2, 20 Schol. - In dieser Weise kommen auch aktive

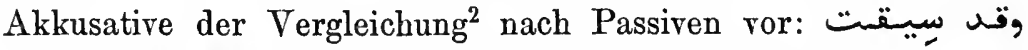
ihre Frauen waren weggetrieben wie man

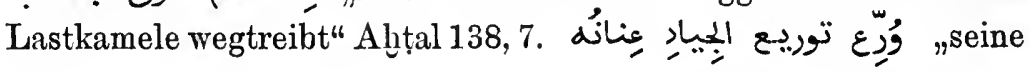

1 Wie ja überhaupt nunpersönliche" Infinitive (التيل ,قتنً ) ganz gebräuchlich sind.

2 Nicht als passive Infinitive $z$ u fassen! 
Zügel werden zurückgezogen, wie man edle Rosse zurückzieht" Farazdak I S. 99, 4. ich werde allein gelassen, wie man ein räudiges Kamel allein läßt" Mu'all. Țar. 54. Sie würden verkauft, wie man Lastkamele verkauft" Hud. 180, 5. - Unterdrückung eines anderen Satzteiles: لو تُعانِنَى شهالى عنادك ,wäre mir meine Linke verleidet, wie du verleidet bist" I. Kut. K. aššír 234, 3. طواه الأَيْيَ die Müdigkeit hat ihn mager gemacht, wie die Nächte (den Mond) mager machen" Sìb. I 150, 12.

Vulg. 'IRĀK. (b) jal timšì mišwata l'grab „O du, der du wie der Skorpion gehst" Arab. Volksl. S. 25 No. 2,1. (c) anā nšid 'alēelc nišd e $\underline{d} \underline{d} \bar{a} h i b \bar{i} n$,ich frage nach dir, wie man nach den verlorenen Kamelen fragt" Neuar. Ged. II S. 82, 2, 3. Sxr. (b) ja nāima nōm eṭtuli „o die du schläfst den Schlaf des Lammes" Pal. Diw. S. 7, c, 1. așukku șakk ilfolwa ,ich schlürfe wie das Fohlen schlürft" Pal. Diw. 39, 12 v. u. 65, 4 v. u. Arabia petr. 177, 7. (b) 'ad dabuini "adāa ithêt "sie quälten mich, wie man den Faden quält" Pal. Diw. 27,9 v. u. 7 v. u. wiruddhum radd ağğiwāzi ,und er treibt sie zurück, wie man Wild zurücktreibt" Pal. Diw. 104, 12 v. u. (346, 13). Ferner 138 Mitte. 326 Mitte. Neuar. Volksp. 31, 78. (d) mațijjät țaij ilhebäli ,gewickelt wie man Seile wickelt" Pal. Diw. 251,6 v. u. ÄG. (b) kiáad bil'adab kivi ād talabet elilm, „er setzte sich anständig, wie sich die Lernbeflissenen setzen" Spitta Gramm., Texte 483, 9. TrIp. hał̌ hašst elkeleb „er kroch heim wie der Hund heimkriecht" Lieder 14, 2, 5. Tonis. (b) şbag̉ șabġan kiüšñl „er färbte sich dunkelrot, wie sich Scharlachbeeren färben“" Märchen S. 88 Ged. 10, 4. MAR. (b) dāru bīh dour elmokjjās ,,sie umgaben ihn wie das Armband" Tlemcen 266, 36.

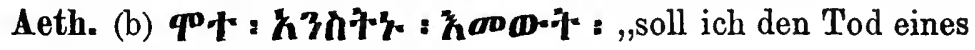
Weibes sterben?" 'Amda Ș. 387, 1.

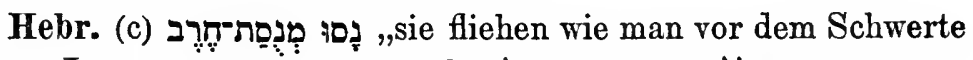

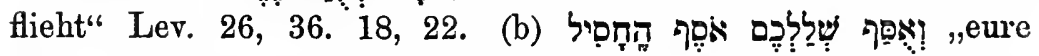
Beute wird weggerafft wie der Heuschreckenschwarm wegrafft"

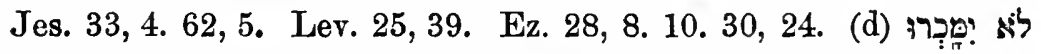
sie sollen nicht verkauft werden wie man Sklaven 


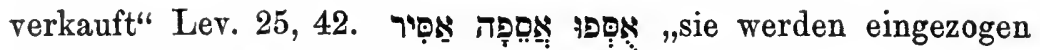
wie man einen Gefangenen einzieht" Jes. 24, 22.

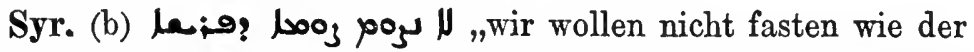

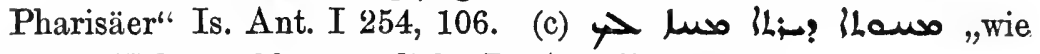
seinen Erben schlägt er dich" Is. Ant. I 190, 291.

2. Da man zur Vergleichung mit Vorliebe Bekanntes heranzieht, ist der Akk. der Vergleichung meistens determiniert, wenn auch oft nur generell determiniert; weniger häufig Ausdrücke wie er hat gewütet wie ein Frevler wütet" Nöldeke Beitr. z. Poesie d. Ar. 186, 9.

3. Natürlich steht der Akk. auch nach Verbalnomina, z. B. Ar. ich wehre die Verse von mir ab wie ein flinker Knabe einen Heuschreckenschwarm abwehrt" Imr. 11, 1. ich sehe mich tiefbetrübt nach ihnen wie die Betrübnis des Schmerzgeknickten" I. Kut. Adab 23, 3. Mas. VI, 139, 9. Und so in Nominalsätzen, wie der ein Knirschen hat wie das Knirschen der Winde mit dem Strick"

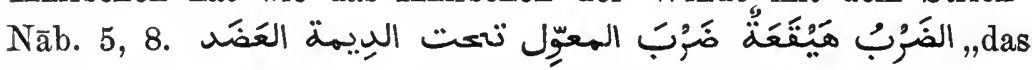
Hauen war ein Krachen wie das Hauen dessen, der unter dem Landregen Zweige abhaut" Hud. 139, 9. Vulg. Srr. uilu iț iț eddaba ",er hat ein Maul wie das Maul der Hyäne" Pal. Diw. 98, 2. TunIs. kettìt nā farde kettu kett ezzemãl ,ich grollte einmal ein Grollen wie das Grollen der Kamele" Märchen S. 94 Ged. 41.

4. Regierendes Verbum und Akk. von verschiedener Konjugation gebildet (vgl. § 23, 4.): Buh. I 60, 10 (و وضًأ VI-I). I. Kut. K. aššír 277, 9 (خلط III-VII). Imr. Mueall. 51 (خدر) VII-I). Hud. 109, 4 (شّ VIII-I). Sỉb. II 260, 16 (طوى خوى V-VII). I. His. 410, 17 (حبّ IV-I).

§ 25. Effizierte konkrete Objekte. 1. Es ist für die effizierten konkreten Objekte kennzeichnend, daß sie zwar vom Subj. mittels seiner Tätigkeit hervorgebracht sind, aber zeitlich nicht notwendig an diese Tätigkeit gebunden sind; sondern sie entstehen unter

${ }^{1}$ Siehe zur Stelle Goldziher Abh. I 872. 
Umständen einerseits erst im Laufe oder gegen das Ende der Tätigkeit und überdauern andererseits meistens die Tätigkeit und unter Umständen selbst das Subjekt; s. Brugmann, Kurze vergleichende Gramm. § 501,2. Im Sprachgebrauch ist die Grenze zwischen Abstrakten und Konkreten oft schwer zu ziehen, da fortwährend ein Übergang namentlich von Abstrakten in Konkreta stattfindet, und es nicht immer möglich ist, den einzelnen Autoren oder den Sprachgemeinschaften nachzufühlen, ob ein Übergang stattgefunden hat. Indes besteht im Gebrauch der effizierten Objekte ein wesentlicher Unterschied darin, daß die Dauer der inneren abstrakten Objekte ( $§ 23$ ) eigentlich genau mit der vom regierenden Verbum bezeichneten Handlung zusammenfällt, wogegen die effizierten Konkreta äußere Objekte sind und, wie bemerkt, weiterdauern. Die effizierten Konkreta hängen ferner gewöhnlich von natürlichen Transitiven ab.

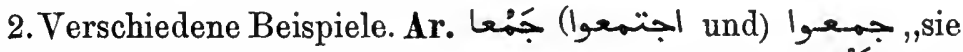

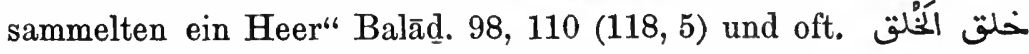
„er hat die Kreatur geschaffen" Tab. I5 2803, 10. „sie bekam Kinder“ Balād. 102, 18. حمى الجِمَى ,er hat die Gemeinweide ausgeschieden“ Tab. I6 2963, 14. ريّب السوائب ريّب رer hat Kamele frei weiden lassen" Buh. III 237,15. عبجنت عبكينى „,ich knetete meinen Teig“ I. Sacd VIII 206, 16. „sie teilten sich in zwei Teile“ Tab. I4 1873, 9.

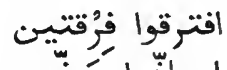
"sie stellten sich in zwei Schlachtreihen auf" Tab. II3 1392, 9. ,sie teilten sich in (verschiedene) Teile" Ḥam. 226 Vs. 4. Ferner I. Hiš. 24, 17. Țab. I4 1865, 18. II3 1428, 15. Balād. 109, 16 usw. er hat dieses Gericht zub bereitet" 1001 N. II 106, 2 v. u. Öfters sind die regierenden Verba

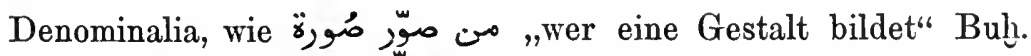

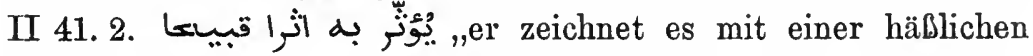

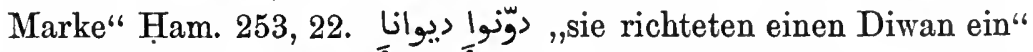

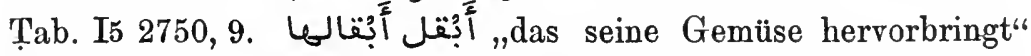
Síb. I 205, 6. sie sandte den Boten“" 'Umar 193, 3.'

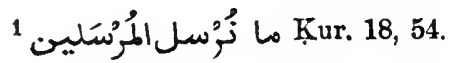


er grub einen Graben" Tab. I5 2265, 15. - Der

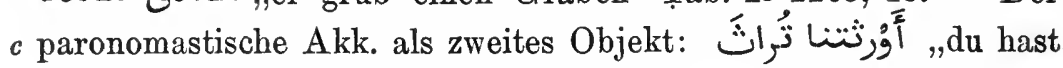
uns ein Erbe hinterlassen" Labīd fr. 14, 10. Die Paronomasie in

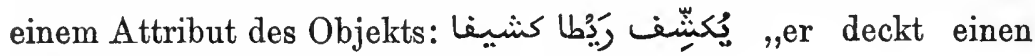
aufgedeckten Umhang auf" Hud. 18, 2.

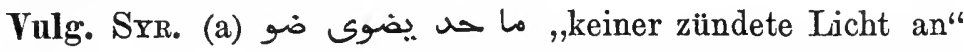
Tales 38, 15. er hat den Ehevertrag geschrieben“ Tales 59, 15. men ješwi šūa „,die einen Braten rösteten“ Pal. Diw. S. 101 Z. 12. so oft er einen Handel anfing, und so oft er ein Geschäft machte" Tales. 193, 7. Ferner Neuar. Volksp. S. 20 Prosa Z. 7. S. 26, 129. Damas 112, 9 v. u. Usw. (b) sammèt bismalla, ,sie sagte: Im Namen Allahs" Pal. Diw. 101 Mitte. ÄG. (a) wildet walad, sie bekam einen Sohn" Contes 1, 7. 11, 4. Tunis. (a) wuldet ulid „sie bekam einen Sohn“ Märchen 3, 4. isīru msìr esbar ,sie legten eine Strecke von einem Monate zurück" Märchen 15, 30. Mar.

(a) wuld wahd lwuld „er bekam einen Sohn" Houw. 30, 9. Maxt. (a) hufret ḩofra ,sie grub ein Loch" Malt. Stud. 45, 25.

Südar. (a) tenafah de nefah "mache diese Arbeit" Sok. II 244, 15. (b) šimtel de metal ,er sprach diesen Vers" II 302, 11.

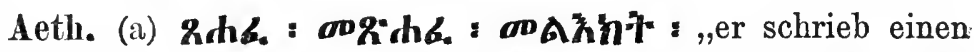

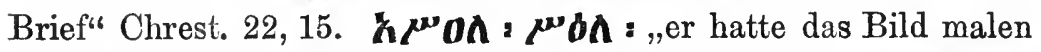
lassen" Rendic. d. Ac. d. Lincei 1893, 816, 6 v. u. Fo-hinh : గ.øhn: : „ich habe keinen Zusatz hinzugefügt" Šarḍa Dengel

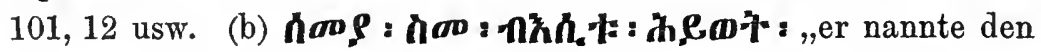
Namen seines Weibes Eva" Gen. 3, 20.

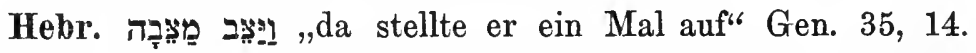

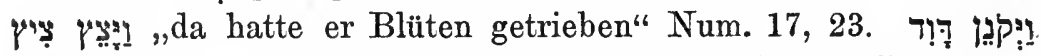
,David stimmte dieses Klagelied an" 2 Sam.1,17.

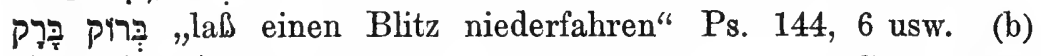

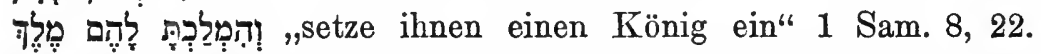
die Erde lasse Kraut hervorsprossen“ Gen. 1, 11.

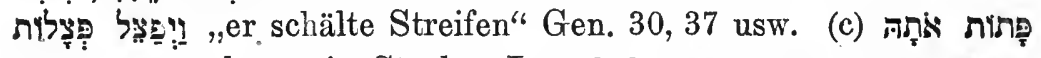

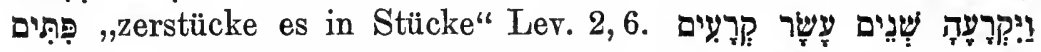

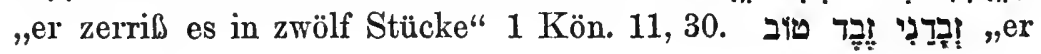


hat mir ein schönes Geschenk gegeben" Gen. 30, 20. MEšA. 'כרת

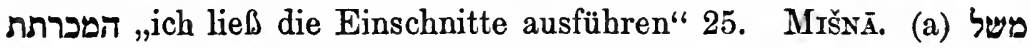
"die Weisen haben ein Gleichnis aufgestellt" Niddā 2, 5. sie haben etwas Neues eingeführt" Kēlīm

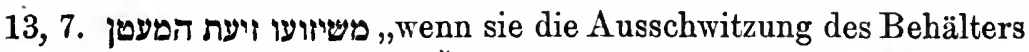
ausschwitzen" Toh. 9, 1. Šabb. 13, 2. Neg. 2, 1. Mak. 3, 6. Makš. 2, 5 usw. (b) sie bildeten Paare" Sanh. 5, 5.

Syr. (a) Sie sammeln Schätze" Afr. II 145,

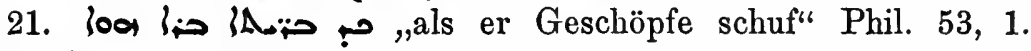

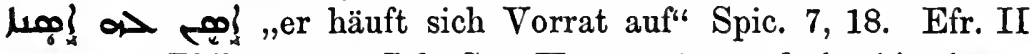

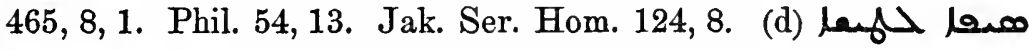
loo $ح$,er schliff ein geschliffenes Schwert" Efr. 477, 10, 8.

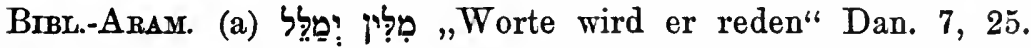
die diesen Bau bauen" Esra 5, 4. NAB. (a) ,er schreibe keinerlei Schrift" CIS 206, 4.

Ass. (a) libnäti albin ,,ich ließ Backsteine streichen" KB I 42, 75. Tiiritu ahrā ,ich grub einen Kanal" Budge-King, Annals 185, 13. šipik epri aspuk, ,ich warf einen Wall aus Erde auf" KB I 126 Col. II, 13. Ferner KB VI 40, 31. 286, 14. II 40, 16. III1 190, 53 usw. (c) isḳušu maškanu ul išakkan ,sein Einkommensrecht wird er nicht als Pfand hinterlegen" KB IV 214, 13.

3. Das paronomastische Objekt kann der Ausdruck für ein unbestimmtes Objekt sein (vgl. § 27, 2), wie Ar. أماحِب ماحبا „,ich habe keinen Gefährten“ Imr. 20, 23. A h̦țal 19, 15. So wenn das Verbum ein Kausativum und das Obj. das Partizip und dgl.

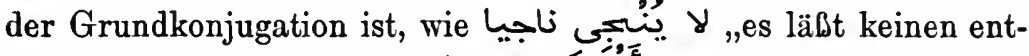
kommen" "Ant. 26, 13. und gab ihm keinen

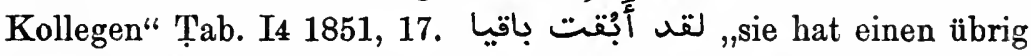
gelassen" Ag. XVII 112, 7. Ferner, wenn das Obj. ein Part. pass. ist, wie ich tötete einen" Hud. 31, 7. Buh. I

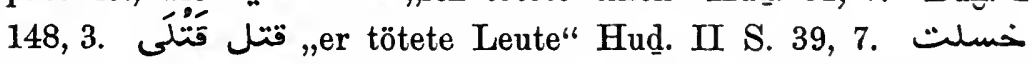

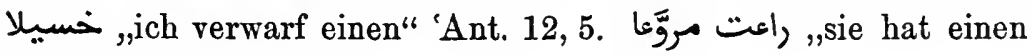
erschreckt" Imr. 37, 1.

Vulg. Sxr. kam deffannālak dafïn = ,wieviel haben wir dir versteckt" Pal. Diw. 8 Mitte. 
§ 26. Affizierte 0bjekte. 1. Der Unterschied zwischen affiziertem und effiziertem Objekt tritt deutlich zu Tage in Fällen

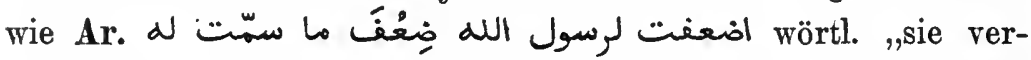
doppelte dem Boten Gottes das Doppelte dessen, was sie ihm genannt hatte" = „sie gab ihm das Doppelte" I. Sacd VIII 9, 16; effiziertes Objekt; als affiziertes Objekt würde es den Sinn ergeben: "sie gab ihm das Vierfache“. Ebenso Farazdak 468, 4. ${ }^{1}$

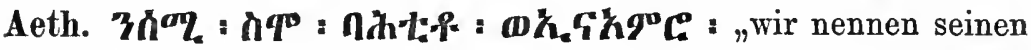
Namen nur [ = sprechen ihn aus], aber wir verstehen ihn nicht" Chrest. 18,7, affiziert; dagegen sonst (z. B. Gen. 3,20) = „einen Namen verleihen", effiziert. Hebr. allen Zehnten zu zehnten" (= zu geben) Deut. 26,12, effiziert; affiziert wäre

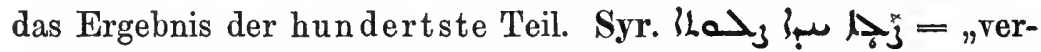
richte ein Gebet" Op. sel. 129,7, affiziert, wenn er ein bereits vorliegendes Gebet aufsagt; effiziert, wenn er es im Augenblick

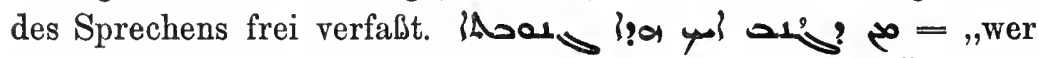
einen derartigen Diebstahl begeht", effiz. Obj.; als affiz. Obj. wäre es: ,wer etwas derartiges (durch einen Andern) Gestohlenes (diesem) stiehlt" Spic. 15, 23. Es gibt Ausdrucksweisen, deren Akk. man ohne Änderung des Sinns sowohl als affiziertes wie als effiziertes Obj. deuten kann, je nachdem man den Akk. einen Gegenstand bezeichnen läßt, der bereits vorhanden ist und durch das regierende Verbum nur seiner Bestimmung zugeführt wird, oder einen Gegenstand, dessen Charakter erst durch das regierende Verbum wirklich hervorgebracht wird, also z. B. Ar. اoمُركّنا $=$ "wir ließen Regen herabfallen" oder $=$,wir bewirkten Regen"

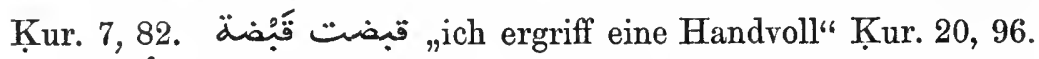
er mietete einen (gewerbsmäßigen) Taglöhner", affiziert, oder „er mietete einen(, der dadurch ein Mietling wurde)" effiziert. Buh. II 41, 12. Syr. IAsoas sow "er gab die Gabe“ Efr. II 429, 1, 4 usw.

1 Vgl.

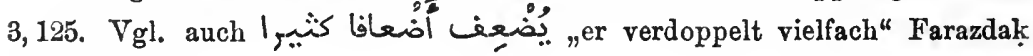
I S. 174, 6 v. u. 
2. Das Verbum ein Denominale: Ar. ich wandte

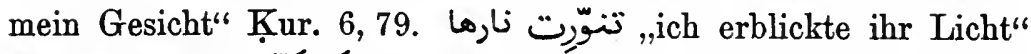
Mu’all. Hāār. 7. sie tragen seidene Unter-

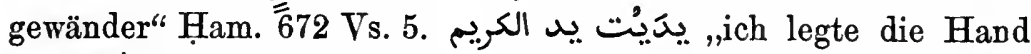
des Edeln an" Ham. 90 Vs. 1 usw. Vulg. 'IRĀK. tehattí ha hatab „die Holz sammelte“ Neuar. Gesch. 12, 10. Sxr. ḳabbalu kiible „sie wandten sich nach Süden" Pal. Diw. 27 No. 4 Str. 2. Str. 3.

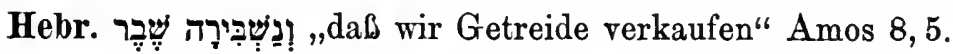

a 3: Was das Begriffsverhältnis zwischen dem Verbum und seinem affizierten paronomastischen $\mathrm{Obj}$. anlangt, so besteht z. B. in vielen Fällen ein innerer Zusammenhang derart, daß es in der Natur des betreffenden Objekts liegt die Handlung des Verbums hervorzurufen, was in mannigfacher Weise geschehen kann, z. B. indem das Objekt die Handlung in eine bestimmte Richtung lenkt, oder zu einer Anerkennung seiner Natur drängt, oder, wenn es ein Werkzeug ist, sich zum Gebrauche darbietet, oder überhaupt die Erfüllung seines Zwecks in dem regierenden Verbum findet. Bei-

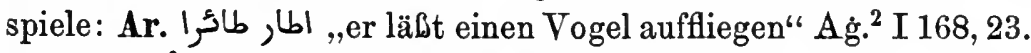

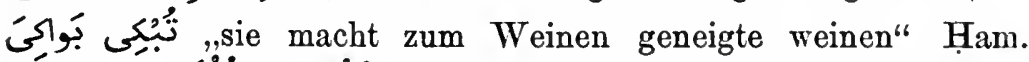

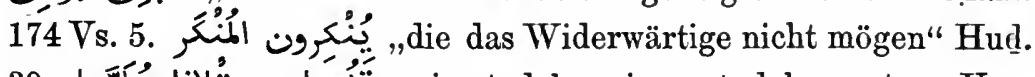

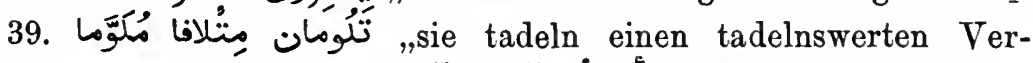
schwender" Hātim ro, 5. daß er das Recht für

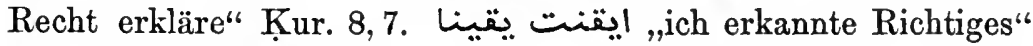

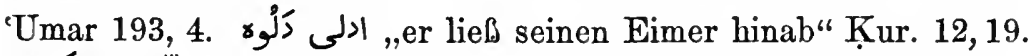
ich hätte euch Halsbänder angelegt" Farazdal I S.

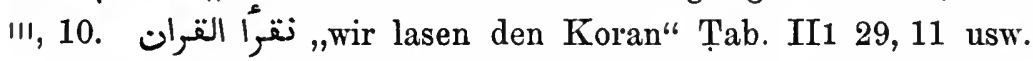

b In andern Fällen wieder übt das Objekt eine Handlung aus und bringt dadurch bei dem Subj. als Reaktion die gleiche Handlung herror, z. B. Ar. er tötete der Mörder seines Vaters" Ag. ${ }^{2}$ II 154, 16. ", wenn ich den

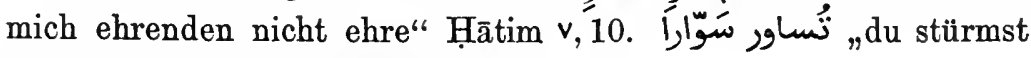
gegen einen Stürmer" Ham. 211, 2 usw.

c Eine Vergleichung und Identifizierung liegt in Fällen wie Ar. ihr habt denselben Trank wie wir getrunken“" 
Tab. I5 2281,2. أعادِى عدوّكم =,indem ich den gleichen Feind wie ihr bekämpfe" Tab. II1 36,12. Vgl. § 38, 1 .

Vulg. 'Ināk.. (b) hạaijar allāh elhaijarōnā „Gott verwirre die uns Verwirrenden" Neuar. Gesch. 30, 30. Sxr. (a) لبس لبسى er zog Derwischkleider an" Tales 74, 20. hammilu arba'in haüml „bringt 40 Lasten“ Damas 62,5 v. u. افرشى الفرشه „breite die Decke aus" Tales 77,11. (c) ošred mušrädak = ,ich vertreibe die, die du vertreibst" Ar. petr. 27,2. Censtralar. (b) min țāwal ațal minhe ,wer es einem größeren zuvortun will" 73, 13. Hap̣. (a) illi jehemmil elhamūl „der die Last trägt" 367,6. MaLt. (a) libes lipsa tare, ,er zog ein fürstliches Gewand an" Malt. Stud. 31,10. jēkol ikel taijep „er ißt feines Essen" 43, 2. ÄG. (a) libis libs ell arim ,er zog Frauenkleider an" Contes 64, 2. rikib rukubtoh "er bestieg sein Reittier" 87, 3. Tunis. (a) elmākela jākelu „das Essen sollen sie verzehren" Märchen 31, 31. MAR. (a) ta'a $a s ̌ a \bar{a}$ " $z a h$,er a sein Abendbrot" Houw. 60, 8. nelbes lebās elharìr , ich will seidene Kleider anziehn“ Tlemcen 232,5 v. u. isemmer elmesmār ,er schlägt den Nagel ein" Tlemcen 256, 4 v. u.

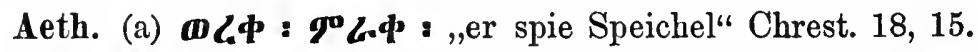

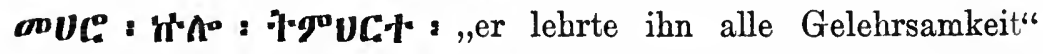

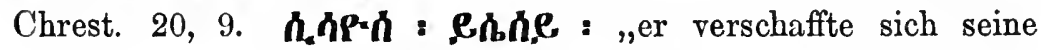

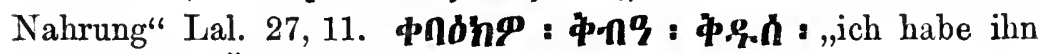
mit heiligem Öle gesalbt" Lal. 40 vorl.

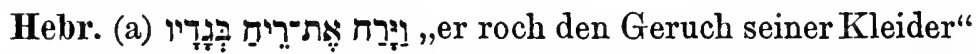
Gen. 27, 27. als er das Gerücht von Jakob hörte" Gen. 29, 13 und sonst. er setzte über

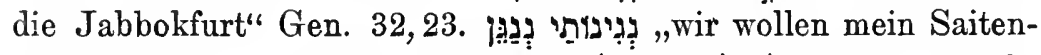

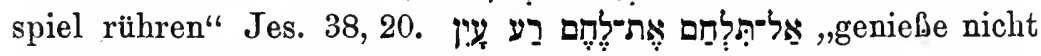
das Brot des Mißgünstigen" Prov. 23, 6. säe deinen Samen" Koh. 11,6. sie sollen den Heiligen

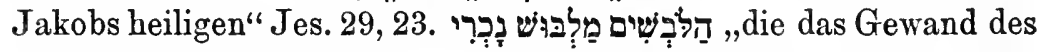
Fremden anlegen" Zef. 1, 8. Ferner 1 Sam. 26,13. 1 Kön. 8, 32. 2. Kön. 19, 7. Jes. 8, 12. Jer. 17, 21. 27. Hos. 3,1. Ob. 1, 17. Ps.

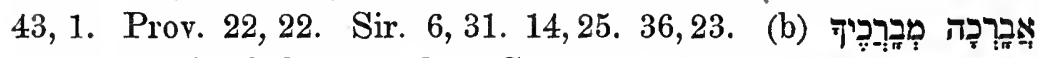
,ich segne die dich segnenden" Gen. 12,3. 
den Mörder" Num. 35, 30. Ferner Ex. 23, 22. 2 Kön. 14, 5. Ez.

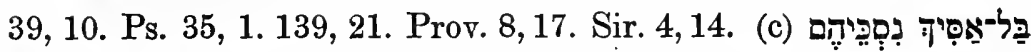
$=$,,ich gieße nicht die gleichen Trankopfer wie sie aus “ Ps. 16, 4 .

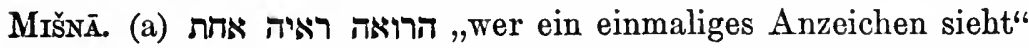
Zābim 1, 1. man öffnet ihm eine Tür" Ned. 2,1. Ferner Gițț. 4, 1. Bābā ḳ. 2,11. Sanh. 11, 6. Kerit. 3, 3.

Syr. (a) sie sollen Trauerkleider an-

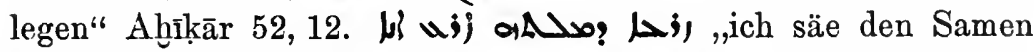
seines Worts" Addai 22,16. ich hörte das Gerücht

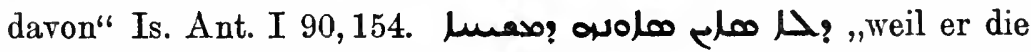

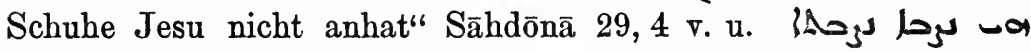
Lo;? „sie pflanzt die Pflanzen des Geistes" Phil. 51,9. Ferner Is. Ant. II 72, 108. Phil. 20,19. Spic. 15,1. Bibl.-Aram. מְלֵ wir genießen das Salz des Palastes" Esra 4, 14.

Ass. lubišti labǐ̌ ,er hat Kleidung an" KB VI 120,38. šarru akalē la ikkal „der König darf Speisen nicht essen" Lpz. sem. Stud. II1 72 No. 6 Obv. 14. lu (amelu) agru igur ,wenn er einen Mietling mietet" Hamm. 10,3. KB IV $162 \mathrm{Kol}$. 3, 13. VI 210, 4.

\$ 27. Objekt und Subjekt. 1. Verschiedene Beispiele. Ar. ل,das Herz wurde eben deswegen

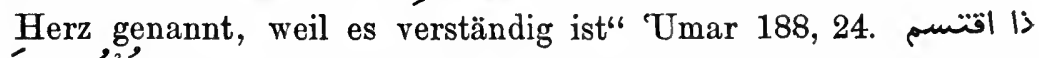
,wenn die Niedrigkeit die Niedrigen verteilt" Farazdak 365, 26. dem Tadellosen nützt die Tadellosigkeit nichts" Mu'all. Hāār. 17. sobald ihm die Boten Jezīds die Botschaft übermitteln" Tab. II1 398, 2. seine Rechte eilt dorthin den andern voran" Kuṭ. 3, 50. Ferner Kur. 2, 233. 5, 119. 24,3. Ruk. 13, 10. Wiener Zeitschrift XVIII 9 No. 1, 2. Hāatim $\varepsilon \varepsilon, 19$ usw. Aeth.

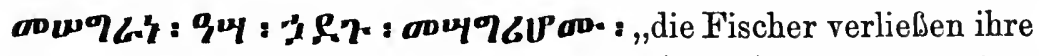

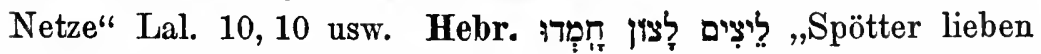

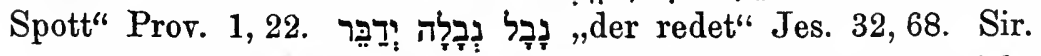

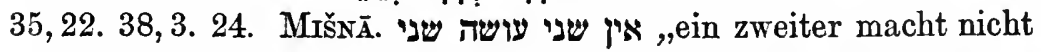

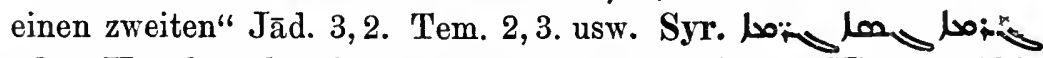
,der Knochen brachte Knochen hervor" Carm. Nis. 97, 104. ,wie viel mehr Tote wird sein Tod 
in ihm beleben" Carm. Nis. 78,136. Efr. II 399,7. Phil. 52,14. 271,19. Ass. summa awelum awelam igur ,wenn Jemand Einen dingt" Hुamm. 21, 69.

2. Das paronomastische Objekt ein unbestimmtes Objekt

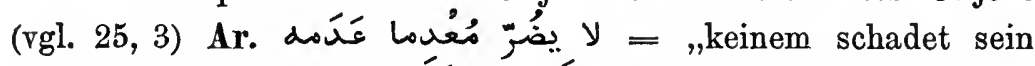
Mangel“" Tar. 19, 8. . so lange einer Gewinn zu machen sucht" Mufaḍ. 33, 2.

§ 28. Sonstige Akkusative. 1. Ortsbestimmungen. Ar. قهil Lies „wir standen an einem Orte" Balād. 94, 10. 217, 19. Bānat

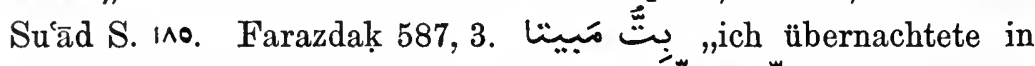

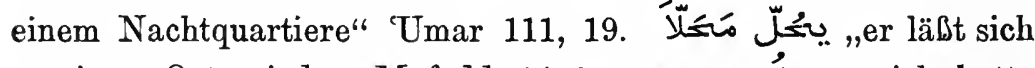
an einem Orte nieder" Mufaḍd. 14, 9. ich hatte ihn an seine Stelle gestellt" Tab. II1 70, 12. Ferner Mutalammis S. 173 Vs. 3. Tab. I4 2111, 4. I5 2285, 12. 2743, 1. 2751, 2-3.

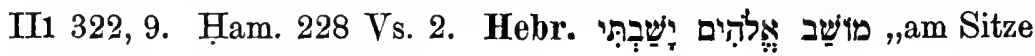
Gottes sitze ich" Ez. 28, 2.

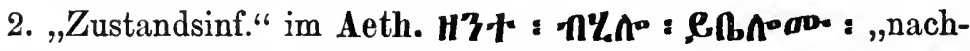
dem er das gesagt hatte, sagte er" "Amda Ș. 381, 1. Fw ZCOoDonwण 6.7 : 9.4 : ,als die Fischer gefangen waren“ Lal. 10, 10.

3. Praedikativum. Ein substantivisches Praedikativum nimmt z. B. sein Beziehungswort wieder auf und spezialisiert es in Ar. wie war ihr Feuer gut, ein Feuer für einen sich wärmenden!“ Hudِ. 95, 4. ن نüber die Länge einer Nacht, eine Nacht die nicht aufhören will" Hud. 264, 2. ein reines Wunder“ Tab. I5 2419 ult.; s. Addenda z. St. die Hölle

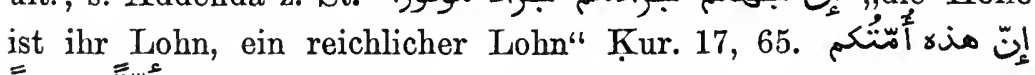
أ أمّةً , ,dies ist eure Gemeinschaft, eine einzige Gemeinschaft"“ Kur. 21, 92. 23, 54. 44, 3-4. Vgl. noch Sìb. I 159, 11. 167, 13.

Beispiele für Paronomasie zwischen Verbum und Praedikativum. Ar. أس 440, 6. die Zeit hätte vollständig gegen mich genügt" Ḥam. 145 Vs. 5. فقافئ = "da erhob er sich denn doch" Hud. II S. 71, 19. 1001 N. II 158, 5 จ. u. Hebr. 
20 er trat immer näher heran" 1 Sam. 17, 41. durch Krankheiten hinsterbend sterben sie“ 旅 "er wird als König regieren“ Jerem. 23, 5. 37, 1. Syr.

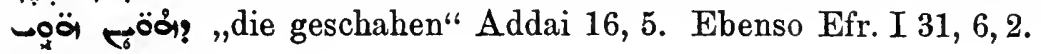
Phil. 278, 22.

Subj. und Praedikativum: Ar. die Schreiben bildeten ein einziges" = ,waren gleichlautend" Tab. I4 1881,11.unser Haus ist nicht dieses Haus" II. Hiš. 32, 13. Ferner Farazdak I r.o, 3. ZDMG XVIII 237, 2 v. u. Ḥātim rq, 9. Tab. II1 325, 17. Buh. III 427, 10. Vulg. Srr. wenn dieses Banner das des Ramad̄ān Aga ist" Lbd. v. Am. 78, 3. 32, 2. Hebr. ,alle Personen betrugen 70 Personen" Ex. 1, 5. Gen. 47, 28. MišNĀ. היה שוחט השוחט ,der Schlächter pflegte zu schlachten“"

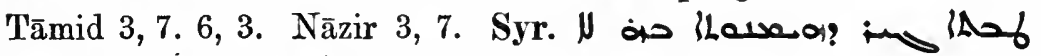
idenn etwas Gutes, womit nicht Glaube verbunden ist, wird nicht als etwas Gutes angesehen"

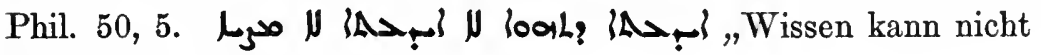
Nichtwissen werden" Op. sel. $31,6$.

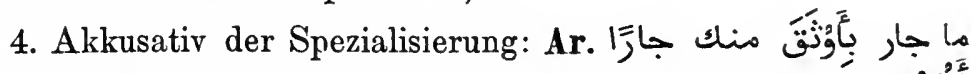

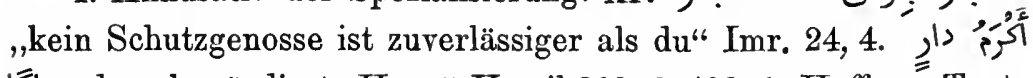
|را „das ehrwürdigste Haus" Kāmil 312, 6. 408, 1. Haffner, Texte

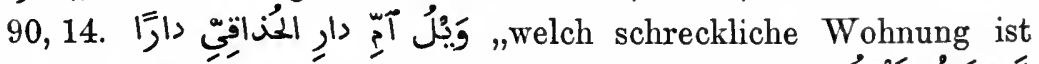

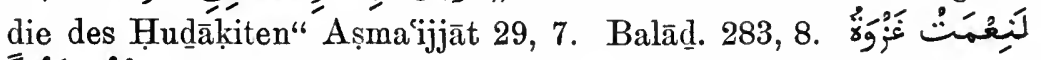

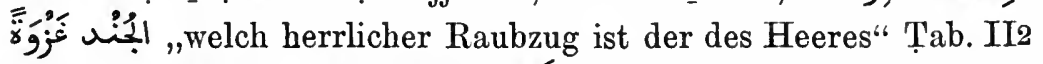

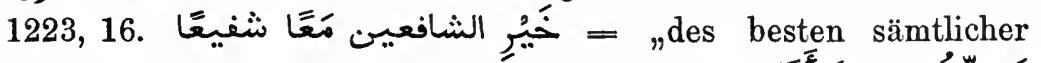

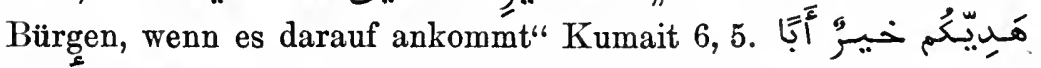
euer Gefangener hat einen besseren Vater als ihr"،

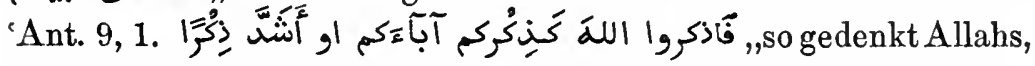
wie ihr eurer Väter gedenkt, oder lebhafter" Kur. 2, 196. 4, 79. Und so zwischen dem Elativ und dem davon abhängigen spezialisierenden Akk., wobei dem Elativ eigentlich nur noch der all-

1 Hier steht sonst bekanntlich der Infinitiv. Beide Ausdrucksweisen 2 Sam. 15, 30 a und $b$. 
gemeine Steigerungsbegriff verbleibt (vgl. $\S 31,4$ b. e.), z. B.

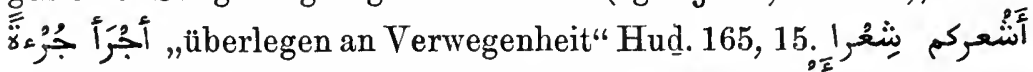

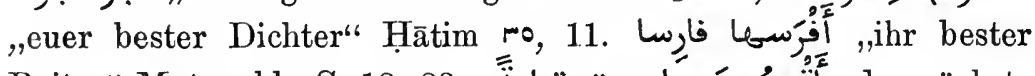

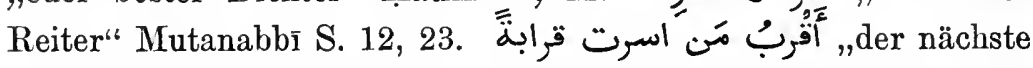
Verwandte unter denen, die du gefangen genommen hast" I. Hiš. 539, 13. . du warst der hervorragendste an Kraft" Tab. I5 2612, 14.

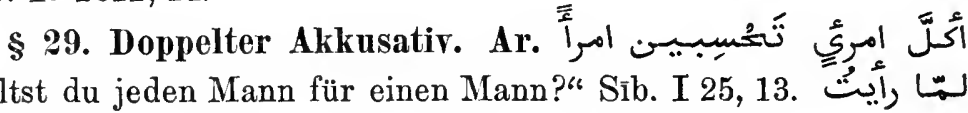

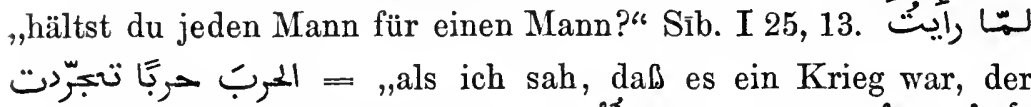

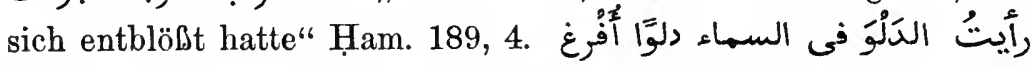
rؤ = ,ich sah, daß der Eimer am Himmel einer war, dessen Wasser ausgegossen wurde" Tab. I5 2266, 9. جعـوا يحبعلون كلَّ مرحلتَين مرحلةً

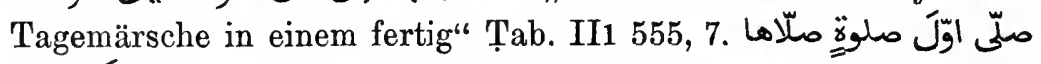
صلr verrichtete als erstes Gebet, das er verrichtete, das Vespergebet" Buh. I 18, 5. er ließ den Boten weitere nachfolgen" Tab. I4 1871 ult. Vulg. SYr. أعطِ gib dem Bäcker sein Brot“ Lbd. v. Am. 38, 13. Hebr.

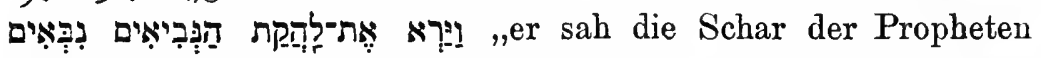
weissagen" 1 Sam. 19, 20. sie haben ihre Zeichen

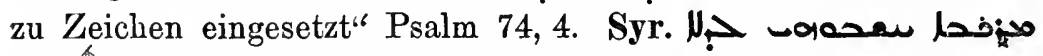

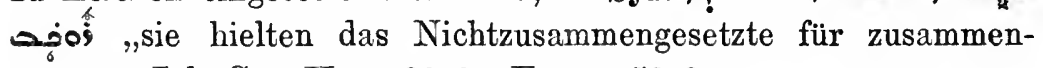
gesetzt" Jak. Ser. Hom. 22, 9. Ferner 53, 2.

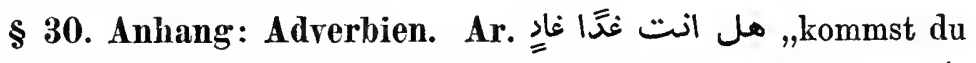

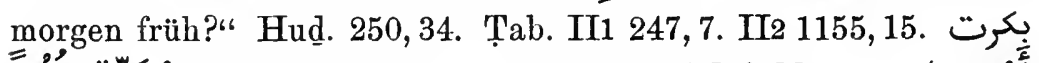

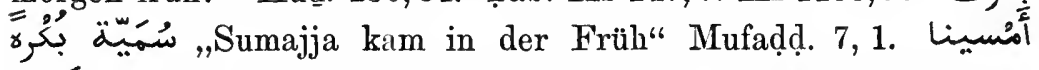

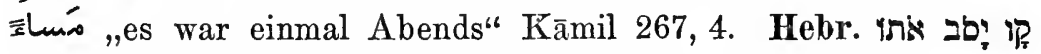

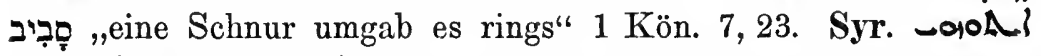
er ist ein Vater mit seinem Kinde in seinem Wesen"Phil.32,6. A

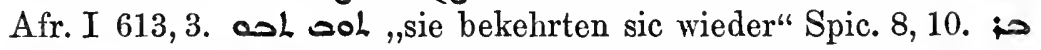
حمن Aldenn der Freiewohnte frei" Phil. 241, 18. Ass. dannan danniš ,sie war sehr stark" KB I70, 114 und öfters. 


\section{Genitiv.}

\$ 31. 1. Genitivus epexegeticus. Ar. سنةِ ثنتين وعشرين سلة „des Jahres 222 [Jahr]“ Littmann, Semitic Inscriptions $\overline{\bar{S}}$. 179 No. 8. Vulg. Mar. jōm ettimn̄ jām ,am achten Tage“ Mar. 164, 11. Hebr. im Jahre 600" Gen. 7, 11 usw. Num. 7, 72. Syr. Jwe, bos „der heutige Tag“ Ahīkāir 39, 7 .

2. Genitiv des Inhalts. Ar. Verse mit Sentenzen" Abū l'aswad Refāéijahandschr. fol. 38 b Vs. 5.

3. Genitivus possessivus. Ar. تغنَ , der Reichtum des Reichen“ Balād. 124, 16. قائبة قوب ,Eierschale eines Küch-

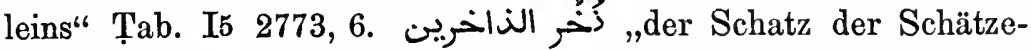
aufhäufenden" "Amr Múall. 62. Vulg. hiuml mhammel „Last

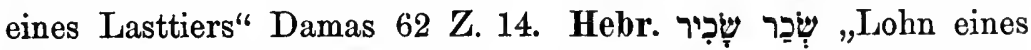

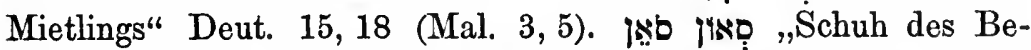
schuhten" Jes. 9, 4. Mišnā. pheilige Gegenstände aus dem Heiligtum" Jeb. 11, 5. Syr. lins? aAurs ,die körperlichen Dinge des Körpers" Phil. 122,9.

4. Genitivus partitivus. ثالِ ثلاثنة

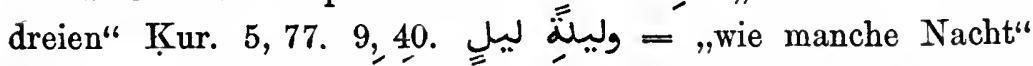
Farazdak 482, 12. 30. Morgens" ${ }^{2}$ Hुansā S. 8 Vs. 9. Ag. ${ }^{2}$ II 6, 24. Kāmil 394, 13. Tab. I5

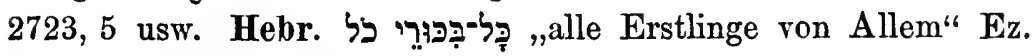
44,30. der Zehnte des Zehnten“ Neh. 10,39 (vgl. Num. 18, 26). Miš́ñ. חצי תצי ,die Hälfte der Hälfte davon“ 'Erūbīn 8,2. דופק דופקין, „der Rand der Ränder" Oh. 2,4. 'Ar. 7,4. Ter. 6,1 .

a Über superlativische Steigerung im Genit. part. s. S. 21 unten. $^{3}$

1 Eigentlich ,der Drei seiende", „der die Nummer Drei trägt".

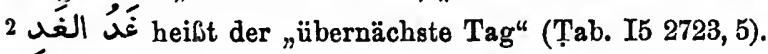

3 "König der Könige“ und Ähnliches wird Gen. obj. sein, s. unten No. 6. Das ist nicht nur ein grammatischer, sondern auch ein sachlicher Unterschied. Wenn „König der Könige" Genitivus objectivus ist, bezeichnet es cinen König, der andere Könige zu Vasallen hat; wenn es Genitivus partitivus ist, bezeichnet es einen primus inter pares. So lautet denn auch 


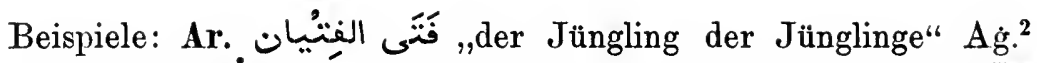

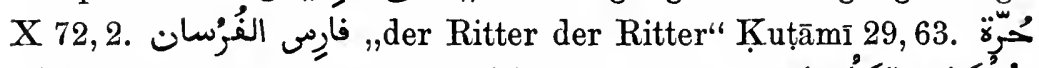

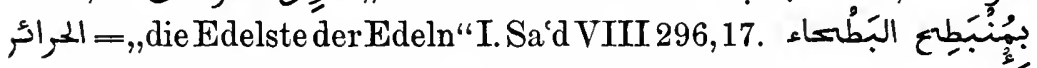

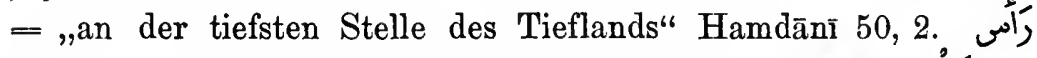

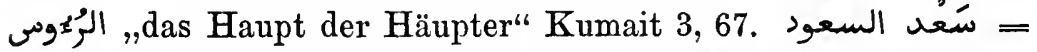
„das größte Glück" Ruk. 11,4. Weiteres Material bei Grünert, Die Begriffsverstärkung durch das Etymon im Altarabischen, S. $b 36$ ff. (Sitzungsber. d. Wiener Ak., Band 125). - Das regierende

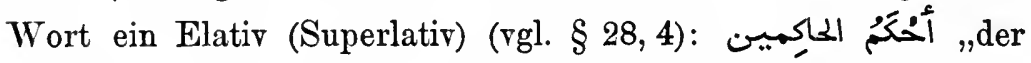
richtendste der Richter" = „der beste Richter" Kur. 11, 47. der Barmherzigste der Barmherzigen" Kar. 12, 64.

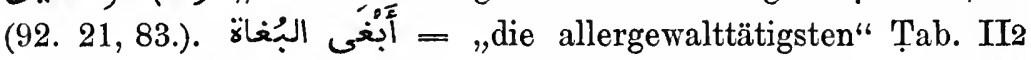

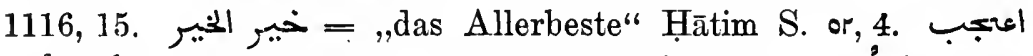

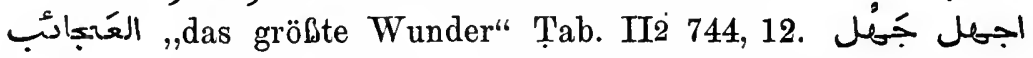
,die größte Roheit der Leute“ I. Kut. K. aššír 370, 18.

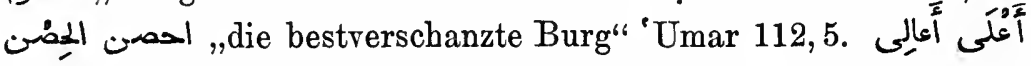
ihre allerhöchsten Kastelle" Ruk. 49, 3. S. noch unten $e$. c - Paronomasie von Eigennamen: مَنَّ الأصغار ,der Șafar der Șafare" = "der hervorragendste der Șafar(monat)e" Tab. I4

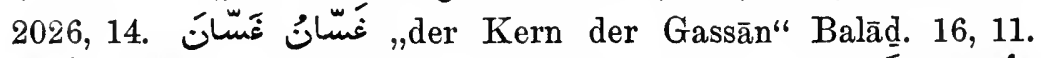

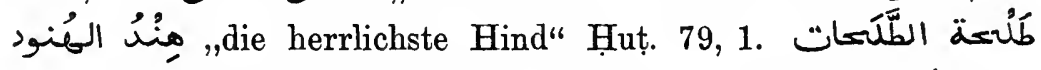
$d$ „der bedeutendste der Talhas" Ruk. 5, 1. - Der Genit. partit. bildet meistens eine determinierte Verbindung, kommt aber doch auch indeterminiert vor ${ }^{1}$, wie

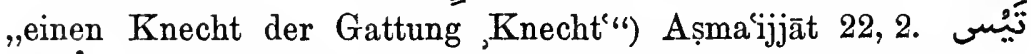
einen Bock unter Böcken" = ,einen rechten Bock" Hudِ

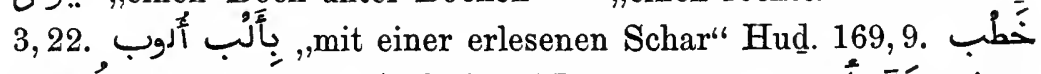

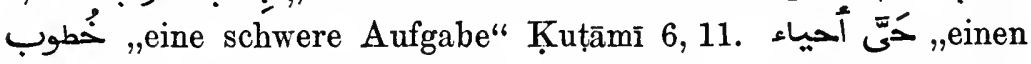
$e$ hervorragenden Stamm" "Urwa 9, 12. So mit Superlativ (vgl. b): ,der ärgste Flüchtling“ (eig. „der fliehendste der

„der Emir der Emire", wenn es indeterminiert und aufgelöst ist, اميب" ein Emir über die Emire" Balād. 109, 5. Vgl. § 33. 1 Über eine andere Form der Indetermination s. $\S 6,3$. 
Gattung ,Fliehender" ") Hudِ. 2,10. اسفل سافل "der allerniedrigste"

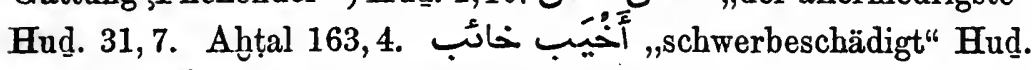
2,20. der allerniedrigste“ Kur. 95, 5.

Vulg. 'TRĀr. (c) ḩamed elhumūd „der edelste Ḥamed" Neuar. Gesch. 44, 15. Srr. (a) bedr ilbidür "der herrlichste Vollmond"“ Pal. Diw. 341 Mitte. (c) șāleh eșswālhe „der herrlichste Șāleh" Ar. petr. 93 Mitte. Maxt. (a) 'alp ta'albi "Herz meines Herzens" Malt. Stud. S. 65 No. 22, 9. ÄG. (b) abjad elbēd ,die allerweisseste" Lieder $\ddot{A} g$. Bau. 121, 1. Trup. jā rühe rūhni „Ach, Geist meines Geistes" Trip. Beduinenlieder 119.

Aeth. $ๆ 4.00,94.073$ : ,der allerschrecklichste" Šarḍa Dengel $128,28$.

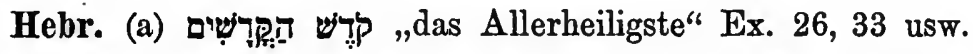

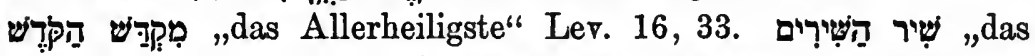
herrlichste Lied" HL 1, 1'. Himmel" Deut. 10, 14. (1 Kön. 8, 27. 2 Chr. 2, 5. 6, 18). (d) הֵָּ

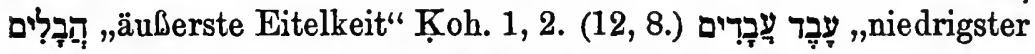

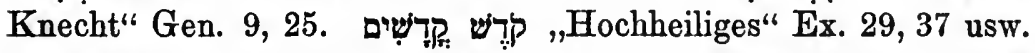
heiligste Eide" Ez. 21, 28. Usw. Die häufige Artikellosigkeit solcher Genitive im Hebräischen ist nicht immer als Indetermination zu verstehen. Es sind z. T. formelhafte, altertümliche Ausdrucksweisen, deren Typus der Zeit vor Ausbildung eines bestimmten Artikels angehört, einer Zeit, die auch sonst noch erkennbar in das geschichtliche Hebräisch hineinragt.

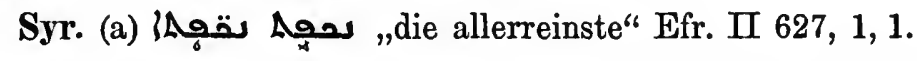

5. Genitivus subjectivus. Der Genitiv verhält sich zu seinem Regens wie ein Subjekt zu seinem Objekt. Meist ist das Regens ein effiziertes Objekt und bezeichnet die rom Subjekt hervorgebrachte Handlung. Der Genitiv ist daher oft, wie das

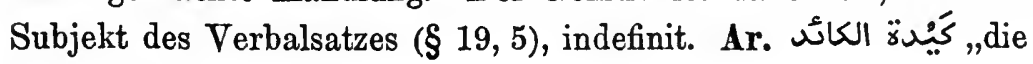

1 Der Zusatz herrlichste Lied, von Salomo". Wäre der Zusatz auf ( $n$ das herrlichste der Lieder, die von Salomo sind"), so hätte nichts im Wege gestanden zu sagen

Rookendorf, Paronomasio. 


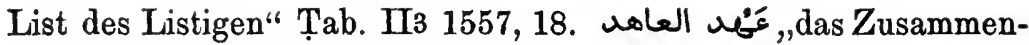
treffen Jemandes“ Tab. I5 2851, 1. شَفَفاعة الشافعين العامين ,die Fürbitte der Leute" Kur. 74, 49. انفبجار الفجبر "das Anbrechen der Morgendämmerung" Tab. II2 620, 16. Ferner I. Sa'd Gesdsch.40, 5. Sīb. I 26, 16. 'Amr Mu'all. 53, 68. Ruk. fr. 2, 2. Ham. 236, 12. 258, 14. 271,8. Kur. 2, 182. Huḍ. 242, 53. Nāb. 24, 3 usw. Der Genitiv ist hier also oft bloß generell determiniert. Indeterminierter Genitiv: داء „der Ruf Jemandes" Hudِ. 4, 6 usw. نظر ناظر ,der Blick Jemandes"

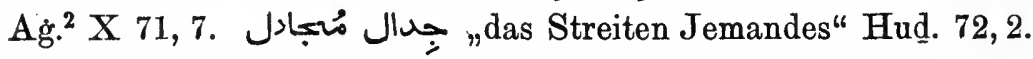
Ferner I. Hiš. 416, 19. Nöldeke Poesie d. Ar. 62 ult. Huḍ. 92, 63. 131, 3. 250, 3. 252, 30. Ḥuṭ. 60, 2. Kurur. 3, 193. 5, 59. Kāmil 734,9 usw.

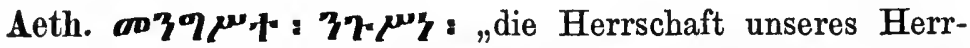

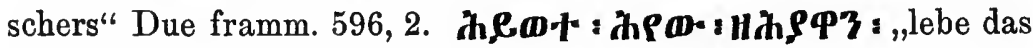
Leben der Lebendigen" Kienē XLV, 1.

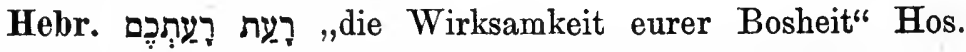
10, 151. die Gerechtigkeit der Gerechten" Jes.

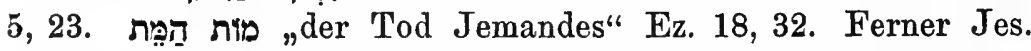
24, 16. 27, 7. 29, 14. Ez. 18, 20. 33, 12. Neh. 3, 4. Ps. 69, 10. Rut 1, 1. — - das Weib Jemandes" Gen. 20, 3. (Deut.

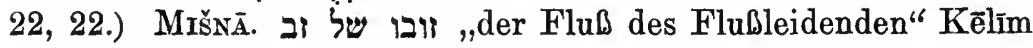

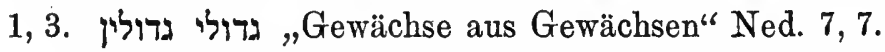

Syr. die Prophezeiung der Propheten" Addai 25, 7. "Uangel der Mangelhaften" Efr. I 171, 16. der Streit der Streitsüchtigen“ Is. Ant. I

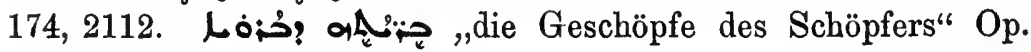
sel. $25,19$.

6. Genitivus objectivus. Ar. تَنْوِين السَواوِِين ,die Ein-

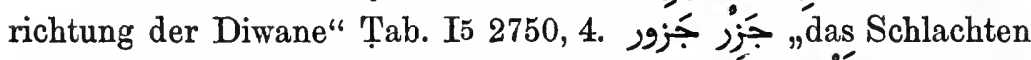
eines Schlachttiers" Tab. I5 2322 ult. die Gier

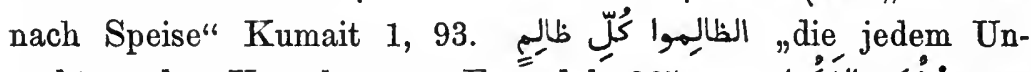

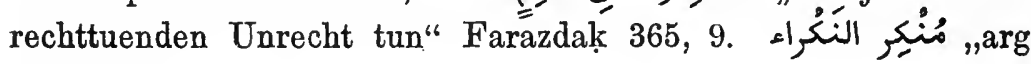

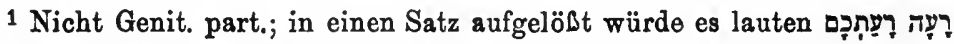

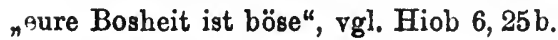


gegen das Arge“ Farazdak 468*, 29. مالك المُلك ,der Beherrscher $b$ des Reiches" Hamad̄ān̄ Rasāil S. 23, 5. - So auch (s. S. 127 Anm. 3.) نقيب النُقَبَاء "Oberster der Obersten" Balād. 6, 3. "Oberster Emir". قاضى القُضَّة "Oberrichter" usw.

Vulg. 'IRĀK. (b) mōla lmuālī „Herr der Herren" Neuar. Ged. II S. 102. No. 23, 1. Srr. (a) d. der Täter dieses Werkes" Tales 4, 3. rakkāb elerkāa ,,der Reiter auf Steigbügeln" Pal. Diw. S. 21, 8. ÄG. (b) šēh elmašäin „Scheich über die Scheiche“ Contes 97, 11. TRIP. güle hellagwāl „das Sprechen dieser Worte" Trip. Beduinenl. 176.

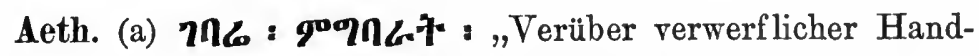
lungen" Nik. 190, 20. (b) C.h : C.h.h3: "Oberbefehlshaber" Šarḍa dengel 4, 13.

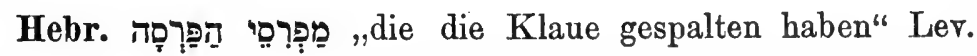

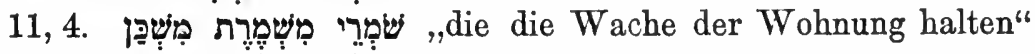

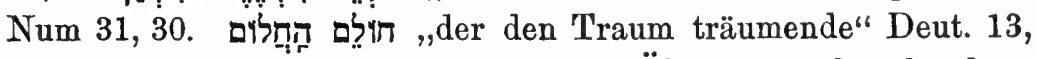

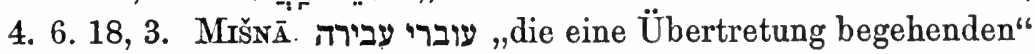
Š́ebīit 5, 9. die Ersatzleute ihrer Ersatzleute" Ber. 3, 1. Gleichnisredner" Sōțā 9, 15.

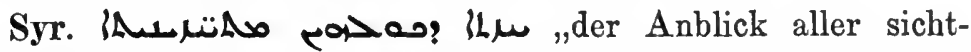

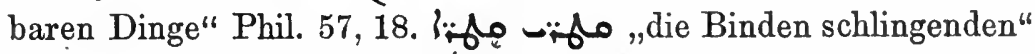

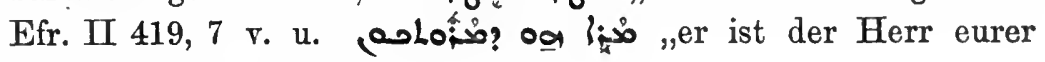
Herrschaft" Bar Șabbāè 734, 11.

Ass. mūrǐs mērištu „Pflanzung pflanzend" BA V 375, 3. pāris purussi, ,der die Entscheidung treffende" KB II 48, 57. mušim šimāti "der die Bestimmungen treffende" KB I2 70 No. 1, 6 und sonst. (šāimu šimtim KB VI 582, 9.) hiirë ḩirītišu, ,ihren Graben zu ziehen" KB II 46, 46. labān libnāte "Ziegel zu streichen" KB II 48, 58. uṣşur uṣurāte „das Bilden von Bildwerken" BA I 271 Col. III, 2.

7. Korrelative Genitivverbindungen. (Vgl. § 7, 3). Ar.

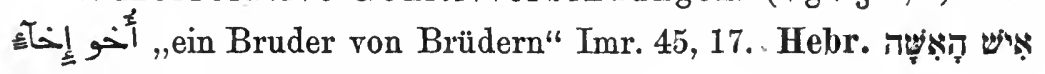
„der Mann des Weibes" Richter 20, 4. 


\section{Praepositionen.}

§ 32. Die paronomastischen Bestandteile. Unter den ziemlich mannigfaltigen Verhältnissen sollen hier jeweils nur diejenigen besprochen werden, die engere Beziehungen der Glieder aufweisen. ${ }^{1}$

1. Paronomasie zwischen dem Verbum und dem von der da-

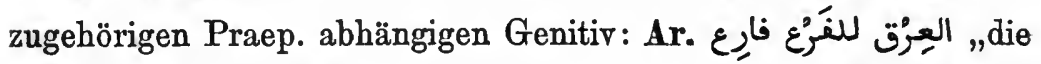

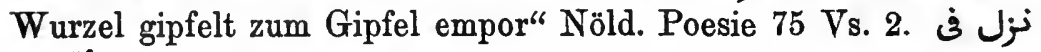
er ließ sich in der Wohnung des Abū Ajjüb nieder" I. Sa'd VIII 118,20. er tadelte mich

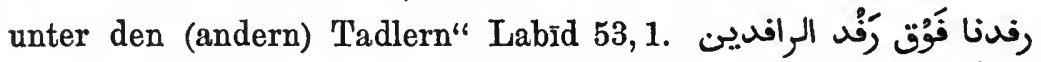
"wir halfen mehr als die Hilfe der (andern) Helfer" 'Amr Mu'all.

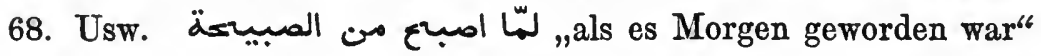
1001 N. I 86,6. Die Angabe eines Werkzeugs ist manchmal eigentlich überflüssig, wenn es schon im regierenden Verbum liegt:

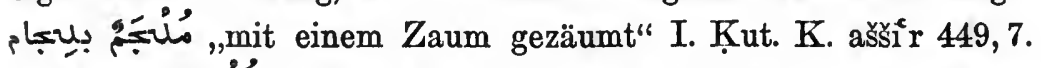
den Gott nicht mit Reichtum bereichert hat" لم يُغْنِهِ الله بالغِنى Ham. 241, 9.

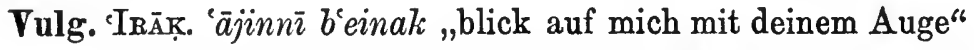
Neuar. Ged. II S. 78, 2, 1. aḥkum 'ala hilicm Mūsa, ich würde entscheiden wie Mūsa" Neuar. Gesch. 74,13. Sxr. mīlī 'amaijälitk "stütze dich auf deinen Stützer" Neuar. Volksp. S. 26, 130. ich entferne mich nicht weit" Lbd. v. Am. 20,12.

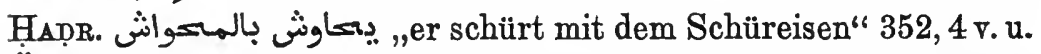
ÄG. Kaffinūha $f \bar{\imath}$ sabah̆ kafanāt "sie wickelten sie in sieben Tücher" Contes 102,3 v. u. tit'allimī 'and elméallime „du trittst bei der Lehrerin in die Lehre" Contes 106, 1.

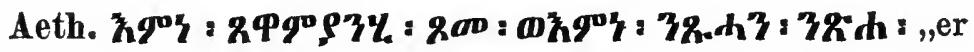
fastete mehr als die (andern) Faster und war reiner als die

1 Es ließen sich z. B, anführen Paronomasien zwischen einem praepositionalen Ausdruck einerseits und andrerseits einem Subj., Obj., praepositio-

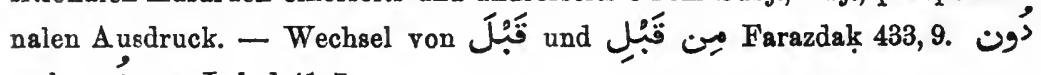

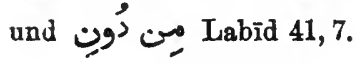




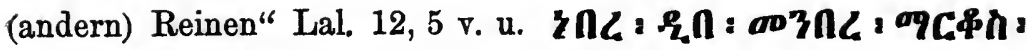
„er hatte auf dem Sitze des Marcus gesessen" Chrest. 23,4 usw.

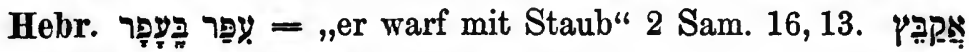
ich sammle seine Gesammelten zu ihm" Jes. 56,8 usw. usw.

Aram. SYr. wen schmerzt es infolge

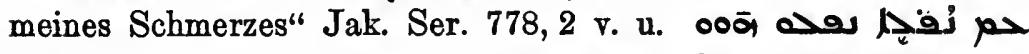
„sie fielen mit den (andern) Fallenden" Op. sel. 4, 10. سجم

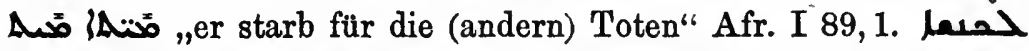
هech = ,ich schloß mich der Versammlung an" Is. Ant. I 92,168 usw. NAB. die in diesem Grabe begraben werden" CIS I 212, 2.

Ass. ša ina kanik belea kankunim "die durch einen Schein meines Herrn bescheinigt sind" BA IV 456, 8. ina šubtišu ušsab "an seinem Wohnsitz wird er wohnen" Hुamm. fr. Rs. $12 \mathrm{a}, 86$ usw.

2. Verbum und Praeposition: Ar. sie traten auf

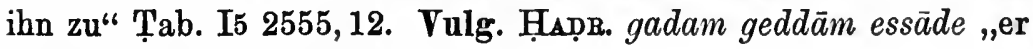
trat vor die Herren" 432, 14.

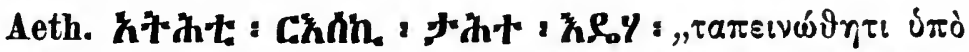

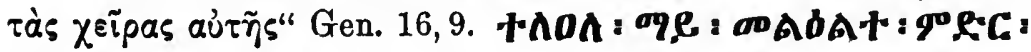

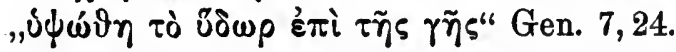

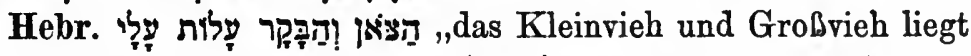

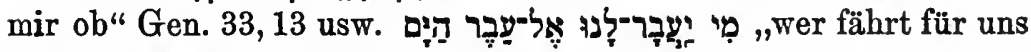
über das Meer" Deut. 30, 13.

Ass. uštamhir miḥrat apsī „er stellte sich dem Ozean gegenüber" KB VI 30,142.

3. Praeposition und abhängiger Genitiv: Ar. بعد بعدها على .,nach ihrer Entfernung" Ag. ,auf ihre Höhe" Ruk. fr. 2, 6.

4. Substantiv und attributiver praepositionaler Ausdruck ${ }^{1}$ : Ar. einen imposanten (Mann) auf

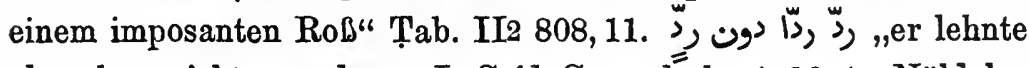
ab, aber nicht geradezu" I. Sa`d Gesandsch. 4, 26 (s. Nöldeke,

1 Hierzu gehört auch der Gebrauch von $\min$ in $\$ 6$. 
Lit. Centralbl. 1889, 1765). أَنُعارٌ جِيادٌ فوق هذا الشعر "treffliche Gedichte, (die) über diesem Gedicht (stehen)" Ág. ${ }^{2}$ VI 106, 5 v. u. "so gut wie gar nicht" Tab. U2 654,3. Hebr. Zֶwischen uns (beiden Parteien), nämlich zwischen uns (einerseits) und dir" Gen. 26, 28.

5. Korrelativ gewordene Praepositionen. Über بين „Zwischen" vgl. § $34 g$ und meine Syntakt. Verhältn. S. 238 u. Zu э

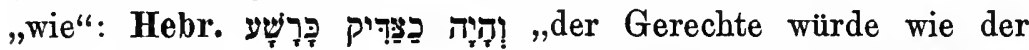

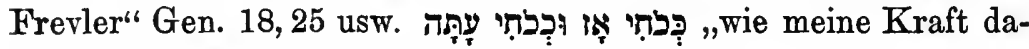
mals war, so ist sie auch heute" Jos. 14,11.

§ 33. Besprechnng einiger Praepositionen. 1. $b i$ "mit". Der praepositionale Ausdruck ist hier oft sinnverwandt einem inneren Objektsakk. in dessen verschiedenen Verbindungen (s. § 23-25), vgl. Syntakt. Verbältnisse § 103., z. B. Ar. يصلّون بصلاته sie beten wie er, machen Rek'as wie er und werfen sich nieder wie er" I. Hanbal I 270, 7. ,er tat einen Wurf nach mir" Ag. ${ }^{2}$ XI 111,4 v. u. لer wolle den schönsten

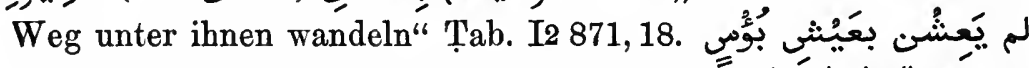
,sie führen kein elendes Leben" 'Umar 88, 7. يغتالها باغتيَيال ",er holt sie im Laufe ein" Hud. 92,40. I. Sa'd Gesandsch. 20,18. 43,22. Ahțal 163,4. Kur. 3,32 usw.

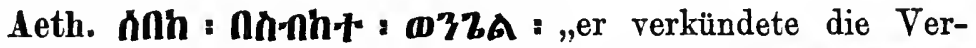
kündigung des Evangeliums" Chrest. 17 ult. h7中nn-ao-:

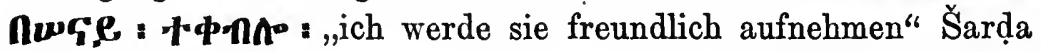
Dengel 136,30.

2. 'ălà ,auf" in steigerndem Sinn, s. S. 45 u.

3. $f_{e} \bar{\imath}$,in" sinnverwandt einem Akk. der Spezialisierung (§ 28): Ar. sie sind die mildesten hinsichtlich der Milde" Kumait 1,41.

4. ka „wie". In ضرب كزيد „er schlug wie Zeid“ ist ka eigentlich ein pronominaler innerer Objektsakk. der Vergleichung, „er schlug Das Zeids"; würde man für $k a$ das dadurch vertretene Nomen einsetzen, so würde der Satz lauten ضرب ضَرْبَ زيد, „er schlug das Schlagen Zeids" (§ 24); s. über $k a$ Fleischer, Beitr. 
VI 49 ff. Unter Umständen ist es nun unumgänglich, zu $k a$ auch noch das dadurch vertretene Nomen hinzuzufügen, sodab Paronomasie mit dem regierenden Verbum entsteht. Ein solcher Fall von notwendiger Paronomasie tritt ein, wenn $k a$ ein Genitivsuffix regieren müßte, was bekanntlich nicht möglich ist, also مَ وَجَنَت مicht empfand wie meinen Schmerz [= wie ich] die Mutter eines Kamelfüllens" "AmrMu'all.19. Ferner, wenn "ك vor eine andere Praepos. zu stehen käme, wie in طافوا به كطوافهم جالكعبة $=$,sie umzogen sie wie die Kaba" I. Hiš. 51,16. .

Aber auch schon die bloße Deutlichkeit läßt manchmal das paro* nomastische Verfahren wünschenswert erscheinen, wie in

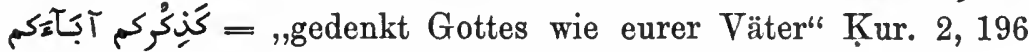
(

Oft ist jedoch die Paronomasie frei gewählt, wie in sie geht wie der Trunkene“ Imr. 19, 10. 41. 4, 52. I. Hiš. 39, 14. Ag. ${ }^{2}$ VI 102, 10. Mufaḍd. 34, 28. Usw.

Ohne ausgedrücktes Subjekt (wie § 24,1c): تطلب ابن عتيل

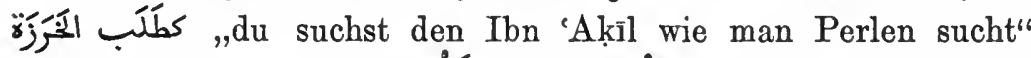
Tab. II1 240, 1. meine Seite wird

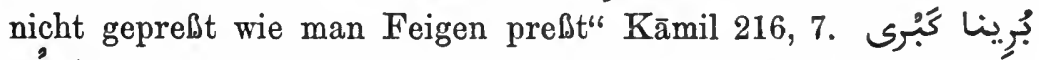
حir sind geschnitzt, wie man Pfeile schnitzt" Kumait 4, 26.

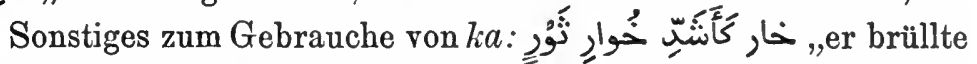
so laut wie ein Stier nicht lauter brüllen kann" Tab. I4 1862, 3. darauf kämpften die Leute so heftig wie nur je Leute gekämpft haben" Tab. П2 656, 5.

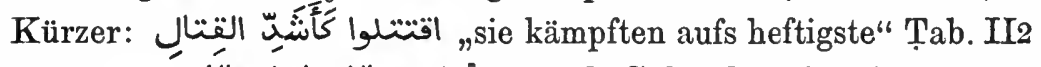

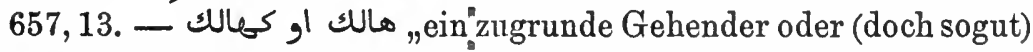
wie ein zugrunde Gehender“ Tar. 10, 8. نin , ناضب او كناضب, weitgedehntes oder (doch sogut) wie ein weitgedehntes" Ruk. 9,8.

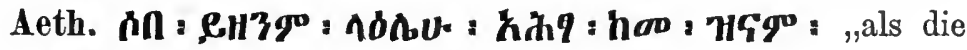
Pfeile wie der Regen regneten" 'Amda Ș. 400, 4 v. u.

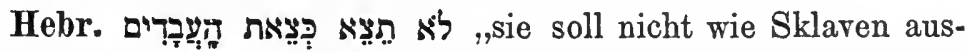

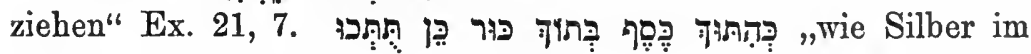

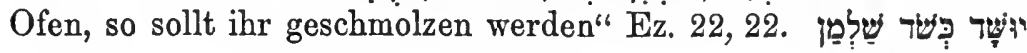


sie werden verwüstet wie Šlalman Bēt Arbēl verwüstet hat" Hos. 10, 14. Ferner Ps. 68, 3. Jes. 19, 14. 25, 10. Usw. -

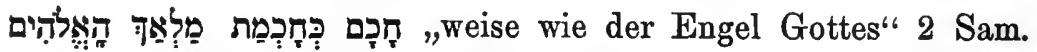

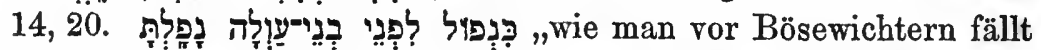

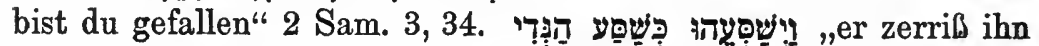
wie man ein Böcklein zerreist" Richt. 14, 6. Jes. 9, 2. 10, 14. 30, 14 usw. sie freuen sich vor dir wie in der Ernte" Jes. 9, 2. 2 Sam. 3, 34. Ez. 23, 44. Sach. 12, 10. Hiob. 13, 9. MıŠNĀ. מטמא כטומאת נבלה ,es verunreinigt wie ein

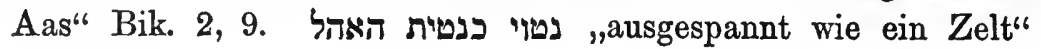
Oh. 7, 2.

5. $m a^{e} a$ führt öfters diejenigen Dinge ein, die die gleiche Handlung wie das Subjekt ausführen, z. B. fallt mit den Niederfallenden nieder" = „fallt mit den andern nieder" Kur. 2, 40. فنحخُهُل مع الخغامل, daß wir mit dem andern im

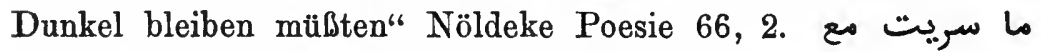
"solange ich mit einem reise" Hansā 64, 2.

6. li sinnverwandt einem Akkus, beziehungsweise einem Geni-

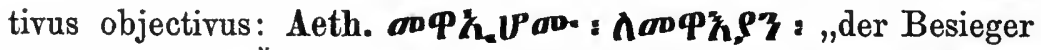

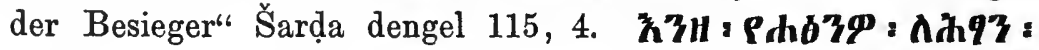
"indem sie das Kind aufzogen" Chrest. 33, 17. Ћ37No: ด72. Due framm. 591, 6. Hebr. sie werden ihre Fort-

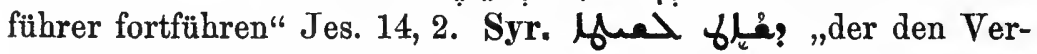

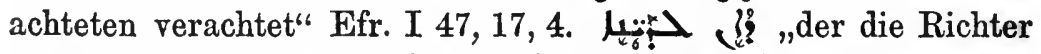
richtet" Efr. I 569, 5, 1. er reinigte die Reinigung der Erstgeborenen" Efr. II 501, 13, 2. I 43, 3,4. 155, 8. 259, 2. Phil. 350, 2.

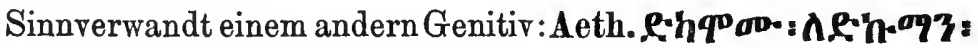
„die Schwachheit der Schwachen" Šarḍa dengel 126, 15. 137, 21.

\section{Beiordnung.}

a $\$$ 34. Wiederholung von Ausdrücken. Die Wiederholung eines Bestandteils in beigeordneten Gruppen hebt die Deutlichkeit 
und ist sogar manchmal aus diesem Grunde unerläßlich, z. B. Ar.

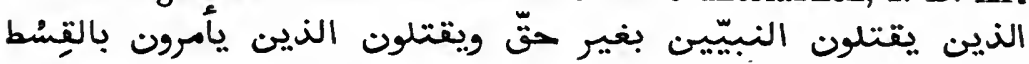
"die die Propheten widerrechtlich töten und die Leute töten, die die Wahrheit anbefehlen" Kur. 3, 20. يومَ يهوت ويوًَ يُبْعَت ,an dem Tage, an dem er stirbt, und an dem Tage, an dem er wieder er-

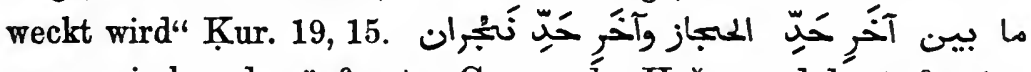
,was zwischen der äußersten Grenze des Heğāz und der äußersten b GrenzeNeğrāns liegt"Balād. 103,19. Oft in Maß-undZahlenangaben, wie zwei Maß Öl und zwei Maß Honig und zwei Maß Essig“ Balād. 215, 1. I. Sacd. Gesandsch. 28, 14 usw. So wird auch in zusammengesetzten Zahlen oft der gezählte Gegenstand bei den Bestandteilen des Zahlworts wiederholt, wie 1500000 Dinare“" c Balād. 227, 9. I. Hiš. 4 ult. usw. - Wiederholung des Verbums bei nachdrücklicherer Gegenüberstellung: تح بايع الناس وبايع قومك =, sowohl das Volk wie die Deinigen haben gehuldigt" Tab. I4 1844, 1. ich bin in ihren Kinderjahren mit ihnen zusammengewesen und bin in ihren Mannesjahren mit ihnen zusammengewesen" Tab. I6 3329 ult. Šrammāh pflegte die Seinen zu schmähen und seinen Gastfreund zu schmähen" Ag. ${ }^{2}$ VIII 99,

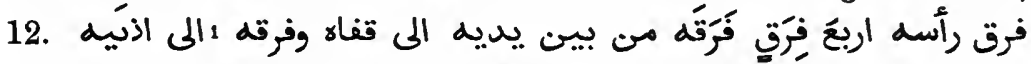
„er hieb seinen Kopf in vier Stücke; er zerhieb ihn von vorn nach dem Hinterkopfe zu und zerhieb ihn von Ohr zu Ohr" Tab. Is 2351, 14. Kur. 4, 63. 73. 48, 11. Ḥātim єr, 14. Balād. 116, 4 flg. $d$ Tab. II2 846, 8 usw. - Wiederholung eines Verbums z. B. in der Konstruktion بr er brach in Tränen aus oder doch

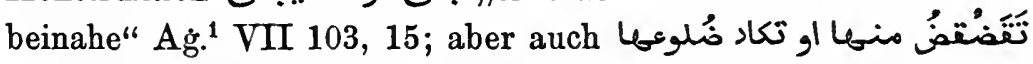
„,von der ihre Rippen springen oder beinahe (springen)“ Nāb. 18,4.

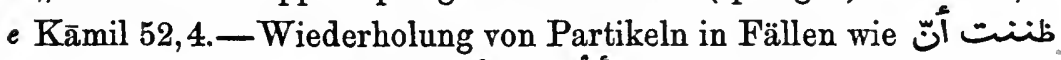
ich glaubte, die Leute wollten mich festnehmen und die Sache sei ihrer Meinung nach nicht wie . . " Tab. II1 41, 13 usw. لينظر اين انتطى واين

1 I. Ḥubaiš ع statt الم 
يريد, damit er sehe, wohin er gelangt sei, und wohin er wolle" $f$ Tab. II1 57, 16. - In der Beiordnung von Eigennamen, die mit usw. gebildet sind, wird der $g$ status cstr., als zum Eigennamen gehörig, wiederholt. Inwieweit sonst ein gemeinsamer status constructus koordinierter Genitivverbindungen wiederholt wird oder nur einmal vor die koordinierten Genitive gesetzt wird, bleibt oft dem individuellen Belieben überlassen, denn nicht immer besteht ein so greifbarer Bedeutungs-

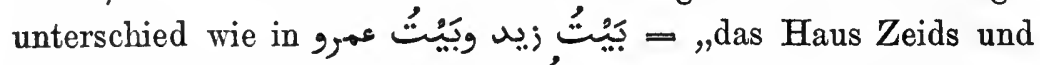
das Amrs" gegenüber بين = ,das (gemeinsame) Haus $h$ Zeids und Amrs". Auch die Wiederholung und Nichtwiederholung von Praepositionen ist oft willkürlich (الى زيد والى عمرو); die proklitischen Praepositionen werden häufiger wiederholt, aber bekanntlich kann sogar بين, "zwischen“ wiederholt werden, was eine freie Paronomasie ist, wenn Substantive zu koordinieren sind, wogegen es eine notwendige Paronomasie ist, sobald einer der beiden Genitive ein Suffix ist بين زيد وبينك), بwischen Zeid und dir"); letzterer Fall, der also schon ursemitisch ist, wird denn auch den Ausgangspunkt der an sich schiefen Ausdrucksweise $i$ gebildet haben (vgl. noch $\S 32,5$ ). Wiederholung von أَّ s. meine $k$ Syntakt. Verhältn. 488 Mitte. Unerläblich ist die Wiederholung des st. cstr., wenn der eine der Genitive ein Suffix ist. -

Vulg. Srr. (c) midri bālhum midri salūni, ,ich weiß nicht, bin ich in ihrem Sinn, ich weiß nicht, haben sie mich vergessen" Pal. Diw. 69 Mitte. 106 Mitte. 318, 10 v. u. Ferner Lbd. v. Am. 120, 4. 12. 122, 15. Mar. (c) dāz jom dāz jōmain, dāzu tlāta ,es verging ein Tag, es vergingen zwei Tage, es vergingen drei" Mar. 166, 1. Houw. 36, 10. 38, 9.

Südar. Sor. (c) belegihi lemkedyah wabelegihi lemitho „er hatte sie um einen Kochtopf geschickt, und er hatte sie um Salz "geschickt" II 81, 17. 140, 26. 172, 8. 292, 25.

Kanaan. MEšs. (c) אנך בנתי קרחה ואנך בנתי שעריה ואנך בנתי ich habe Korha erbaut, und ich habe ihre Tore erbaut,

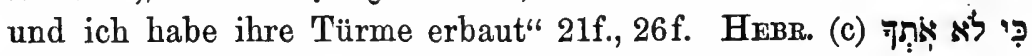

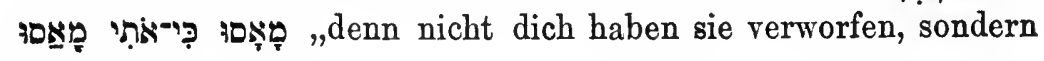


mich haben sie verworfen" 1 Sam. 8, 7. (d) 1 Kön. 20, 31. 2 Sam. 15, 21.

Syr. (d) ? Nöldeke, Syr. Gr. § 369.

§ 35. Verstärkung durch Doppelsetzung. 1. Die Doppelsetzung (vgl. noch S. 70) ist entweder subjektiv verstärkend und bezeichnet den Affekt des Sprechenden oder objektiv verstärkend und steigert die Quantität oder Qualität des Wortbegriffs.

So bezeichnet die Doppelsetzung die Überzeugung von der $a$ Gewißheit einer an sich auffallenden oder unwahrscheinlichen

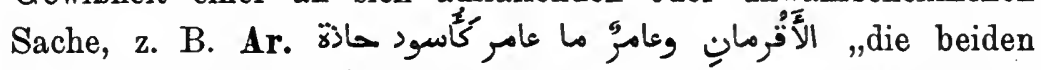
Aḳrame und 'Āmir, 'Āmir! waren wie die Löwen von Hāạa" Hud.

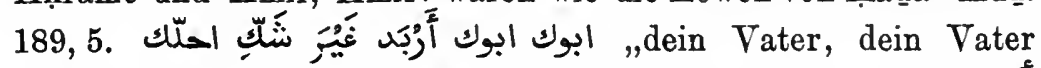

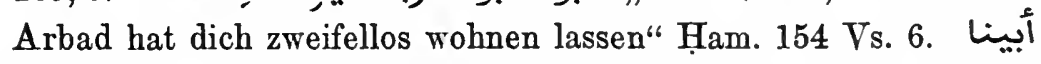
ابين "wir wollen nicht, wir wollen nicht" 'Ant. 26, 8. I. Hiš. 122, 1. 449, 1. Ḥātim 1 , 6. Ag. ${ }^{1}$ VII $99,8={ }^{2} 93,21$. Hud. 268, 2. Tab. II2 1054, 14. ich werde es zu dir, zu dir führen“ Nāb. 29, 6. بنو الرَّيان لا ياتون لا له لdie Banū $b$ rrajān kommen nicht, nein" Labīd fr. 42, 1. - Als Ausdruck der

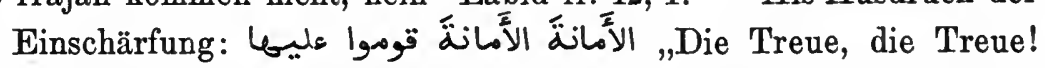
Haltet fest an ihr“ Tab. I5 2803, 11. Zurück, zurück!“ 'Amr Mu'all. 73. erwachet, erwachet!“ I. Hǐ. 231,

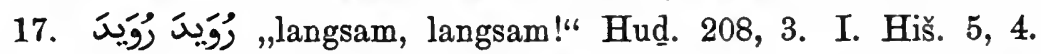
Tab. 14 1846, 9. 1001 N. II 30,4-3 v. u. 33, 2 usw. Es läbt sich nicht immer ausmachen, ob die Wiederholung der Ausdruck einer eifrigen Aufforderung (subjektiv) oder einer Aufforderung c zum Eifer ist (objektiv). Wiederholung eines Vokativs, ${ }^{1}$ z. B. an der Spitze aufeinanderfolgender Sätze Hud. 9, 1f. 53, 1. 2. 7, 1 f. d 8,1f. und so oft. - Doppelte Verneinung, die keine Bejahung

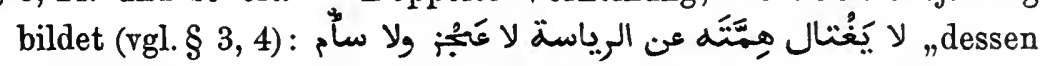
Trachten nicht von der Herrschaft ablenkt nicht Unfähigkeit und nicht Widerwillen" Zuh. 17, 36.

Vulg. Srr. (a) hydèna ttēar jabn ummi hgdèna, wir nahmen die Rache, o Sohn meiner Mutter, wir nahmen" Pal. Diw. 156, 8.

1 Die Rufpartikel steht manchmal erst beim zweiten Vokativ. 


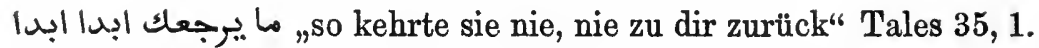
mnèn 'abüsač ja 'arìs imnën, ,wo soll ich dich küssen, o Bräutigam, wo" Neuar. Volksp. S. 40, 82. Tales 28, 19-20. 205, 23. Arabia petr. 447 Mitte. (b) bilh $\bar{a} d \bar{\imath}$ bilh $\bar{a} d \bar{\imath}$,gemach, gemach" Neuar. Volksp. S. 15 Vs. 15. hannūnì ja nās hannūnī „wünscht mir Glück, o Leute, wünscht mir Glück" Neuar. Volksp. S. 44 Vs. 123. Lbd. v. Am. 54 ult. 72, 17. (c) Lbd. v. Am. 22, 2 v. u. 76, 12. 114, 17. 126, 3 v. u. 132, 1. (d) lā tšūf là unta ulà dakar „die sehe weder Weib noch Mann" Pal. Diw. 168, 3 v. u. شا شفنا wir sahen keinen zu deiner Tochter gehen, weder bei Nacht noch bei Tage" Tales 61, 5 . 189, 19. 195, 16. Lbd. v. Am. 6, 12. ÄG. Spitta Gramm. § 180. (a) Spitta Gramm. § 137. § 131 Ende. (d) Spitta Gr. § $197 \mathrm{~b}$. TRIP. (c) azreg ja lazreg "stahlfarbiges, o stahlfarbiges" Trip. Beduinenl. 31. Mar. (a) mendera mendera, "wer weiß, wer weiß" Tlemcen 224 Vs. 1. (b) 'ammar 'ammar "fülle dich, fülle dich" Houw. 25, 12.

Südar. SoK. (a) dilosim losim, „ich will sterben, sterben“ II 278, 9. (b) neheg teloh teloh „sie spielen Verstecken“ II 143, 5. 18. MEHRI. (c) firhīn jā firhīn „Stute, o Stute!" I 77, 25.

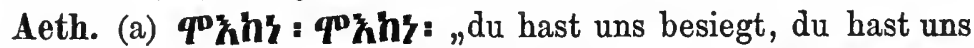

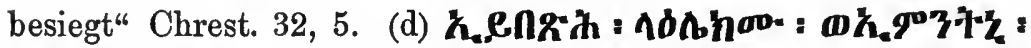

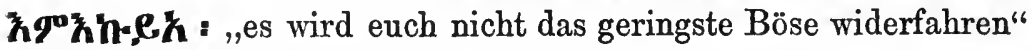

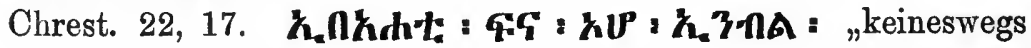
stimmen wir bei" Chrest. 76, 1. 91 ult. 30, 16. 39, 10. 73, 14. Lal. 59, 2.

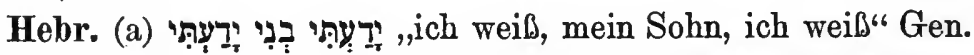

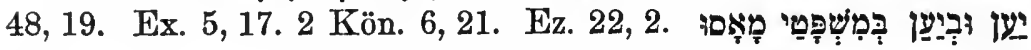
„weil sie eben meine Rechte verworfen haben" Lev. 26, 43. der Gerechtigkeit, der Gerechtigkeit sollst du

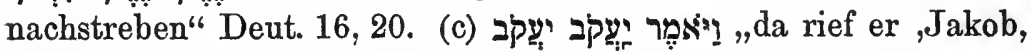

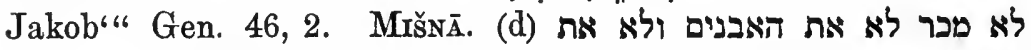
er verkauft weder die Steine noch die Rebstöcke" Bābā b. 4,9 .

Syr. (a) auch du hast zwei Taufen" Phil. 276, 14. Ebenso Carm. Nis. 2, 82. Jak. Ser. Hom. 
194, 7 usw. (d) Niemand sieht nicht Bildhauer und nicht Maler" Spic. 17, 4.

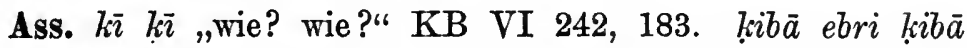
ebri „sage, mein Freund, sage, mein Freund" KB VI 262 Kol. IV 1.

2. Objektive Verstärkung (s. oben No. 1), und zwar asyndetisch:

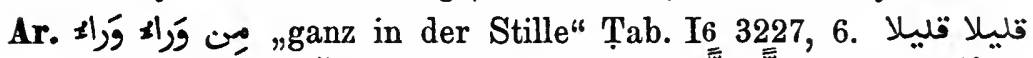

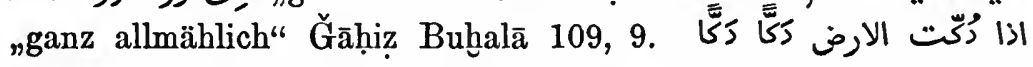
„wenn die Erde in lauter Stücke zerschlagen wird" Kiur. 89, 22. 23. ,meine Augen, fließt immer zu!“ Hansā S. r.

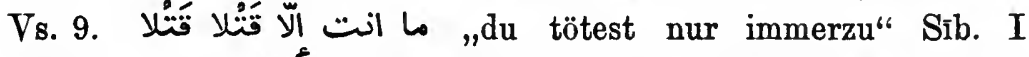

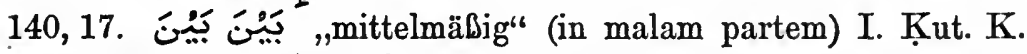
aššír 144, 1. مشى شويه شويه ,er ging ganz langsam" 1001 N. II 116, 4 v. u. $127,2$.

Vulg. IRĀḲ. (a) nârič bilgal(u)b tāğid (u)kbâr (u)kbär ,dein Feuer brennt stärker und stärker im Herzen" Neuar. Ged. S. 104, 4 v. u. Srr. Tage und Nächte, Nächte und Tage" Tales 1, 10. ich haue dich in Stücke" Tales 2, 8. 'ahwitkum murra murra = „euer Kaffee ist sehr

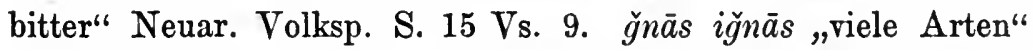
Pal. Diw. 133, 4. 'öllijjet abu selīm țabājiłk țabājik = „der Söller des Vaters von Selim besteht aus vielen Stockwerken" Pal. Diw. 307, 2. sa'rak irmãh irmäh "dein Haar ist wie lauter Lanzen" Neuar. Volksp. S. 20 Vs. 54. S. 31 Vs. 78. Damas 118,5 v. u. sie gingen immer, weiter" Tales 2, 16. er stand, stand und fuhr fort zu stehen" Tales 163, 9. ich denke in einem fort nach" Tales 144, 9. er schwamm immer weiter" Tales 54, 23. Hịpr. jihallih sawa sawa ,er schneidet es ganz gleich" 247,2 v. u. MaLt. kutu kutu nizel "ganz leise stieg er heraus" Malt. Stud. 5, 17. 23. dorga gbīra gbìra „ein großer, großer Krug“ 17, 25. jimš̃ jimš̃ jim $\ddot{s} \bar{\imath}$,er ritt, ritt, ritt immer weiter" $31,11.25 .32,2$. $26,18.49,11$. jakta thops farka farka ,er zerschnitt das Brot in lauter kleine Stückchen“ 6, 23. k kam bilmōt bilmōt „er stand ganz leise auf" 7, 28. 39. Ferner 10, 31 (,immer höher") 12. 34.17, 25. 
27, 7-8 (vgl. 7, 28). 52, 11 (,schneeweiß"). 67 No. 37, 3. ÄG. sikkinetek hüuṣa hūṣa „dein Messer ist sehr fein" ZDMG 33, 627, 6 v. u. ahadet el'ūd hïja wetišrab tišrab tišrab ,sie nahm die Pfeife und rauchte, rauchte, rauchte" Spitta Gramm., Texte 442, 15. TRIP. haffeg hefeg „er zuckte in einem fort" Trip. Beduinenl. 299. Tunis. ḩažra ḥažra „Stein für Stein" Märchen 48, 1. Ka $a^{\complement}$ det tibki tibki "sie weinte in einem fort" 18, 9. 41, 32. 47, 4. 60, 2. Mar. iruddek teraf teraf „er wird dich in Stücke hauen“ Mar. 198, 20. muois muois „ein ganz, ganz kleines Messer" Houw. 34, 2. Tlemcen 218, 2. 258, 1. Mar. 162, $9(172,6.166,14$.) 162, 11. birrah birrah ,er ließ immerzu ausrufen" Houw. 48, 27.

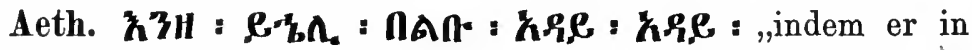
seinem Herzen lauter Schmutz dachte" Due framm. 597, 8.

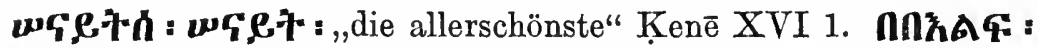
Ћへ6.: "Tausende von Malen" Kenē XIX 4.

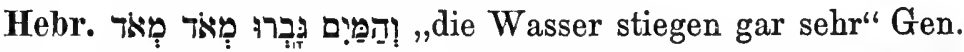

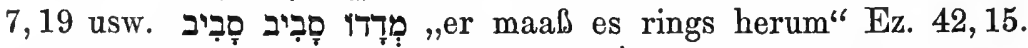

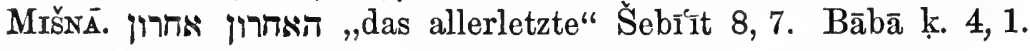
wer sein Feld in lauter Bete teilen will" Kil. 2, 6.

Syr. "ganz allmählich" Op. sel. 56,21. Jak. Ser. 782, 12 usw. woliar se se werden dich gar übel zerreißen" Sāhdōnā 398, 14. 314, 6. Addai 42,6 v. u. 2 \% $~$ if

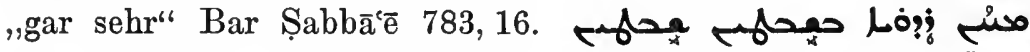
„der Züchtiger schlug uns mit lauter Stöcken" Jak. Ser. Hom. 271,6 v. u.

Ass. $j\left[\right.$ [paš lumna lumna ,er fügt mir lauter Böses $\mathrm{zu}^{\prime}$ Tell el am. 106, 36. adanniš adanniš likrubu ,mögen sie sehr, sehr gnädig sein" BA IV 508, 28. idullušu ilāni idullušu ilāni „die Götter laufen immerzu um ihn herum" KB VI 24,63.

3. Objektive Verstärkung, syndetisch: Ar. مئون مئون, ,viele

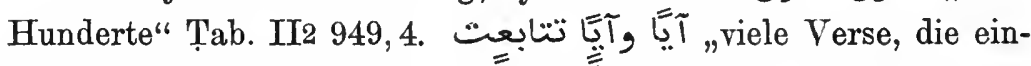

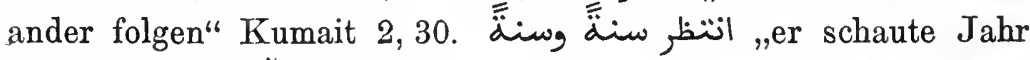
um Jahr aus" Ğāhiz Buh. 23, 4 v. u. هَن ,die ver-

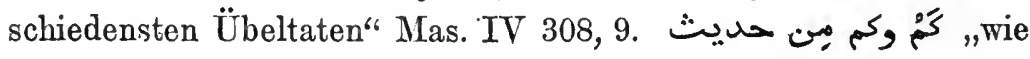


manche Geschichte!" 'Umar 126, 7. 8. Ebenso mit كَ Kāmil 62, 3. Mutanabbi 15, 39. 30. die Morgenregen mögen dich mit Regen und wieder Regen tränken" Ḥam. 425 Vs. 1. indem ich Reiter um

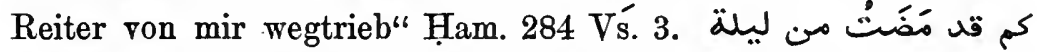
wie manche Nacht und wieder Nacht ist vergangen!“

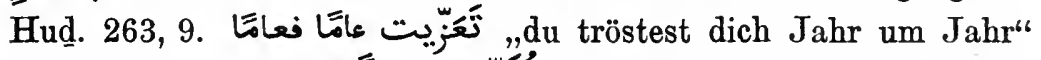
Hudِ. 242, 23. wir hauen sie nieder, Trupp auf Trupp". Kumait 2, 59. I. Hiš. 950, 16. Sīb. I 150, 12. "هie so trefflichen Leuten über die Kraft gingen““

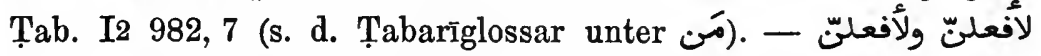
نظرت ich werde etwas schreckliches tun" Tab. I2 852, 2. "sie schaute aus und schaute aus" (schaute in einem fort aus) Buh. II 345, 8. alsbald kam sie

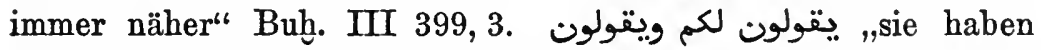

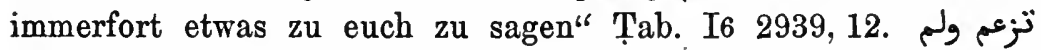

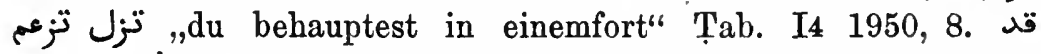
sie haben mich erprobt und wieder erprobt"

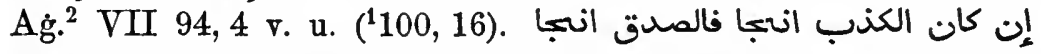
"wenn die Lüge rettet, so rettet die Wahrheit erst recht" 1001 N. I 365,6 v. u. sie sab lange, indem sie mit mir plauderte" II 154,6. ساروا ولم يزالوا سايرين "sie gingen und gingen in einemfort" III 234, 2.

Vulg. Syr. wil hamā' 'aktar w'aktar, ,und die Stiefmutter (haßt) noch viel mehr" Journ. as. 1903 II 100 Vs. 4. 'arīsnā 'ahllā w'ahla „unser Bräutigam ist überaus schön" Neuar. Volksp. S. 25 Vs. 115. er sab und weinte in einem fort" Tales 144, 7. ÄG. Spitta Gramm. § 133 c. dịll il așāri mäl umāl ,der Nachmittagsschatten hat sich geneigt und geneigt" Lieder $\ddot{A} g$. Bau. 68, 1. TRIP. kšōof ukšōof "betrachte immerfort" Lieder No. 7, 1. ezzāabih wazzābih ,töne drauflos!" No. 17, 1. Mar. släm. wustām „Friede über Friede!" Tlemcen 262, 4.

Südar. Sox̣. tšemetolen wumetolen "schwatzet drauf los" II 172,1 .

Hebr. Ist dein 
Herz aufrichtig? Da antwortete Jehonadab: Es ist es sehr" 2

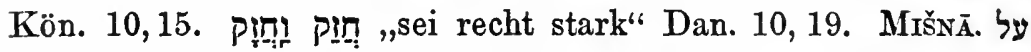
פרק וטען פרק .um wie viel mehr!" Makkōt 3,15, אתת כמה וכמה שלחה .wenn er immer wieder ab- und auflud“ Bābā m. 2, 10, וטען wenn er sie hat fliegen lassen, und sie ist immer wieder zurückgekehrt" Hul. 12,3. הפוך בה והפוך בה "wende sie immer wieder" Ā bōt 5, 22.

4. Die paronomastische Beiordnung bildet in verschiedenartiger Gestalt den Ausdruck der Totalität. Z. B. Ar. "wie mancher Weinende und manche Weinende" Ag. ${ }^{2} \mathrm{X} 73$ ult. die Diener und Dienerinnen" Balāḍ. 408, 7.

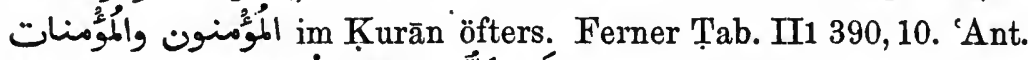

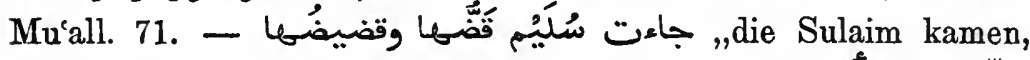

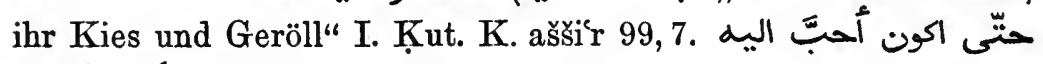
bis ich ihm lieber bin als seine Kinder und sein Vater" Buh. I 12,2. 2. dort sei Kampf und

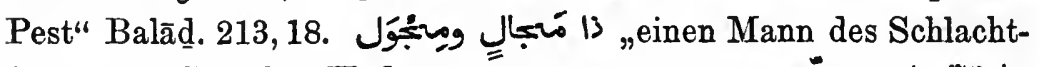
felds und Schilds" Hud. 98, 13. ما قاتلوا عن ربتهم وعن ربيبمهم „sie kämpften nicht für ihren Herrn und ihren Pflegling" Imr. 57,3. sie erreicht den Edeln und den an

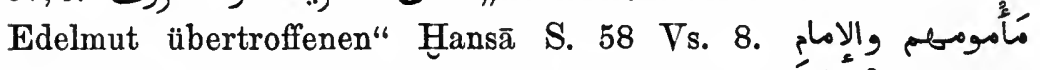
,,ihrer Geleiteten und des Leiters“ Kumait 1,46. 'Ag. ${ }^{2}$ X 72, 25

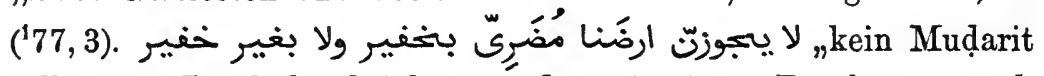
soll unser Land durchziehen, weder mit einem Beschützer noch ohne einen“ Ahțal (ed. Griffini) 17,3. dort gibt es keinen Wein und keine Betäubung" Abū Nuwās ed. اذا بلغن عاسها - Ferner Tab. I4 2115, 11. "wenn sie auf lauter Unerschrockene stoßen" Ḥam.

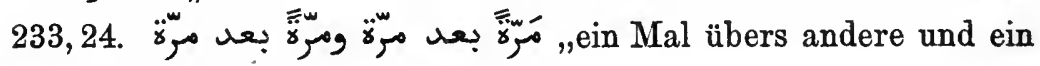
Mal übers andere" Tab. I2 930, 8.

Vulg. Srr. alla mhaiji lwārid wilwārda wilwārid „Gott grüße den zum Brunnen gehenden und die gehende und den gehenden" Pal. Diw. 45 Mitte. eššbb waššbbān minhu hijārhum „der Jüngling und die Jünglinge, wer ist. ihr Bester?" Pal. Diw. 35, 6. 


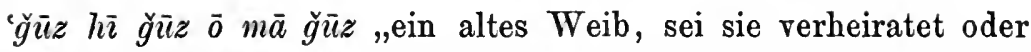
nicht" Pal. Diw. 47 Mitte. lā tāajjar wală țār „er ließ nicht fliegen und flog nicht" = er hatte in keiner Weise mit dem Fliegen zu tun. Pal. Diw. S. 13 No. 4 Vs. 3. ما تعرف شُغْل ولا شَغْله ,kennst du nicht irgend ein Handwerk?"“ Tales 28, 13.

Hebr. die Stimme der Sänger und Sängerinnen“

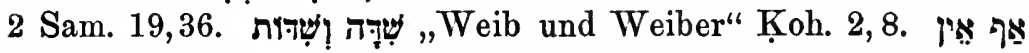
weder ein Verkünder noch ein Ver-

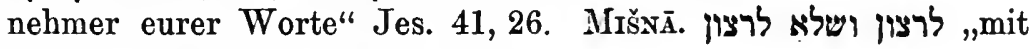
oder ohne Absicht" Kēlīm 8,11.

Syr. das Volk und die Heiden" Is. Ant. I 148, 1489. hohe Berge zergehen und Hügel gibt es nicht mehr" Efr. II 403, 26. حصلر ملإقل ماف تصس .mit und ohne Maaß" Efr. II 335,7,

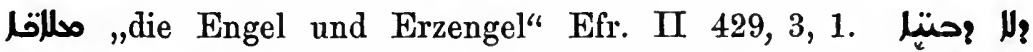

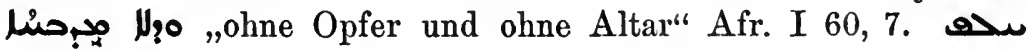
- wowïlo segen seiner Brüder und Verwandten“ Op. sel. $200,25$.

Ass: mereš und Töchter" KB IV 54 No. 7, 3. 322 Kol. 3, 34. VI 62, 8.

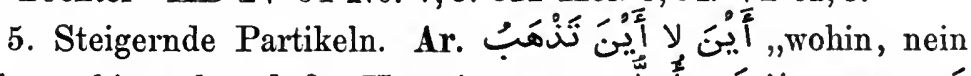

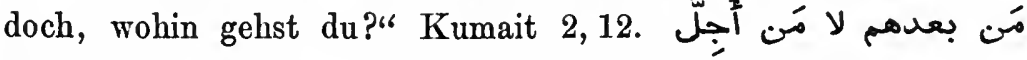
„wen nach ihnen, nein doch, wen nach ihnen werde ich hoch halten?" Kumait 2,17. - Nein, bei Gott, auch nicht einen eisernen Ring" Buh. III 416,16. لا لا "Nein, bei Gott, auch nicht im Entferntesten“ Tab. II1 310,6. wir werden es nicht tun, auch nicht zum Gefallen" Hud. 153 Einl. 15. Ham. 579, 25. - أَوْلَى

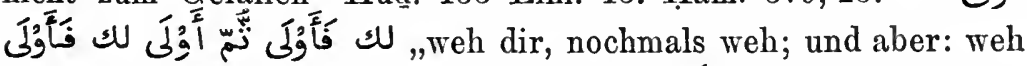

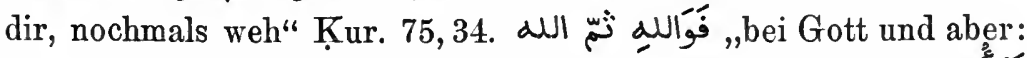

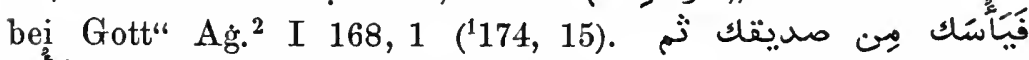

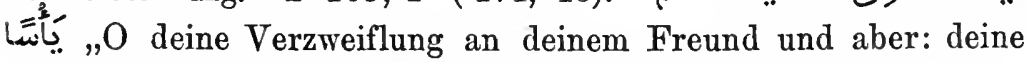
Verzweiflung" Hud. 155, 2. Kur. 74, 20. 78, 4. 82,18. 102, 3. 6. Sīb. 136, 19. Kumait 1, 63. 94. 1001 N. I 203, 11 (nimm dich ja in Acht). Weitere Beispiele s. Syntakt. Verhältnisse S. 472. 
6. Mehrfache Paronomasie. Ar. Bei Gott,

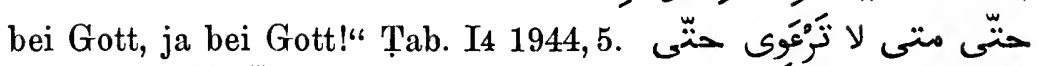
,wie lange läßest du nicht ab, wie lange, wie lange und bis wie lange?" Abūl'atāh. 8,2 v. u.

Vulg. Srr. katạ oh sakaf sakaf sakaf ,er schnitt ihn in viele Stücke“ Damas 120,1. Mar. keidorbū keidorbū keidorbu „er hieb und hieb und hieb auf ihn los" Houw. 30, 15.

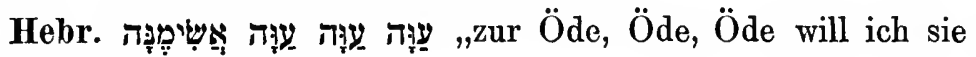
machen" Ez. 21,32 usw.

Ass. ana mimmuka danniš danniš danniš lü šumu ,allem Deinigen sehr, sehr, sehr Heil!" Tell el am. No. 20, 12. KB VI 24, 63,

7. Unvollständige Wiederholung. Ar. Gott

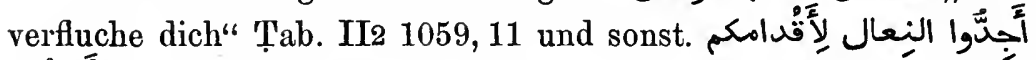

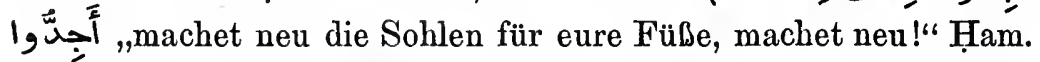
647, Vs. 4. Tجَماد لها جَهاد ,Verwünscht sei sie, verwünscht!““ Mutalammis 8, 4. woher hast du diesen Apfel, woher?" 1001 N. I 360, 1.

Hebr. Mišnā. wurde es bei Tag geschrieben und bei Tag gesiegelt; bei Nacht und bei התקדשי לי בכום וה של "ין ונמצא הacht gesiegelt . . "Git. 2, 2. wer sagt, Sei mir verlobt durch diesen Becher mit Wein' und es stellt sich heraus, es war Honig; ,mit Honig' und es stellt sich heraus, es war Wein ..." Ḳid. 2, 2. und so öfters.

§ 36. Distributive Ausdrücke. 1. Anschaulicher als ein einfaches Substantiv mit der Pluralendung, die einen bereits abgeschlossenen Vorgang zum Ausdruck bringt, ist die distributive Wiederholung eines Subst., da sie die Entstehung der Vielheit miterleben läßt. ${ }^{1}$ Hierbei bildet die meistens nur zweimalige Setzung des Worts die Abkürzung für eine unbestimmt große

1 In einigen formelhaft gewordenen Ausdrücken hat sich im Arab. die altertümliche Nominalform ohne unbestimmten Artikel erbalten, s. Brockelmann, Grundriß $\S 246$ A a $\alpha$. 
stetige Fortsetzung der Reihe1. Beispiele: Ar. أن نَآثِّنَ الخزّرج قصرا

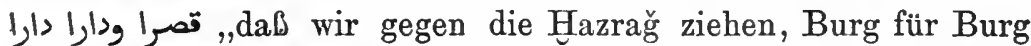
und Gehöft für Gehöft" Ag. ${ }^{2}$ XV 157 paenult. استقراهم (164 ult.) er durchwanderte sie Stamm für Stamm" Ag. ${ }^{2}$ IX 6, 1 $\left({ }^{1} 6,9\right)$.

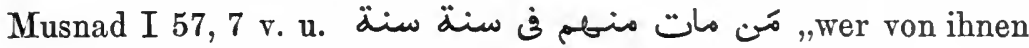
in jedem einzelnen Jahre stirbt" Mas'ūdì K. attanbīh 4, 17. 1, er gab dem Heere je einen Denar“ Tab. II3

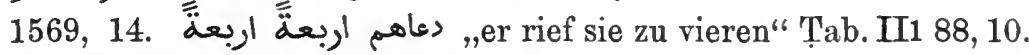
er gab denen, die bei ihm waren,

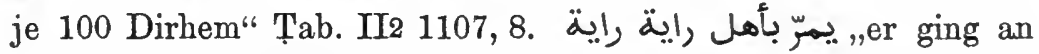
den Leuten jedes Feldzeichens vorüber" Tab. II2 950, 12. Ferner Tab. I1 16, 6. II3 1881, 11. I. Sa'd VIII 78, 14. Gesandsch. 56, 12. Ag. ${ }^{2}$ I 161, 10. ('167, 12). Ham. 304, 7 usw. 1001 N. I 218,7 .

Vulg. 'IRĀK. Neuar. Gesch. § 45 c. SYR. سلم علينا واحص واحد „er grüßte jeden Einzelnen von uns" Tales 172, 19. Hị̂̉. "ala wāhed wāhed, ,jeden für sich" 263 Mitte. ÄG. jilakkat habbàjje habbāje ,er pickte Korn für Korn auf" Contes 10, 7 .

Südar. Soḳ. nim tri tri leșahaan ,je zweien gab man eine Schüssel" II 229, 14. 288, 14.

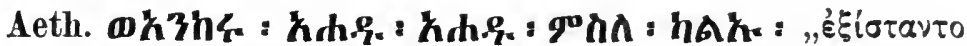

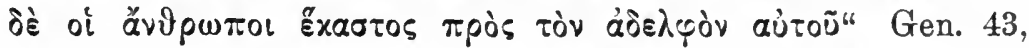

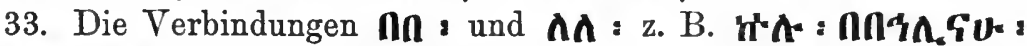
PaAh: ,jeder verehrt die Götter nach seinem Sinn" Chrest.

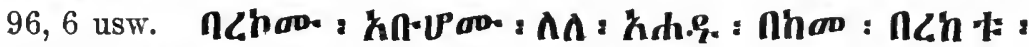

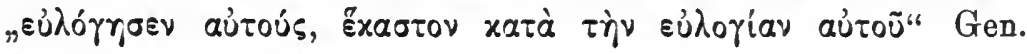
49, 28 usw.

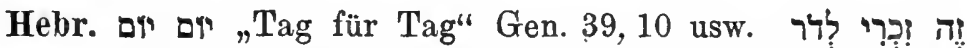
לר ,dies ist mein Andenken von Geschlecht zu Geschlecht" Ex.

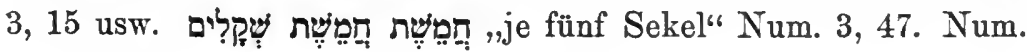

1 Es kann sich allerdings zufällig treffen, daß die ganze Reihe nur aus

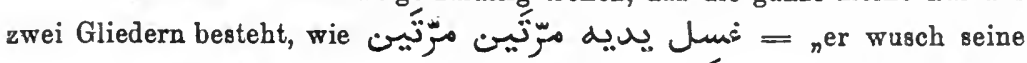

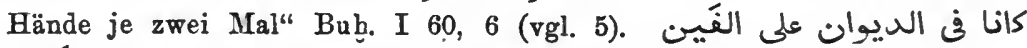
sie (beide) standen im Diwan mit je 2000" Tab. II1 96, 1. 
28, 13. Gen. 7, 2. Num. 17, 17. 2 Kön. 17, 29 usw. Mišxā. אהרי

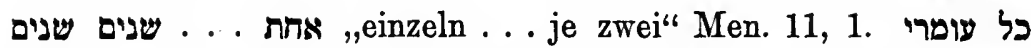

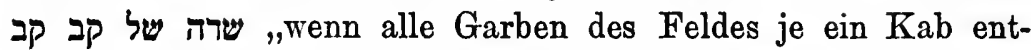
hielten" "Ē שלשה תצרות של שני שני בתים .drei Höfe von je zwei Häusern“ 'Arākin 9, 6. Ter. 11, 6 („Stück für Stück“) Mikw. 2, 5.

Syr. iLl 3Ll taus den verschiedenen Orten" Bar Șabbāe 832, 11. sie taten allerhand Böses" Op.

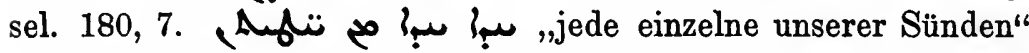
Op. sel. 329, 26. Spic. 12, 8. 18, 16. Is. Ant. I 188, 219. Afr. II 1, 17. Efr. I 55, 2, 5.

Ass. sattum šatti „Jahr für Jahr“ Lpz. sem. Stud. II, Heft 1, 34,3 v. u.

2.So wird also auch das schrittweise Anwachsen, das Allmähliche bezeichnet; vgl. noch Ar. تناخّي قليلا قليلا, sie zieht sich mehr und

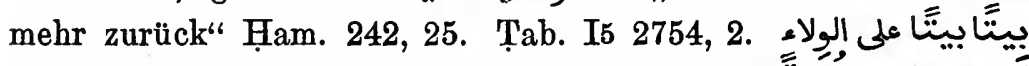
"Vers für Vers, der Reihe nach" Ham. 2, 2. كنزعوا دارى طوبة طولة طُوبة

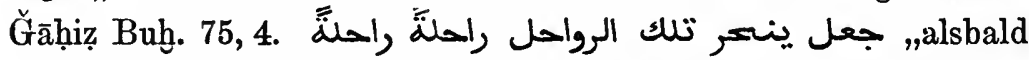
schlachtete er jene Reittiere Stück für Stück (nach Bedarf)“ Balād. 110, 16. I. Hiš. 36, 12. Tar. Múall. 14. 1001. N. 231, 7. 358,4 . 2 v. u.

Vulg. SrR. daḳ̣ ennīl škāl iškāl baddna nūșif wașfatha „die blaue Tätowierung, Art für Art wollen wir sie beschreiben" Pal. Diw. 120, 4 v. u. tanakkalna darağe darağe „wir zogen dahin Schritt vor Schritt" 190, 11. šwoije šwoije hīlu ttrāb "schüttet allmählich die Erde auf" 297 Mitte. ÄG. Spitta Gramm. § 131. MAR. min elwakt elwakt „von Zeit zu Zeit" Mar. 160, 7. šwoija swoija = „nach kurzer Zeit" 164, 3 u. sonst.

Aeth. nח3n-1:7 : 3nt: a "ganz allmählich" Chrest. 33, 18.

Hebr. sich immer weiter wendend geht

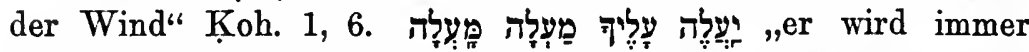

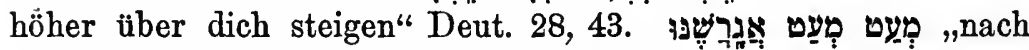
und nach werde ich ihn vertreiben"Ex. 23, 30. MIŠñ. עצ ,er mag Knochen für Knochen sammeln“ 'Ēd. 8,.5. Oh. 
16,5. 5man kann Glied für Glied abschneiden“ Hul. 4, 2.

3. Beispiele für Duale und Plurale: Ar. تأخبّوا اخوَين اخوَين

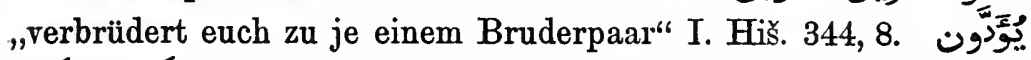
es wurde ihnen jeweils doppelte Sühne entrichtet“

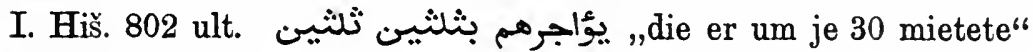
Tab. II2 800, 1.

Vulg. Srr. das geringste ist je 50" Lbd. v. Am. 74, 5 v. u.

Hebr. das Tal Siddim war voller Asfaltquellen“" Gen. 14, 10. Ex. 8, 10. 1 Sam. 2, 3. 2 Kön. 3, 16. 2 Chr. 31, 6. Joel 5, 6. Mišnā. שנים שנים ,je zwei" Sanh. 5, 5. man holt es Glieder für Glieder heraus" Oh. 7, 6.

Syr. ,aus beliebigen Gründen" Op. sel. 221, 6 viele Mengen" Jak. Ser. Hom. 14, 9. Efr.

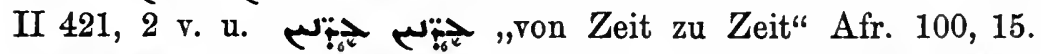

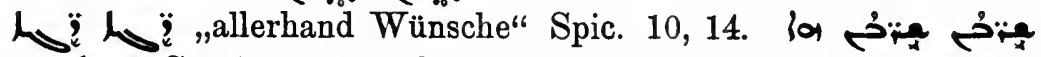
Geschlecht für Geschlecht sind sie verzeichnet" Carm. Nis. 62, 75 .

4. Zusammengesetzte Ausdrücke: Ar. أطى مَن معه مائة درم er gab denen, die bei ihm waren, je 100 Dirhem“ Tab. II2 1107, 8. Balād. 166, 20.

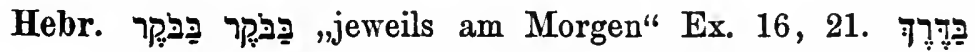
ich werde immer nur auf dem Wege gehen" Deut.

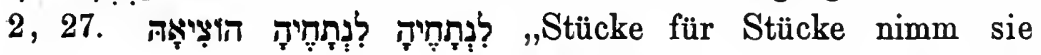

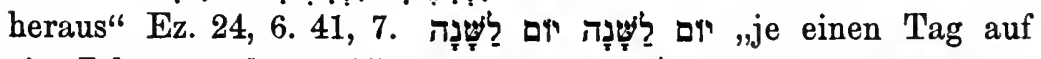

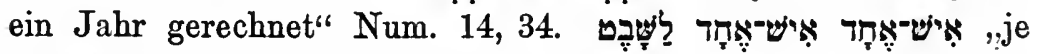
ein Mann für den Stamm" Jos. 3, 12. Num. 7, 11. Ferner Ex. 28, 34. Ez. 46, 21.

Syr. ",allmählich" Is. Ant. I 8, 150. II 56, 17. 94, 101 v. u.

Ass. išten amelu išten amelu, ,je einen Mann" Tell el am. No. 124, 27.

5. Syndetische Ausdrucksweise: Ar. نادى رجل ورجل, jeder 
einzelne Mann rief“ Tab. I4 2024, 11 , sie

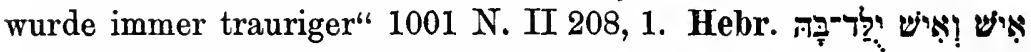

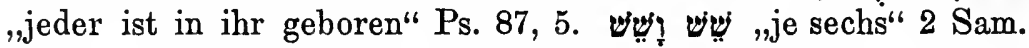
21, 20. welche sind es alle, die gehen sollen?" Ex. 10, 8. 1 Chron. 28, 14 f. 2 Chron. 34, 13. Est. 1, 22. 8, 9 usw. Ex. 25, 33. 26, 21. Mršnā. in so und so viel Körben" Mãaśer š. 5, 4.

Bemerkenswert ist der Gebrauch von Ar. $َ \dot{ }$ in Fällen wie ${ }^{1}$

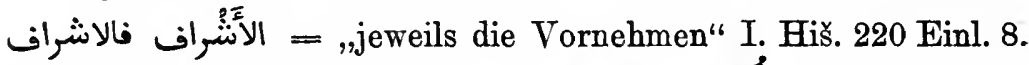

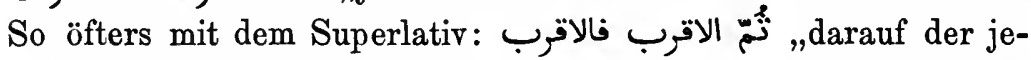
weils nächste" Tab. I5 2412, 8. 2750, 14. 2751, 11. Ham. 145, 9. daß die Unglücksfälle gerade immer über den Trefflichsten hereinbrechen" Țab. I2 893,4. الاّول فالاوّل ,jeweils der erste" = „einer nach dem andern" Ğāhiz Buh. 168 ult. I. Hiš. 4, 4. mit einem trefflichen Worte von dir nach dem andern" (eig. ,mit dem trefflichsten und dann dem nächsttreftlichen") Kumait 5, 7.

6. Das Distributivverhältnis durch ל usw. verdeutlicht: Ar.

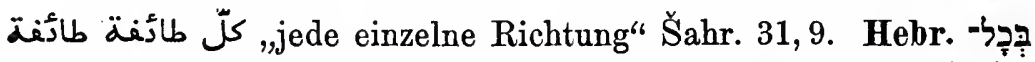

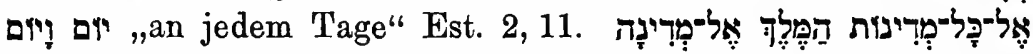
in alle Provinzen des Königs, in jede einzelne Provinz"

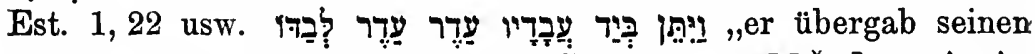

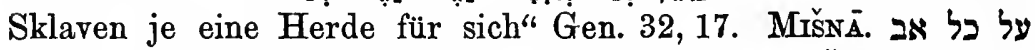
לכל .wegen jeder einzelnen Hauptarbeit" Šb. 7, 1. מלאכה ומלאכה ffür jede einzelne" Jeb. 11, 3. Ned. 2, 3. Hōr. 1, 5

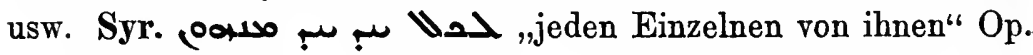
sel. 166, 19.

\$ 37. Reziproke Ausdrücke. Ar. mit der du scherzest, und die mit dir scherzt" Buh. III 414, 16. راسَلونا ,sie schickten Boten an uns und wir an sie" Tab. I4

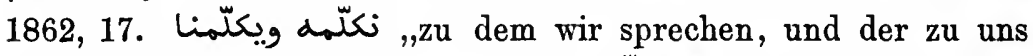
spricht" Tab. I5 2267, 11. sie gehören zu mir

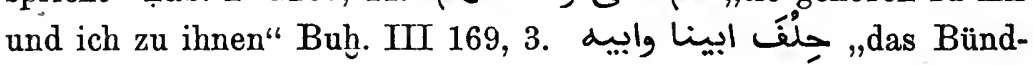

1 Über den Kasus nach is. Sìb. I 168, 10. 
nis unseres Vaters mit seinem Vater" I. Hiš. 806, 2. الخبيشنات Nichtswürdige Frauen gehören zu nichtswürdigen Männern und nichtswürdige Männer zu nichtswürdizen Frauen" Kur. 24, 26. Ferner Kur. 2, 183. 6, 52. 5, 7. 30, 18. 31,28 . Buh. II 240,12 . Tab. I4 1979, 1. 1983, 16. I5 2689, 11. II1 434, 10. IǏ 970, 13. I. Hiš. 223, 15. Sīb. I 16, 23. Nāb. 29, 14. Ruk. 40, 2. - - Haus an Haus“ Sìb. I 235, 14 .

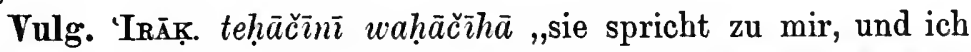
spreche zu ihr" Neuar. Ged. I 102, 3. Srr. gōm ğuna uğı̄nāhum „Leute kamen zu uns, und wir kamen zu ihnen“ Pal. Diw. 98 No. 8. färaḳtaku färaḳtūni, ,ich schied von euch, ihr schiedet von mir" Pal. Diw. 328 Mitte. Neuar. Volksp. 55, 112. ḩākāni uhăkētu „er sprach mit mir, und ich sprach mit ihm“ Pal. Diw. 73, 3. Marr. thopp ilkulhat ukulhat kin ihobba, sie liebte jeden, und jeder liebte sie“ Malt. Stud. 17, 14. häres leija häarset leih, ,er sah sie an, sie sah ihn an" 25,17 . S. 65 No. 18, 2. 4. ̈̈G. hīje mišjet ľnuddāmoh vehūwa miš̀ warāha ,sie ging vor ihm, und er ging hinter ilh" Contes 75, 4 v. u. Tunis. farhet bīh ufrạ bih „sie bewillkommnete ihn, und er bewillkommnete sie" Märchen $36,24$.

Südar. Sor. 'atiburš ta'tibirjen, ,ich sehe dich an, du siehst mich an" I 180 N. 45, 1. lahmod 'ans wahmid 'anhi, ,ich liebe dich, und du liebst mich" II $171,10$.

2. In dieser zweiteiligen Weise wird die Wechselbeziehung manchmal auch dann ausgedrückt, wenn sie schon in dem einzelnen Bestandteil liegt, so daß also eine Tautologie entsteht. Z. B. die mit uns wetteiferte, und mit der wir

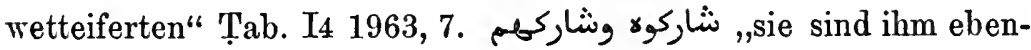

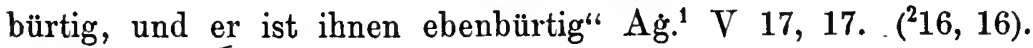

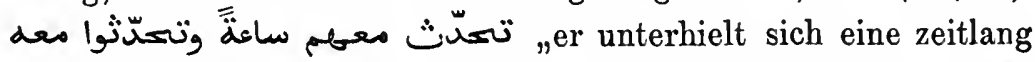
mit ihnen, und sie unterhielten sich mit ihm" I. Hiš. 552, 5. بعد مارك "nach unserm Zusammensein und deinem Zusammen-

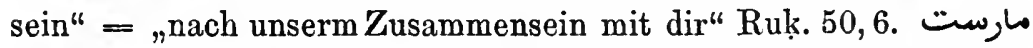
ich habe es mit Männern zu tun gehabt, und sie haben es mit mir zu tun gehabt" Ḧam. 210 ult. 
Vulg. Tunis. sär bīha sâret bīh ,er zog mit ihr, sie zog mit ihm" Märchen 60, 18.

3. Ähnlich werden in Vergleichungen Ausdrücke, die die Wechselbeziehung der beiden Seiten der Vergleichung bezeichnen,

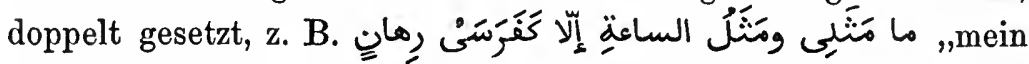
Gleichnis und das Gleichnis der Stunde ist nicht anders als zwei Rennpferde" $=$,ich verhalte mich zur Stunde nicht anders als sich zwei Rennpferde zu einander verhalten" Tab. I1 12, 16. nicht gleicht sich das Schöne und nicht das Häßliche" = „das Schöne gleicht nicht dem Häßlichen"

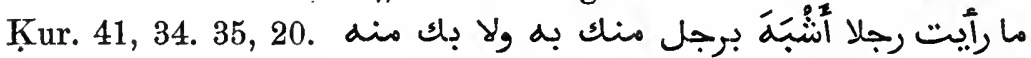
„,ich habe keinen einem andern Mann ähnlicheren Mann gesehen als du ihm bist und er dir ist" I. Hiš. 51, 4.

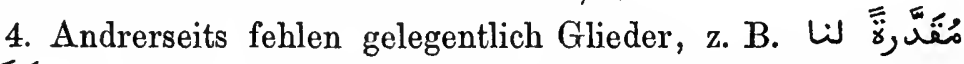
indem es uns bestimmt ist und wir (ihm) bestimmt sind"، 'Amr Mu'all. 8. wenn ich (ihn) geschmäht hätte, und er mich geschmäht hätte" Farazdak 420, 2.

\section{Nebensatz.}

\$ 38. Allgemeines. Die grammatischen Beziehungen der paronomastischen Glieder werden hier schon so mannigfaltig und verwickelt, daß nur das Wichtigste besprochen werden kann. Z. B.:

1. Die paronomastischen Glieder des Hauptsatzes und des Nebensatzes stehen in Gegensatz oder heben einander auf; so namentlich in Relativsätzen. Ar. ich trinke trübes Wasser, das (sonst) nicht getrunken wird" Ag." I 168, 3. sie sieht, was Kamele (sonst)

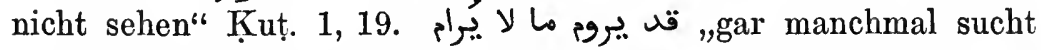
er; was (sonst) nicht gesucht wird" I. Kִuṭ. šír 121, 2. تحجود du bist freigebig mit einer Seele, mit derengleichen man nicht freigebig ist" Farazdak 269, 11. "mit vier (scheinbar) festgefügten Füßen, die (aber doch) nicht (wirklich) festgefügt sind" Mutanabbi S. 203, 11. wir hatten kaum ein 
wenig gekämpft" Tab. II2 691, 9. Ferner Hud. 151, 11. 'Ant. Mu'all. 7. 'Umar 212, 4. Farazdak S. 9^, 12. Hebr.

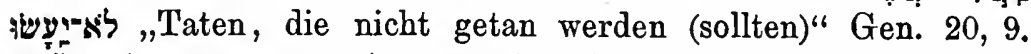
Mišnā. alles beschützen sie, außer einem Tongefäß, das nur Speisen beschützt" Kel. 10, 1. Syr. oa nil nannte sie Stimme des Horns, obwohl es kein Horn war" Jak. Ser. Hom. 21, 6.

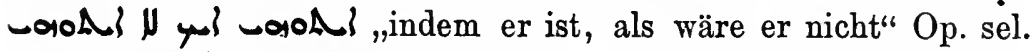
70, 2. la lil ooo N! lasil "Götter, die keine waren" Efr. I 157, 18. denn der Beredte kann nicht reden" Phil. 357,10. dab er das, was unsichtbar ist, sieht" Phil. 41,4. Ferner Carm. Nis. 96, 34. Efr. II 335, 3. 345, 3. Spic. 1, 18. 9, 3. 10,4. 12, 23. 20, 26.

2. Der Nebensatz führt ein Wort des Hauptsatzes weiter aus. $a$ Der Hauptsatz enthält z. B. ein Verbalnomen, der relativische Nebensatz schildert die Ausfübrung der Handlung. ${ }^{1}$ z. B. Ar. هُناد , ein Unglücksfall, der eintritt" Ag.

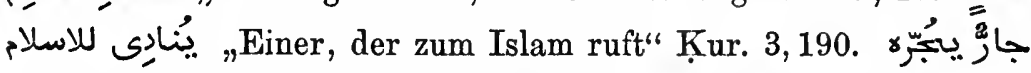
,einer, der ihn zurückhält" Ahțal 85, 9. بür einen von ihnen, den sie getötet haben"Buh. I 40, 14. قادِم يقدم مكنة إن الخاسرين الذين .einer, der in Mekka ankam" I. Hiš. 284,2. ,diejenigen, die sich selbst verderben“ Kur. 39, 17. wie eine vom Gießbach zurückgelassene, ḋie am Ránde des Bachbetts zuruickgelassen ist"“ Mufad. 11, 33. Totengräber, die gruben" I. Sąd VIII 80,10. Ferner Kuur. 83,10. Labīd 39,83. Hiätim ع., 7. $b$ Ham. 129 Vs. 3. - Ein Subst. mit Genitivsuffix erhält einen Relativsatz, der das Subst. in ein Verbum, das Genitivsuffix in dessen Subj. verwandelt und das Verhältnis des Subst. zu dem Genitivsuffix deutlicher auseinanderlegt, ${ }^{2}$ z. B. Ar. فُ مَلّاه الذَى

1 Das Leitwort des Relatirsatzes ist dann für uns oft ein bloßes Korrelativum. Weiteres über Korrelativa s. Syntakt. Verhältn. § 203.`231.

2 Eine solche Vorwegnahme des Subjekts des Relativsatzes durch ein

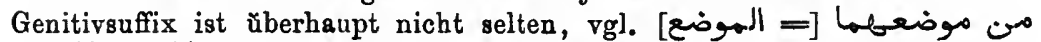
"von ihrem Platz, an dem sie sich befanden" Tab. I4 1978, 16. 
an seiner Gebetsstätte, an der er zu beten pflegt" Buh. II 21, 4. unsere Lage, in der wir uns

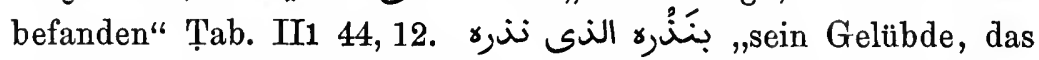
er abgelegt hatte" I. Hiš. 98, 5. Ferner Kur. 26, 18. 26. I. Hiš. c 17, 10. Tab. I1 163, 11. III1 470, 12. - Ein indirekter Fragesatz führt ein Nomen des Hauptsatzes weiter aus: عن تزويج in Betreff der Heirat dés Boten Gottes mit Maimūna, ob er sie im Ihrām heiratete"

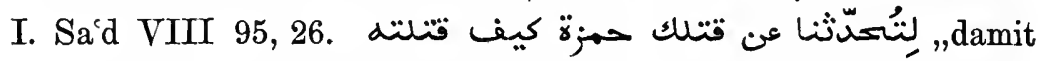
$d u$ uns von deiner Tötung Hamzas, wie $d u$ ihn getötet hast, er-

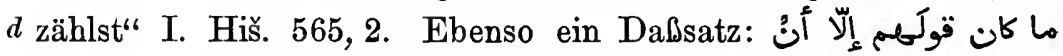

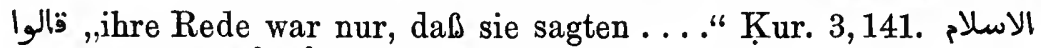

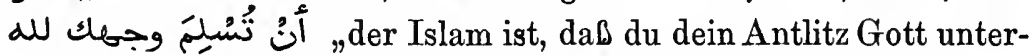
ea wirfst" I. Ḥanbal I 319, 5. Verschiedenartige Adverbialsätze dieser Art ${ }^{1}$ zu Infinitiven usw.: er beschützt ihn im Winter, wenn es [eig. er] Winter wird“ = "wenn er eintritt" Hud. 2, 12. als ich den

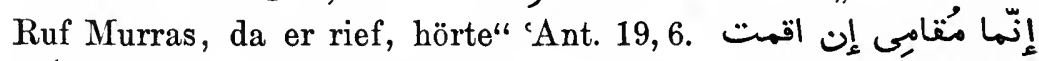
"wenn ich bleibe, so geschieht es nur für einen Tag oder weniger" Tab. II2 1231,19. كان ذلك النُخان من تَنَفَّسى

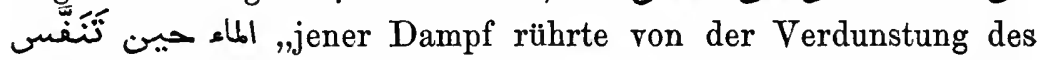
Wassers her, als es verdunstete" Tab. I1 52, 21. Ferner Kur. 2, 172 (|ذ|). 6, 99 (|ذ|). 17, 37. I. Hiš. 353, 3. Kumait 2, 45. -

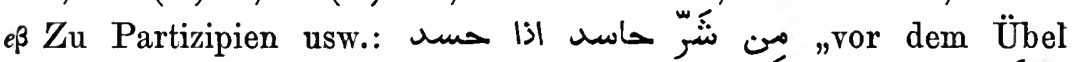

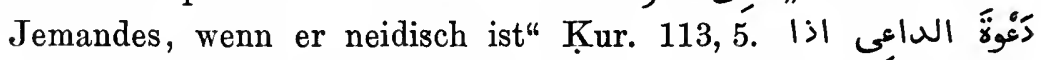
(عانى ,den Ruf Jemandes, wenn er zu mir ruft" Kúr. 2, 182. bei einem Unglücksfall, wenn er einträte“ Tab. er II1 12, 18. Zu einem Relativsatz: was die Leute zeugten, als sie zeugten" Ahțal 68,8.

sein Heer, an dessen Spitze er stand" Tab. II1 7, 13. Ferner Kur. 2, 136. İ. Hiš. 149, 1. 547, 10. I. Sa'd Gesandsch. 70, 1. Tab. I4 2065, 3. 2088, 10. Hud. II S. 36, 2 v. u. Vgl. Syntakt. Verhältn. S. 392.

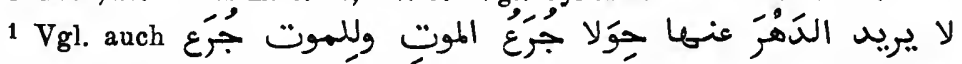
"Die Tränke des Todes wünschen ḱeine Veränderung mit ihr; der Tod hat ja Tränke" Mufad. No. 34, 65. 
Vulg. Srr. (a) imnādi jnādì „einer der ruft" Neuar. Volksp. 18,35. (ea (e) "ein Gelübde ihres Vaters, weil er nämlich gelobte, er werde ..." Lbd. v. Am. 58, 8. (eß) بعث معلم er schickte einen Lehrer, um die beiden zu unterrichten" Tales 104,6. halli limhanni jhanni "lasset den Gratulanten gratulieren" Neuar. Volksp. S. 19, 44. HẠp. (b) 'agiratuh illi jágorha "seine Opfertiere, die er opfert" 434,4. ÄG. (eß) rulht lilfașșăl jefașșalhā $l i$,ich ging zum Zuschneider, daß er mir sie zuschnitte" Lieder äg. Bau. No. 109, 3. 4. Tuxis. (a) dellāl idellel 'alabagien „einen Ausrufer, der ein Maultier zum Verkauf ausrief" Märchen 60, 5 .

Südar. (a) חדיתת חדיתת "Ereignisse, die eintraten" CIS IV 80,4.

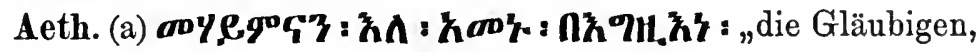
die an unsern Herrn Jesus Christus glaubten" Chrest. 18, 19.

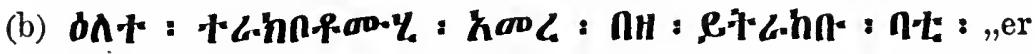
bestimmte einen Tag ihrer Versammlung, an dem sie sich versammeln sollten" Šarḍa Dengel 24,14.

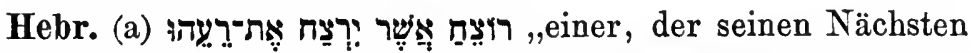

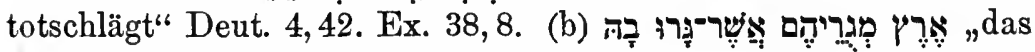
Land ihres Aufenthalts, in dem sie sich aufgehalten haben" Ex. 6, 4 .

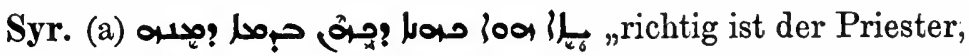
der mit seinem Blute Priesterdienst tut" Carm. Nis. 130, 46.

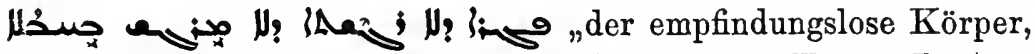
der die Verderbnis nicht empfindet" Addai 47,6. Ferner Is. Ant. I 92,187-9. 238, 300. Sāhdōnā 245,16. Spic. 1, 20. 21, 2. Marc. 7,19. (d) loo "über seinen Sender, warum und wie er ihn gesandt hatte" Addai 8,5. N ol "auch der Umstand, daß sie nicht glauben, steht ihnen nicht fest, daß sie nämlich wirklich nicht glauben" Spic. 3,1. Afr. I 175, 5-6.

Ass. (a) nadin iddinušam „den Verkäufer, der es verkauft hat" Hamm. 7, 19.

§ 39. Substantivsätze. 1. Asyndetische, genitivische Sub-

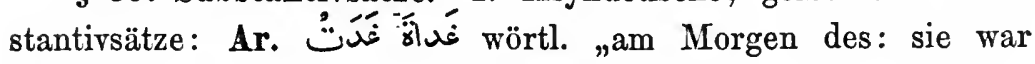
Morgens" = "als es morgens wurde, da..." oder nals sie 
Morgens ...." Ant. 7, 1. Ebenso Imr. 4, 13. Ahțal 58, 9. 123,15.

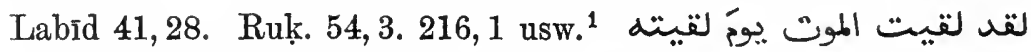
„ich habe den Tod getroffen, am Tage da ich ihn traf $[=$ da-

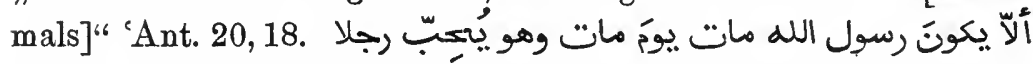
„daß der Bote Gottes nicht gestorben sein möge am Tage, da er starb, indem er einen gerne hatte, der ..." I. Sacd III 188, 15.5. Ferner Ḧam. 84 Vs. 1.

2. Daßsätze: فيمكثث بذلك ما شاء الله أن بمكث so trieb, so lange Allah wollte, daß er es triebe“ = „indem er das so eine zeitlang trieb" Hud. 19 Einl. 4. (vgl. § 38, 2.) ich werde erkannt, weil mich die Einwohner der Stadt erkennen" 1001 N. I 206,2.

أنّ الحُبّاج لثّا ندب الناسَ الى فiederaufnahme von Wörtern daß Hağğăğğ, nachdem er die Leute aufgefordert hatte, sich dem Mohallab in Bașra anzuschließen, und sie sich eingefunden hatten, Ḥağğăğ abzog..."

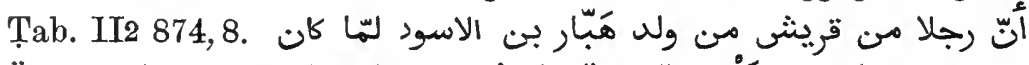

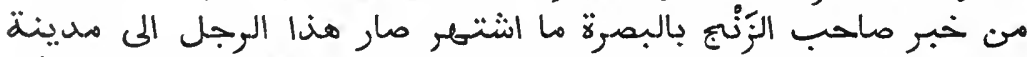
daß ein Mann von den Kuraiš [= ein Kuraišit], ein Nachkomme des Habbār ibn elaswad, als jene bekannten Ereignisse mit dem Führer der Zenğ in Bașra eingetreten waren, reiste dieser Mann nach der Stadt Sīrāf" Mas. I 312, 10.

\$ 40. Relatirsätze. 1. Die paronomastischen Bestandteile: Praedikat - Praedikat, z. B. Ar. Wer

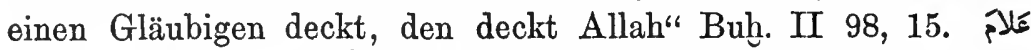
warum hast du mit meinem Kopf gemacht, was du soeben damit gemacht hast" I. Hianbal I

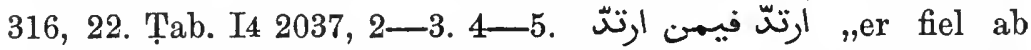
unter denen, die abfielen" = „er fiel mit den andern ab" Tab. I4 1995, 4. Ebenso ferner Tab. I4 1984, 3. 1997, 11. I5 2550, 9. Ḥātim

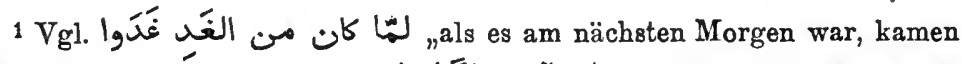
sie-Morgens" Țab. II2 799, 7. هل هل "kommst du Morgens?"

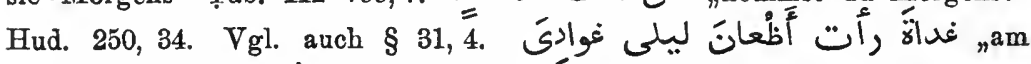
Morgen, als es die Sänften Lailas Morgens dahinziehen sah" Ag. ${ }^{2}$ II 9, 6 . 
r,12. Die Wiederholung des Verbums (statt eines einfachen secundum comparationis) nach dem Komparativ mit ơ ermöglicht es, über den Kasus des secundum comparationis frei zu verfügen, während ohne die Wiederholung des Verbums das sec. compar. von abhängen und immer im Genitiv stehen würde, gleichviel welches seine natürliche Beziehung wäre (vgl. unten $\S 41,2 b$ ). Z. B. Ar. من ,nicht hat mich einer mit etwas Schönerem als du getröstet" Balād. 99, 12 (ك) könnte auch be-

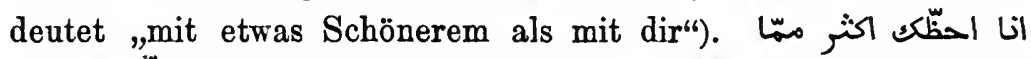
مأبح ich verleihe dir mehr als dir Mohammed verliehen

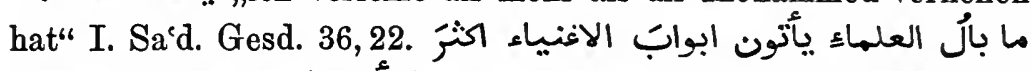
ما بأ warum kommen die Gelehrten an die Türen der Reichen häufiger als die Reichen an die Türen der

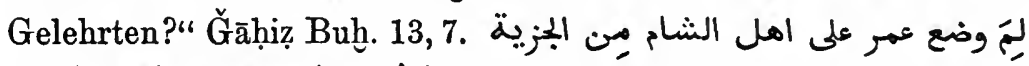
warum legte Omar den Syrern mehr Kopfsteuer auf als den Jemeniern?" (Vermeidung des Zusammenstoßens zweier selbständiger Praepositionen vgl. § 41,2 d) Balād. 73, 2. - Beispiele für Relatirsätze mit man $(m \bar{a})-\min ^{1}$ finden sich unten in No. 5 in größerer Zahl (vgl. auch S. 159 Anm. 1);

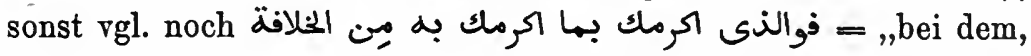
der dich geehrt hat mit dem Chalifat, mit dem er dich geehrt hat" Tab. III1 527, 13. أٌَّ هذيلٍ يُوازِن رِن اعدائنا ما نُوازن, welcher Hudailit nimmt es mit denjenigen unserer Feinde auf, mit denen

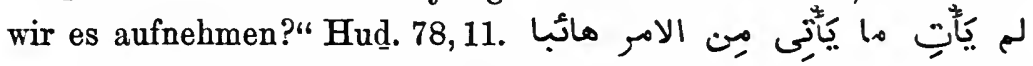
$=$,er macht . sich nicht furchtsam an die Sache, an die er sich macht" Ham. 32 Vs. 1. لو أنّ ما عند ابث بَبْرُة عندها من الغهمر ,wäre der Wein, der bei Ibn Bağra ist, bei ihr" Ag. ${ }^{2}$ VI 55, 6 v. u. ,sie ging unter mit denen, die untergingen“ $b=$,mit den andern" 1001 N. III 380, 5. Öfters mit Hervorhebung der gemeinsamen Beziehung der beiden Praedikate auf das Relativpron. (rgl. $§ 26,3$ c), z. B. Ar. امروا بما امر به حنيغة „er befahl ihr (dasselbe), was er Hudaifa befohlen hatte“ Tab. I4 1977, 17. 1 . du hast nicht die (gleiche) Ansicht

1 S. meine Syntakt. Verhältn. § 199. 


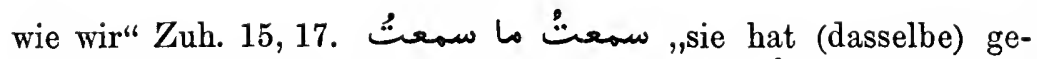

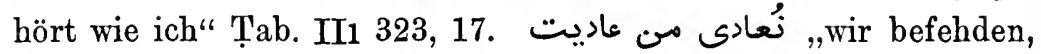
wen $d u$ befehdet hast" Tab. I6 3373, 2. Ferner I. Hiš. 24, 9. 13. 434, 3 v. u. Balād. 134, 4. 139, 1. Vulg. Srr. (a) بدهم sie wollen ihm eine Hochzeit bereiten, wie noch keine bereitet worden ist" Lbd. v. Am. 94, 3. illi birìd jihli bihli, ,wer sich rasieren lassen will, läbt sich rasieren" Neuar. Volksp. S. 103 Z. 24. Happ. (b) illi 'arrab eddāir hagg elbìr 'arrabhin ,derselbe der die Mauer des Brunnens gegraben hat, hat auch sie gegraben" 437, 4. ÄG. (b) tälit jōm 'amal ze $m \bar{a}$ 'amal el'auwal ,am dritten Tage tat er dasselbe, was er am ersten getan hatte" Contes 160,3. Aeth. I-16.

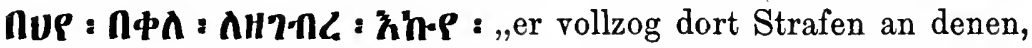

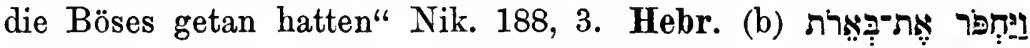
,er grub dieselben Zisternen, die sie gegraben hatten" (grub sie wieder auf) Gen. 26, 18. Syr. مصرم lehrt hatte, wurden wir siegen gelehrt" Sāhdōnā 28, 12. ه̄̄ ه مخ: doarch ihn tat er alles, was er tat" Jak. Ser. Hom. I 50, 15. Ferner Efr. I 41, 26, 4. 47, 16, 1. II 463, 5, 3.

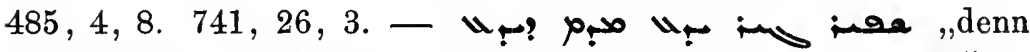

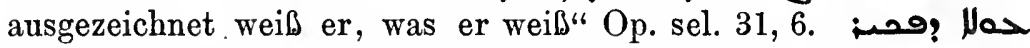
Jo; ג Tyrannen" Jak. Ser. 776, 15. Ferner Spic. 3, 6. 9, 3. 12. 12, 23. Efr. I 351, 12. II 345, 3. Carm. Nis. 113, 23. Sāhdōnā 308, 3.

Leitwort - Subjekt des Relativsatzes, z. B. Ar. مُنافِق معلوَ نein Heuchler, dessen Heuchelei bekannt ist" I. Hanbal I $382,15$.

a Leitwort - Praed. des Relativsatzes (vgl. $\S 38,2$ a), z. B. Ar. به ,einen Ruf, dessen ich mich bedienen soll" Buh. I 214, 16. Rückstände, die vorhanden waren“ Tab. I2

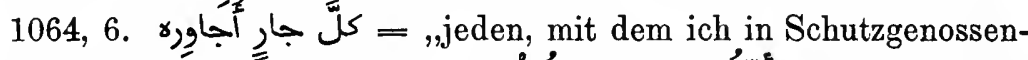

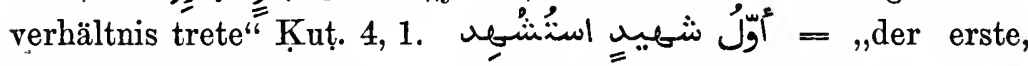
der den Märtyrertod erlitt" I. Sacd. VIII 193, 16. قeiner von euch, den ich getötet habe" Tab. II1 330, 7. 
an einem Platze, an dem der Elefant, wenn er an ihm stände, zittern würde" Bānat Súād $1 \wedge$. شاعرًا لا شُاعِرَ رِفُلُه Kāmil 659, 6. Ferner Kuur. 2, 56. 5, 115. 30, 29. 53, 4. I. Ḥanbal I 299, $b$ 12. Tab. I4 1849, 13. 1850, 5. Hierher gehören zahlreiche Relativsätze, die einen paronomastischen Akkusativ ( $(23 \mathrm{flg}$.) auflösen, deren Rückweisepronomen (عائد) also einen paronomastischen inneren Akkus. vertritt'; z. B. الصنع الذى منعته ,der Tat, die ich begangen habe" Ag. ${ }^{2}$ IV 49, 14. das Bündnis Allahs, das er mit ihnen geschlossen hatte" Tab. I1 93, 9. فَرْحتان

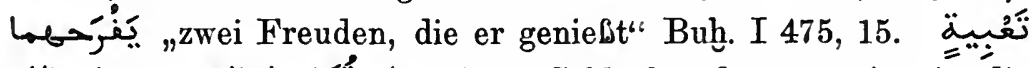
ثرَوه

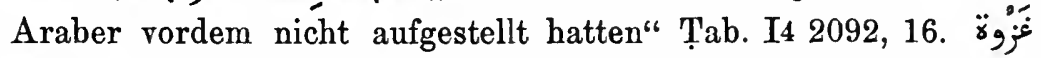

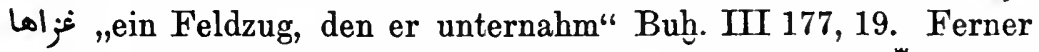

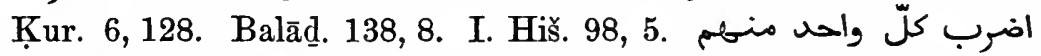
ich schlage jeden von ihnen doppelt so viel wie mich" 1001 N. II 279, 5. Ferner Beduinengesch. 9, 12. c So bei nominalem Praedikat (mit Genit. obj.): انَغْرَما انت غنارِ التَطُل الذى "eine Schuld, die du zahlen mußt" Ag. "den Zahlungsaufschub, den ich machen will" Nöldeke Beitr. Poesie d. Ar. 185, 5. die Belohnung, $d$ die er erwirbt" Farazdak I S. Iع^ ult. - Passivisch gewendet

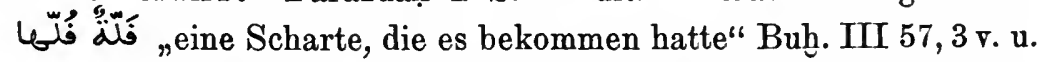

Vulg. 'IRĀḲ (a) ellī máa a llāh Allāh meāh ,wer mit Gott ist, mit dem ist Gott" Neuar. Gesch. 8, 7. (b) wușije auașșīk „einen letzten Willen, den ich dir äußere" Neuar. Ged. S. 92, 1. Neuar. Gesch. 38, 19. Sxr. (a) مكتوب كان هو كتبو ,einen Brief, den er geschrieben hatte" Tales 75, 16. mašwara ašâwarak fīh $\bar{a}$,etwas, worüber ich dich um Rat fragen will" Neuar. Volksp. 28, 11. (b) das Geschrei, das er machte“ Tales 1, 18. Lbd. v. Am. 14, 6. 86, 11. Neuar. Volksp. 31, 77. 45 hinter

1 Mit mā - min (8. oben S. 157): ما فتحع الله عليه مِن فَتُّح مكّة $=$,die Eroberung Mekkas, die Allah für ihn gemacht hatte"I. Hiš. 840, 7. .die Ausgaben, die ihr macht" Kur. 2, 273. 
Vs. 1. ÄG. (a) kalām jitkallim boh, ,ein Wort, das er gesprochen hatte" Spitta Gr. (Texte) 482, 1. (b) 'tta'ab elli tïibtuh ,die Qual, die ich ausgestanden habe" Contes 72 ult. Malt. (b) limhabba linhobbok "die Liebe, mit der ich dich liebe" Malt. Stud. S. 64 No. 15, 3.

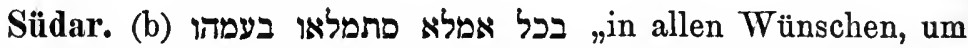
deren Erfüllung sie ihn gebeten hatten" CIS IV 2, 9. כל מלמל אלא סבאו "alle Züge, die sie unternommen hatten" CIS IV 2,10. 37, 7.

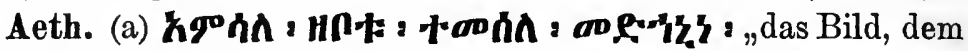

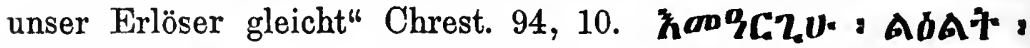

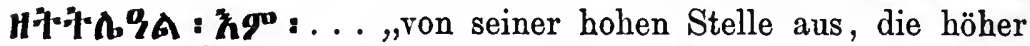

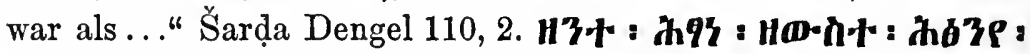
"dieses Kind an meiner Brust" Takla Hājm. 116b, 20. Ferner Chrest. 18, 19. 27, 24. Gadla Arag. 68 b, 10. Lal. 51, 10. Sarḍa

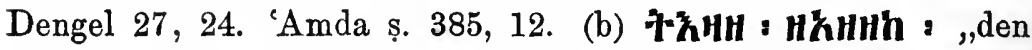

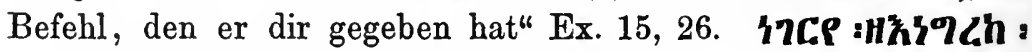
"das Wort, das ich zu dir rede" "Amda Ș. 323 ult. ong̈hF: , H\&h6." „der Brief, den er schrieb" Chrest. 70, 3 usw. (d)

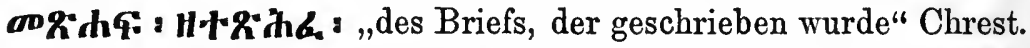

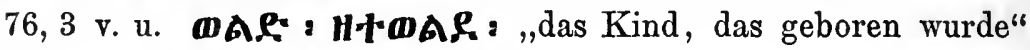
Gadla Ar. 56a, 3 v. u.

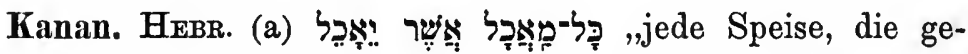
gessen wird" Gen. 6, 21. Lev. 11, 34. Deut. 28, 54 usw.

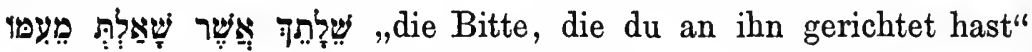
1 Sam. 1, 17. MIŠNa. (a) גרולה שבגדולות ,die große unter den

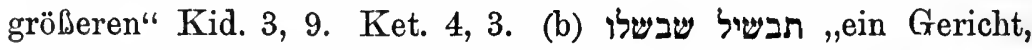
das sie gekocht haben" 'Orlā 3,4. Ned. 10,4. Naz. 5, 4. PнöN. (b) ,für jedes Opfer, das er darbringt" CIS I 165, 15. Lidzbarski, Nordsem. Epigr. S. 434 No. 10, 2.

Syr. (a) ojon? "sieben Leuchter, die leuchteten" Is. Ant. I 160, 1774. 92, 187-9. Efr. I 43, 3, 4. (b) \{Läo'

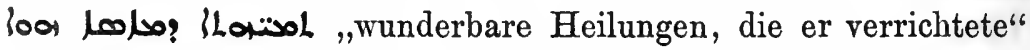

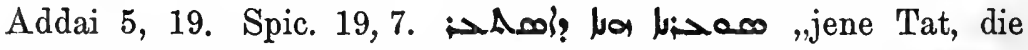
begangen worden war" Addai 16, 7. 6, 22. Is. Ant. I 92, 166.

Ass. (b) ina dīn idinu, in dem Prozeß, den er geleitet hat" Hamm. 6, 15. 
Status constr. - Praed. eines genitivischen Relatirsatzes

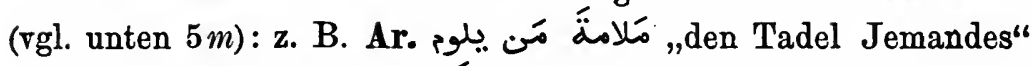

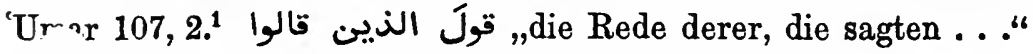

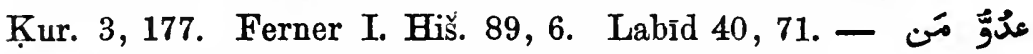
حُبُّ .der Feind derer, die sie befehden" Balādِ. 82, 15. عاداهما die Liebe zu der, die mich nicht liebt" Ağ. ${ }^{2}$ I 176,

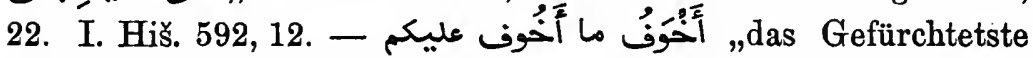
dessen, was ich für euch fürchte" = „das, was ich am meisten für euch fürchte" ${ }^{2}$ Mas. IV 454 ult. I. Hišs. 151, 18.

Ein Wort des attributiven Relativsatzes - ein anderes Attribut: Ar. eine leichte Waschung, die Amr für sehr leicht erklärte" Buh. I 220, 14. Syr. مالحمب و (3)? „deinem erhabenen Vater, der uns erhoben hat" Afr. II $100,14$.

2. Das Verhältnis des gesamten Relativsatzes zu andern Satzteilen: Der Relativsatz einem andern Satzteil koordiniert oder

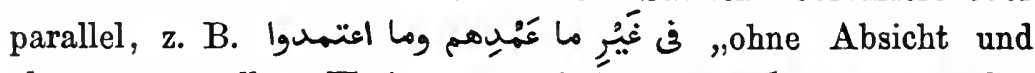

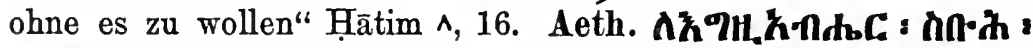
H+h-nh, "Gott den Gepriesenen, der gepriesen ist" Due framm.

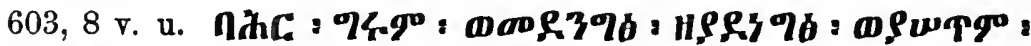
$n^{\prime} n^{-}:$,des fürchterlichen und schrecklichen Meeres, das alles in

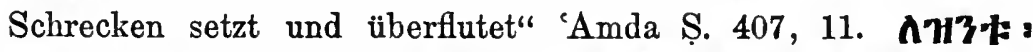

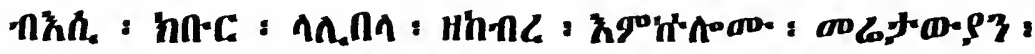
„dieses bedeutenden Mannes Lālỉbalā, der bedeutender war als

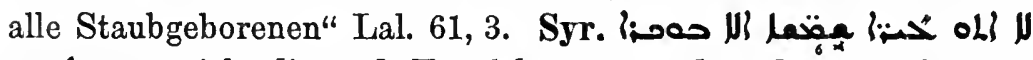
, "nacht dienende Engel kamen, sondern der erstgeborene, der bedient wird" Efr. II 465, 8, 5 .

- 3. Der Relativsatz enthält eine nähere Bestimmung, die dem Leitwort ebensogut unmittelbar beigegeben sein könnte; das

1 Also, wenn es ein Genit. subjectivus ist, gleichwertig mit (s. $\S 31,5$ ).

2 Vgl. § 31,4e. Ein anderer Fall ron Paronomasie in dieser bekannten Konstruktion ist sie harrten mit einander aus das Stärkste dessen, was es an Ausharren gibt" Ham. 254 ult. ihn ${ }^{*} 1001$ N. II 24,1 .

Reckendorf, Paronomasie. 
Leitwort verhält sich zum Relativsatze wie ein Korrelativum (vgl.

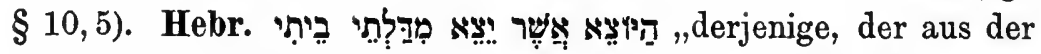

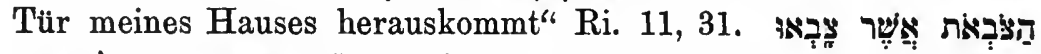

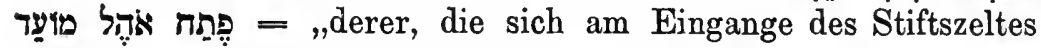

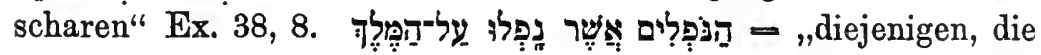

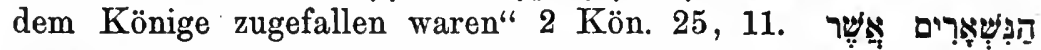
מִן von jenen Rossen, die darin

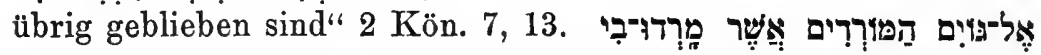
= ,zu jenen Völkern, die sich gegen mich empört haben“"Ezech. 2,3.

- 4. Der Hauptsatz ist Subj., der Relativsatz ist als Ganzes إتّما المؤمنون الذيث آمنوا بالله Rominales Praedikat, z. B. Ar. die Gläubigen (sind) diejenigen, die an Allah und seinen Boten glauben" Kur. 24, 62 (49, 15). هie (sind), was

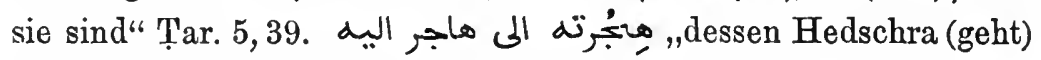
dahin, wohin er sie gemacht hat" Buh. III 35, 9 .

- 5. Der Relativsatz ist indefinit, indem er Alles wiederholt, was sich aus dem Inhalte des Hauptsatzes ergibt ${ }^{1}$; alles Andere ist ihm gleichgiltig $(a-f)$. Die Gleichgiltigkeit kann dann praegnant werden, indem Wert darauf gelegt wird, festzustellen, daß sie vorhanden ist; oder sie kann fingiert sein, indem bedeutsam auf einen Vorgang angespielt wird und auf den Hörer ein leiser Zwang ausgeübt wird, die Anspielung in der richtigen Weise zu beziehen $(g-k)$.

a Der Gebrauch dieser Konstruktion ist also mannigfaltig. Zunächst Sätze, die nur leicht indefinit sind: Ar. هرب من هوب من "es floh, wer unter ihnen floh" = "es floh eine Anzahl von

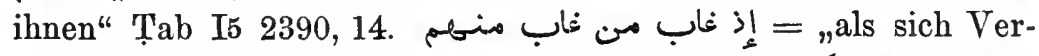

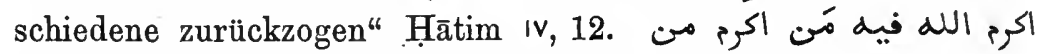
=, an dem Allah gewisse Gläubige ehrte" I. Hiš. $571,9 . . .$. . . sie haben gewisse Zahlen...

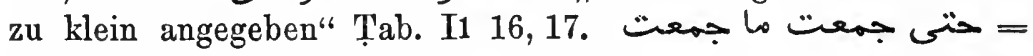
„bis ich eine gewisse Menge gesammelt hatte" Bub. III 65 ult.

1 Gleichwertig einer substantivischen Ausdrucksweise wie فعلت "sie führte ihre (bekannten) Taten an ihm aus" Ahțal 155, 1. 
= die Ursache, um derentwillen der Bericht mancher unter ihnen verworfen wird" Tab. I1 6, 13. Ferner Kur. 51, 9. Tab. I1 218, 5. I4 1952, 11. II2 1154, 9. Buh. III 26, 3 v. u. I. Hiš. 31, 12-13. Ḥam. 262, 21. -

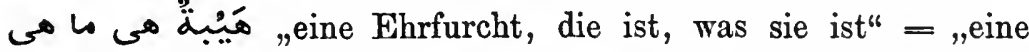
gewisse Ehrfurcht" Kāmil 260,12. So ferner Tab. II1 483, 15. Kāmil 301, 18. - مب مب مب ,er war jung was [= so lange] er jung war"1 $=$,er war eine zeitlang jung" Ham. 380 Vs. 3. So ferner I. Hiš. 98, 26. Hamdān̄i Geogr. 209, 22.

$b$ Das Genauere über den Relativsatz ist oft aus den unmittelbar oder in größerem Abstande rorangehenden Worten bekannt, z. B. als Obaid Allah den vorhin er-

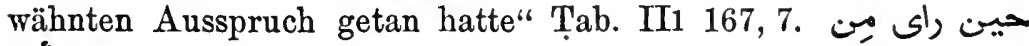
,als er den eben geschilderten Widerstand

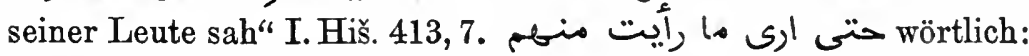
„bis ich sähe was von ihnen ich gesehen habe“"2 Tab. I5 2745, 11. nicht durch Menge haben wir jene

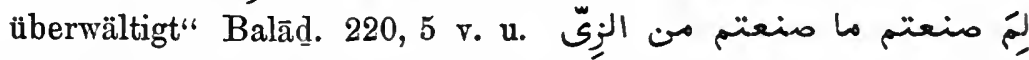
, ,warum habt ihr jene Kleidung angelegt" Tab. II2 1278, 17. ,als er sich aufjenem seinem Rachezuge befand" Tab. I4 1902, 10. Ferner I. Hiš. 120, 7. 149, 3. $413,7.547,10.584,10$. I. Sa'd Gesandsch. 2, 23. T. Kut. K. al máārif 132, 14. Tab. IIi 68, 9. II2 979, 5. Balād. 220, 4 v. u. فعلت = ich tat das" 1001 N. I 196, 3. 223,3. Beduinengesch. 10,6.

c Oder es ist sonstwie aus der Erfahrung oder Geschichte, oder aus dem Sprachgebrauche bekannt. Z. B. بلغتم ما بلغتم بالاقتباء $=$,ihr habt eure Erfolge durch Nachahmung errungen" Tab. I5 2803,15. was ist es, was jenen Fehltritt bei euch herbeigeführt hat?" Tab. I4 1957, 1. darüber hat der Bote Gottes seinen

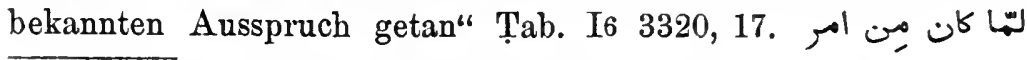

1 Siehe meine Syntakt. Verb. § 209 und S. 581. Anm. 3.

2 رايت gehört zu Lo, nicht zud so öfters; es ist wie $S_{8} 45$ 
, als die Sache Husains die bekannte Wendung nahm" Tab. II2 308, 13. افتتحع من ارض فارس ما افتتحع =, er machte seine Eroberungen in Persien" Balād. 403, 9. عاد منار "dies Herz sucht das alte Liebesleid heim" Hud. 132, 1. Ferner Tab. II2 793, 5. Ag. ${ }^{2}$ II 14, 20. Kumait 2,90. Huṭ. 74, 2. Kur. 53, 10. I. Hiš. 410, 6 .

d Stärker tritt das Indefinite in Sätzen wie die folgenden hervor: (mag es begehren, wer es begehrt" = "mag es begehren, wer will" Ahțal 33, 14. Allah erhört, wen er will“ Tab. I4 1916, 10. darf sie sein, was sie auch sei?" Ag. ${ }^{2}$ V 158,5 v. u. من قبلنى على هذا كانس wer mich unter dieser Bedingung aufnimmt, mag mich aufnehmen" Ag. ${ }^{2}$ V 7, 4. Ferner Tab. Í 2935, 15. II1 299, 9. Hud. 171, 9. Ḥam. 30 Vs. 1. 254, 22. 295, 8. Nöldeke Beitr. z. Poesie d. Ar. 120 Vs. 5.

Da der Inhalt des Relativsatzes hier derselbe ist, wie der des Hauptsatzes, da also Alles, was unter den Relativsatz fällt, auch unter den Hauptsatz fällt, so ergibt sich unter Umständen die Vorstellung der Totalität, Ausnahmslosigkeit und damit verbunden

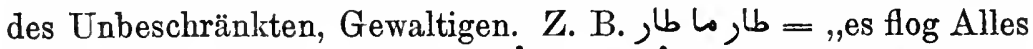

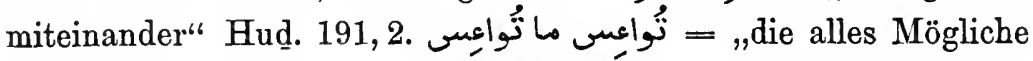

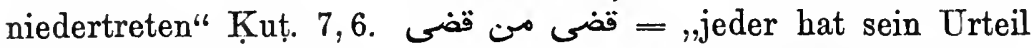
dahin abgegeben daß .."Hud. 99, 27. sie

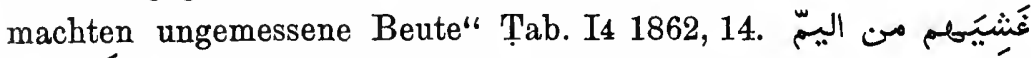

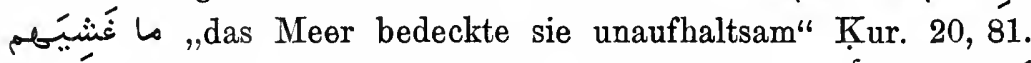
f Und' ferner die Vorstellung des Unabänderlichen مَن حان حائن "خلا ما حلا "wer untergeht, muß untergehen" Ag.

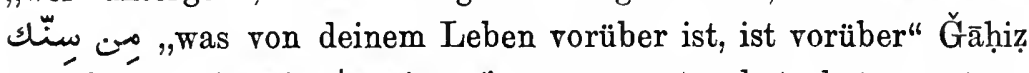
Buhalā 116, 5. قد من منع ما منع "was er getan hat, hat er getan"

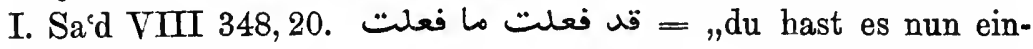

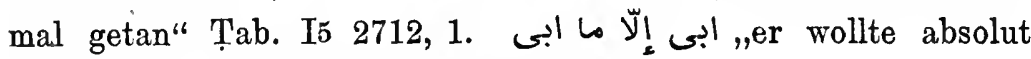
nicht" I. Sa'd V 110,9 (ZDMG 61, 457).

Während sich in obigen Sätzen der Inhalt des Nebensatzes deswegen mit dem des Hauptsatzes deckte, weil es unmöglich oder unnoòtig war, ihn reicher zu gestalten, wird in den folgenden Fällen 
der Inhalt des Nebensatzes geflissentlich so dürftig gehalten, obwohl es eigentlich nötig wäre, deutlicher zu reden.

$g$ Der Relatirsatz ist geheimnisvoll, wie اقبل يُريد ما يريد إنو $h$ kam in bestimmter Absicht" Tab. I4 1955, 10. Er kann bedeutsam die erste Person umschreiben يَمِرْ مَعْبِلَ الحتّ الذى هو مائر "es wird Hort des Rechts der, der es werden kann" (= ich) $i$ Labỉd 27, 22. Oder er enthält eine boshafte Anspielung, wie ,über die die Leute gewisse Dinge

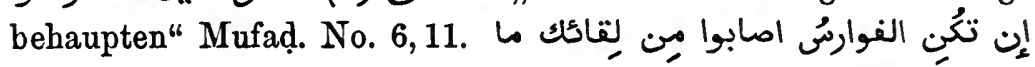
ا إبوا "wenn die Reiter ein gewisses Zusammentreffen mit dir $k$ gehabt haben" Nāb. 4,5. Oder es ist dem Erzähler zu peinlich,

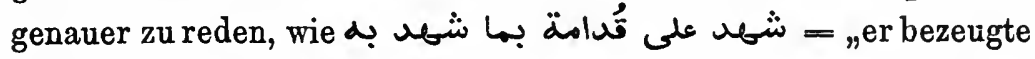

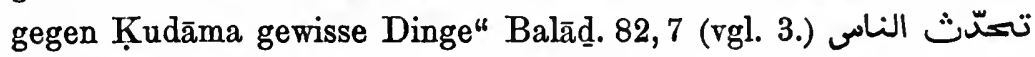

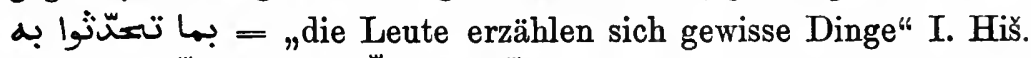
733, 16. deren Bewohner sich etwas derartiges gegen mich herausgenommen haben" Tab. I6

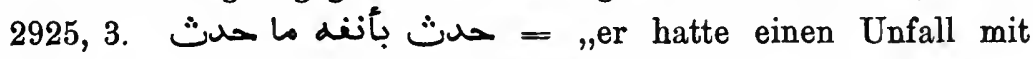

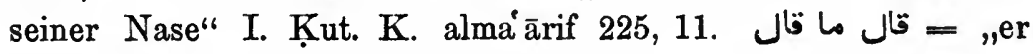
sprach das furchtbare Wort" Ruk. 59,4.

$l$ Das durch den Relativsatz nur obenhin gestreifte Ereignis wird manchmal nachträglich genauer mitgeteilt, z. B. أن ينول daß er jenen seinen Ausspruch tat, daß er nämlich den Menschen nicht gliche" Tab. I1 471, 5.

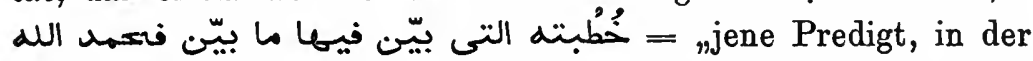
er seine bekannten Auseinandersetzungen vortrug; er pries nämlich Allah usw." I. Hiš. 968, 6. Ruk. 59, 4 (s. Barth ZDMG 57,390 z. St.)

Bisweilen hängt der Relativsatz von einem Nomen ab (vgl. oben S. 161 sowie § 31,5), wie des Abfalls

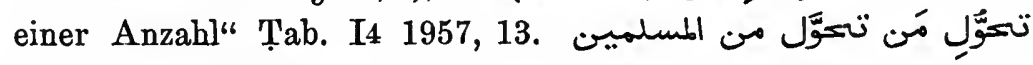
„der Auswanderung einer Anzahl von Gläubigen" Tab. I5 2481, 14. den Abscheu solcher, die Abscheu empfinden" 'Umar 89, 18. انت القائل فى زياد ما قلت ل, du bist der, der über Zijãd jenen Ausspruch getan hat" Tab. II1 70, 9 (akkusativischer Satz). 
Selten sind solche Relativsätze mit النى gebildet, wie ,wenn zur Zisterne geht, wer zu ihr geht“

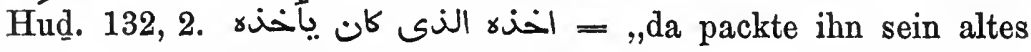
Fieber" Tab. I4 1943, 3. Labīd 27, 22.

Vulg. "IrâK. (d) mahmā fa'altu f'alū ,tut was ihr wollt" Arab. Volksl. S. 56 No.3, 7. Srr. (a) kān mā kāan hatta kān tlāta bnät uhwät „es geschah, was geschah, da waren drei Schwestern" = „es waren einmal drei Schwestern" Damas 56, 8 v. u. und so öfters am Anfang von Geschichten. (f) مضى مض مضى مضى , gangen ist, was vergangen ist" Lbd. v. Am. 38, 11. حمل (der Bräutigam hat, erreicht, was er erreicht hat" Lbd.v. Am.88, 16. (k) تانو مار الم صار , bis diese böse Geschichte geschehen ist" Tales 89,16 . (1) habbūili mã habbüli habbüli šakfet $k a k_{k i}$,sie versteckten mir etwas; sie versteckten mir ein Stück Kringel" Pal. Diw. 18 No. 4,2. Hạpr. (d) dar dār ma $d \bar{a} r=$,eine Mauer die alles umgibt" 395, 4 v. u. ÄG. (a) weahadu elli hadīh = „und sie nahmen etwas" Spitta Gr. (Texte)

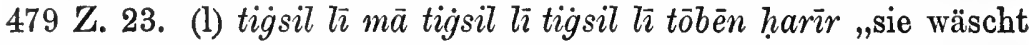
für mich, was sie für mich wäscht; sie wäscht für mich zwei seidene

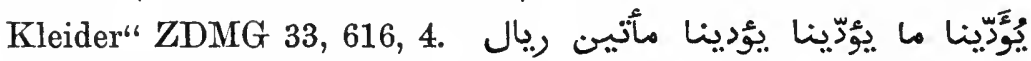
„er zahlt uns, was er uns zahlt; er zahlt uns 200 Rijāl“ ebenda 630,4 . MaLт. (a) kien mā kien štraina . . = =, wir kauften einmal" (s. o. bei Syr.) Malt. Stud. S. 67 No. 37, 1. Mar. (a) had du li hyeddo = ,einst" Houw. 14, 3. 52 ult. usw. (e) sadd mā itšadd wurh $\bar{a}$ ma titnarha $=$ „er schnürte alles und lockerte alles" Mar. 182, 13. 188, 21.

Südar. Sותן, so daß starb, wer starb" CIS IV $126,12$.

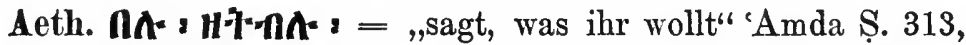
8. 417, 6. (f) Hhy : hqक a ,was geschehen ist - sein Geschehensein!" = „es ist nun einmal geschehen“ Dillm. Gr. § 199 b.

Hebr. (b) (b) , da opferte Salomo jenes Friedensopfer für Jahve" I Kön. 8, 63. (c) (c)

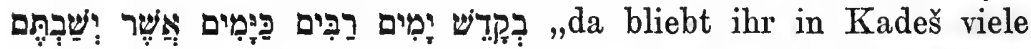
Tage, die bekannte Anzahl von Tagen" Deut. 1, 46. רֶּ 


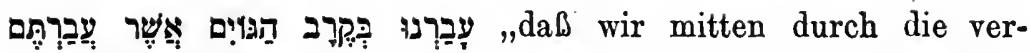

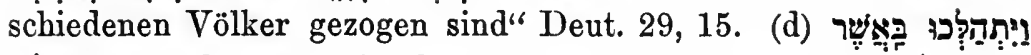

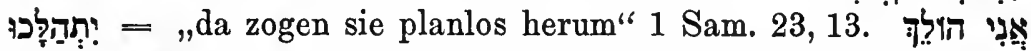
,ich gehe ohne bestimmtes Ziel" 2. Sam. 15,

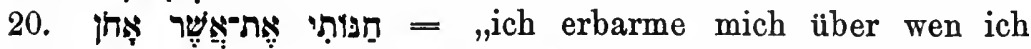

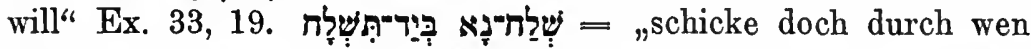

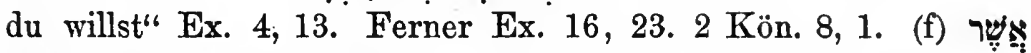
wer dem Tode verfallen ist, ist dem Tode verfallen"

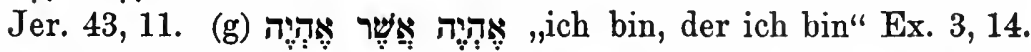
Mišsü. (f) מה שנתן להם אביהם נתן ,was ihnen ihr Vater gegeben

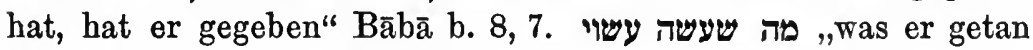
hat, ist getan" Bek. 4, 4. Ferner Tāmīd 1, $2(5,2$.$) Bek. 5, 6$.

\$ 41. Adverbialsätze. 1. Die paronomastischen Bestandteile. Am meisten Beachtung verdient auch hier die Paronomasie der

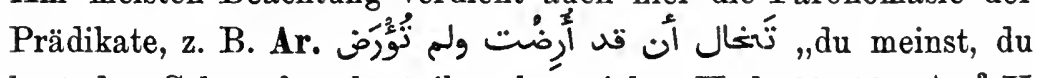
hast den Schnupfen, hast ihn aber nicht" Hud. 20, 12. Ag. $^{2} \mathrm{X}$ 71, 8. ( = 175, 16). ich pflegte zu sein" I. Sacd

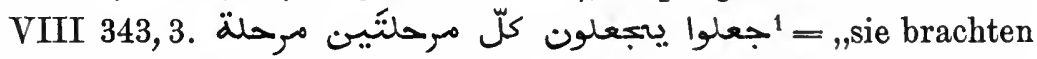
alsbald je zwei Tagemärsche in einem fertig" Tab. IIa 555, 7. wenn er ein neues Kleid angetan hatte“ Beduinengesch. 4, 11. Wohin sich der Wind mit ihm bewegt, dahin bewegt er sich" Ag. ${ }^{2}$ I 167,

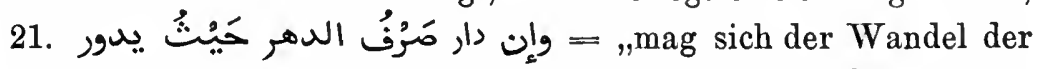
Zeit drehen wie er will" I. Kut. K. aššir 434, 5. Ag. ${ }^{2}$ IV 48, 22. أنr kleidet sich nur in Eisen, wenn

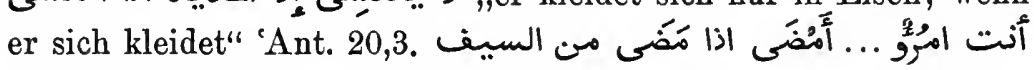
„du bist ein Mann, durchschneidender, wenn er durchschneidet, als das Schwert" Ḥuṭ. 32, 5. Ag. ${ }^{2}$ VIII 100, 19 (= $\left.{ }^{1} 104,13\right)$. Ham. 342 Vs. 2. - Allah hat sie nun einmal geschaffen" I. Hanbal I 358, 2. Ferner 'Amr Mu'all. 103. Ag. ${ }^{2}$ IV 44,14 ( ${ }^{1} 44,4$ v. u.). Kāmil 747,19 . - لهّ

1 Verba in Verbalabhängigkeit sind Nebensätze. Vgl. zu obigen Ausdrücken im Syr. (jedoch bei anderem syntakt. Verhältnis) -oäg No -ö̈ "was vorgefallen war" Addai 16,15. al loa loo L Lo "er war ihr Arzt gewesen" Carm. Nis. S. 40 Vs. 19. 
,als sie die Person des Amr ibn 'Āmir trafen, trafén sie in ihm eine Rache" Kāmil 735, 5.

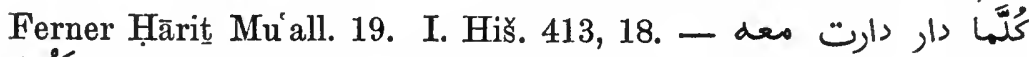
"so oft er herum ging, ging die Schüssel mit ihm herum" I. Sa'd VIII 116, 22. - إن نفر منك نفر هنّى "wenn er vor dir flieht, flieht er auch vor mir" Ag. ${ }^{2}$ II 13, 29. Ferner Ham. 154

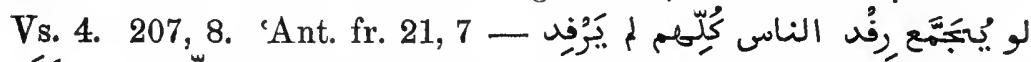
لَ, wenn die Wohltätigkeit aller Menschen zusammengezählt würde, wären sie doch nur weniger wohltätig als er" Ahțal 72, 9. Ferner 'Ant. 19, 20. 'Ag. ${ }^{2}$ VIII 104, 21. Ham. 75, 20.

Vulg. 'IRĀṛ. Killmā ğād elfahad ğādat nwāmīsah =,,je tapferer der Panther wird, um so mehr nimmt sein Ehrgeiz zu" Neuar. Ged. I S. 102, 4 v. u. Srr. 'in kiān $l \vec{\imath}$ 'ab jâa ni ìm kân $l \bar{\imath}$,hätte ich einen Vater, o welch Glück besäße ich" Neuar. Volksp. S. 30, 55. Lbd. v. Am. $68,15.108,3-2$ v. u. ÄG. tili lamma tili barra 'Tbeled $=$,er' ging bis vor die Stadt hinaus" Spitta Contes 159, 8 (Vermeidung des Zusammentreffens von Konjunktion und

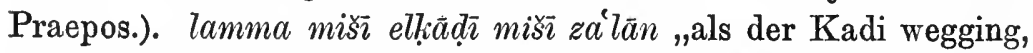
ging er zornig weg" Spitta Contes 81, 2 v. u. MaLt. umalli wasal fei kellu jâsal ,,und als er gelangt war, wohin zu gelangen ihm bestimmt war" Malt. Stud. 28, 21. Tusis. kî̀f nmūtū nmütü ižmīá „wenn wir sterben, sterben wir zusammen" Märchen 54, 15.

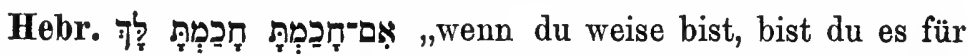
dich" Prov. 9, 12. Mišnã. אם מתו מתו לו "wenn sie sterben, sterben sie für ihn" Jeb. 7, 1. Ned. 9, 7. Bābā m. 8, 8 usw.

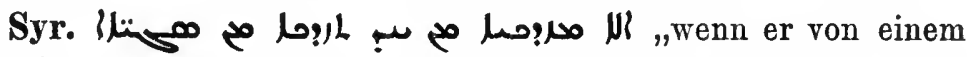
nicht besiegt wird, wird er von vielen besiegt" Phil. 431, 5.

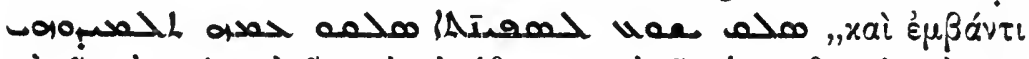

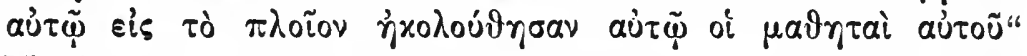
Matth. 8, 23. $\boldsymbol{\omega}_{3}$ : $\boldsymbol{\nu}_{3}$ مa ,so betete er, als er betete" Jak. Ser. Hom. 232, 14. Ferner Phil. 39, 12. Afr. II 101, 5. Phil. 407, 11. Ahīkār 36, 20.

2. Unter den verschiedenen Arten der Nebensätze sind es hauptsächlich die Vergleichungssätze, die zu Paronomasien Anlaß 
geben, indem in ihnen das tertium comparationis aus dem Haupt-

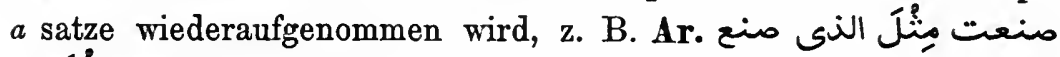
[إنّى . ich machte es wie er es machte" I. Hanbal I 242, ich werde vom Fieber befallen, wie zwei Männer von euch befallen werden" I. Hanbal I 381, 4 v. u. ich warf mich auf dem feuchten Boden herum, wie sich ein Lasttier herumwirft" Buh. I 98, 7.

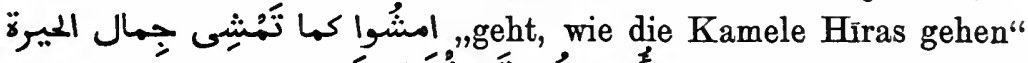
Hud. 14, 1. ich bin den Huzāa nicht zugetan, wie ein Freund zugetan ist" Hud. 63, 1. Ferner Ham. 192, 9. 15. Buh. I 59, 4. I. Hiš. 23, 13. Tab. I4 1864 ult. Hud. 260, 4. 261, 21. 273, 28. 1001 N. I 18, 5-6 usw. ${ }^{1}$

b Durch die bloße Vergleichungspraeposition würde eine streng grammatische Beziehung des secundum comparationis entstehen, von der die Art seiner natürlichen Beziehung auf das Verbum beim primum comparationis oft verdunkelt würde; eben dies wird durch Wiederholung des Verbums und Verwendung einer Konjunktion statt einer Praeposition verhindert, vgl. oben S. 157. Vgl. Sätze wie يَعْرفونه كها يعحِفون أَبْناءهم sie erkennen es, wie sie

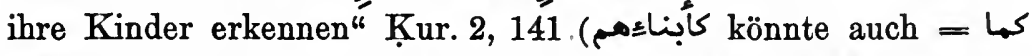
sein). Kur. 4,50 usw. Ein wirkliches Mibrerständnis würde allerdings dem denkenden Leser nur selten unterlaufen.

c Ferner wird von der Praeposition der Vergleichung naturgemäß zunächst nur der von ihr abhängige Genitiv nebst seinen Attributen und Dependenzen betroffen, nicht aber ein weiterer Satzteil des secundum comparationis (Objekt, praepositionaler Ausdruck), der vielmehr in vielen Sätzen grammatisch eigentlich immer nur auf das regierende Verbum im primum comparationis bezogen werden könnte. Auch hier wird größere Genauigkeit und Abrundung dadurch herbeigeführt, daß das Verbum beim secundum comparationis wiederholt wird und ihm die Form eines Satzes gibt.

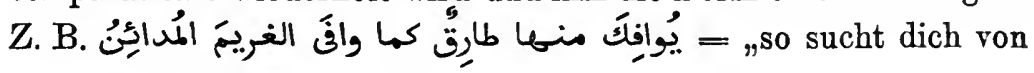

1 Vgl. auch هؤلاء كها أرى أرى sind sie nun einmal" Tab. П1 242, 3. 
ihr ein nächtlicher Besucher auf, wie den Schuldner der Gläubiger"

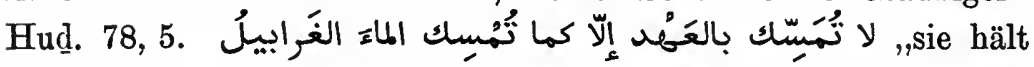
den Bund nicht besser als die Siebe das Wasser" Bānat Súād S. vv. Ferner Hud. 88, 2. 131,11. Ruk. 17,7 usw. - يُنْبُتون كمان

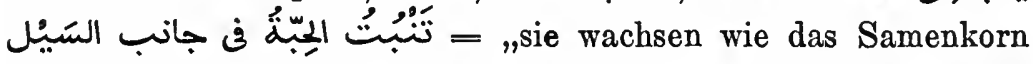
am Ufer des Bachs" Buh. I 13, 3 v. u. نُرنا كها دارت على

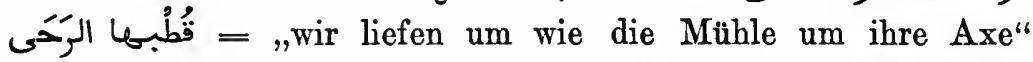
'Ant. 7, 13. Ferner Hud. 247, 7. 'Ant. Mu'all. 25. Tab. I4 1877, 6.

Einige der angeführten Vergleichungsausdrücke sind unter Beibehaltung dieser ihrer Wortstellung schon deswegen nur in Gestalt von Sätzen möglich, weil sonst die Vergleichungspraeposition unmittelbar vor eine andere Praepos. zu stehen kommen würde (vgl. S. 157.) So ist denn ein paronomastischer Satz immer erforderlich, wenn das secundum comparationis nur aus einem

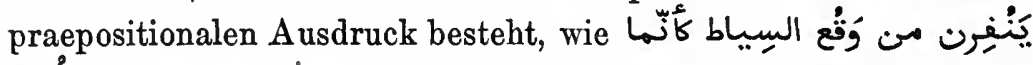
, sie scheuten vor dem Niedersausen der أُ لا تبنُلَ للروم . Peitschen wie vor einem Löwen" Hud. 90, 28 daß du den Byzantinern nicht das gleiche

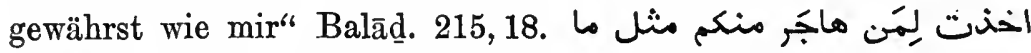
ich habe denen unter euch, die die Hedschra gemacht haben, das gleiche vorbehalten wie mir selbst" I. Sacd كُتِب عليكم الصبام كها كتب على اللّين من قبلكم . Gesandsch. 13,11 $=$ „das Fasten ist euch vorgeschrieben wie denen, die vor euch waren" Kur. 2, 179. Ebenso [kann nur im Satze ein adverbialer حدّثنى Akkusativ nach der Vergleichungspartikel vorkommen, wie ,er erzählte mir wie beim ersten Male“ I. Hanbal IV 44, 17.

e Auch kann nach der Praepos. s kein Genitivsuffix stehen, daher heißt es notwendig من فعل كما افعل اؤل =,wer es macht wie

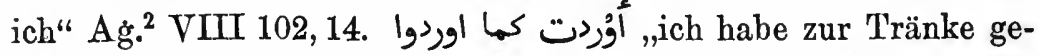
führt wie sie" Kāmil 187, 1. Ferner Hudِ. 266, 28. Nāb. 5, 35. I. Kut. K. aššír 526, 21.

Vulg. Srr. (a) 'allā jižčlō mbārak mitil mā bārak limsīh „Allah segne ihn, wie er den Messias gesegnet hat" Neuar. Volksp. 
S. 21, 63. (c) bērūt țāa atlu miț mā jețāet traija lalmejāzīni = „Berut gehorchte ihm wie das Siebengestirn dem Orion" Pal. Diw. 210 No. 1. 305 No. 4. (d) bi'addmū lum mitil mā'addamū lirrža $\bar{l}=$,man bietet ihnen an wie den Männern" Neuar. Volksp. S. 16 Mitte. Tales 63, 15. (e) nāmū 'alā l'ard kamā nimnā

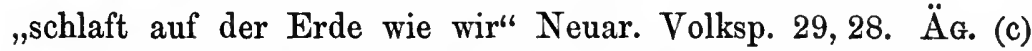
a'mil zēji $m \bar{a}$ 'amalt ennōba dikha fi 'lkalb ,tue, wie du damals dem Hund getan hast" Spitta Contes 144,5 v. u. (e) a azzibhā $z \bar{e} j i{ }_{\bar{a}}$ 'azzibetn $\bar{\imath}$,ich will sie quälen wie sie mich gequält hat" Spitta Gr. (Texte) S. 447, 11 v. u. MaLt. (a) dalferh dām daḳs kem dāmu lfūss ,diese Freude dauerte solange wie das Geld مايف كما ايصيف عشب (a) (a) مalt Stud. 6, 12. TRIP. مer welkt dahin wie das Gras der Frühlingsweide dahinwelkt" Lieder No. 27, 1, 4. TuNis. (a) dažž̀t kmā dažz̆ maḥūḳ ,,ich bin in Aufregung geraten wie einer, der sich verbrannt hat" Märchen 93 Ged. 38.

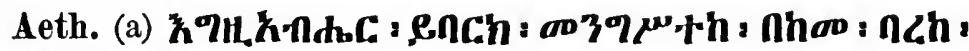

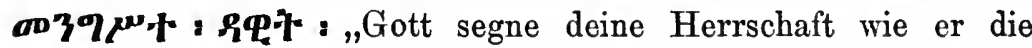
Dawids gesegnet hat" Gadla Ar. 72b, 7 v. u. 'Amda Ș. 415,6-7.

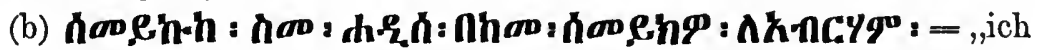
gab dir einen neuen Namen wie dem Abraham" Takla Hājm.

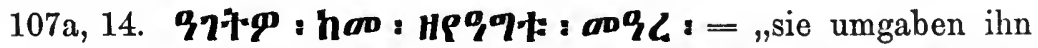

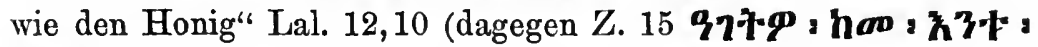
ongC).

Hebr. Viele Stellen mit Tempuswechsel, wie

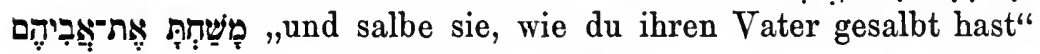
Ex. 40, 15. Lev. 16, 15. Deut. 6, 16 usw. ${ }^{1}$ Vgl. noch dreifache

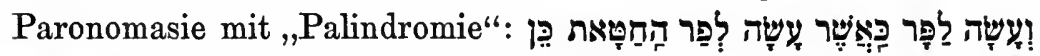

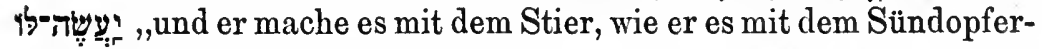
stier gemacht hat, so mache er es" Lev. 4, 20. - Mišñ̄. (d) מאיימין man ängstigt sie wie man Zeugen in Blutsachen ängstigt" Sōṭā 1,4. Ket. 6,6.

1 Zusammentreffen zweier selbständiger Praepositionen ist im Hebr. nicht ausgeschlossen (Num. 21, 34 usw.), würde also kein Hindernis für die Verwendung der Praep. ๖ bilden. 
3. Sind Bedingungssätze mit Verschiebung (s. meine Syntakt. Verhältn. § 232) paronomastisch, so enthält der Hauptsatz meistens eine Bestätigung und Verallgemeinerung, z. B. كَن سَاءه فَسِى "wem es unangenehm ist, nun, dem geschieht eben Unangenehmes"

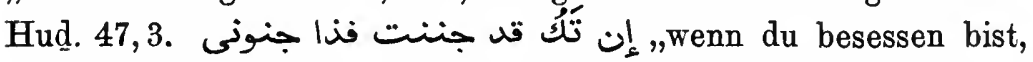
nun, so ist das meine Besessenheit" Ag. wenn sie uns getötet haben, nun, so haben

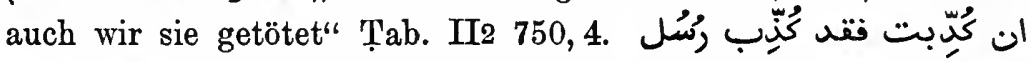
wenn ich für einen Lügner erklärt werde, nun, so sind ja auch Boten vor mir. für Lügner erklärt worden" Tab. II2 685, 5. أن عاقبت نأنت وليَّ العُقوبة ,wenn du strafst, nun, so

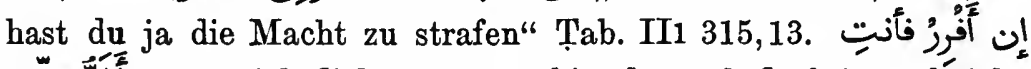
,wenn ich fliehe, nun, so bist du noch flüchtiger alś ich“ Hud. 240, 2. Ferner Kur. 12, 77. Hud. 77, 1. Nāb. 4, 1. Mưall. Ḥārit 65. Ham. 5.5 Vs. 4. 209 Vs. 4. Delectus 7 ult. I. Hiš. 588, 3. Tab. I4 1922, 14. I5 2423, 3 usw. ${ }^{1}$

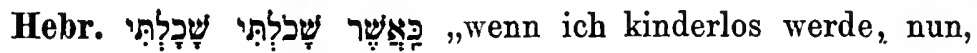
so werde ich kinderlos" Gen. 43, 14. Esther 4, 16. Vgl. auch 2 Kön. 7, 4. MišNā. . אם נתרפא נתרפא = ,wenn er geheilt wird, hat es nichts zu sagen" Šabb. 22,6. Ferner Pes. 3, 3. Sōțā 1, 5.

4. Adverbialsätze auf Nomina bezogen (s. Syntakt. Verhältn.

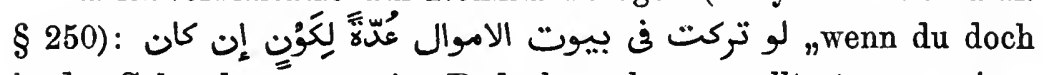
in den Schatzkammern eine Bedeckung lassen wolltest wegen eines Unfalls, wenn er eintreten sollte“ Tab. I5 2414,17. حلفت بربّ ich schwöre bei dem Herrn der dahinziehenden,

1 Dem Sinne nach verwandt sind indefinite Relativsätze wie wer immer wegen einer unrechten Handlung getötet werden mag - du wirst wegen einer rechten getötet" Tab.

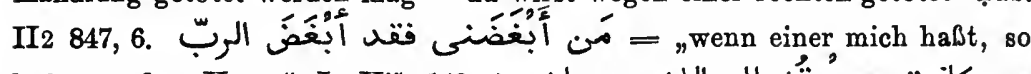

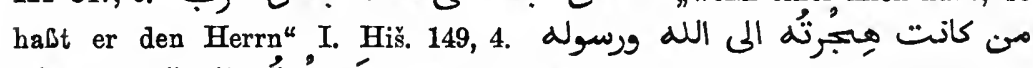

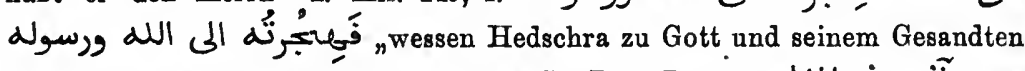

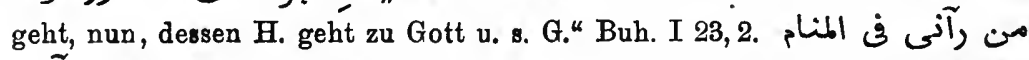
"wenn mich einer im Schlafe sieht, so hat er mich (wirklich) gesehen" Buh. I 40, 7. Vgl. noch Syntakt. Verhältn. § 230 und S. 728 unten. 


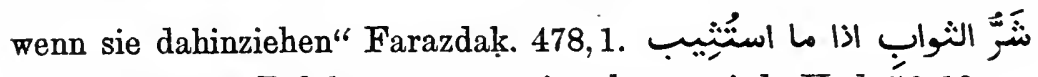
„die schlimmste Belohnung, wenn sie erbeten wird" Hud. 56, 13. مورً كمe

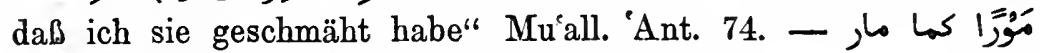
mit einem Wogen, wie das Schiff mit geschwellten

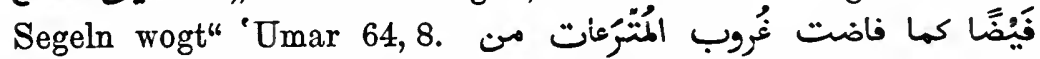
mit einem Guß, wie die Schläuche der wasserbeladenen Bewässerungskamele gießen" Nöld. Beitr. z. Poesie d. Ar.170 Vs. 2. ein Zufluchtsuchen [= in einer Weise], wie die Tauben vor dem Habicht Zuflucht suchen" Tab. II2 777, 2. Ḩam. 135, 3. I. Hiš. 238, 4 .

§ 42. Paronomasie bei Vereinigung zweier Nebensätze: wenn Ḥasan dich mit 100,000 Schwertern hätte schlagen wollen, würde er es getan

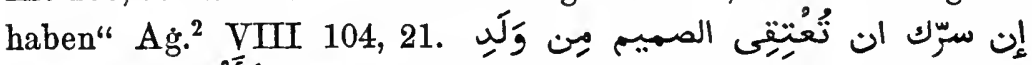
wenn es dir Freude macht, echte Nachkommen Ismaels freizulassen, so laß von diesen frei" Kāmil 265, 10. Buh. III 433, 13 usw. Vulg. Srr. وقت ما حسن بشوف als Hasan sah, daß seine Mutter betrübt

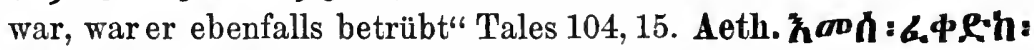

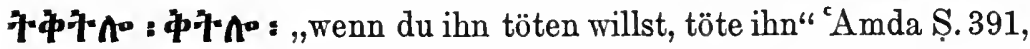

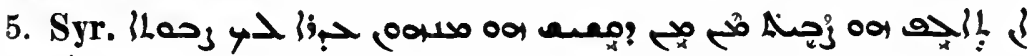
حأ (L) "wenn du lernen willst, ist es zweckmäbig, von Jemand,

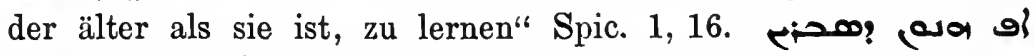
إمهده مسمى loa N, ,auch jene, die meinen, sie beständen gegenüber, bestehen nicht durch Kraft" Spic. 20,25. Phil. 431, 21.

\section{Isolierung. ${ }^{1}$}

§ 43. Wiederholung des isolierten Wortes statt Rückweise-

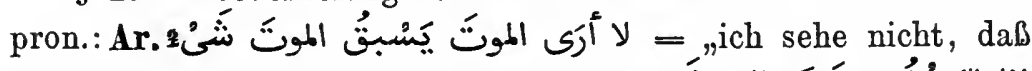

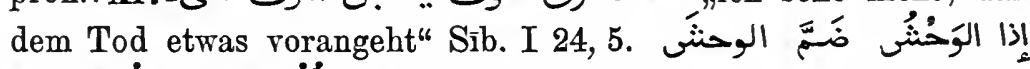
wenn die wilden Tiere Eintritte von Hitze unter ihren Schattendächern zurückhalten" ebenda 7 und

1 S. meine Syntakt. VerhäItn. Kap. XXXIII. 
sonst. ich sehe, daß dem Tode der vor ihm fliehende nicht entrinnt" Ham. 157 Vs. 4. -

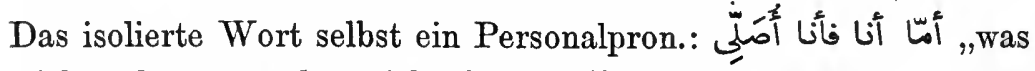
mich anlangt, so bete ich" Buh. III 411, 3. Vulg. Srr. 'ihnnā $\operatorname{tarānă~biwiğhač~,uns~mögest~du~mit~deinem~Antlitz~(freundlich)~}$ ansehen" Neuar. Volksp. 32, 5 v. u. māl mā 'endana māl „Besitz - bei uns ist kein Besitz" Musil Ar. petr. III 454, 14. ̈̈G. Einzelnes aus Spitta Gr. § 136. MaLт. ent min ent „du, wer bist du?"، Malt. Stud. 39, 38.

a Paronomasie zwischen dem isolierten Wort und dem Subj. des

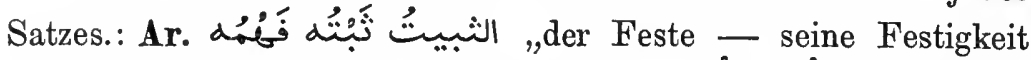

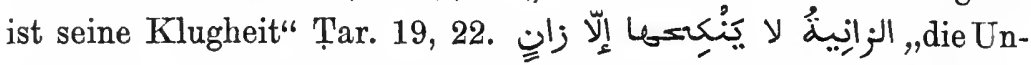

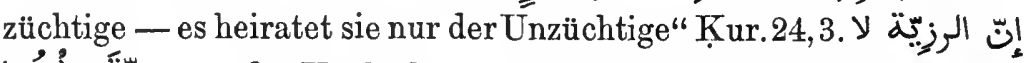

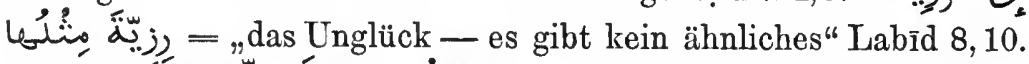

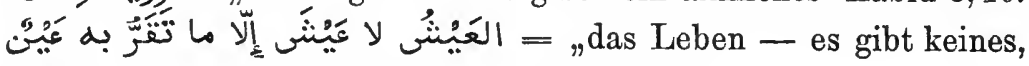
außer das worin man beglückt ist" Kuṭ. 1, 7.

b Zwischen dem isolierten Wort und dem Praed.: على القَباكيل على Mann gesetzt" Tab. I4 1930, 9. تميهم" اذا تمّت عليك رايتها (Temīm - wenn es gegen dich ganz zu Felde zieht, siehst du es..." Farazdak I S. 54, 3 v. u. was ihren Tag anlangt, so ist es einer voll Unglück" Tar. 7, 7.

c Zwischen isoliertem Wort und Objekt:

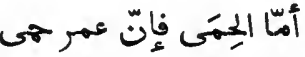
"was die Gemeinweide anlangt, so hat Omar sie ausgeschieden" Tab. I6 2963, 14.

Vgl. noch Sīb. § 90. 91.

Vulg. Srr. (b) il'āail jęāgil 'alēh, „der Zurückgebende - (Gott) gebe ihm zurück" Pal. Diw. 54,4 v. u. ‘ēn 'ali ‘öddha ‘èn il‘agāb, „das Auge Alīs - seine Art ist die des Adlers" Pal. Diw. 340, 3.

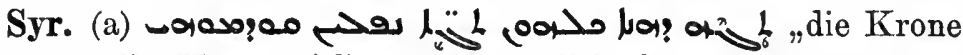
dieses - alle Kronen fallen vor ihm" Jak. Ser. Hom. 93, 6 v. u.

Bei zweimaliger Isolierung (s. Syntakt. Verh. S. 784 Mitte): "Siehe Katīir - Katīr - die Vortrefflichkeit seiner Gabe ist hoch" Farazdak 384, 4. 


\section{Index.}

Paragraphen karsiv. Kapitel in römischen Zahlen.

Adjektiv. Substantivierung. 17,2.108. Adverbialsätze 38,2 ea. 41 .

Adverbium 108. 30 .

Akkusativ $X$. Innerer, abstrakt 17. 76. 23. Durch einen Relativsatz aufgelöst 40b.c.d. A. der Vergleichung 24. 26,2c. Effizierter, konkret 25. 26,1. Affizierter 26 . A. des Orts 28,1. Praedikativer 28.3. A.der Spezialisierung (Tamjīz) 28,4. Doppelter 23,3. 25,2c. 29. Unterdrückung von Objekten 73. 14,3f. Objekt und Subjekt $2 \%$.

Attribut 34. IX.

B edingung s ätze 42,3 .

Beiordnung XIII. 40,2. Verstärkende 3. 35. Unvollständige $36, \%$. 37,4. Die Konstruktion كَتَبَ 14,3e.

Da s ätze s. Substantivsätze.

Demonstrativum. $7,5 d$. III. Regiert keinen Genitiv 22,2.

Determination. 6. 7,5. 76. 19,56. D. der Eigennamen 22,3. Des Genitivs 951. D. der Subjektsaffixe 89!. D. des Attributs 95. D. des Akkusativs der Vergleichung 24,2. Bestimmter Artikel 129. Generelle D. 24,2. 31,5 . Indetermination 2 . 6. 7,5a.e.f. 10,1. 19,5a. 31,4d. 129.

Diminutivum. 24. 25.

Distributive Ausdrücke. 36 .

Dual. $5 i . \quad 82 . \quad 21,3 . \quad 23,8 . \quad 36,3$. D. a potiori 251.

Eigennamen. 10. 4,2. 22,3. 31,4c. Femininum 5e.f.
Fragesatz. $38,2 c$.

Genitiv 17,1. XI. 34g.k. Vom st. cstr. nicht trennbar 22,1. Determination des G. 6,1. 951. 22,3. $31,4 d$. Umschreibung des G. 10,2 . 3. G. epexeg. 31,1. G. des Inhalts 31,2 . G. possess. 31,3 . G. partitivus 21. 6,3. 31,4. G. subj. 31,5 . 1611. G. obj. 31,6 .

Hom onyme. 1,3 .

Imperativ. 18,2 .

Indefinitum. 3,5. 7,2. 58. 22,4 . 25,3. $27,2 . \quad 40,5 . \quad 172^{1}$

Infinitiv. 17. 5c. 19,2. 24,1c. Aus Passivpartizipien gebildet 23,5. Zustandsinf. 28,2. Mit Objektsakk. 23,2. Isolierung. XV.

"Ja“ 10,6 .

Komparativ. 23. $5 b . \quad 20,1 . \quad 157$. Korrelative B egriffer, $3.31,7.32,5$. Metrum. Einflüsse des M. 2,3. 26. 75. Nebensatz. XIV.

Negation Generelle 2. Doppelte $3,4.35,1 d$. N. von Verbalnomina 75. Nomen II. III. Im Kontrast 8. 7. N. und Verbum VI.

Nominalsatz. VII.

Onomatopoiesie. 10.

Parenthesen. $10,2$.

Partizip. 14,2. 20,2. 38,2e $\beta$. Mit Objektsakk. 23,2.

Personalpron. (vgl. Pronomen). Genitivsuffix 110. 41,2e.

Plural. 81. 21,3. 23,8. Pl. a potiori 251, Pl. paucitatis 5d. Pl. distributiv aufgelöst 36,1 . 3 .

Possessivu m. 10,4. 
Praepositionen. 111. XII. Koordiniert $34 h$. Attributiv 94. 32,4. $\cup$ nach Verben der Bewegung 6 . Vermeidung von Doppelpraep. 41,2d. $171^{1}$.

Pronomen. III. 73.

Relativiatz. 542. 109. 38,1.2a.b. ey. 40. Vorwegnahme durch ein Genitivsuffix 1532. Korrelativum 10,5. $153^{1}$.

Reziproke Ausdrücke. 7. $3 \%$

Substantivsätze (einschließlich der Daßsätze) $38,2 d$. 39 .

Superlativ. $34.31,4$.

Synonyme. 2ff. 8. 5. 12.

Tautologie 37,2 .

Totalität $3 \tilde{5}, 4 . \quad 40,5 \mathrm{e}$.

Übersetzungen 13.

Verbalsatz VIII.

Ver bu m.IV. Nomen und VerbumVI. Allgemeine Verba V. Denominalia 677 . $74^{2}$. 92. 25,2b. 26,2.
Reflexiv 70. 72. Reziprok 37. Intransitiv 101. Passiv 31. 11,2. 68. 70. 72. 16,4. 101. 24,1d. Täter beim Passiv 61. Tempora 11,1. 12,1. Konjugationen 11,3. 4. 12,2. 14,3b. 23,4. 24,4. Subjektsaffixe 891 . Vergleichung 551. 57,3. 157. 41,2 Vokativ 18,2. 952. $35,1 c$.

Wortstellung 14.

$\mathrm{Zahlwörter.} \mathrm{5h.} \mathrm{Ordinalia} 1271$.

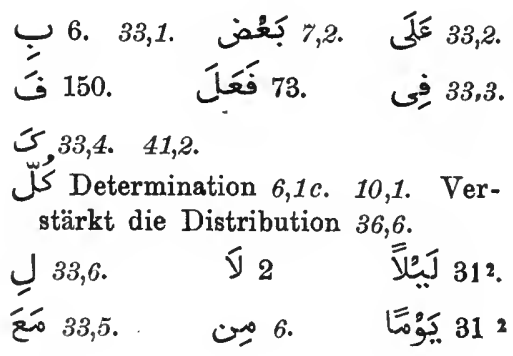

\section{Nachträge und Berichtigungen.}
S. 1 Z. 11 l. "war" statt "ward"
S. 3 Z. 18 1. $99^{\circ} \mathrm{C} 1$

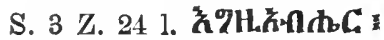
S. 3 Z. 26 1. nWnZ :
S. 3 Z. 27 l. wahn
S. 3 Z. 29 l. H'n I
S. 3 Z. 29 1. Heीh̆
S. 6 Z. 11 1. nU'L

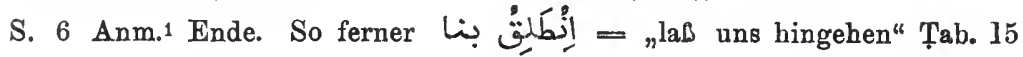 2744, 1.
S. 7 Z. 23 1. (Var. ساءل) Hud. 17, 2. S. 11 Z. 8 v. u. 1. har
S. 16 Z. 12 v. u. 1. "3.e?:
S. 29 Z. 1 1. ด190

S. 22 Z. 7. So auch يدور aus" Hiam. 529 Vs. 3.

S. 29 Z. 2 1. "des Friedens" statt "über den Sieg".

S. 31 Z. 13 1. h.tP\%?

S. $32 \mathrm{Zu}$ § 6, 3: So ferner trotz eines so hoffnungslosen Zustandes" I. Kut. K. aššír $395,2$.

S. 79 Z. 12 - 11 v. u. streiche die Klammern vor "Labīd" und nach "usw."

S. 84 Z. 17 l. "dem Zusammenhang nach ist aber der Vok."

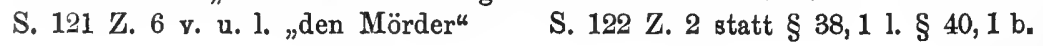


$\therefore$ 


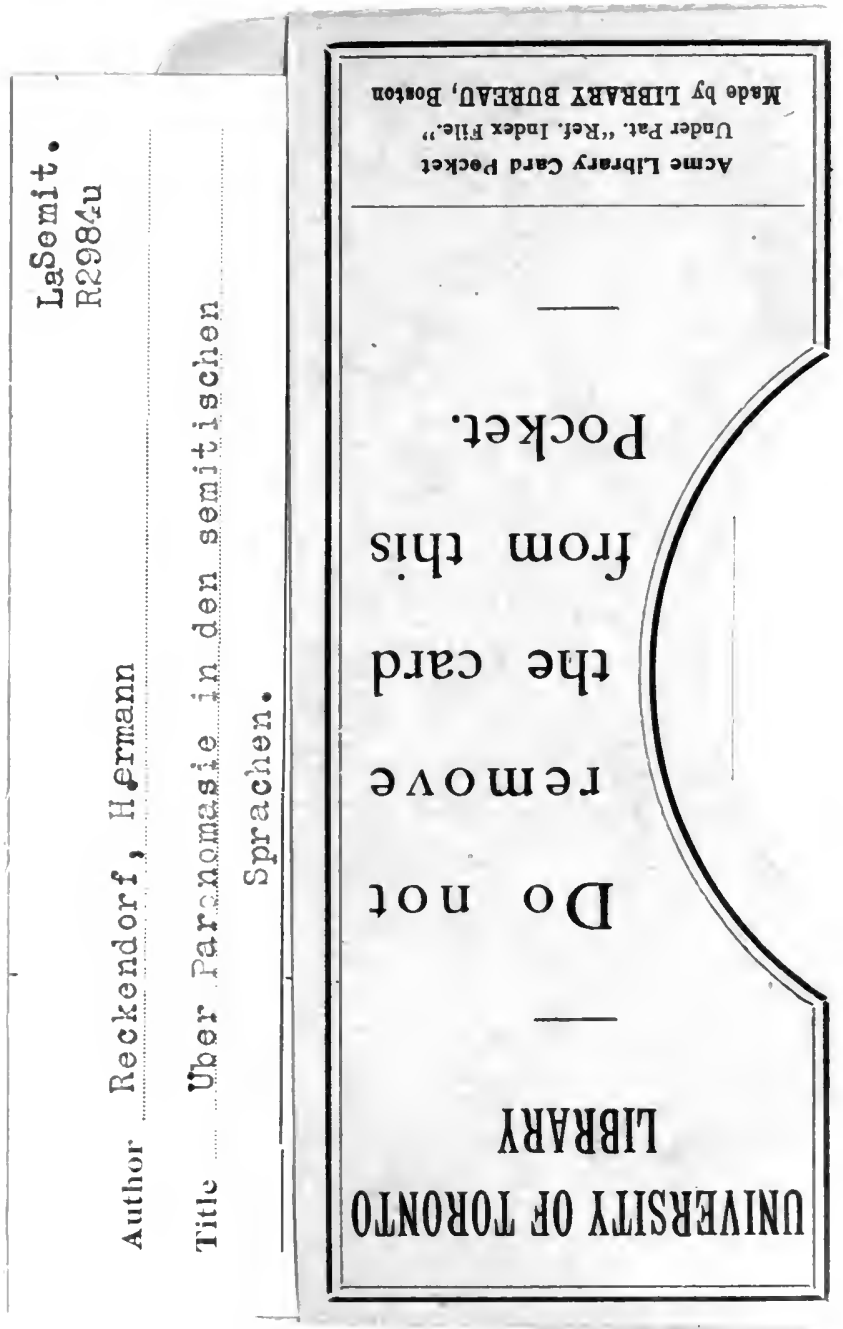


